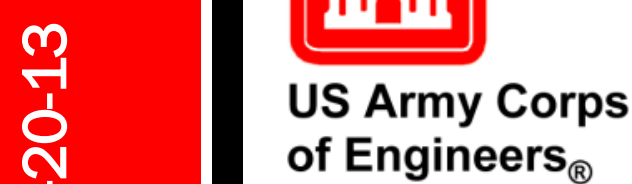

Engineer Research and

Development Center

Strategic Environmental Research and Development Program (SERDP)

\title{
Improving Design Methodologies and Assessment Tools for Building on Permafrost in a Warming Climate
}

Kevin L. Bjella, Yuri Shur, Misha Kanevskiy, Paul Duvoy,

September 2020

Bruno Grunau, John Best, Stephen Bourne, and Rosa Affleck

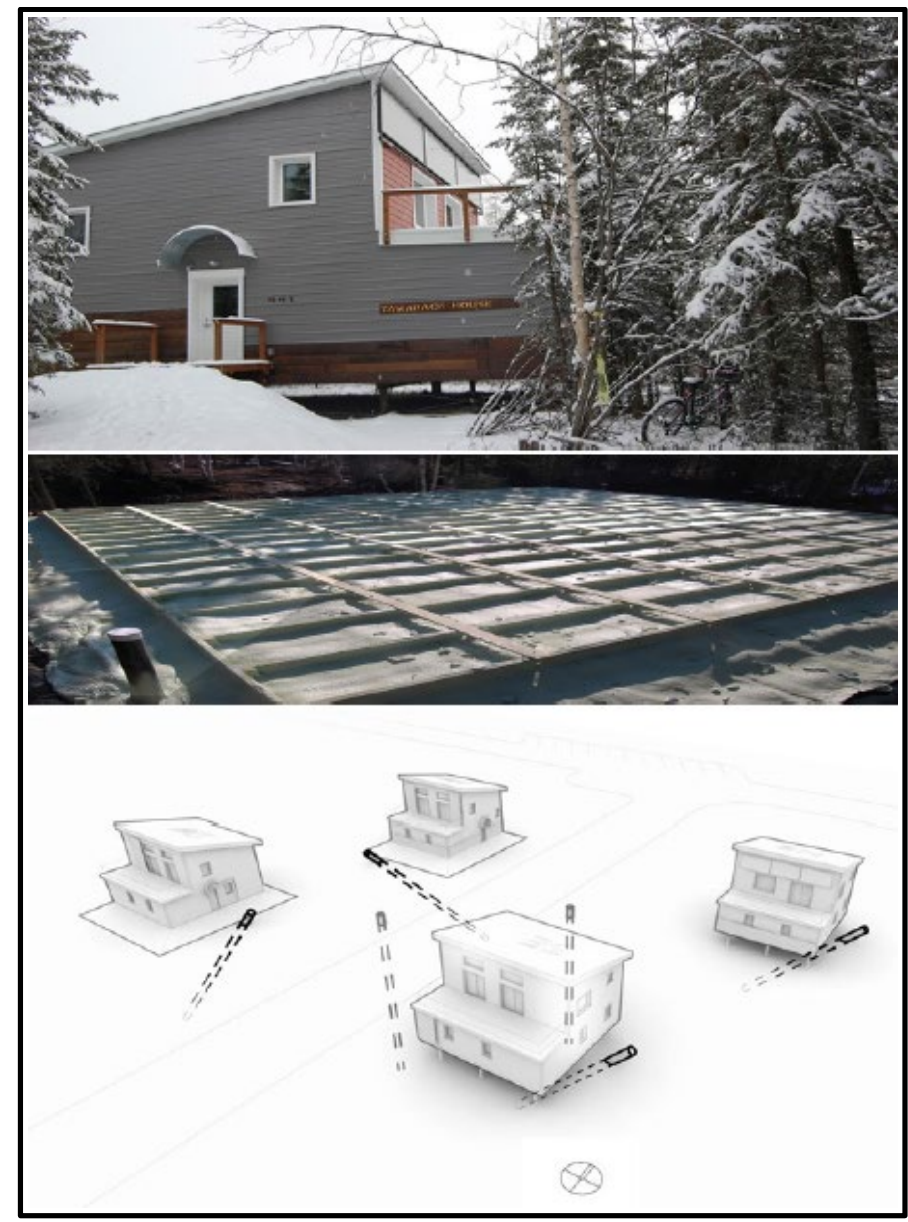


The U.S. Army Engineer Research and Development Center (ERDC) solves the nation's toughest engineering and environmental challenges. ERDC develops innovative solutions in civil and military engineering, geospatial sciences, water resources, and environmental sciences for the Army, the Department of Defense, civilian agencies, and our nation's public good. Find out more at www.erdc.usace.army.mil.

To search for other technical reports published by ERDC, visit the ERDC online library at https://erdclibrary.on.worldcat.org/discovery. 


\section{Improving Design Methodologies and Assessment Tools for Building on Permafrost in a Warming Climate}

Kevin L. Bjella and Rosa Affleck

U.S. Army Engineer Research and Development Center (ERDC)

Cold Regions Research and Engineering Laboratory (CRREL)

72 Lyme Road

Hanover, NH 03755-1290

Yuri Shur, Misha Kanevskiy, Paul Duvoy, and John Best

University of Alaska Fairbanks

505 South Chandalar Drive, Fairbanks, AK 99775

Bruno Grunau

Cold Climate Housing Research Center

955 Draanjik Drive, Fairbanks, AK 99775

Stephen Bourne

Atkins North America

2318 Mill Rd \#1040, Alexandria, VA 22314

Final Technical Report (TR)

Approved for public release; distribution is unlimited.

Prepared for Strategic Environmental Research and Development Program (SERDP)

Alexandria, VA 22350-3605

Under SERDP Resource Conservation and Resiliency Project RC-2436 


\section{Abstract}

The U.S. Department of Defense (DoD) operates numerous Arctic and Subarctic installations, including Alaska. Changes to permafrost can threaten critical built infrastructure. It is critical to accurately characterize and compare site conditions in permafrost regions to enable the efficient, cost-effective design and construction of an infrastructure well suited to the permafrost environment and that meets DoD requirements. This report describes three research efforts to establish (1) field investigation approaches for ground ice detection and delineation, (2) methods and modeling for early warning detection of thawing permafrost under infrastructure, and (3) an outline of a decision support system that determines the most applicable foundation design for warming and degrading permafrost. Outcomes of these interrelated efforts address needs to improve construction of DoD mission critical infrastructure on Arctic and Subarctic permafrost terrains. Field investigation processes used systematic methodologies including borehole data and geophysical measurements to effectively characterize subsurface permafrost information. The Permafrost Foundation Decision Support System (PFFDSS) tool implements and logically links field survey information and foundation type assessments. The current version of PFFDSS is designed to be accessible to design-engineers of a broad range of experience, that will reduce the effort and cost, and improve the effectiveness of site assessment. 


\section{Contents}

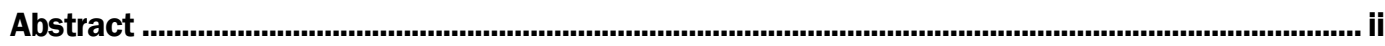

Figures and Tables.............................................................................................................................

Preface ......................................................................................................................................... xiii

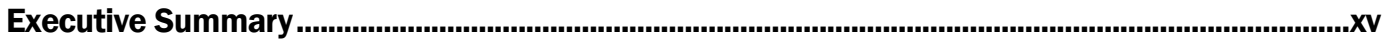

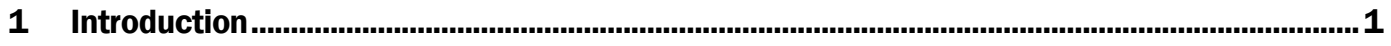

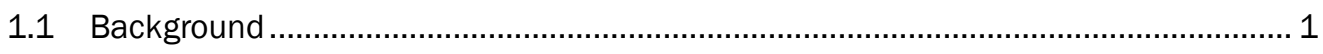

1.2 Importance ....................................................................................................... 3

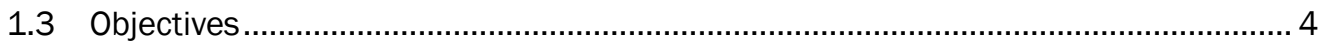

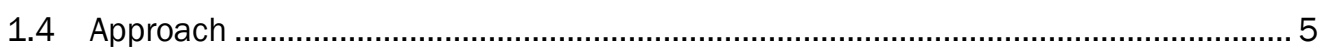

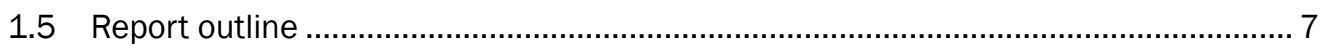

2 Enhanced Site Characterization .......................................................................................... 9

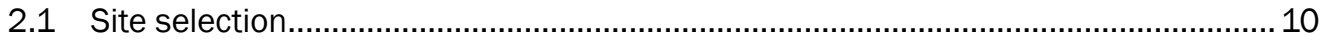

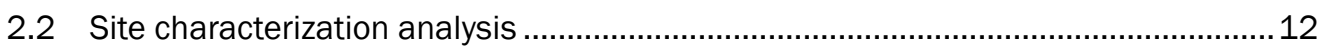

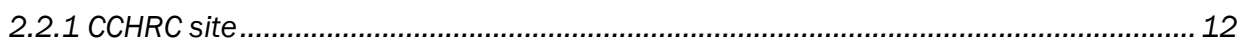

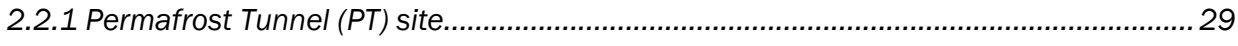

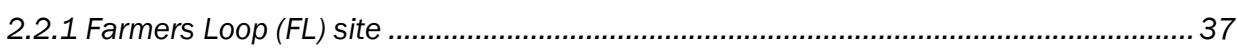

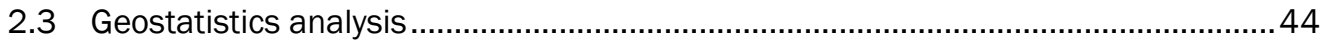

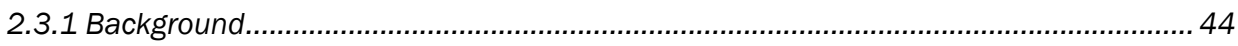

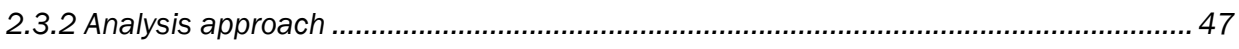

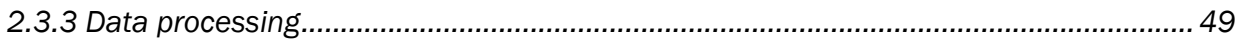

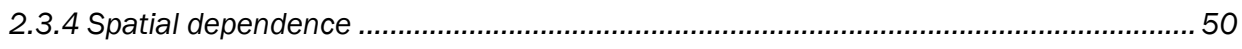

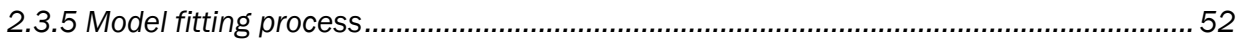

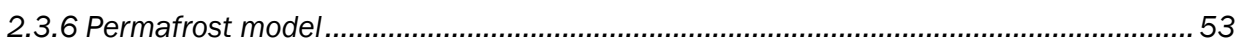

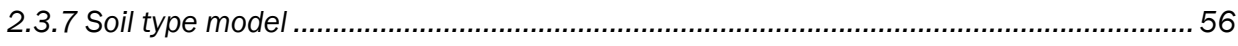

2.3.8 Water content model..................................................................................................... 56

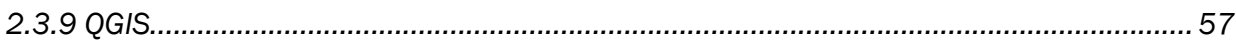

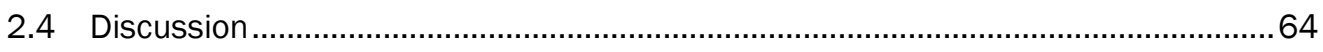

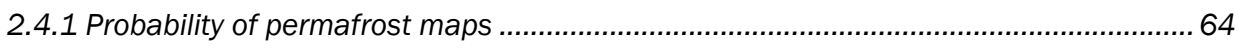

2.4.2 Probability of soil type and water content maps...................................................... 73

2.5 Geostatistical analysis summary ................................................................. 75

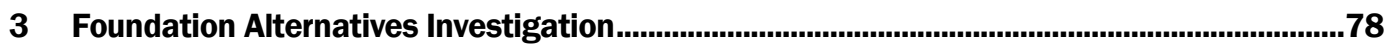

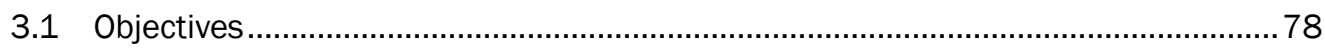

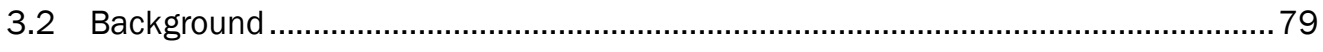

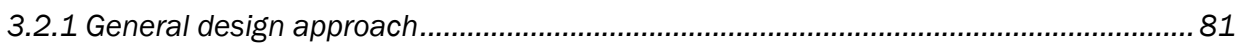

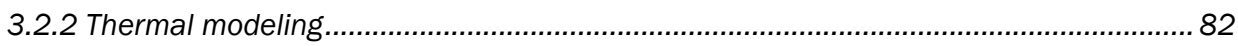

3.3 CCHRC foundations: Designs and thermal monitoring............................................ 84 


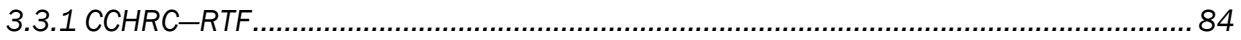

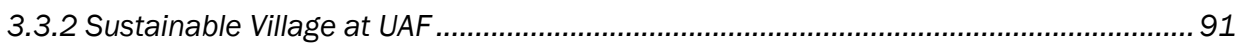

3.4 Early Warning Detection System (EWDS) ……....................................................102

3.4.1 EWDS evaluation and processes................................................................................. 103

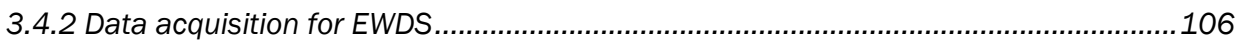

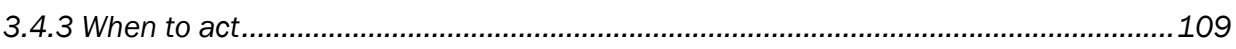

4 Permafrost Foundation Decision Support System (PFFDSS)...........................................111

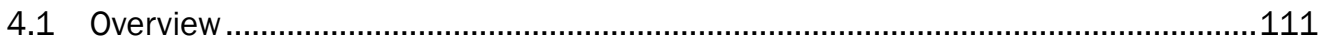

4.2 PFFDSS technological design.......................................................................113

4.2.1 Desktop assessment process .............................................................................. 113

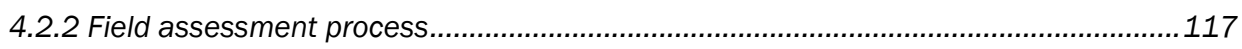

4.2.3 Foundation type risk and cost assessment process ................................................ 124

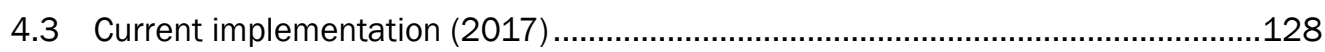

5 Conclusions, Recommendations, and Future Work................................................................130

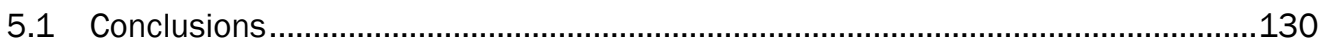

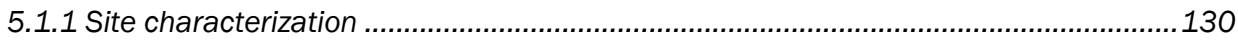

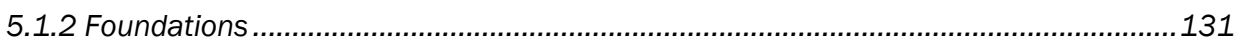

5.1 .3 Decision support system ................................................................................. 132

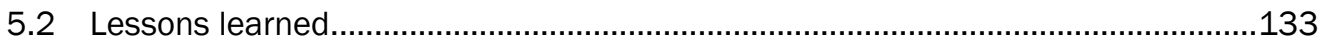

5.3 Recommendations for future efforts ..........................................................133

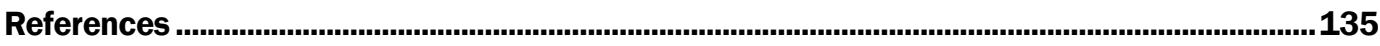

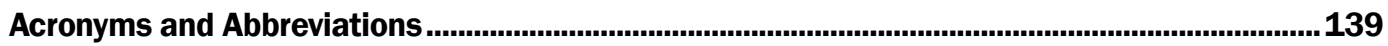

Appendix A: Cryostratigraphic Classification of CCHRC Cores from Transect 3

Boreholes..............................................................................................................................................141

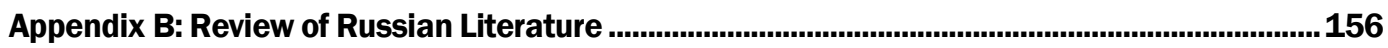

Appendix C: PFFDS Model Design Diagram ........................................................................ 176

Report Documentation Page (SF 298) .................................................................................... 192 


\section{Figures and Tables}

\section{Figures}

$1 \quad$ Flowchart illustrating the integrated approach used in the study ......................................

$2 \quad$ Location of the test sites near Fairbanks, AK............................................................... 12

$3 \quad$ Historic aerial photography of the region around the CCHRC test site; the year in which photo was taken is indicated in the upper left corner. The red box on the 2013 image locates the CCHRC test site.

$4 \quad$ Recent false color LiDAR image of the CCHRC test site in 2010, with elevational changes shown. Patterns indicative of former stream channels or sloughs are evident in the eastern third of the image to right of the red line. Alluvial-fan deposits lie to the left of the red line. Trails through vegetation occur in the western two-thirds; roads with embankments are clearly evident.

$5 \quad$ ERT profile Transect T1 at CCHRC site; transect begins on left and trends W to $\mathrm{E}$. Location is shown by long red line on aerial photograph. Two zones of high resistivity indicate ice-rich subsurface materials. Blue zones are thawed area resulting from previous disturbance to the vegetation and soils. Borehole locations denoted by BH\#. North is to the top. Resistivity transect is expressed in ohm-m and profile in meters

6 Location of Transect T1 with results of CCR survey shown. Red denotes high resistivity (ice-rich); blue low resistivity (ice-poor). North is to the left. Resistivity transect is expressed in ohm-m and profile in meters

Location of geophysical Transects T1 to T5 (orange) during initial phase of the CCHRC site subsurface investigations. Borehole locations (green, yellow) were cored for ground truth to interpret the CCR and ERT data cross sections. North is to the top

CCR resistivity cross sections for Transects $\mathrm{T} 2$ to $\mathrm{T} 5$ at CCHRC. Depth is typically $6 \mathrm{~m}$. Red signifies high resistivity values; blue low resistivity values. Resistivity transect is expressed in ohm-m and profile transect in meters

GPR profile of Transect T1 at the CCHRC site acquired at $330 \mathrm{MHz}$ in April 2014. This profile is representative of the surveys conducted on Transects T1 to T5. It begins on the west in the alluvial-fan terrain and transitions into the channelized slough terrain at $\sim 140 \mathrm{~m}$ mark. The lack of returns in the alluvial-fan section is due to high attenuation by the frozen alluvial silt deposits, whereas the stronger and deeper returns from the channel deposits is likely due to their coarser composition. Only the base of the active layer is evident in some locations due to its frozen condition in April.

Section of Transect T3 chosen for closely spaced (3 m [10 ft]) boreholes and highly detailed sampling of cores. The section traverses from the eastern swale and slough terrain into the western alluvial-fan terrain. Yellow dots mark borehole locations. The blue dots mark the location of the high-resolution ERT survey for a three-dimensional modeling of the subsurface resistivity. North is to the bottom

11 Cryostratigraphic cross-section of Transect T3 based on $3 \mathrm{~m}$ spacing of boreholes and detailed (30 cm [12 in.] depth) sample analyses. Capital letters indicate sections of differing structure and properties. Subsections are identified in the cross-section (A, B, C, D) based on similarity in their cryostratigraphic structure and material properties 


\section{Figures}

13 Visible ice content classification of the high-resolution Transect T3 section.

Subsection B would be a high-risk area for foundations; subsection A, which is unfrozen, is the lowest risk location for construction.

Three-dimensional model of the resistivity values from the survey along Transect T3 in September 2014. Depth is $\sim 7 \mathrm{~m}$ ( 23 ft) on the $16 \mathrm{~m}^{2}$ (172 sq ft) grid, with nodes spaced every $2 \mathrm{~m}$ (7 ft). X-axis lies parallel to Transect T3; $Y$ perpendicular to it. Highest resistivity values indicate ice-rich sediments at depth .....

Location of transects within the western two-thirds of the CCHRC site relative to original Transects T1 to T5 and borehole locations. This area consists of deposits of former alluvial fan; they are distinctly different in terms of sediment types and ice content than the eastern third of the site. North is to the top.

LiDAR image of the Permafrost Tunnel site obtained in May 2014. The transect illustrated was used for the initial reconnaissance data gathering using resistivity methods. The two CRREL Permafrost Tunnels are located at the western edge of the vegetated uplands. They were cut into the scarp formed by placer gold mining in the Goldstream Valley (upper left). Most of the terrain consists of poorly drained, coalesced alluvial fans, largely composed of perennially frozen silt in the Glenn Creek drainage. Thermal erosion has expanded the gullies draining into the valley. Trails are evident crisscrossing the site. North is to the top.

17 Interpretation of composite seismic refraction profiles (adapted from Sellmann, 1967) along Transect T2 at the Permafrost Tunnel site. The dashed line is the interpreted interface between Holocene and Pleistocene sediments, all of which are re-transported silts of eolian origin. Dots indicate projected depth to bedrock from the seismic information.

Location of the three transects investigated with GPR, CCR, and ERT geophysical methods at the Permafrost Tunnel site. North is to the top

Composite resistivity section for Transect T1 at Permafrost Tunnel site. The survey begins $\sim 800 \mathrm{~m}$ ( $\sim 2624 \mathrm{ft})$ uphill from the tunnel and terminates near the escarpment. The data are a composite of five surveys using multiple receivers at a spacing that changed the depth of penetration from shallow to deep ( $\max \sim 20 \mathrm{~m}$ [ $\sim 66 \mathrm{ft}]$ ). We interpret the data to show the lower ice content active layer and upper Holocene silt deposits to $\sim 2.5 \mathrm{~m}$ to $3 \mathrm{~m}$ ( $\sim 8 \mathrm{ft}$ to $10 \mathrm{ft}$ ) depth, overlying the high ice content Pleistocene silt deposits. The very high resistivity values (deep red) may indicate the presence of ice wedges and other massive ice types; the lower resistivity values at both ends of the transect indicate reduced ice content, possibly due to previous thaw and refreezing of the deposits.

20 ERT resistivity profiles for Transect T2(A) (starts at edge of escarpment on left) and Transect T3(B) (starts at Glenn Creek on left) at the Permafrost Tunnel site. The central parts of both profiles cross the poorly drained, tussock and sedge upland terrain, and delineate ice-rich subsurface materials, but which are variable in apparent content with depth into the gravels and bedrock

21 A $360 \mathrm{MHz}$ GPR profile of Transect T2 at the Permafrost Tunnel site. The profile begins $40 \mathrm{~m}$ (131 ft) before the actual start of Transect T2. The active layer, top of permafrost, and snow cover are well defined, but depth penetration is limited to several meters 


\section{Figures}

A $150 \mathrm{MHz}$ GPR profile beginning at Transect T1 after $100 \mathrm{~m}$. Within the first $480 \mathrm{~m}$ (1574 ft) distance, we interpret the general horizon at $2 \mathrm{~m}$ to $3 \mathrm{~m} \mathrm{(7 \textrm {ft } \text { to }}$ $10 \mathrm{ft}$ ) depth to be the bottom of the Holocene silt. After $480 \mathrm{~m}$ this horizon weakens and degenerates into a series of diffractions, beneath which isolated events occur to $10 \mathrm{~m}$ (33 ft) depth in the older perennially frozen silts.

23 Location of boreholes along Transect T2 at Permafrost Tunnel site (Fig. 18) with 18 boreholes every $6 \mathrm{~m}$ starting at T2-148 and ending at T2-250 .

24 Historic aerial photography of the Farmers Loop site. Changes in infrastructure, vegetation and physical features such as expansion of the ponds in area adjacent to the road are evident in full size images

Geologic map of the Farmers Loop area and geologic cross-section based on logs of water wells. The cross-section trends northwest from Birch Hill across the Steese Hwy. and Farmers Loop Road

Transects T1 and T2 at the Farmers Loop site. The location of these transects were previously established for an earlier CRREL project, with boreholes (yellow circles) drilled as a part of that study. The red triangle dots indicate locations for the detailed coring (every 6 meters) and analysis of the permafrost for this investigation

Resistivity profiles for Transect T1 (top) and T2 (bottom) at the Farmers Loop site. Left end is on the east end, near the road. The low resistivity values near the road indicate some areas of low ice content and/or unfrozen zones at depth, perhaps associated with thermokarst from disturbance, while the dark red indicates a high ice content beneath the western edge of the tussock and dwarf spruce area, particularly beneath the coniferous forest

Migrated GPR profile at $360 \mathrm{MHz}$ from Transect T1 at Farmers Loop site acquired in April 2014. The 0-meter mark lies at the western end of this transect and the $400 \mathrm{~m}$ (1312 ft) mark occurs adjacent to Farmers Loop Road. The data are limited in penetration, and subsurface features shown are limited to a sporadic active layer of $1 \mathrm{~m}$ to $1.5 \mathrm{~m} \mathrm{(} 3 \mathrm{ft}$ to $5 \mathrm{ft}$ ) thickness (e.g., $300 \mathrm{~m}$ to $360 \mathrm{~m} \mathrm{[984 \textrm {ft }}$ to $1,181 \mathrm{ft}]$ ), but in most cases, the base of the snow cover and top of active layer are difficult to distinguish.

Migrated GPR profile at $360 \mathrm{MHz}$ of Transect T2 at Farmers Loop. Profile begins at

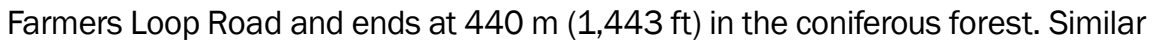
to Transect $\mathrm{T} 1$, there is only limited penetration and a sporadic active layer revealed.

Surface terrain features map for the CCHRC test location showing borehole sample locations and transition boundaries between terrain units. Terrain units (geology) are Qrf, Alluvial-Fan Silt (overlies floodplain alluvium); perennially frozen; Qcs, Swale and slough deposits (silt and silty sand, contains organic material); Qcs-1, perennially frozen near the surface; and Qcs-2, lowered permafrost table (after Péwé et al. 1977). Map orientation, south up, correspond to data analysis in Fig. 31

31 Charts showing: (top) CCHRC resistivity profile along the track of borehole locations, (middle) borehole core analysis derived subsurface permafrost map, and (botttom) soil conditions from interpretation of borehole core analysis from Transect T3 drilling (Fig. 46). Borehole locations are overlaid on the permafrost and soil condition profiles with location numbers increasing from left to right. Surface terrain feature regions are shown as: A for Qcs-2, B for Qcs-1, and C \& D for Qrf (Fig. 46) 


\section{Figures}

32

(20)

The relationship between log-resistivity and logistic water content is linear, but dependent on soil type.

QGIS Main Interface with the layer page on the left for displaying the feature data (cores, topography, vegetation, geology, resistivity, etc.) and a map on the right... 58

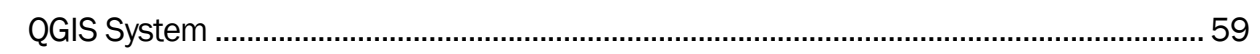

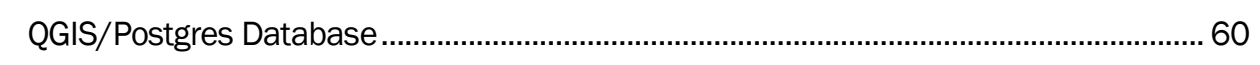

Format of QGIS Tables .................................................................................................61

Transect (above left), resistivity output (above right), and drilling profile (below) for

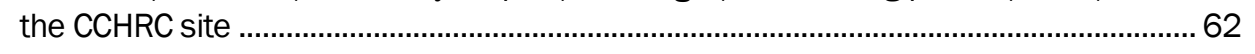
QGIS surface features definition with polygons... 63

Basic QGIS web interface showing vegetation for spruce forests with moss cover (green polygon), mixed forest (purple polygon) and destroyed vegetation (not shown).

Most likely soil type using boreholes at 40 m, 80 m, and 140 m (131 ft, $262 \mathrm{ft}$ and $459 \mathrm{ft}$ ).

Entropy of soil type prediction using boreholes at $40 \mathrm{~m}, 80 \mathrm{~m}$, and $140 \mathrm{~m}$ (131 ft, $262 \mathrm{ft}$ and $459 \mathrm{ft}$ ). Entropy is highest far from boreholes and at the border between two observed soil types.

Predicted water content using resistivity and boreholes at $40 \mathrm{~m}, 80 \mathrm{~m}$, and $140 \mathrm{~m}$ $(131 \mathrm{ft}, 262 \mathrm{ft}$ and $459 \mathrm{ft})$

Width of the $80 \%$ credible interval for water content. A wider interval represents higher uncertainty.....

Calculated probability of permafrost using resistivity and boreholes at $50 \mathrm{~m}, 62 \mathrm{~m}$,

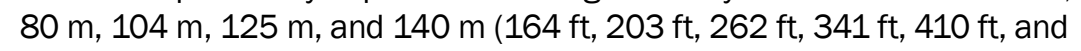
$459 \mathrm{ft})$. The blue line represents the surface elevation. Note that the vast majority of points where we have resistivity measurements are permafrost...

Entropy of predicted permafrost using resistivity and boreholes at $50 \mathrm{~m}, 62 \mathrm{~m}$, $80 \mathrm{~m}, 104 \mathrm{~m}, 125 \mathrm{~m}$, and $140 \mathrm{~m}$ (164 ft, $203 \mathrm{ft}, 262 \mathrm{ft}, 341 \mathrm{ft}, 410 \mathrm{ft}$, and $459 \mathrm{ft})$. Higher values represent greater uncertainty. The areas of low uncertainty surround the locations of the boreholes. Highest uncertainty occurs in the area between observations of permafrost and thawed soils.

46 Most likely soil type using boreholes at $40 \mathrm{~m}, 62 \mathrm{~m}, 80 \mathrm{~m}$, and $104 \mathrm{~m}(131 \mathrm{ft}$, $203 \mathrm{ft}, 262 \mathrm{ft}$, and $341 \mathrm{ft}$ ).

47 Entropy of soil type prediction using boreholes at $50 \mathrm{~m}, 62 \mathrm{~m}, 80 \mathrm{~m}, 104 \mathrm{~m}$, $125 \mathrm{~m}$, and $140 \mathrm{~m}$ (164 ft, $203 \mathrm{ft}, 262 \mathrm{ft}, 341 \mathrm{ft}, 410 \mathrm{ft}$, and $459 \mathrm{ft}$ ). Entropy is highest far from boreholes and at the border between two observed soil types....

$48 \quad$ Predicted water content using resistivity and boreholes at $40 \mathrm{~m}$ (131 ft)..... 69

49 Width of the $80 \%$ credible interval for water content. A wider interval represents higher uncertainty.....

50 Calculated probability of permafrost using resistivity and boreholes at $50 \mathrm{~m}, 80 \mathrm{~m}$,

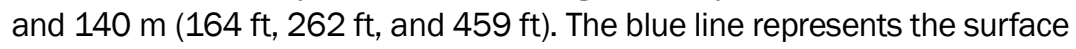
elevation. Note that the vast majority of points where we have resistivity measurements are permafrost. 


\section{Figures}

51 Entropy of predicted permafrost using resistivity and boreholes at $50 \mathrm{~m}, 80 \mathrm{~m}$, and $140 \mathrm{~m}$ (164ft, $262 \mathrm{ft}$, and $459 \mathrm{ft}$ ). Higher values represent greater uncertainty. The areas of low uncertainty surround the locations of the boreholes. Highest uncertainty occurs in the area between observations of permafrost and

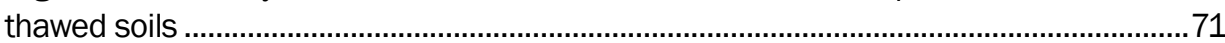

The four residential buildings in the Sustainable Village built in 2012. (Photo J. Fiely)

The RTF foundations. The green shows the original building, and the blue is the building addition

Adjustable spread footer design in the RTF Building addition. Left: The jacking plate is attached at the column and a hydraulic jack is placed between the jacking plate and the jacking column. Middle: The hydraulic jack is expanded to raise the grade beam away from the spread footing. Right: Structural foam is injected into the void between the grade beam and spread footing.

57 Temperature string installed beneath the RTF Building addition

Subsurface temperature data under the north lab foundation in the RTF. The data show temperature sensor drift over time; sensor placement is grouped by color. The grey line is the air temperature.

Subsurface temperature data shown as trumpet curves under the RTF from 2008 (left) and 2016 (right). The comparative graphs indicate the permafrost table depth has increased by approximately $1 \mathrm{~m}(4 \mathrm{ft})$

The change in subsurface temperatures in the building addition

Trumpet curves under the building addition

One of the two Sustainable Village homes on pile foundations installed on permafrost ground

The two Sustainable Village homes on the insulated raft foundations installed on the ground

Raft foundation as it was being installed under one of the two Sustainable Village homes.

Subsurface temperatures directly under the northwestern Sustainable Village house that used the insulated raft foundation. Sensor failure occurred over time starting in December 2012.

A timeline of data collection changes under the UAF Sustainable Village houses ......... 95

The thermistor string locations under the homes of the Sustainable Village

The thermistor string installation under the piling foundation under a Sustainable Village Home.

The thermistor string installation under the insulated raft foundation under a Sustainable Village Home.

Transition from the failing thermistors to the new data system. The thermistors failed too much to create meaningful whiplash curves.

New data system data from the Northwest house. The temperature sensors were moved in September 2015 to be closer together. 


\section{Figures}

The new locations of the temperature sensors under the northwest house. Notice the large difference in the $y$-axis to enlarge the interface near the top of the permafrost

74 Temperature data under the northeast house. There are no data under this house before 2015. The sensors were moved in September 2015.

Temperature under the northeast house. The sensors are in a new location; notice the change in the $y$-axis

Preparing the foundation for concrete pouring. The white buckets are full of sensor wires. The sensors are already in the conduit in the ground. The wires are in 1-in. Loctite conduit running back to the buckets. The buckets make the wiring more visible to the building crew....

A directional drilling rig. Drilling a sensor tube hole under an existing house at the Sustainable Village at UAF....

Borehole stability indices (composited) along a transect.

to stable layer, depicted in swaths. Swath width is calculated based on subsurface data and variability among borehole samples.

Conceptual model of the PFFDSS Potential Borehole Thaw Settlement Algorithm......123

Conceptual model of the PFFDSS Potential Thaw Settlement Area Assessment Algorithm

87 Conceptual model of PFFDSS Foundation Type Risk and Cost Assessment Algorithm

A-1 Unfrozen peat (Sub-unit 2UF), T3-50, depth $110 \mathrm{~cm}$ to $140 \mathrm{~cm}$ (43 in. to 55 in.)...... 148

A-2 Frozen peat, no visible ice (Sub-unit 2A), T3-56, depth $90 \mathrm{~cm}$ to $110 \mathrm{~cm}$ (35 in. to 43 in.)

A-3 Thawed and refrozen organic-rich silt with lenticular to layered cryostructure (Subunit 3B), T3-56, depth $120 \mathrm{~cm}$ to $150 \mathrm{~cm}$ (47 in. to 59 in.)

A-4 Boundary between ice-poor epigenetically frozen sandy silt (Sub-unit 6B) and icepoor epigenetically frozen fine to medium sand (Unit 7), T3-56, depth $380 \mathrm{~cm}$ (149 in.)

A-5 Contact between the ice wedge and the ice-rich syngenetically frozen silt with micro-braided cryostructure (Sub-unit 3A), T3-62, depth $135 \mathrm{~cm}$ to $150 \mathrm{~cm}$ (53 in. to 59 in.)

A-6 Ice-rich syngenetically frozen silty sand, very fine to fine, strongly oxidized, with micro-braided cryostructure and thick ice belts (Sub-unit 6A), T3-62, depth $210 \mathrm{~cm}$ to $230 \mathrm{~cm}$ (83 in. to $90 \mathrm{in}$.)

A-7 Ice-rich quasi-syngenetically frozen silt (intermediate layer) with ataxiticcryostructure and thick ice belts (Sub-unit 3A), T3-65, depth $110 \mathrm{~cm}$ to $130 \mathrm{~cm}$ (43 in. to 51 in.) 


\section{Figures}

A-8 Ice-rich quasi-syngenetically (or syngenetically) frozen peat with organic-matrix to micro-braided and ataxiticcryostructure and thick ice belts (Sub-unit 2B), T3-68, depth $80 \mathrm{~cm}$ to $95 \mathrm{~cm}$ (31 in. to $37 \mathrm{in}$.)

A-9 Epigenetically frozen very fine to fine silty sand, with thin layers of organic detritus (Sub-unit 6B), no visible ice, T3-68, depth $390 \mathrm{~cm}$ to $410 \mathrm{~cm}$ (153 in. to $161 \mathrm{in}$.).....151

A-10 Ice-rich quasi-syngenetically frozen silt with ataxiticcryostructure (Sub-unit 3A), T371 , depth $185 \mathrm{~cm}$ to $200 \mathrm{~cm}$ (73 in. to 79 in.) ............................................................ 151

A-11 Contact between the ice wedge and syngenetically frozen sandy silt with microlayered cryostructure (Sub-unit 6A), T3-83, depth $225 \mathrm{~cm}$ to $235 \mathrm{~cm}$ (88 in. to 92 in.)

A-12 Boundary between epigenetically frozen sand, fine to medium, with inclusions of very coarse sand (Unit 7) and sandy gravel (Sub-unit 8B), no visible ice, T3-98, depth $670 \mathrm{~cm}$ (263 in.)

A-13 Syngenetically frozen silty sand, friable, with micro-layered cryostructure (Sub-unit 6A), T3-101, depth $310 \mathrm{~cm}$ to $315 \mathrm{~cm}$ (122 in. to $124 \mathrm{in.}$.)

A-14 Quasi-syngenetically frozen silt (intermediate layer), with micro-braided to microataxiticcryostructure and thick ice belts (Sub-unit 2B), T3-107, depth $90 \mathrm{~cm}$ to $110 \mathrm{~cm}$ (35 in. to 43 in.).

A-15 Quasi-syngenetically frozen peat (buried), with organic-matrix to microataxiticcryostructure (Sub-unit 4B), T3-107, depth $220 \mathrm{~cm}$ to $240 \mathrm{~cm}$ (86 in. to 94 in.)

A-16 Quasi-syngenetically frozen silt (buried intermediate layer), with braided to ataxiticcryostructure (Sub-unit 5A), T3-107, depth $280 \mathrm{~cm}$ to $295 \mathrm{~cm}$ (110 in. to 116 in.)

A-17 Epigenetically frozen laminated silty sand / very fine to fine sandy silt with thin layers of organic detritus (Sub-unit 6B), no visible ice, T3-137, depth $370 \mathrm{~cm}$ to $380 \mathrm{~cm}$ (145 in. to 149 in.)

A-18 Quasi-syngenetically frozen silt (intermediate layer), with braided to ataxiticcryostructure (Sub-unit 3A), T3-146, depth $70 \mathrm{~cm}$ to $80 \mathrm{~cm}(28 \mathrm{in}$. to 31 in.) 155

B-1

Three recommended types of piles.

Proposed four main cases of pre-thawing.... 162

B-3 Icing from leaking utility in the ventilated crawl space of multistory building........... 168

B-4 Thaw strain of weathered bedrock with water content ..................................................171

B-5 Thaw strain of gravel vs. water content........................................................... 171

B-6 Allowable bearing capacity of mineral frozen soils as a function of maximum soil temperature: (1) gravel, (2) coarse sand, (3) medium sand, (4) fine sand and silt, (5) silty clay and clay, (7) any soil with ice layers, $(8)$ ice $\left(1 \mathrm{~kg} / \mathrm{c} \mathrm{m}^{2}\right.$ is equal to $100 \mathrm{kPa}$ )

C-3

MVC Layout for PFFDSS code 


\section{Figures}

C-6 PFFDSS User-sketched Assessment Area (gold outline) with overlay of Péwé's (1975) Surficial Geologic Terrain Units (blue lines) ........................................................184

C-7 PFFDS Assessment: Map Query Results ....................................................................185

C-8 User-sketched transect for geophysical surveys and borehole placement (gold line:

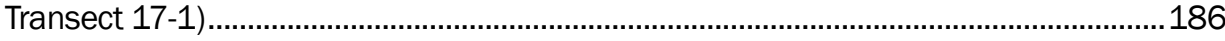

C-9 PFFDSS Upload page for imagery from geophysical transects.......................................187

C-10 Geophysical transect image (2D vertical) plot ........................................................... 187

C-11 Importing borehole data into the PFFDSS ......................................................................189

C-12 Examining building footprint impacts around the site .....................................................190

C-13 Foundation Type Assessment Results....................................................................... 191

\section{Tables}

1 Test sites for evaluating site characterization methodology 11

2 Results of analysis using Monte Carlo method to examine effects of sampling interval on ice content based on $30 \mathrm{~cm}$ (12 in.) depth sampling scheme on highresolution section of Transect T3 at CCHRC .27

3 Soil types used and their abbreviations. Based on a simplified USCS code .................. 49

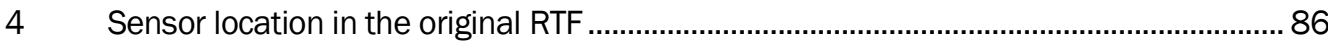

$5 \quad$ Overall approaches and suggestions for EWDS .......................................................104

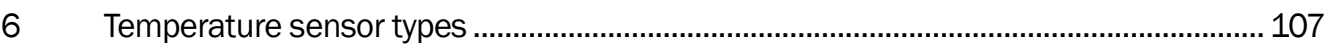

A-2 (Tbl B-1 simplified). Visible ice content (VIC) and gravimetric moisture content (GMC) of cryostratigraphic units and sub-units, segments A, B, C, and D of the profile T3 147

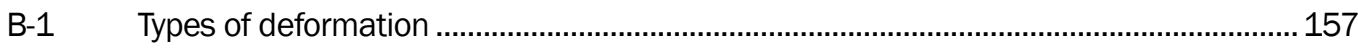

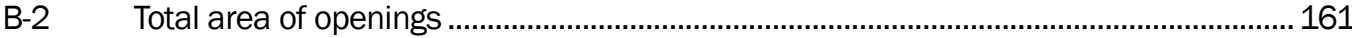

B-3 Thaw settlement for some soils in relation to their initial void ratio and pressure ........163

B-4 Average along freezing layer, tangential frost heave stress (kPa/psi).................... 164

B-5 Relationship of thaw strain for fine-grained soils..........................................................169

B-6 Long-term strength of frozen soils (MPa [psi]) of Yakutia as a function of

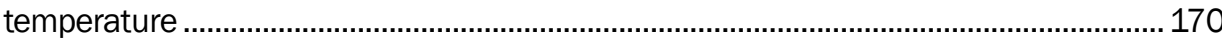

B-7 Adfreeze strength of frozen soils with concrete ............................................................. 170

B-8 The allowed bearing capacity (MPa) of frozen soils in Yakutia .......................................171

B-9 The allowed bearing capacity of saline soils ................................................................... 172 


\section{Preface}

Funding for this demonstration was provided by the Strategic Environmental Research and Development Program (SERDP) under Customer Order W74RDV33512287 in FY14 Resource Conservation and Resiliency Project SERDP RC-2436, "Improving Design Methodology and Assessment Tools for Building on Permafrost in a Warming Climate." The technical monitor was Dr. Kurt Preston.

The work was performed by the Force Projection and Sustainment Branch, U.S. Army Engineer Research and Development Center, Cold Regions Research and Engineering Laboratory (ERDC-CRREL). At the time of publication, Mr. J.D. Horne was acting Chief of the Force Projection and Sustainment Branch and Chief of the Research and Engineering Division. The Deputy Director of ERDC-CRREL was Mr. David B. Ringleberg, and the Director was Dr. Joseph L. Corriveau.

The authors gratefully acknowledge the technical reviewers for providing sound feedback: Ms. Lynette Barna of Cold Regions Research and Engineering Laboratory and Mr. John Rajek Chief, Geotechnical and Materials Section U.S. Army Corps of Engineers Alaska District.

COL Teresa A. Schlosser was Commander of ERDC, and Dr. David W. Pittman was the Director. 
THIS PAGE INTENTIONALLY LEFT BLANK 


\section{Executive Summary}

This report documents an extensive research project that focused on built infrastructure and future risks associated to climate in Interior Alaska and in cold regions for Strategic Environmental Research and Development Program (SERDP) statement of need. The research project focuses on the ability to establish new methods for ground ice detection and delineation, on methods for early warning detection of thawing permafrost under infrastructure, and on an outline of a decision support system to determining the most applicable foundation design for warming and degrading permafrost. These three tasks address the immediate needs to advance the ability to effectively construct mission critical infrastructure on Arctic and Subarctic permafrost terrains.

\section{Introduction}

The Arctic and Subarctic have been key regions of geopolitical concern since World War II and continue to have strategic importance for the Department of Defense (DoD). A vast majority of the region is characterized by permafrost landscape. Because landscape dynamics influence the physical and biological processes within the terrain, military installations must overcome many challenges related to their infrastructure, facilities, and other logistical operations throughout most of the permafrost regions. The physical properties of the permafrost landscape can differ vastly depending on its soil and ground ice content characteristics, even within relatively short distances. These permafrost properties are critical in determining landscape responses to disturbance from construction activities, infrastructure emplacement, and mobility operations.

Another part of the landscape dynamics is the permafrost subsidence, which is primarily related to the phase change of ground ice to water at or near to $0{ }^{\circ} \mathrm{C}$ and to the soil thermal regime changes due to human activity, infrastructure emplacement, or systemic shifts related to weather and climate. Such subsidence may be rapid and catastrophic (within days), very slow and systematic (over decades), or potentially intermediate (over months or years). These changes to permafrost can notably increase risks to the structural stability of critical built infrastructure (i.e., shifting, or cracking) that caused damage to foundations and buildings. Such damage requires costly mitigation that disrupts planning, operations, and budgets. 
DoD guidelines for effective construction of infrastructure on permafrost landscapes have existed for decades. Construction in this environment is commonly built to high standards requiring multi-decadal longevity. Designers apply these guidelines first by characterizing upper permafrost and surficial properties at specific building locations, then by carefully evaluating foundation options based on cost and risks, and finally by making an informed selection from the most appropriate construction techniques. The location of proposed infrastructure on a given site and selection of the best foundation construction approach will require a comprehensive investigation to assess the conditions of the entire building footprint from the surface down to the effective engineering depth. However, the reality of hard constraints on timing, budgets, and logistics prevents practitioners from conducting such complete assessments. The consequent lack of comprehensive assessments can result in costly overbuilt construction that accounts for unknown permafrost conditions, or construction that allows undue risks to the stability and integrity of critical DoD infrastructure. In either case, a substantial amount of subsurface information is necessary to minimize construction cost (i.e., reduce the tendency to overbuild in permafrost-affected regions) while ensuring long-term integrity.

Currently and in the foreseeable future, the needs for DoD design and construction dictate that design and engineering work be distributed among personnel with a mix of experience, with a range of institutional knowledge to effectively design and construction on permafrost landscapes, from highly experienced experts in permafrost construction to less experienced individuals with the appropriate engineering backgrounds. Engineers new to permafrost can benefit from direct guidance and assistance in site assessment and design selection, while the more experienced engineers can increase efficiency by contributing more refined site assessment approaches. This holistic approach addresses the knowledge gap for both site assessment and design selection, and benefits practitioners at all levels of institutional knowledge of permafrost. This Strategic Environmental Research and Development Program (SERDP) project seeks to address these gaps to maximize the resilience of built infrastructure constructed on permafrost, under existing conditions and also under conditions of increased future risk associated with climate change.

\section{Objective}

The objective of the SERDP project was to provide a process or guide for site assessment and design selection using holistic methods. The methods 
required various steps and parallel activities (Figure ES-1), including (1) choosing the optimal location for infrastructure within a given site, (2) compiling existing information and acquiring data for determining promising foundation alternatives, (3) developing finite-element thermal modeling parameters for estimating foundation impacts to permafrost and (4) assessing long-term monitoring options for identifying threats to infrastructure early on, while they can best be mitigated.

Figure ES-1. Flowchart illustrating the integrated approach used in the study.

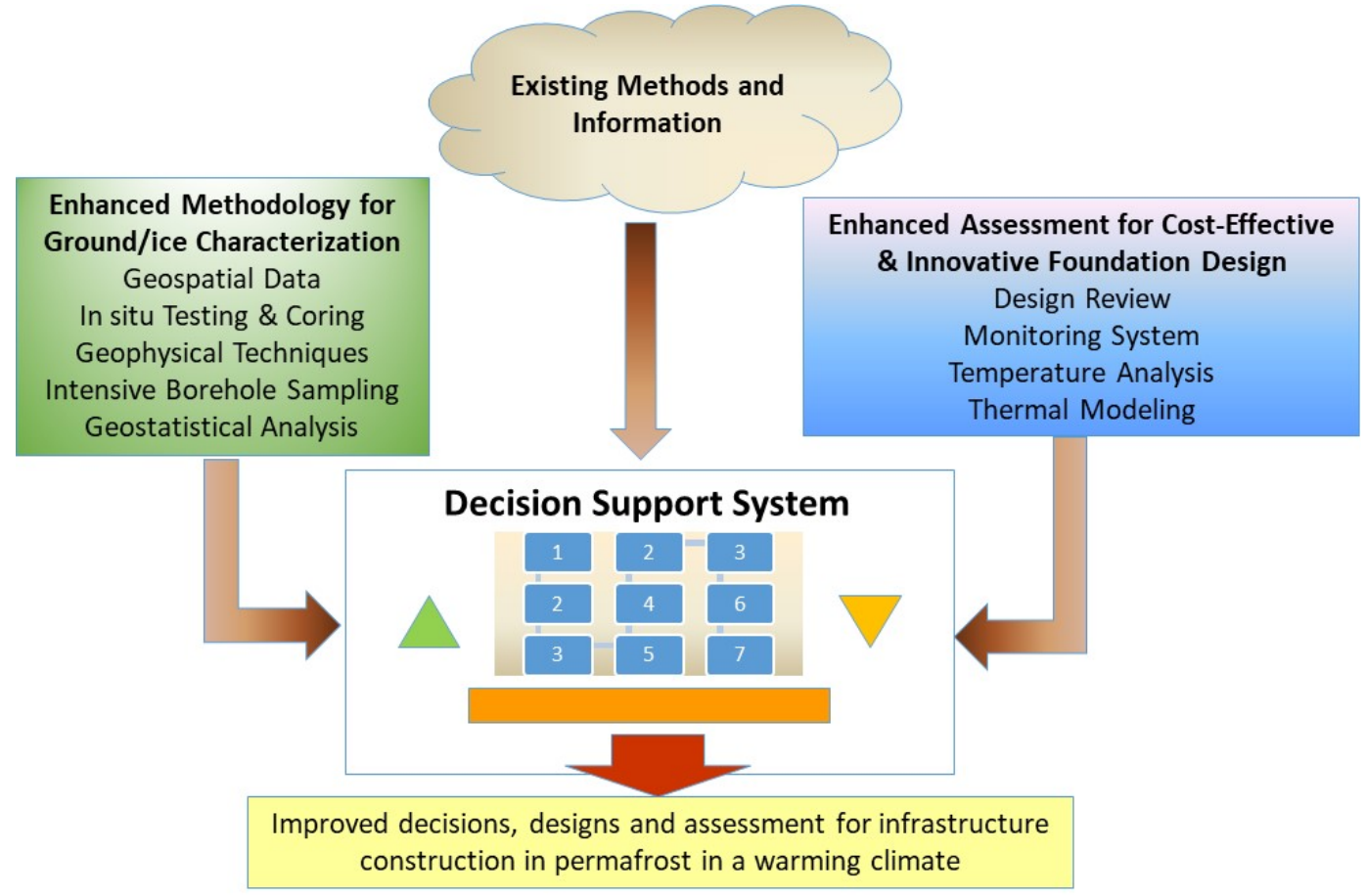

This research project used emerging technologies, higher resolution information, and models to provide statistically supported, theoretical underpinnings for a system that both enhances the effectiveness of site assessment in permafrost regions, and reduces the effort and cost associated with that activity. A further goal that emerged from this study was to develop a holistic approach that provides the knowledge to guide engineers new to permafrost in permafrost reconnaissance while offering spatially explicit data storage and visualization options to seasoned permafrost engineers, ultimately facilitating the most efficient and cost-effective result.

\section{Technical Approach}

To develop this systematic methodology, the first part of the project was a site characterization study to measure for detection and delineation of ground ice. Three test sites (Cold Climate Housing Research Center 
[CCHRC], CRREL Permafrost Tunnel, and CRREL Farmer's Loop Test site) that represent various ranges of permafrost conditions and terrain in Interior Alaska were studied for site characterizations. Various tools and methods were used at the three sites to effectively characterize the subsurface information of the permafrost. Ancillary data for background information of the sites such as aerial photos and Light Detection and Ranging (LiDAR) imaging revealed details of terrain, vegetation cover and type, and surficial features that suggest geologic origins, ground ice presence (polygonal ground), drainage, and other characteristics. Surface terrain features can indicate whether (or not) permafrost exists at depth. Geophysical instruments for continuous subsurface transects were conducted using electrical resistivity tomography (ERT), capacity coupled resistivity (CCR), and ground-penetrating radar (GPR). Figure ES-2 shows an example of CCR surveys that reveals (in dark red colors) distinctive ice content features along each transect. The borehole data and geophysical measurements provided the variation of permafrost or its ice content as a function of depth or areal extent. The ground soil type, the frozen or unfrozen state of the ground, and moisture content from the borehole core data provided the physical information to improve the correlation between ground resistivity and subsurface conditions at the specific location of interest.

Figure ES-2. Resistivity profiles along two transects (in meters) at the Farmers Loop site indicating (in dark red) pockets of high ice content in the ground.
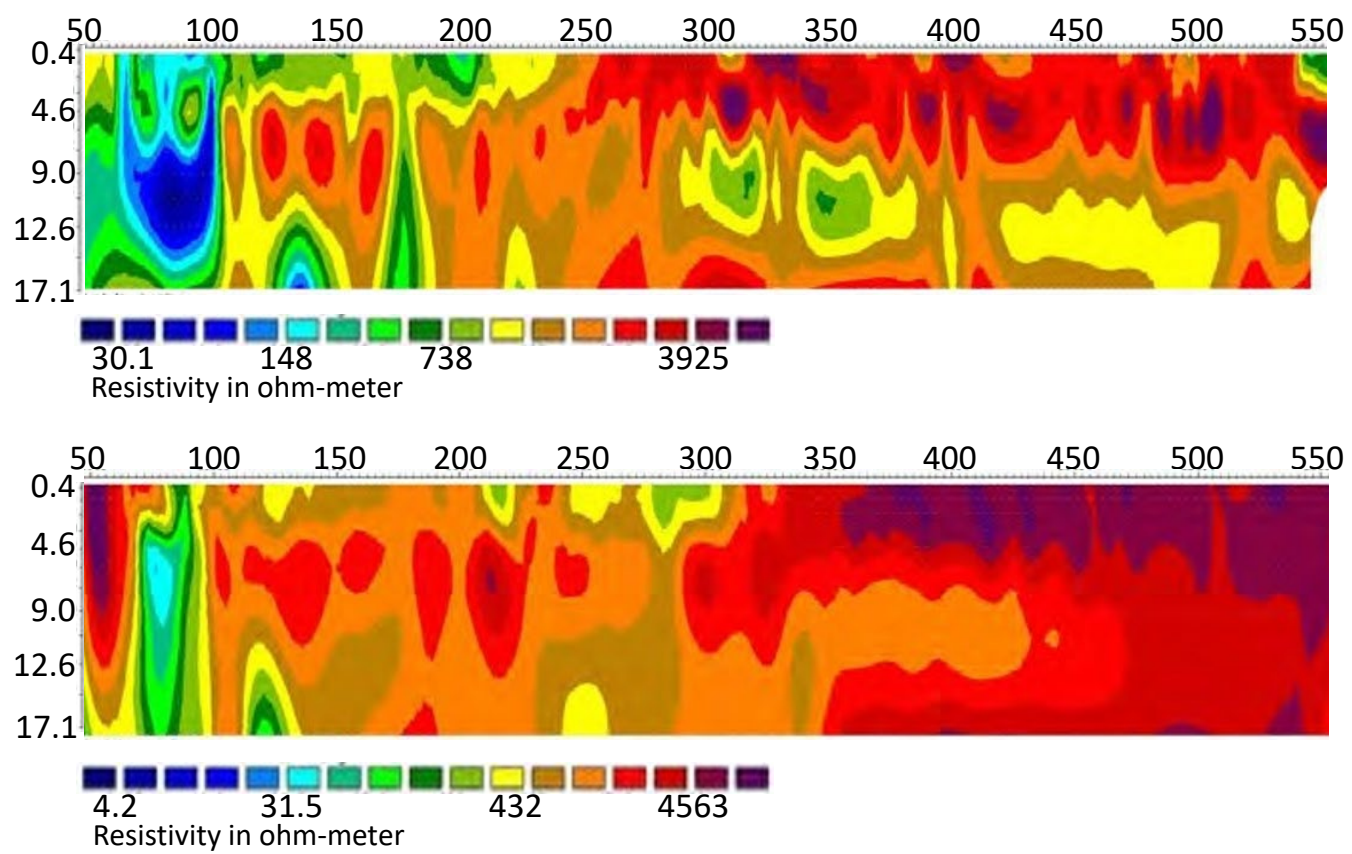
In addition, a geostatistical analysis based on a Bayesian Gaussian model using the surface terrain features, ground resistivity measurements, and limited borehole data was used to map the probability of subsurface permafrost, soil type, and soil water content. A surface terrain feature-derived probability of permafrost based on expert opinion (terrain prior) was used to identify the location and type of permafrost that might be present. Also, a probability relationship determined between ground resistivity and permafrost (resistivity prior) was used to predict the variation of probabilities of permafrost. The preliminary probability of permafrost map was used to identify regions of variation in the probability of permafrost, which were used to select locations to drill boreholes that were then used to provide ground truth and to improve the accuracy of permafrost maps. Data from borehole core analysis on the presence of ice, soil type, and water content were used to replace the resistivity prior with a resistivity-permafrost probability relationship based on local measurements. Calibrated relationships between resistivity and soil, and resistivity and water content were developed using core data from boreholes; these data were then used to create probability of soil type, water content, and distribution of permafrost (Figure ES-3).

Figure ES-3. Entropy of predicted permafrost using resistivity and boreholes at $50 \mathrm{~m}, 80 \mathrm{~m}$, and $140 \mathrm{~m}$. Higher values represent greater uncertainty. The areas of low uncertainty surround the locations of the boreholes. Highest uncertainty occurs in the area between observations of permafrost and thawed soils.

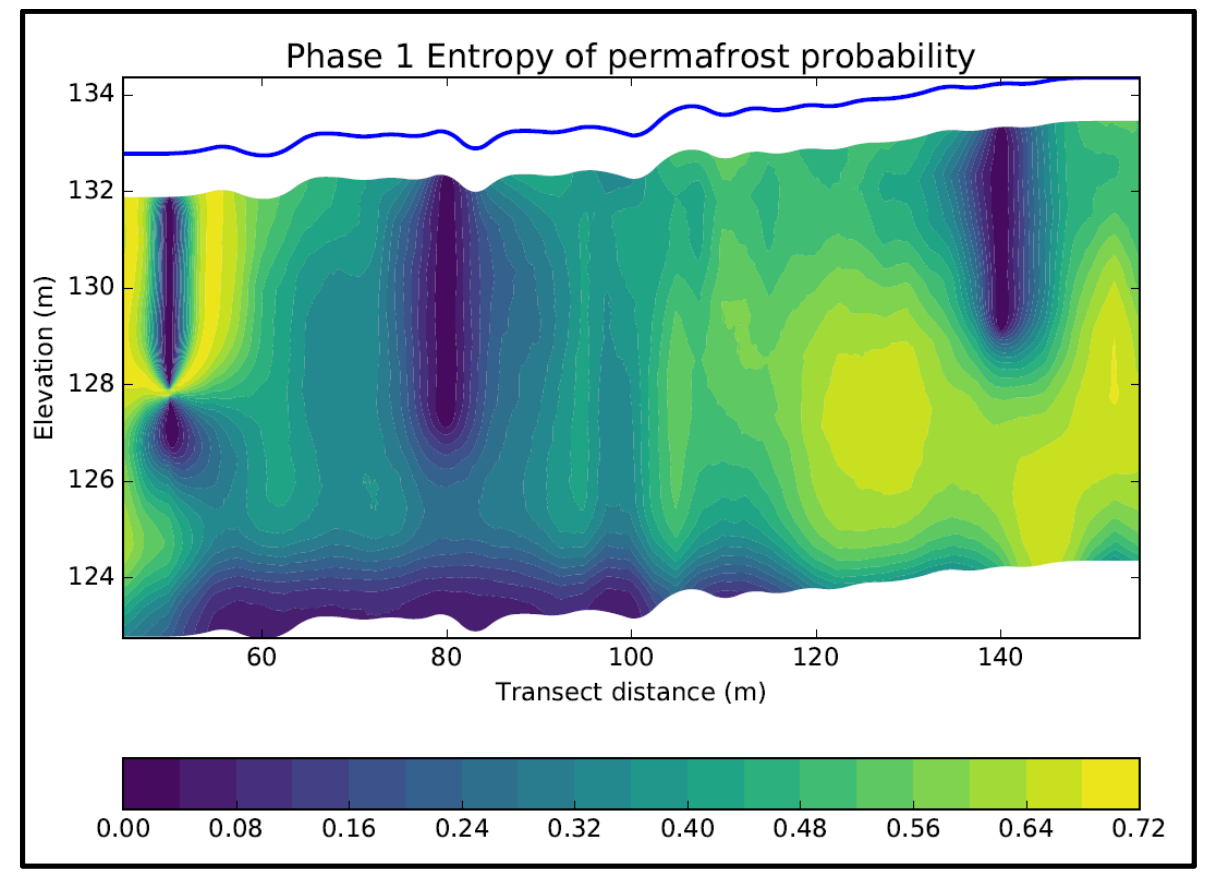


Likewise, the data analysis was conducted using up to 8 years of extensive subsurface temperature data that monitored the performance at five structures situated on epigenetic permafrost in Fairbanks, Alaska. (An epigenetic means the permafrost was formed after the deposition of the soil material.) These data were analyzed to provide a better understanding of the ground and foundation response in permafrost and to identify any deficiencies in the instrumentation installed on these foundations so that existing instrumentation can be augmented, or to ensure that data are sufficient to answer foundation performance questions. Also, a finite-element thermal modeling was developed to evaluate temperature in complex scenarios, such as beneath structures. This method permitted a model of various configurations for soil, insulation, and building geometries while accounting for complex considerations of properties such as the latent heat of water, unfrozen water content, varying air temperatures, $n$-factors (which represent surface conditions), and variability of ground thermal conductivity as a function of temperature. This modeling process allows for more accurate calculations of more complex geometries.

This study also formulated empirically vetted recommendations for an Early Warning Detection System (EWDS) for detecting when permafrost thaw is producing instability that may impact a building's foundation and climate effects. EWDS involves monitoring ground temperatures in critical areas under foundations; however, this temperature information must be considered in the context of how the changing subsurface thermal regime could adversely affect the building structure. This project describes the overall approach used for the EWDS process together with that used for thermal modeling; it leveraged long-term experience at CCHRC to recommend robust, effective approaches and designs for integrated modeling and monitoring.

Moreover, this study developed the Permafrost Foundation Decision Support System (PFFDSS). The PFFDSS is a web-based tool that allows engineers to harness the expertise developed through our site characterization, geostatistical analyses, and evaluation of foundations to make better-informed selections of foundation types for vertical and horizontal infrastructure on permafrost landscapes. The tool is intended to be open to all audiences and to benefit multiple users: 
- Engineers New to Permafrost Conditions. Students and engineers new to design atop permafrost can use the tool to learn about issues unique to building on permafrost, and to better frame and inform their approach to site assessment and foundation design selection.

- Experienced Engineers. Experienced engineers will find the data integration capabilities of the PFFDSS useful for quick, efficient, and highly visual assessments of proposed sites.

- Engineering/Research Offices. The PFFDSS provides a stable, central location for long-term storage and archival of baseline data for use in further studies and future design work.

Information derived from existing literature and expert knowledge were incorporated into the PFFDSS (Figure ES-1) to provide guidance and best practices for selection of foundation type. The existing literature is based on historical information compiled from Russian literature starting in the 1950 , including valuable data on various material physical properties, lessons learned, and protective measures for the design of foundations in permafrost areas. For example, the first experimental building designed and constructed according to the passive design alternative was a nursing home on permafrost in the Vorkuta region, in Russia, which was built in 1946 with a ventilated crawl space; most buildings since the late 1940s have been constructed with permafrost protection.

The PFFDSS can accept both geophysical transect data and borehole sample data, and can integrate that data geospatially for mapping, displaying vertically-aligned transect charts. These depict transect elevation/topography, spatially explicit resistivity values, interpreted soil type and stability, and potential thaw settlement. A benefit of this capability is that users can aggregate all of their data in a single location and keep track of multiple sites as they evaluate foundation types in the design process.

The geographic information system (GIS) data sources that inform the Desktop Assessment in the PFFDSS include surficial geologic features and ground ice content. The geologic features layer consists of digitized U.S. Geological Survey (USGS) quad maps covering much of the region around Fairbanks, Alaska. These data were the product of surveys conducted by Péwé (1975). These data contain a moderate level of detail, but comparable data were unavailable beyond this geographic area and throughout permafrost-affected parts of Alaska. As a result, Desktop Assessments must be undertaken without the benefit of these data in most areas. The USGS ground 
ice content dataset does cover the entire region, but these are rough estimates at coarse resolution for a parameter that is markedly variable spatially. Also, the ground ice content dataset is highly critical for effective site assessment and is extremely difficult to estimate with accuracy using surface proxies, as this dataset has. These GIS-based ground ice data should therefore only be used as a rough guide within the Desktop Assessment.

The PFFDSS currently facilitates an overall prototype site assessment through the Desktop Assessment, Field Survey, and Foundation Type Assessment phases. Algorithms are integrated for evaluating the Development Difficulty Factor (DDF), stability of soil layers at the site, and potential thaw settlement at the building site if a "reference foundation" is used. Our definition of a reference foundation is a slab-on-grade, heated structure. The algorithm for Foundation Type Assessment consists of five foundation types, which are compared against the data from the site that depict permafrost conditions; the respective estimates of cost and risk for each foundation option is also incorporated as part of the algorithm. All of these algorithms in the PFFDSS were developed in consultation with the entire project team, which reached a consensus on the outcome from data, analytical methods, and results.

\section{Results and Discussion}

Site Characterization: The Bayesian geostatistical analysis using surface terrain features, ground resistivity measurements, and limited borehole data was integrated to map the probability of subsurface permafrost, soil type, and soil water content to characterize potential building sites. Surface terrain feature-derived probability of permafrost based on expert opinion (terrain prior) was applied to identify the location and type of permafrost that might be present. The variation of probabilities of permafrost were determined through an iterative process. The primary permafrost map based on resistivity priors is probably adequate to map where permafrost exists or is not present. Transition regions between permafrost and non-permafrost regions may be missed due to the volume averaging of resistivity from both permafrost and non-permafrost data. The probability of a permafrost map based on three boreholes (approximately $50 \mathrm{~m}$ between drill holes) is adequate to predict the spatial variation of permafrost and to identify the transition between permafrost and non-permafrost regions. A fourth borehole (approximately $33 \mathrm{~m}$ between boreholes) would significantly improve the resolution of probability of permafrost, soil type, and water content maps. This is demonstrated by the significant improvement 
in data for soil type and water content from using six boreholes (approximately $25 \mathrm{~m}$ between boreholes) as compared to three boreholes to provide data to the geostatistical analysis. In general, the approach generated reasonable probability mapping and profiles of permafrost (Figure ES-3). Given the high probabilities of permafrost and the resolution for soil type and water content probability maps, additional boreholes would likely not provide data to significantly improve probability maps of permafrost, soil type, and water content.

Foundation Assessment: This study reviewed the temperature sensors and data installed in the instrumented CCHRC's Research and Testing Facility (RTF) and neighboring University of Alaska Fairbanks Sustainable Village. The RTF has three distinct foundation types: basement, slab-ongrade, and heated slab-on-grade. Two of four residential homes of the Sustainable Village are built on steel piles that extend $10 \mathrm{~m}$ into the ground, while the two western homes were constructed on polyurethane spray foam raft foundations, $254 \mathrm{~mm}$ thick, which are directly on the ground. Of the 237 original temperature sensors installed in and around the CCHRC, there are approximately 67 temperature sensors remaining in the original foundation providing useful data. Similarly, most of the sensors under the RTF Building were malfunctioning due to sensor failures. Of the instrumentations installed in 2012 to monitor the ground in the four residential homes of the Sustainable Village, only the sensors under the northwest building were functional and most of the temperature sensors under the western houses had ceased to function within a few months after they were installed due to a combination of moisture infiltration and power irregularities. Because these sensors were not accessible and could not be replaced, a new set of sensors and loggers were installed in October 2014 in new holes drilled from outside the houses.

However, available temperature data taken from the ground under the north lab foundation in the RTF indicated that permafrost depth has increased (or degraded) by approximately $1.2 \mathrm{~m}$ over the 8 years (between 2007 and 2016). Variations of permafrost depth from $1.75 \mathrm{~m}$ in 2016 to $5 \mathrm{~m}$ in 2013 were observed under the northwest building of the Sustainable Village. On the other hand, the permafrost depth was much shallow (i.e. $1.2 \mathrm{~m}$ in 2016) under the northwest building of the Sustainable Village.

The primary lesson learned from our assessment was that the monitoring of the original RTF and Sustainable Village included insufficient sensor 
metadata and lacked a clear plan for data analysis; these deficiencies made it difficult to interpret the data. A clear plan should be established before the installation to ensure that sensors are placed in optimal locations and also into the permafrost to ensure that measurements below the permafrost table are taken to reflect any indications of permafrost degradation. Instrumentation and other data system infrastructure should be properly installed in PVC pipe or conduit to increase their long-term durability, and regularly checked by reviewing the data to ensure that the systems are properly functioning. A data management plan should be established to ensure that the data-logging equipment is functioning properly and if necessary, that it is properly adjusted. The plan should include documentation that describes the sensor layout and that includes a regular schedule to review the data for consistency. The instrumentation design should be flexible enough to allow the sensors to be adjusted to accommodate needed measurement changes (e.g., to obtain better resolution in a region where the permafrost has more potential to thaw).

More importantly, thermal modeling could be a useful tool for predicting the permafrost table depth, which is information that can then be used to adjust the locations of the sensors; the data from the sensors can be used to verify the model. Understanding the changes in frozen soil beneath the foundation is crucial to model verification since the integrity of the foundation may depend on soil-bearing capacity and on the assumption that the ground remains frozen.

Early Warning Detection System (EWDS): Guidance for developing an EWDS has been in progress at CCHRC since 2006 when the RTF was originally built. This project has allowed researchers to explore the progress of this development. The development of these EWDSs has led to the current system, which puts the temperature data into context to provide useful information to the building manager/engineer. Additionally, a distributed temperature sensor (DTS) was deployed under one of the structures at the Sustainable Village during the winter of 2015-2016 to test its effectiveness in illustrating locations of thermal bridging, and to determine the optimal placement of the EWDS. Note that the DTS was not originally part of the proposal for this project.

Finally, as the EWDS is being developed, it is important to emphasize that the system comprises a process with an end product, the ultimate purpose of which is to adequately detect subsurface thermal conditions that pose a 
threat to structures. Finite-element thermal modeling should be employed to determine where critical locations exist for EWDS installation.

\section{Permafrost Foundation Decision Support System (PFFDSS):}

The PFFDSS is currently a fully constructed and functioning prototype, in which all three assessment phases are in place and logically linked. The current version of the PFFDSS offers

- A simple step-by-step interface to introduce engineers without permafrost experience to the important factors and considerations in permafrost foundation design.

- A partitioning of the assessment process into desktop and field surveys, which allows the user to refine the list of specific locations within the site, and to focus costly field data collection transects after a walking survey of the site.

- A central location for users to aggregate and integrate their data.

- Assessment algorithms that reflect the consensus of the expert team and, as such, that offer a theoretically-sound, technically valid point of embarkation for future development and refinement.

- Innovative methods for presenting results that help users understand their data. (An example is the swath analysis, which interprets the borehole sample data into a map-based surface of depth to a stable layer in the subsurface and a map-based surface of potential thaw settlement if a reference foundation type [slab-on-grade heated structure] were built there.)

This report describes and illustrates the PFFDSS technological design, including the structure of the interface and the general system architecture; it also includes the user guide and instructions. The current version of the PFFDSS is a fully constructed, in which all three assessment phases are implemented and logically linked. The tool is considered to be an affirmative proof-of-concept that provides a solid foundation for continued refinement and expansion. It is the team's considered opinion that the prototype PFFDSS is not yet suitable for fully vetted site assessments. This is mostly due to the complex nature of the analyses and permafrost conditions at hand, coupled with the pure novelty of the approach. Nevertheless, iterative, long-term testing, refinement, and expansion of the tool that leverages progressive feedback from willing testers and beta-users will yield a reliable, practical utility that will serve a broad user base. 


\section{Implications for Future Research}

Based on the findings of this project, there is a critical need to:

- Refine and expand the PFFDSS. The current version of the PFFDSS is a fully constructed and functioning prototype that implements and logically links all three assessment phases. The tool is currently an affirmative proofof-concept that accommodates continued refinement and expansion.

- Further develop the concept of thermal modeling. Thermal modeling is a complex and useful tool that provides feedback to the foundation designer to better account for the thermal impacts of their structure on frozen ground. Thermal modeling can be used to predict the permafrost table depth and to provide ancillary information to the PFFDSS tool. The scope of this work mainly included a consolidated resource for sometimes hard-to-find pertinent thermal modeling parameters used in defining material properties and pertinent boundary conditions in cold climates. Additional guidance for building the thermal model would provide users the skills necessary to understand model output and evaluate the appropriateness of the model results.

- Generate and compile suitable parameters for finite-element thermal analysis. This work developed finite-element thermal modeling to evaluate temperature in complex scenarios, such as beneath structures to permit modeling of various configurations. Further development of this modeling process would allow for more accurate calculations of more complex geometries, e.g., to determine where critical locations exist for EWDS installation.

- Develop a separate tool to assist engineers or designers to improve the long-term performance of infrastructure under conditions of increased future risk associated with climate change. This tool would be used to examine the mean annual air temperature (MAAT) value for predicting temperature projections and providing indicators of potential changes to permafrost conditions. 


\section{Introduction}

\subsection{Background}

Permafrost (defined as any ground substrate remaining colder than $0{ }^{\circ} \mathrm{C}$ for more than 2 consecutive years) is a fundamental landscape in the Arctic and Subarctic. This landscape is characterized by dynamically controlled physical and biological processes. Permafrost properties are extremely variable, often including vast differences in soil properties and ground ice content within relatively short distances (Jorgenson et al. 2010, 2013). These widely variable properties of permafrost affect its response to thermal changes and cycles that impact the foundation's long-term performance (Jorgenson et al. 2010, Osterkamp and Jorgenson 2009, Osterkamp et al. 2009, Walker et al. 2015). This is especially important as development of the Arctic continues; and key U.S. Federal agencies, such as the U.S. Department of Defense (DoD), will be establishing facilities in these remote locations (Hinkel et al. 2003, Walker et al. 2015).

Understanding the complex nature of permafrost and surficial properties is central to foundation engineering and to mitigating potential future impacts to the built infrastructure. Key parameters affecting performance for infrastructure engineering are ground ice extent and quantity (gravimetric moisture content), soil type, material properties (both frozen and upon thawing), active layer thickness, ground temperature, and thermal profile (Andersland and Ladanyi 2013, Johnston 1981). Perennially frozen materials may have highly variable ice content laterally and vertically due to the permafrost and ecosystem geomorphology (Jorgenson and Kreig 1988, Shur and Jorgenson 2007). Properties linked with these factors include the texture of the material (which influences pore ice content) and highly complex distributions of massive bodies of ice (ice wedges and sills, large lenses, thin discontinuous layers, and segregation ice) (Jorgenson and Kreig 1988, Pastick et al. 2014, Raynolds and Walker 2008).

To minimize both risk and cost, there is a need to interpret the heterogeneous conditions fully and thoughtfully, and to apply a sophisticated approach that characterizes a potential infrastructure site. The current routine method, which is simply to drill regularly (or less systematically) spaced boreholes, is costly and only partially informative. Each borehole 
provides information about only a single point location; drilling multiple holes often completely misses critical variability and spatial relationships between boreholes. Additionally, this method often does not specifically capture the boundary zones where critical permafrost-bearing capacity changes occur.

However, boreholes also provide indispensable exploratory and confirmatory site data that absolutely must be collected; the key is to employ a strategic, comprehensive approach that maximizes the value of a minimal number of deliberately placed boreholes with some level of interpretation between the boreholes. Ancillary data to inform borehole placement and to enable comprehensive analysis can be acquired through multiple primary methods and sources, including aerial and satellite imagery, geophysical measurements, geologic and topographic maps (including digital elevation models [DEMs]), and geospatial statistical analysis. In some cases, other high-resolution data are obtained through aerial or drone surveys, such as Light Detection and Ranging (LiDAR), and three-dimensional photography, as well as advanced computer vision techniques (e.g., structure from motion) for analysis.

Site analysis should ideally be approached as an iterative, multi-disciplinary process that builds progressively on knowledge gained from each previous step, and that synthesizes data from each surface and subsurface characterization technique and analysis that is done. The first step is to perform a background analysis using existing imagery of the site, which can provide information on terrain, landforms, vegetation, and hydrologic features, and which can yield some preliminary understanding of permafrost distribution (Jorgenson and Kreig 1988, Kreig and Reger 1982, Panda et al. 2010). Geologic investigations that have been completed, however general, will provide information on the subsurface geology and may include other data such as permafrost depths or ice distribution (Péwé 1975). Landforms or terrain units that are often identified as part of such investigations (Péwé et al. 1977) usually include a general description of their subsurface structure and sedimentology. In some instances, very detailed analyses of conditions affecting foundations, infrastructure, and construction are available (Péwé and Bell 1974, 1976a, 1976b, 1976c). 
Ideally, to best locate infrastructure within a given permafrost-affected regions and to select the best foundation construction approach that simultaneously minimizes risk and cost, the design-engineer will fully investigate conditions from the surface downward to the effective engineering depth, and laterally to encompass the entire areal footprint. In practice, hard limits on timing, budgets, and logistics typically prevent such complete assessments. This practice often results in either costly overbuilds to account for unknown permafrost conditions, or "underbuilds" that expose critical DoD infrastructure to undue risks of instability and integrity compromise.

A substantial amount of subsurface information is necessary to minimize construction cost (i.e., reduce the tendency to overbuild in permafrost-affected regions) while ensuring long-term integrity. However, at present and into the foreseeable future, the needs of DoD construction dictate that design and engineering work be distributed to personnel with a mix of experience. This includes both personnel highly experienced in permafrost construction, and those with the appropriate engineering backgrounds who may not yet have acquired the vast institutional knowledge of permafrost construction necessary to effectively design for permafrost landscapes. Engineers new to permafrost may benefit most from direct guidance and assistance for both site assessment and design selection; more experienced engineers can increase efficiency with more refined site assessment approaches. This work was undertaken to investigate the statistically supported, theoretical underpinnings for a tool, accessible to designengineers of a broad range of experience, that will reduce the effort and cost involved in site assessment and improve its effectiveness.

\subsection{Importance}

The Arctic and Subarctic have comprised key regions of geopolitical concern since World War II and continue to pose myriad important, and sometimes urgent, challenges for DoD mobility, operations, and infrastructure in the 21st century. Permafrost presents significant difficulties in the design, construction, and maintenance of horizontal and vertical infrastructure in Interior Alaska, where the Department of Defense (DoD) has five major installations and spends billions of dollars a year on MILCON projects. Interior Alaska permafrost is particularly problematic because it is "warm" (near $\mathrm{O}^{\circ} \mathrm{C}$ ) and ice-rich with massive ice features such as wedges, lenses, and segregation ice. This makes the permafrost susceptible to thaw settlement, 
which can have adverse to catastrophic impacts on built structures. Changes to permafrost can threaten critical built infrastructure.

Ground subsidence, and stability are primarily related to the phase change of ground ice to water at or near to ${ }^{\circ}{ }^{\circ} \mathrm{C}$. These can change when the soil thermal regime changes (by human activity, infrastructure emplacement, or systemic shifts related to weather and climate). Such subsidence may occur rapidly and catastrophically (in days), very slowly and systematically (over decades), or somewhere in between. Regardless of the time it takes for these changes to manifest themselves, they can ultimately decrease a building's structural stability, often by shifting, cracking, and otherwise damaging its foundation and by permanently compromising its structural integrity. DoD guidelines for effective construction on permafrost landscapes have existed for many decades. However, there is a crucial need for updated guidelines to account for the actual changes, to accurately characterize the site conditions in Alaskan permafrost regions for design and construction of infrastructure that is well suited to the site environment. It is important to make an informed selection of the most appropriate techniques for construction that will ensure the building's integrity over its prescribed lifespan.

\subsection{Objectives}

Our objective is to develop of set methodologies and knowledge-based decision tools that will provide better information to DoD planners and engineers faced with building in this challenging environment. These tools will aid in the full spectrum of tasks to provide resources to help engineers and designers perform the following activities:

1. Choosing the optimal location for infrastructure within a given site

2. Determining promising foundation alternatives

3. Developing finite-element thermal modeling parameters for estimating foundation impacts to permafrost

4. Assessing long-term monitoring options for identifying threats to infrastructure early on, while they can best be mitigated.

This study used an integrated approach (Figure 1), the goal of which was to (1) draw from the vast amount of information and methods useful in permafrost reconnaissance and essential for engineers new to permafrost, and (2) provide spatially explicit data storage and visualization options for seasoned permafrost engineers. 


\subsection{Approach}

This major project employed an integrated methodology and advanced approaches (Figure 1) to meet its goals and to fill SERDP's needs. This work involved three major efforts (Figure 1) including the primary components for:

1. Enhanced Site Characterization. Improved site characterization approaches that incorporate emerging technologies to enable the best selection of locations for infrastructure based on permafrost conditions within a site.

2. Foundation Alternatives Investigation. Improved foundation design selection criteria based on higher resolution site characterization of permafrost properties with clearer implications for short- and long-term infrastructure impacts.

3. Permafrost Foundation Decision Support System (PFFDSS). Creation of a web-based site characterization tool that allows for systematic foundation alternatives methodology. The PFFDSS allows for visualization of site characterization data, archives the data, and contains guidance for finite-element thermal modeling and temperature early warning detection.

a. Desktop Assessment. The PFFDSS initially engages the user through a series of questions to determine the type of building under consideration and to identify site conditions drawn from observations made while walking the site. These answers, coupled with Geographic Information System (GIS) based databases about permafrost and geological conditions in the area, allows the tool to provide an initial, rough assessment of the site. This includes a Development Difficulty Factor (DDF), which estimates the general difficulty likely to be encountered at the site based on superficial evidence of overall permafrost conditions (e.g., vegetation and hydrology).

b. Field Survey Assessment. This uses subsurface data collected in the field to get a detailed picture of permafrost conditions. The user is guided through scoping of geophysical data, including electrical resistivity tomography (ERT), capacity coupled resistivity (CCR), ground-penetrating radar (GPR), and borehole sample collection, which are then uploaded to the assessment tool. After upload, the user can review the integrated data to interpret potential soil stability and thaw settlement and distribution of subsurface characteristics including ground ice.

c. Foundation Type Assessment. Finally, the PFFDSS assesses the potential suitability of various foundation types against the conditions encountered in the field, providing a qualitative estimate of cost and risk for each for each foundation option in the context of site conditions. 
Figure 1. Flowchart illustrating the integrated approach used in the study.

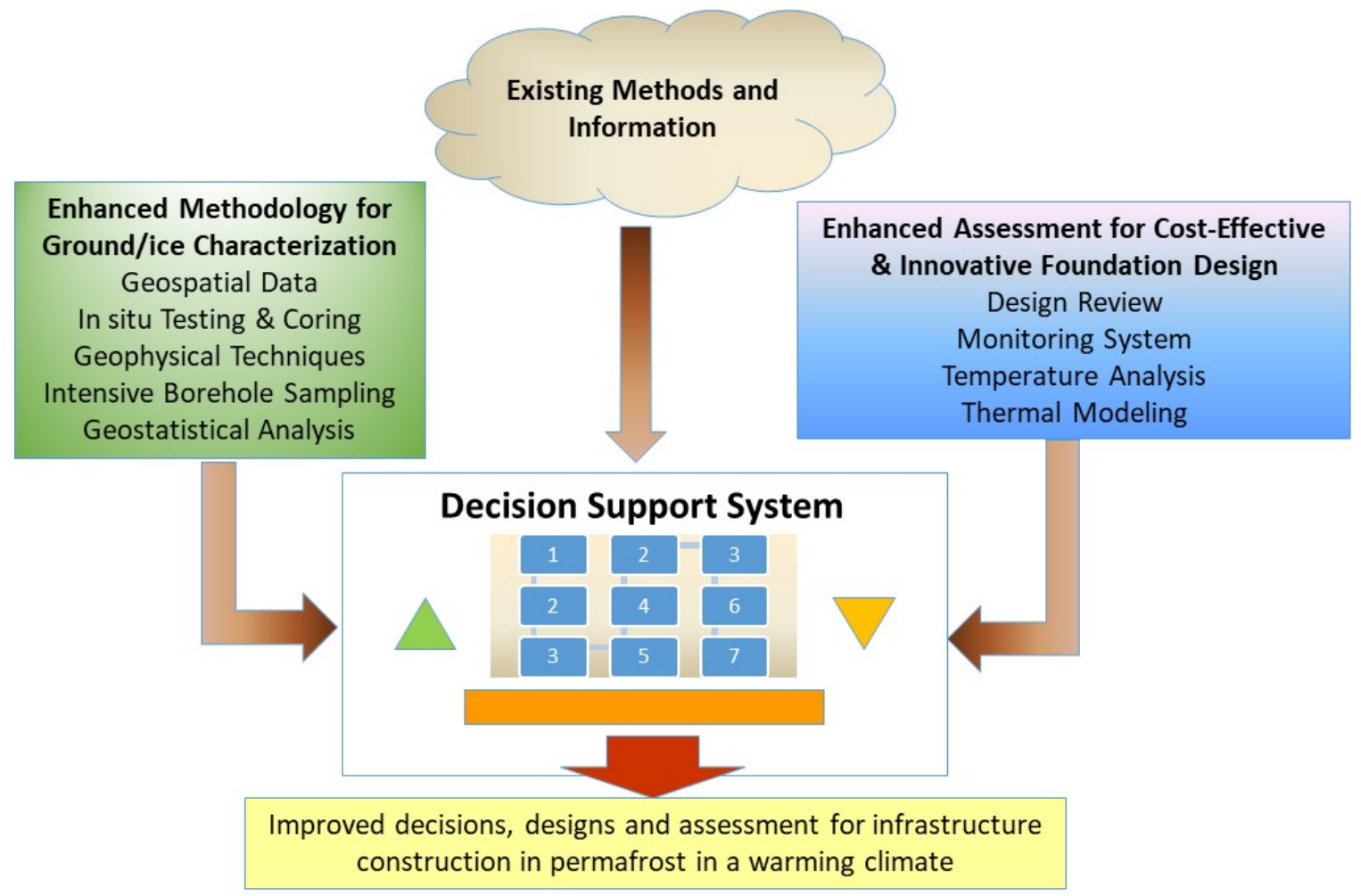

Because interrelationships among substrate, vegetation, hydrology, geomorphology, and disturbance determine permafrost properties are complex, it is necessary to synthesize information and analyses from multiple disciplines. To maximize long-term stability and integrity while minimizing cost, this overall design-phase approach includes the following specific components:

1. A linking of existing permafrost conditions with local landscape properties to better account for potential impact trajectories

2. The targeted use of contemporary geophysical techniques for subsurface characterization

3. The adoption of refined geostatistical routines to inform and hone costly drilling reconnaissance

4. A framework that allows the adaptation of finite-element thermal analysis for modeling the permafrost conditions

5. An assessment of contemporary foundation and ground-monitoring protocols to identify permafrost-degradation problems before they occur, or early in the process of their development

6. An expansive survey of global permafrost engineering approaches 
7. The incorporation of relevant knowledge into a coherent framework, as a tool in a Decision Support System (DSS) that allows both experienced and novice permafrost design-engineers to interact using the information in an organized way at any desired level.

For example, historical information from Russian literature were valuable for this study. These included lessons learned and protective measures that are helpful for design of foundation in permafrost areas. Information derived from existing literature and expert knowledge are incorporated into the DSS as best practices for selection of foundation type. Collectively, this holistic approach will provide design-engineers and practitioners with innovative technologies, models, and tools to:

1. Manage vulnerability through scenario planning specific for permafrost regions including Alaska

2. Guide the design, monitoring, and maintenance of infrastructure under shifting climate conditions

3. Markedly increase the efficiency and effectiveness of site assessments, characterizing relevant permafrost conditions.

The results of this project provide statistically supported, theoretical underpinnings for reducing site assessment effort and cost while also enhancing its effectiveness.

\subsection{Report outline}

The flowchart shown in Figure 1 illustrates the organization of this report. This introductory chapter is followed by general descriptions of the study locations as well as by the geophysical survey methods used in the study.

Chapter 2 describes data used for site characterization, including geospatial data to reveal details of vegetation cover and type and surficial features suggestive of geologic origins, ground ice presence (polygonal ground), drainage, and other characteristics. The site characterization section (2.2) also includes the acquisition of geophysical survey data on subsurface resistivity profiles to identify transects across the major terrain units. Section 2.3 describes the geostatistical analysis for fusing indirect data about the subsurface permafrost and soil conditions with direct measurements obtained through analysis of borehole cores. 
Chapter 3 relates the thermal modeling from empirical temperature data collected in instrumented foundation buildings constructed on permafrost terrain of varying ice content. Chapter 3 also outlines the processes for foundation designs, and systematic monitoring guidance (i.e., EWDS) for buildings.

Chapter 4 outlines the web-based tool based on the site characterization, geostatistical analyses, and evaluation of foundations to make better-informed selections of foundation types for vertical and horizontal infrastructure on permafrost landscapes.

Finally, Chapter 5 provides a summary and conclusion of the study findings for the project.

Appendix A classifies and describes in detail the stratigraphy pertaining to the site characterization efforts from the boreholes.

Appendix B includes a literature review of Russian publications on building on permafrost that focuses on topics that guided our recommendations and that are implemented in the web-based tool.

Appendix $\mathrm{C}$ illustrates and describes the web-based tool, including the structure of the interface and the general system architecture. Appendix $\mathrm{C}$ also contains the user guide and instructions for the Permafrost Foundation Decision Support System (PFFDSS). 


\section{Enhanced Site Characterization}

Site characterization was one of the three major efforts of this SERDP project undertaken to establish new methods for ground ice detection and delineation. Three test sites were characterized using existing aerial photographs, ERT and CCR measurements, and closely spaced continuous core boreholes: (1) Cold Climate Housing Research Center (CCHRC), (2) Permafrost Tunnel (PT), and (3) Farmer's Loop (FL) in Interior Alaska (Figure 2). The three sites are representative of a range of permafrost types in Interior Alaska (Table 1). The three types represented are (Bray, French, and Shur 2006)

1. Epigenetic permafrost (meaning the permafrost was originally formed after the deposition of the soil material) in active and abandoned floodplains generally containing ice and ice wedges, but less than syngenetic permafrost in silt located at CCHRC

2. Ice-rich syngenetic alluvial-fan silt deposits with some locations of lowered permafrost table found at FL

3. Syngenetic permafrost (permafrost that formed through a rise of the permafrost table during the deposition of additional sediment or other earth material on the ground surface) in silts where ice contents may exceed 100 to $200 \%$ and where numerous large ice wedges are present at depth found at PT.

Geophysical techniques such as ERT and GPR have been used successfully for subsurface profile imaging. ERT measures the transient response of subsurface materials to an electrical impulse, where frozen ground is higher in resistivity while thawed or wet soils are high in conductivity. The energy is input either by direct electrical conductors (galvanic) or via CCR, the latter of which allows for long continuous surveying beneficial in surveying linear infrastructure. GPR records velocity changes of a radar frequency impulse into the subsurface, where differences in dielectric permittivity cause velocity and polarity changes of the return signal, indicating depth and location of major subsurface changes. Layered strata such as sediments and manmade earthen projects can be imaged readily, also phase change boundaries such as the permafrost table and water table are easily discernable.

ERT and CCR were initially used to acquire the data on subsurface resistivity to identify transects across the major terrain units where subsurface data from drilling boreholes can provide ground truth to help interpret the 
resistivity data. The Advanced Geosciences Inc. Super Sting R-8 System for ERT and the Geometrics OhmMapper TR5 for the CCR were used to measure resistivity and the Geotomosoft Solutions software RES2D/RES3D used to process the raw data. Boreholes were drilled at a $3 \mathrm{~m}$ spacing at CCHRC and at a $6 \mathrm{~m}$ spacing at the PT and FL test sites, because it was determined that changes in subsurface conditions could be readily captured with a $6 \mathrm{~m}$ separation between drilled borehole. Each borehole was cored continuously and subsampled at every $0.1 \mathrm{~m}$ depth to characterize soil type and the thawed or frozen state of the soil. The cores were subsampled every $0.3 \mathrm{~m}$ for moisture content measurements. Drill holes at CCHRC generally extended to about $7 \mathrm{~m}$ depth to the contact with a layer of relatively impervious frozen gravels.

Laboratory analyses of soil core data done at vertical sampling intervals of $0.3 \mathrm{~m}, 0.6 \mathrm{~m}$ and $1.20 \mathrm{~m}$ indicated that $0.6 \mathrm{~m}$ sampling provided the best resolution of changes in moisture content. A detailed database of soil type and moisture content for CCHRC Transect $\mathrm{T} 3$ was used for developing the geostatistical analyses to calibrate the CCR and ERT resistivity survey data to subsurface properties of the permafrost. The data were also used to determine the effects of degrading the resolution data while still producing a representative cross-section of subsurface permafrost properties relevant to infrastructure construction. All data and geospatial map layers are stored in the Postgress database linked to the QGIS geographical information system.

\subsection{Site selection}

The three test sites (Figure 2) contain four ranges of permafrost conditions that are representative of terrain in Interior Alaska (Table 1). The four main types of permafrost represented are: (1) epigenetic permafrost in active and abandoned floodplains, generally containing ice and ice wedges, but less than syngenetic permafrost in silt (CCHRC), (2) syngenetic permafrost in silts where ice contents may exceed 100-200\% (Bray, French, and Shur 2006) and where there are numerous large ice wedges at depth below an ice-poor Holocene layer (PFT, the CRREL Permafrost Tunnel), and (3) mixed ice-moderate to ice-rich syngenetic permafrost in silty colluvium overlain by an ice-rich intermediate layer (FL, the CRREL Farmers Loop Site). The CCHRC site, which is the flagship of the three, served as 
the site that accommodated the most intensive analysis of the basis of permafrost terrain variability and of sophisticated permafrost designed infrastructure. The excellent accessibility that this site allowed us to conduct geophysical analyses on multiple transects and provided good access for our drilling rig to repeat and expand borehole patterns as required by our iterative site analysis. Results from the CCHRC were used to complement our knowledge base using the CRREL Permafrost Tunnel site (using similar methods, slightly increasing the spacing of boreholes and reducing sampling frequency), and the Farmers Loop site (Figure 2).

Table 1. Test sites for evaluating site characterization methodology.

\begin{tabular}{|l|l|l|l|}
\hline Location & Type & Characteristics & Unique Attributes of Site \\
\hline $\begin{array}{l}\text { Cold } \\
\text { Climate } \\
\text { Housing } \\
\text { Research } \\
\text { Center } \\
\text { (CCHRC) }\end{array}$ & $\begin{array}{l}\text { Types 1 and 2: } \\
\text { Epigenetic } \\
\text { permafrost in } \\
\text { floodplain } \\
\text { alluvium }\end{array}$ & $\begin{array}{l}\text { Ice-poor sand and gravel } \\
\text { deposits; at places silt } \\
\text { deposits with the ice-rich } \\
\text { intermediate layer on top. }\end{array}$ & $\begin{array}{l}\text { The site is bisected by a buried } \\
\text { meander channel common to } \\
\text { these alluvial deposits. The } \\
\text { meanders are composed of } \\
\text { stratified finer grained material } \\
\text { and organics that are generally } \\
\text { ice-rich. }\end{array}$ \\
\hline $\begin{array}{l}\text { CRREL } \\
\text { Permafrost } \\
\text { Tunnel } \\
\text { (PT) }\end{array}$ & $\begin{array}{l}\text { Type 4: } \\
\text { Syngenetic } \\
\text { permafrost in } \\
\text { upland loess }\end{array}$ & $\begin{array}{l}\text { Massive silt deposits, with } \\
\text { the ice-rich intermediate } \\
\text { layer on top underlain by } \\
\text { relatively ice-poor silt; ice- } \\
\text { rich silt with large ice } \\
\text { wedges from the depth of } \\
\text { 4to6 m upto15to 20 m. }\end{array}$ & $\begin{array}{l}\text { Underlain by tunnels that allow } \\
\text { permafrost. } \\
\text { Numerous drill cores; electrical } \\
\text { power and climate records. }\end{array}$ \\
\hline $\begin{array}{l}\text { CRREL } \\
\text { Farmers } \\
\text { Loop Site } \\
\text { (FL) }\end{array}$ & $\begin{array}{l}\text { Type 4: } \\
\text { Syngenetic } \\
\text { permafrost in } \\
\text { alluvial-fan silt } \\
\text { deposits }\end{array}$ & $\begin{array}{l}\text { Silt deposits, ice-rich from } \\
\text { some depth; at places } \\
\text { with the lowered } \\
\text { permafrost table. }\end{array}$ & $\begin{array}{l}\text { Linnel plots; Army Technical } \\
\text { Manual TM-5-852-3 (HQDA 1954), } \\
\text { done here. Electrical power and } \\
\text { climate records. }\end{array}$ \\
\hline
\end{tabular}


Figure 2. Location of the test sites near Fairbanks, AK.

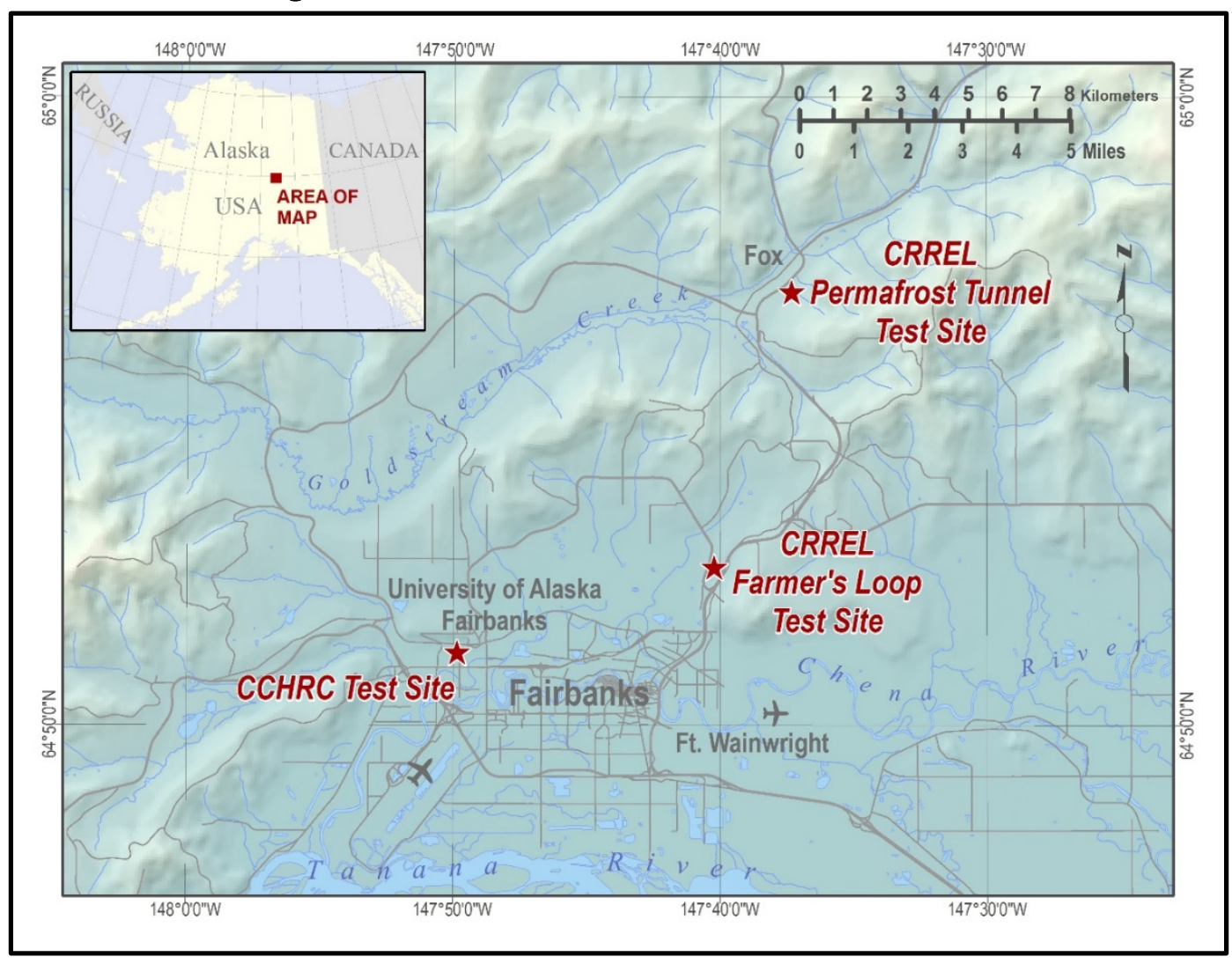

\subsection{Site characterization analysis}

\subsubsection{CCHRC site}

We conducted the initial research on permafrost site characterization at the CCHRC test site beginning in April 2014. We focused our efforts on intensively investigating the subsurface through multiple techniques done in stages and on oversampling the permafrost in boreholes (every $3 \mathrm{~m}$ along a transect) so that the results could be used for the geostatistical analysis to define optimum data requirements when building on permafrost. In this section, we document the results obtained sequentially to illustrate the methodology of investigations of sites underlain by permafrost.

Following a background search on existing surficial and subsurface information in the literature and in the records at the CCHRC, our first appraisal of the test site was done using historic aerial photography from 1949 through 2013 (Figure 3). Analysis of these photos (at a larger scale 
than in the figure) revealed details of vegetation cover and type and surficial features suggestive of geologic origins, ground ice presence (polygonal ground), drainage, and other characteristics.

Combined with a 2010 LiDAR image of the site (Figure 4), the terrain features (alluvial fan, low gradient stream channels [swales, sloughs]) are evident. These landforms were previously classified by Péwé et al. (1977) and the primary depositional sequences and associated subsurface materials were described, providing an initial appraisal of what we would potentially encounter in our detailed site investigations. The alluvial-fan deposits are largely ice-rich silt, whereas the stream deposits are coarser, stratified silty sand, and silt with organic matter.

Detected changes to the terrain, such as along the roads or other disturbances, over the time period of the photography revealed that thaw and settlement (thermokarst) may have occurred, which may indicate the presence of ground ice (Figure 3). Similarly, the vegetation cover had changed; vegetation increased since 1949 in the western two-thirds of the site, while less change was observed in the area of the swale and slough deposits. Evidence of disturbance and infrastructure development in 2013 were observed in the area, including the CCHRC Research and Testing Facility (Figure 3, upper left, 2013) and four residential buildings (Figure 3, upper right, 2013). Paths and off-road vehicle trails have crisscrossed the site, some of which appeared to have induced thaw due to disturbance of the vegetation and soils. 
Figure 3. Historic aerial photography of the region around the CCHRC test site; the year in which photo was taken is indicated in the upper left corner. The red box on the 2013 image locates the CCHRC test site.
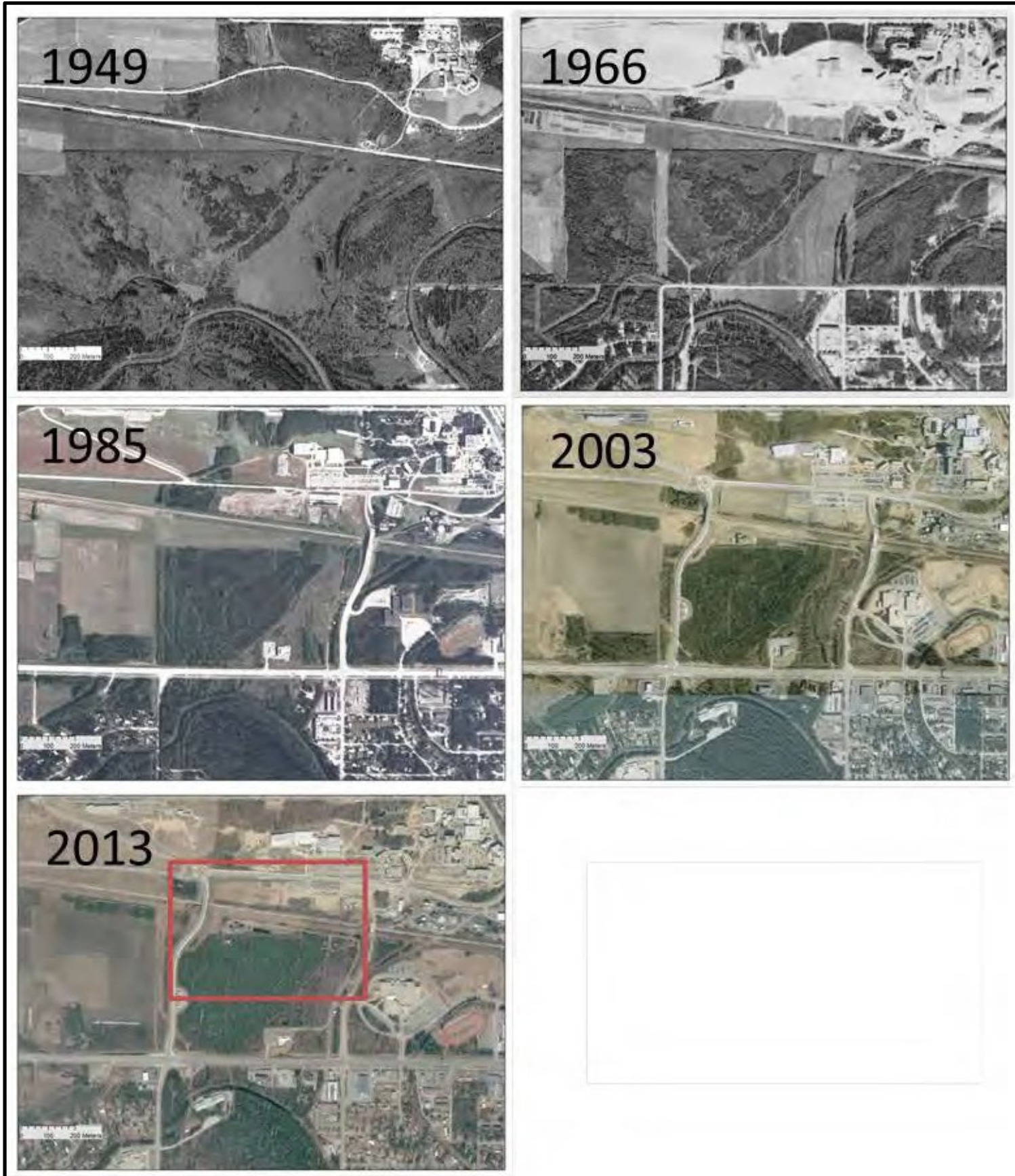
Figure 4. Recent false color LiDAR image of the CCHRC test site in 2010, with elevational changes shown. Patterns indicative of former stream channels or sloughs are evident in the eastern third of the image to right of the red line. Alluvial-fan deposits lie to the left of the red line. Trails through vegetation occur in the western two-thirds; roads with embankments are clearly evident.

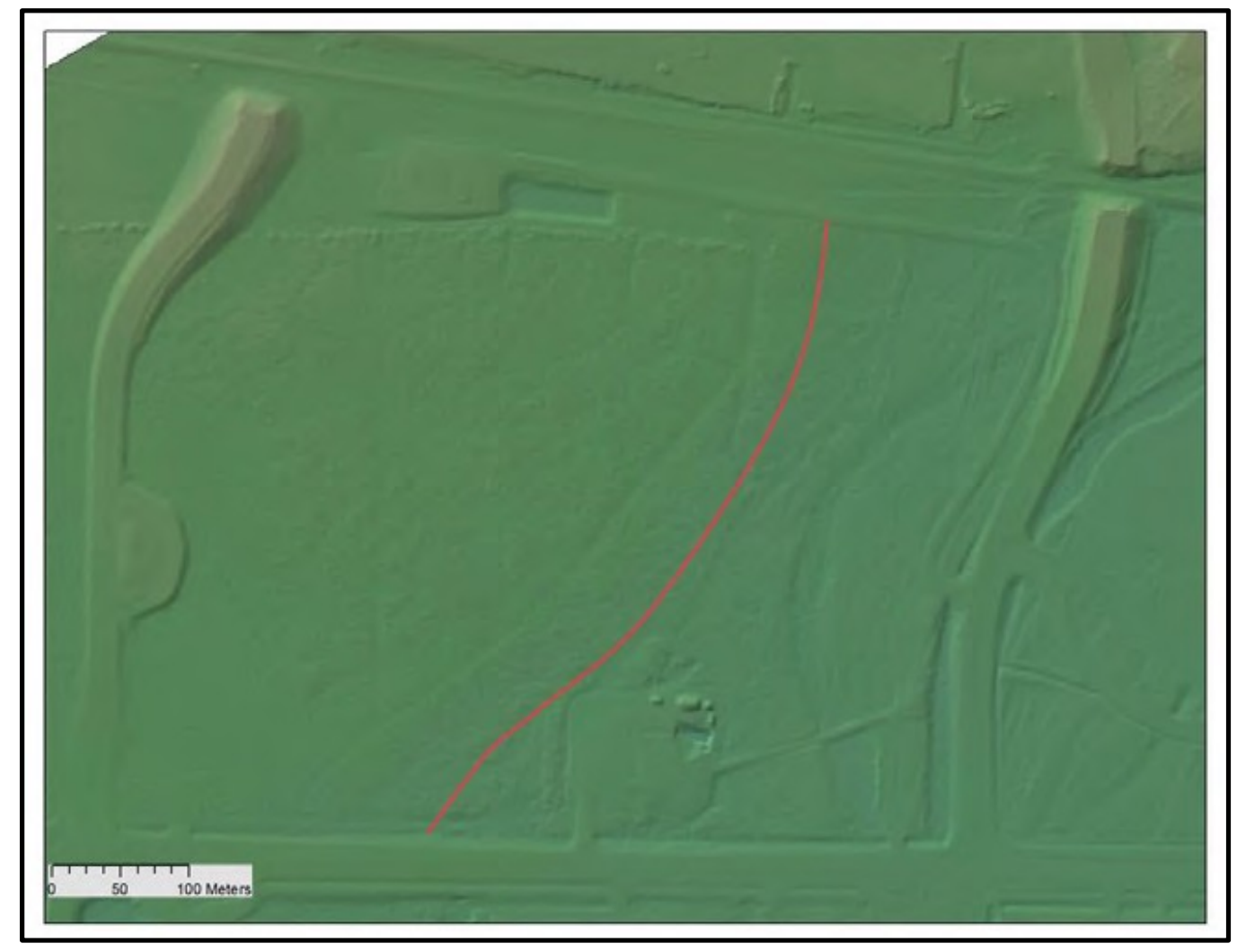

Our initial reconnaissance site visit examined the terrain and hydrology using the various paths and trails across the site. Based on the background information and the visual assessment, we decided to first investigate the eastern section, to provide a direct link to the CCHRC residential test buildings located at the northern end of the eastern section.

To begin assessing subsurface conditions, we ran ERT transects adjacent to the instrumented residential buildings. This led us to establish the first transect (Transect T1) along an existing trail that extended from the road at the north end of the site between the buildings and into the swale area at the southern end (Figure 5). The ERT resistivity data (Figure 5) clearly reveal thaw in the area disturbed by the railroad and gravel access road to the main CCHRC test facility, as well as between the residential buildings (low intensity resistivity, mostly blue in Figure 4). The central part of the ERT cross-section shows higher resistivity and two apparently ice-rich 
zones centered at $\sim 70 \mathrm{~m}$ and $114 \mathrm{~m}$ distance. We subsequently extended Transect T1 to traverse the entire site and acquired both CCR and ERT data along its length (Figure 6).

Following preliminary analysis of these data, we established four additional transects along existing trails across the eastern section of the property. We selected locations for five boreholes in the swale and slough terrain to provide ground truth based on the variation in intensity and anomalies in the resistivity data on Transects 1 to 5 (Figure 7). Subsequently, we added six additional boreholes along Transect 4 to examine the high resistivity patterns in the alluvial fan deposits. The boreholes verified high ice content and existence of ice wedges at these locations.

The east-west transects extended across the swale topography and into the forested alluvial-fan deposits. Transect $\mathrm{T} 4$ extended $\sim \mathrm{N}-\mathrm{S}$ entirely within the forested section (Figure 8). Figure 6 shows the CCR imagery cross-section of each transect (Transects $\mathrm{T}_{2}-\mathrm{T}_{5}$ ). Ice-rich and ice-poor zones are clearly evident in each transect. However, in general, the forested alluvial fan had much high resistivity values and complex patterns than did the stream deposits. These suggest both a high ice content and ice-wedge compositions. 
Figure 5. ERT profile Transect T1 at CCHRC site; transect begins on left and trends $\mathrm{W}$ to $\mathrm{E}$. Location is shown by long red line on aerial photograph. Two zones of high resistivity indicate ice-rich subsurface materials. Blue zones are thawed area resulting from previous disturbance to the vegetation and soils. Borehole locations denoted by BH\#. North is to the top. Resistivity transect is expressed in ohm- $m$ and profile in meters.

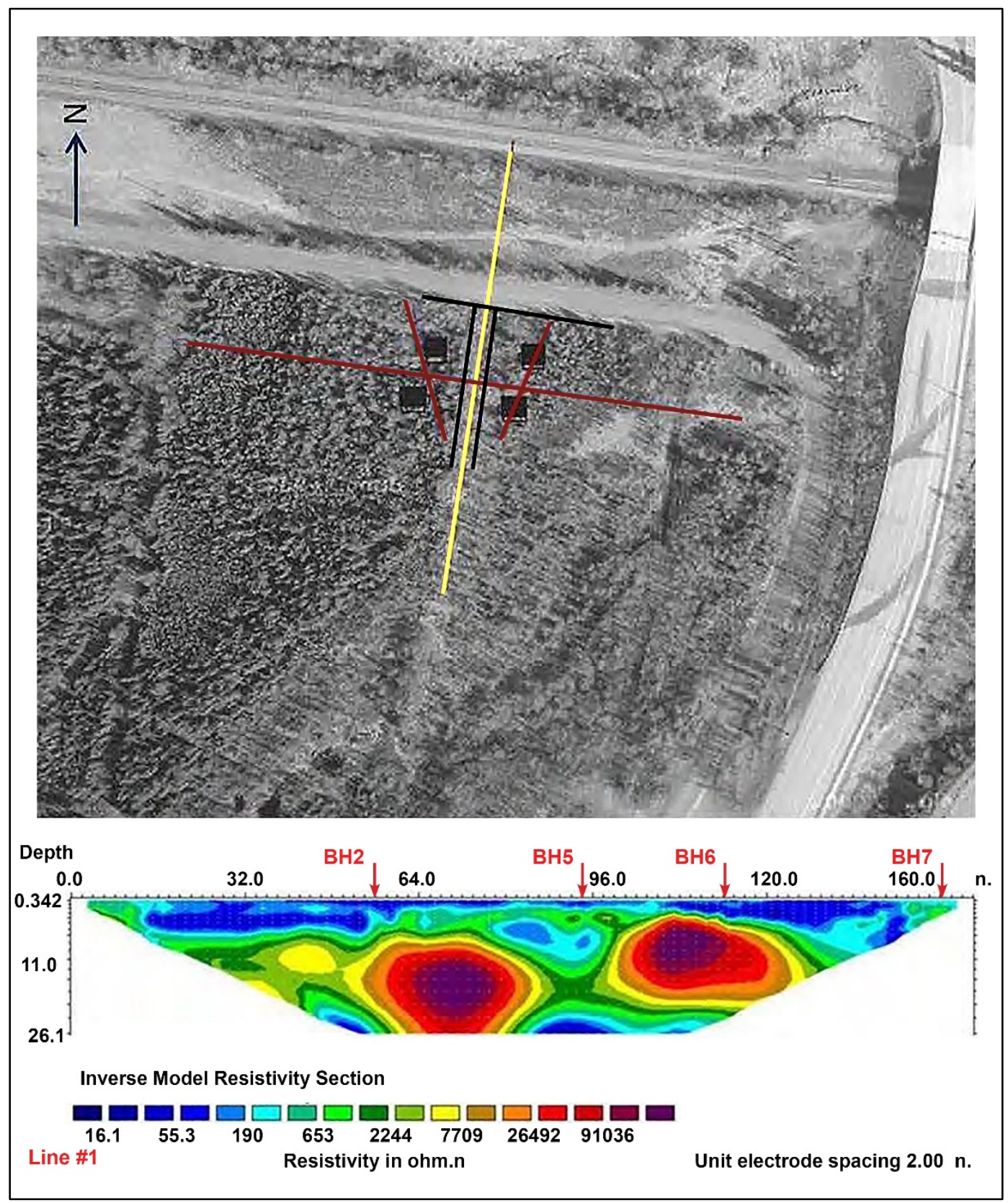


Figure 6. Location of Transect T1 with results of CCR survey shown. Red denotes high resistivity (ice-rich); blue low resistivity (ice-poor). North is to the left. Resistivity transect is expressed in ohm-m and profile in meters.

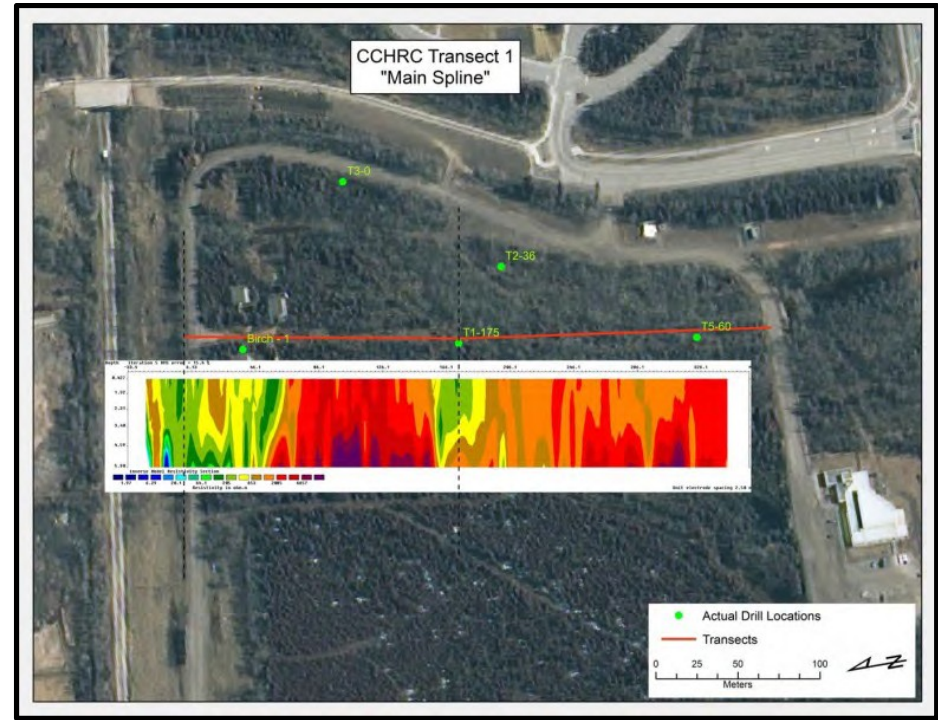

To verify and further interpret the resistivity data, we selected locations for five boreholes in the swale and slough terrain to provide ground truth based on the variation in intensity and anomalies in the resistivity data on Transects T1 to T5 (Figure 7). Subsequently, we added six additional boreholes along Transect T4 to examine the high resistivity patterns in the alluvial-fan deposits (Figure 7). The boreholes verified high ice contents and existence of ice wedges here. 
Figure 7. Location of geophysical Transects T1 to T5 (orange) during initial phase of the CCHRC site subsurface investigations. Borehole locations (green, yellow) were cored for ground truth to interpret the CCR and ERT data cross sections. North is to the top.

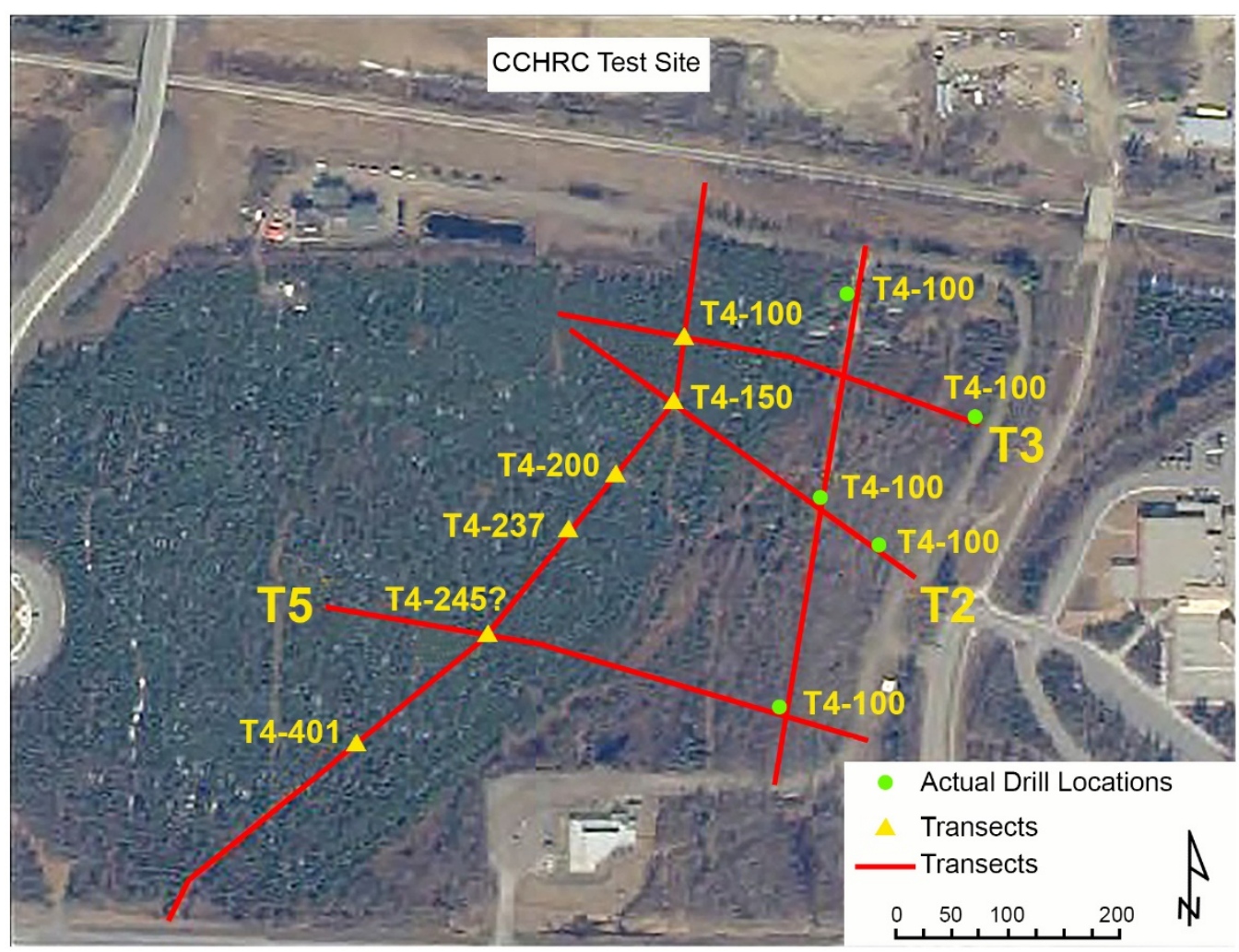




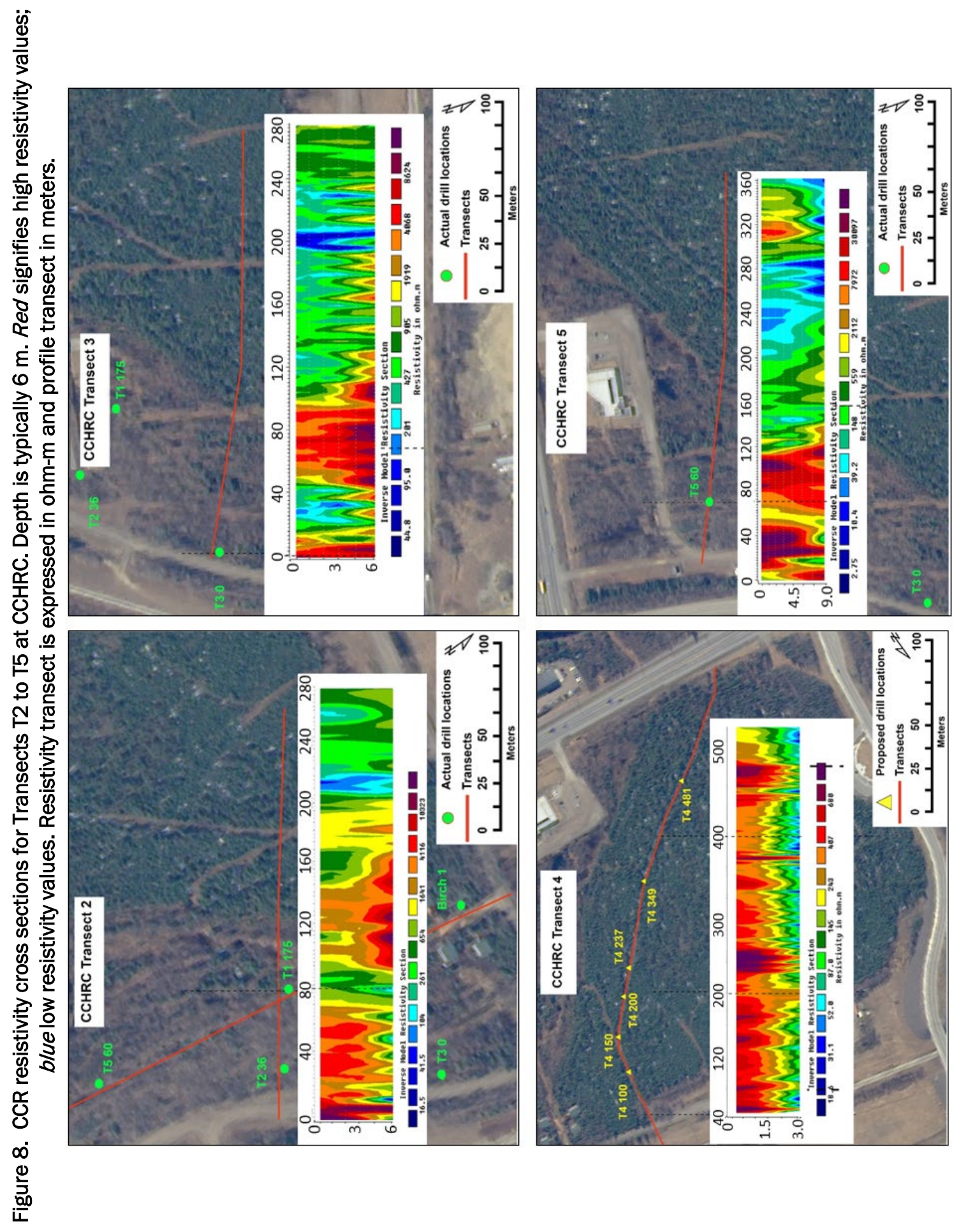


In addition, we ran GPR surveys on Transects $\mathrm{T} 1$ to $\mathrm{T} 5$. The profile of Transect T1 (Figure 9) is representative of the results we obtained. This transect crosses from the alluvial-fan terrain (left side of profile to $\sim 140 \mathrm{~m}$ mark) into that of the channel and slough deposits. The area of alluvial-fan deposits had very limited penetration $(\sim 1.5 \mathrm{~m}[\sim 5 \mathrm{ft}])$, while that within the slough area revealed features to depths of $\sim 4 \mathrm{~m}(\sim 13 \mathrm{ft})$. This response is likely due to highly attenuating silt deposits in the fan while coarser materials occur within the channel deposits.

Figure 9. GPR profile of Transect T1 at the CCHRC site acquired at $330 \mathrm{MHz}$ in April 2014. This profile is representative of the surveys conducted on Transects T1 to T5. It begins on the west in the alluvial-fan terrain and transitions into the channelized slough terrain at $140 \mathrm{~m}$ mark. The lack of returns in the alluvial-fan section is due to high attenuation by the frozen alluvial silt deposits, whereas the stronger and deeper returns from the channel deposits is likely due to their coarser composition. Only the base of the active layer is evident in some locations due to its frozen condition in April.

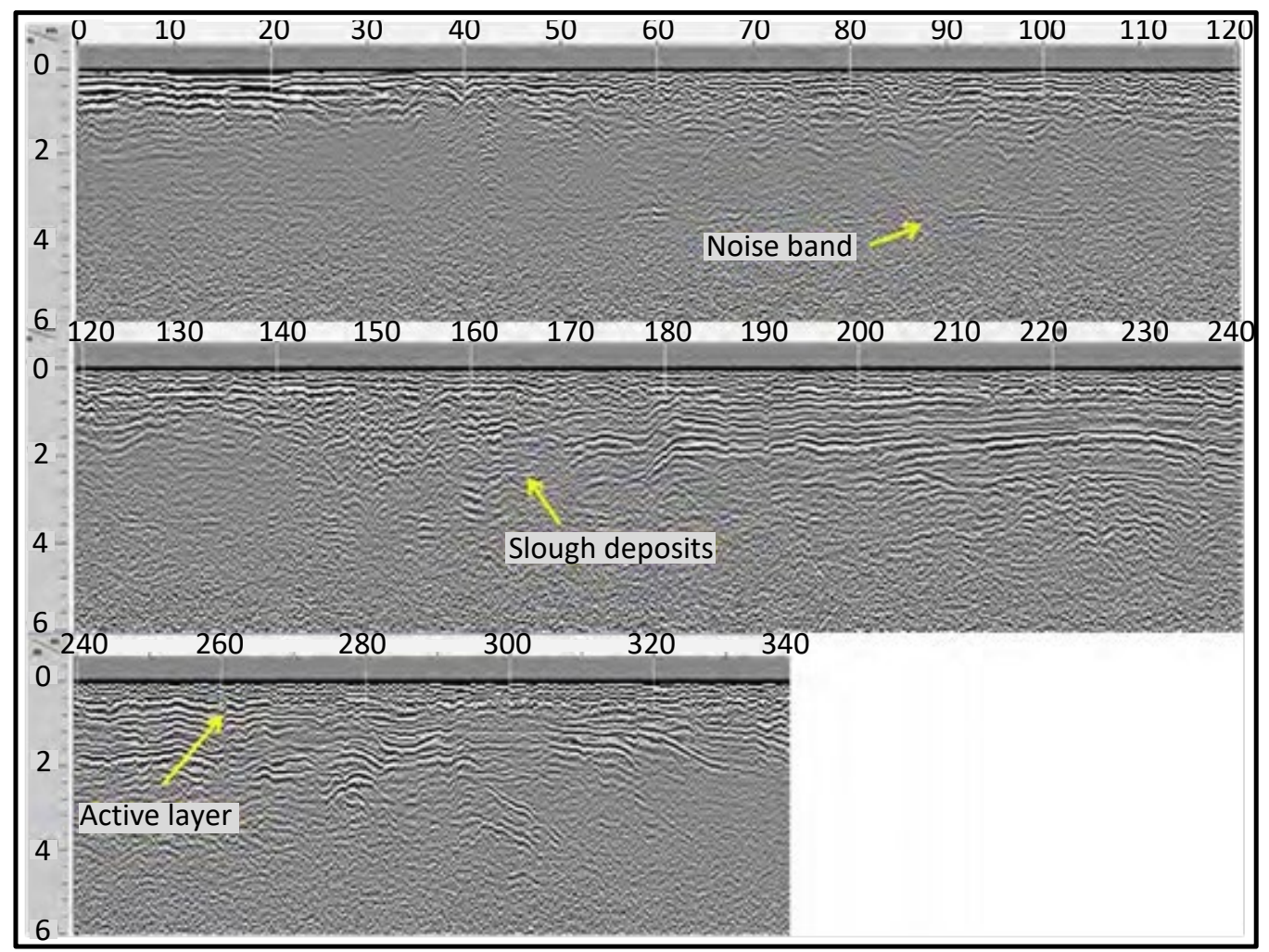

Continuing on the iterative analysis, we selected a section of Transect $\mathrm{T} 3$ to conduct the detailed drilling and sampling of the subsurface properties for the initial work on the geostatistical analyses and to improve interpretation methodology for the CCR and ERT resistivity data. Boreholes were drilled at 
a $3 \mathrm{~m}$ (10 ft) spacing from $70 \mathrm{~m}$ to $150 \mathrm{~m}$ ( $230 \mathrm{ft}$ to $492 \mathrm{ft}$ ), in the section located to south of the CCHRC residential buildings (Figure 10). Each hole was cored continuously and subsampled every $30 \mathrm{~cm}$ (12 in.) depth; most holes extended $\sim 7 \mathrm{~m}(\sim 23 \mathrm{ft})$ deep to the contact with a layer of relatively impervious, frozen gravels at the base of the sequence. We used our newly developed cryostratigraphic logging of these cores, which is described in some detail in Appendix A, including photographic examples of cores and their cryostratigraphic classification.

Figure 10. Section of Transect T3 chosen for closely spaced (3 $\mathrm{m}$ [10 ft]) boreholes and highly detailed sampling of cores. The section traverses from the eastern swale and slough terrain into the western alluvial-fan terrain. Yellow dots mark borehole locations. The blue dots mark the location of the high-resolution ERT survey for a three-dimensional modeling of the subsurface resistivity. North is to the bottom.

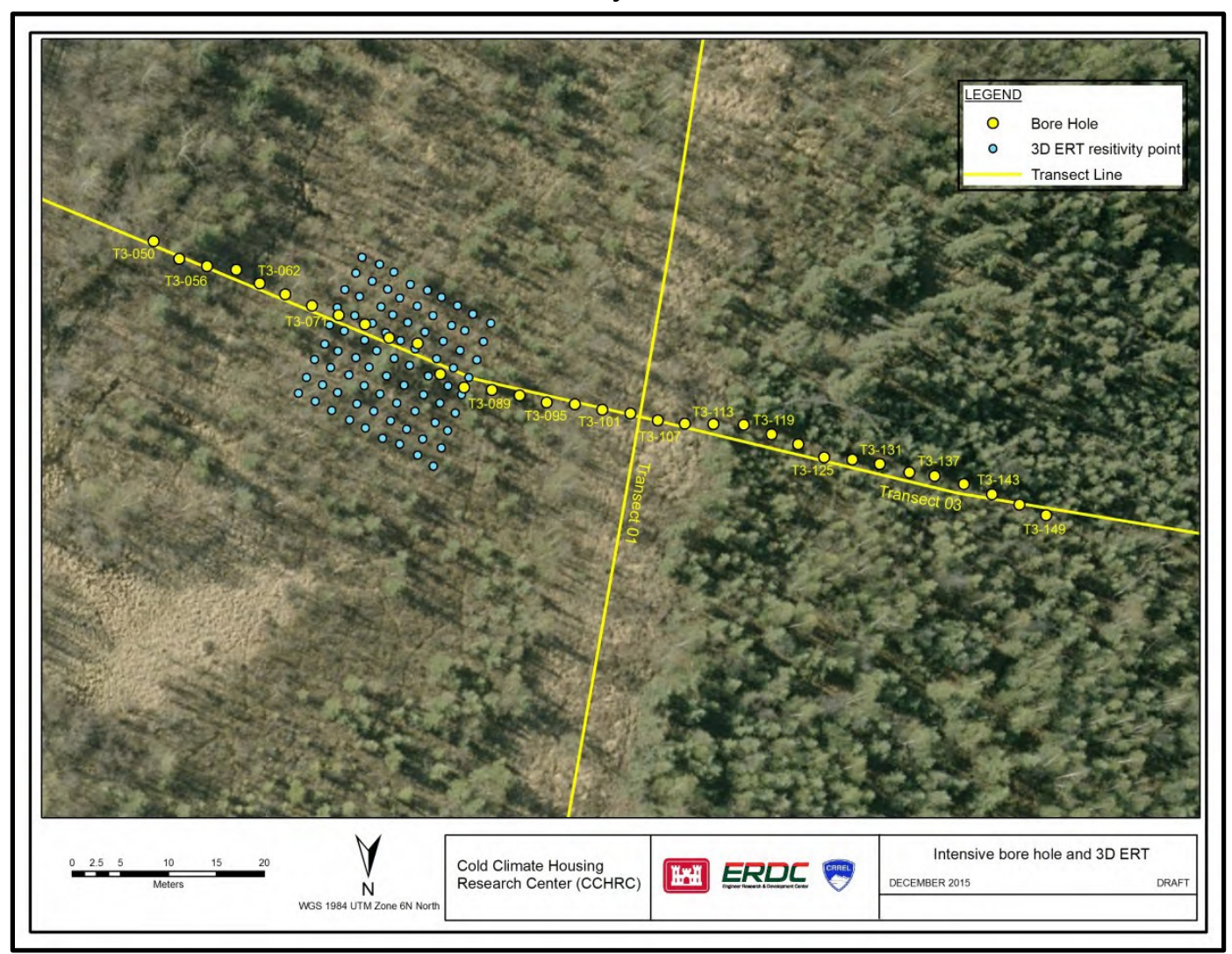

Figure 11 shows the geologic cross-section based on the cryostratigraphic logging, which describes each unit in detail, including tabulated laboratory analyses of moisture content at the base of the figure. 


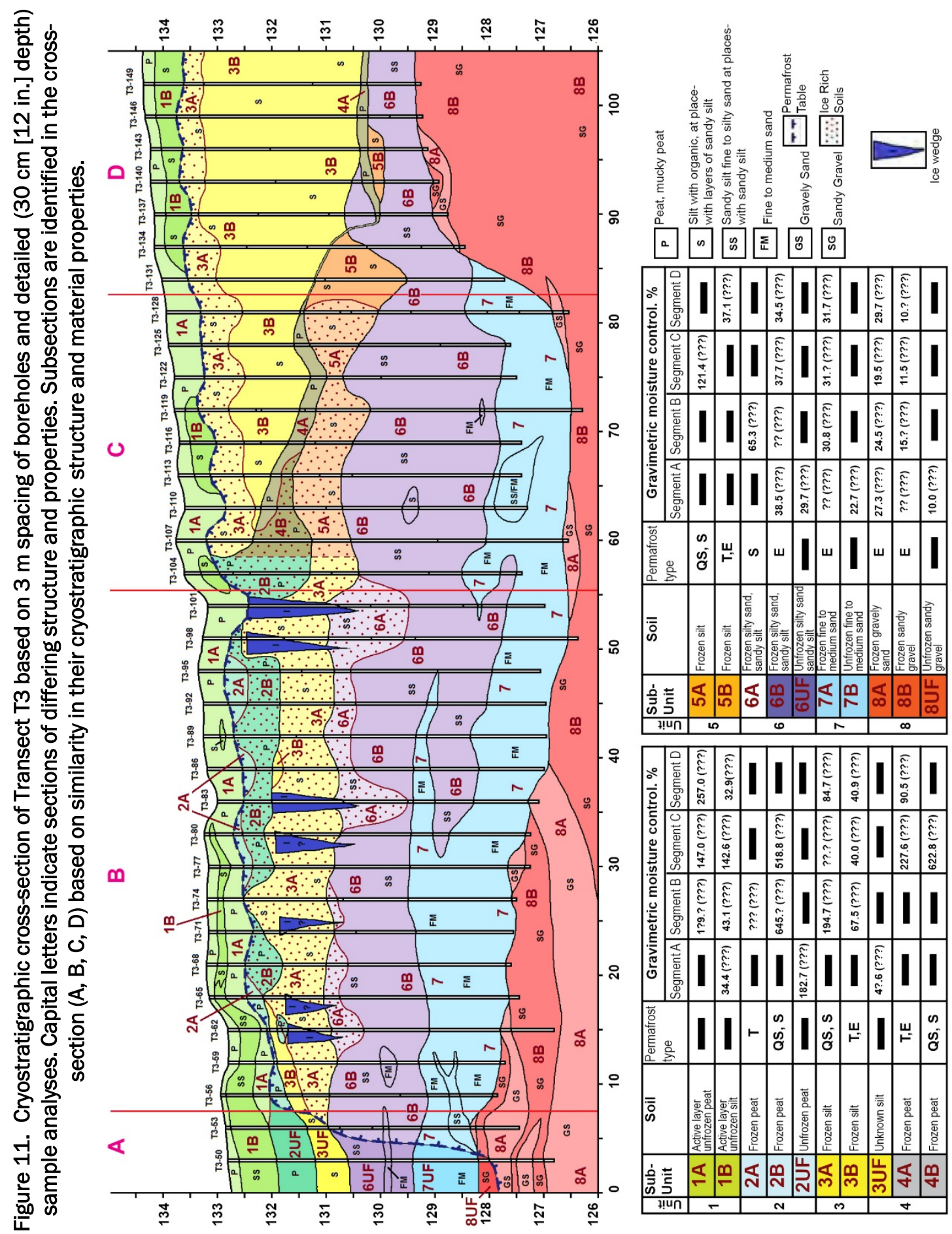


The detailed database for Transect $\mathrm{T} 3$ was used for the geostatistical analyses (Section 2.3) to essentially calibrate the CCR and ERT resistivity survey data to subsurface properties of the permafrost, as well as determine the effects of degrading the resolution and still produce a truly representative cross-section of the subsurface permafrost properties relevant to infrastructure construction.

For the purposes of determining the efficacy of the high-resolution drilling and sampling, we also chose to simplify the classification with respect to material properties and ice content as it affects foundation planning. Figure 12 shows the geologic interpretation and Figure 13 shows the distribution of visible ice in the cores as classified in the field for various ranges of ice content. The results show a marked improvement in delineating icerich zones of concern for engineers and in outlining soil types for engineering decisions.

We used a Monte Carlo estimation of the probability of a boring to detect ground ice based on its gravimetric moisture content at various sampling intervals with depth, using the Transect T3 with $30 \mathrm{~cm}$ (12 in.) sampling interval as the basis upon which detection is assumed to be $100 \%$. The analysis found that the information concerning the amounts detected is degraded if the sampling intervals are reduced to $60 \mathrm{~cm}$ and $120 \mathrm{~cm} \mathrm{(24} \mathrm{in.}$ and $47 \mathrm{in}$.); however the best reproducibility is found to be at a $60 \mathrm{~cm}$ (24 in.) interval (Table 2). At $120 \mathrm{~cm}$ (47 in.) intervals, individual horizons often deviated greatly from the amount at $30 \mathrm{~cm}$ (12 in.) interval, while some intervals are not represented due to the thickness of those horizons (Table 2).

We conducted various tests of CCR methodology on Transect T3 to refine the technique and improve the resolution. These tests, which involved repeating transects using different electrode spacing and altering transmission and reception parameters, showed some improvement, mainly through variations in the speed of acquisition. The high-resolution data from drilling on Transect $\mathrm{T}_{3}$ and the core logging provided essential data for discriminating the effects of altering data acquisition. 


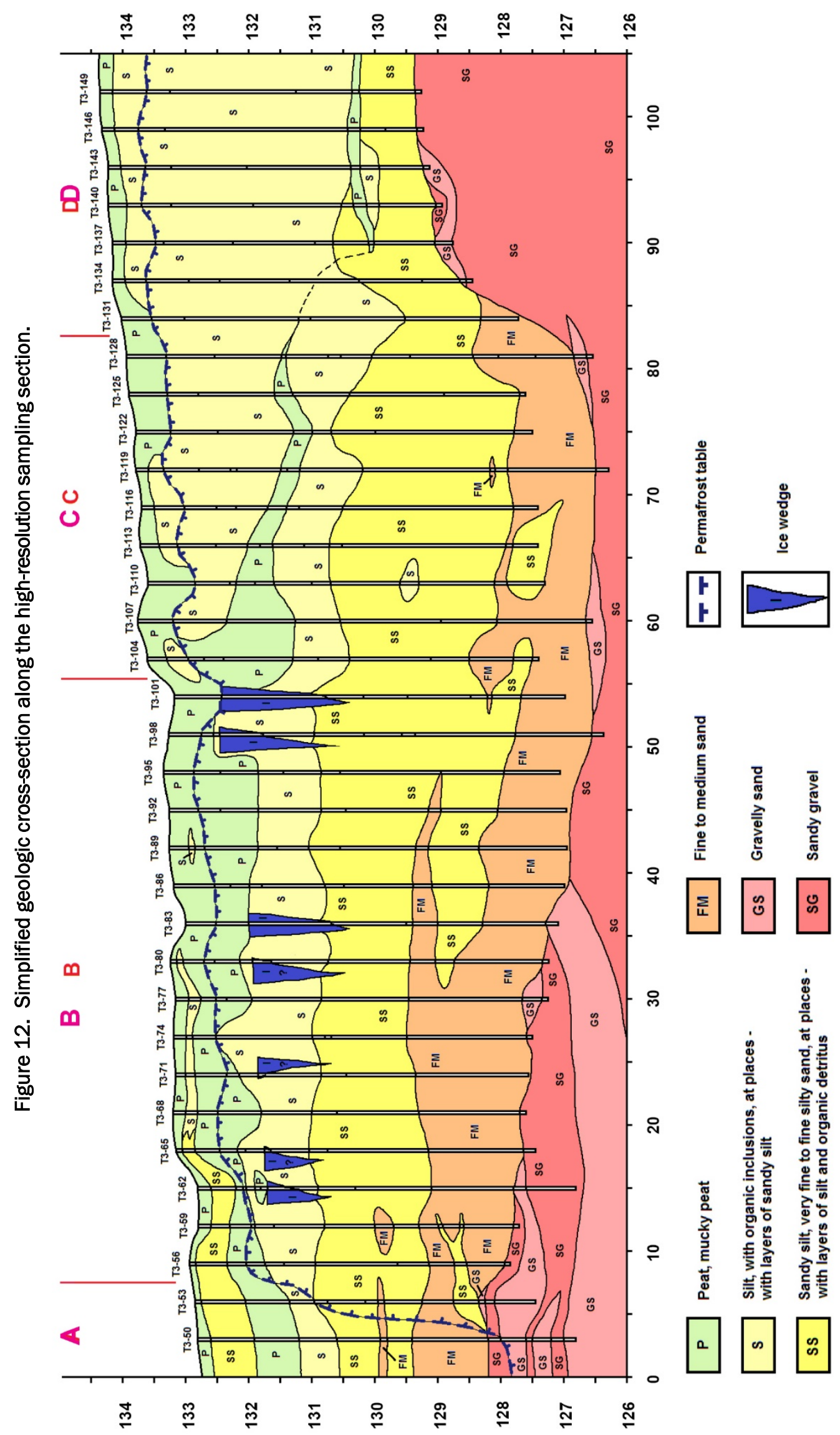




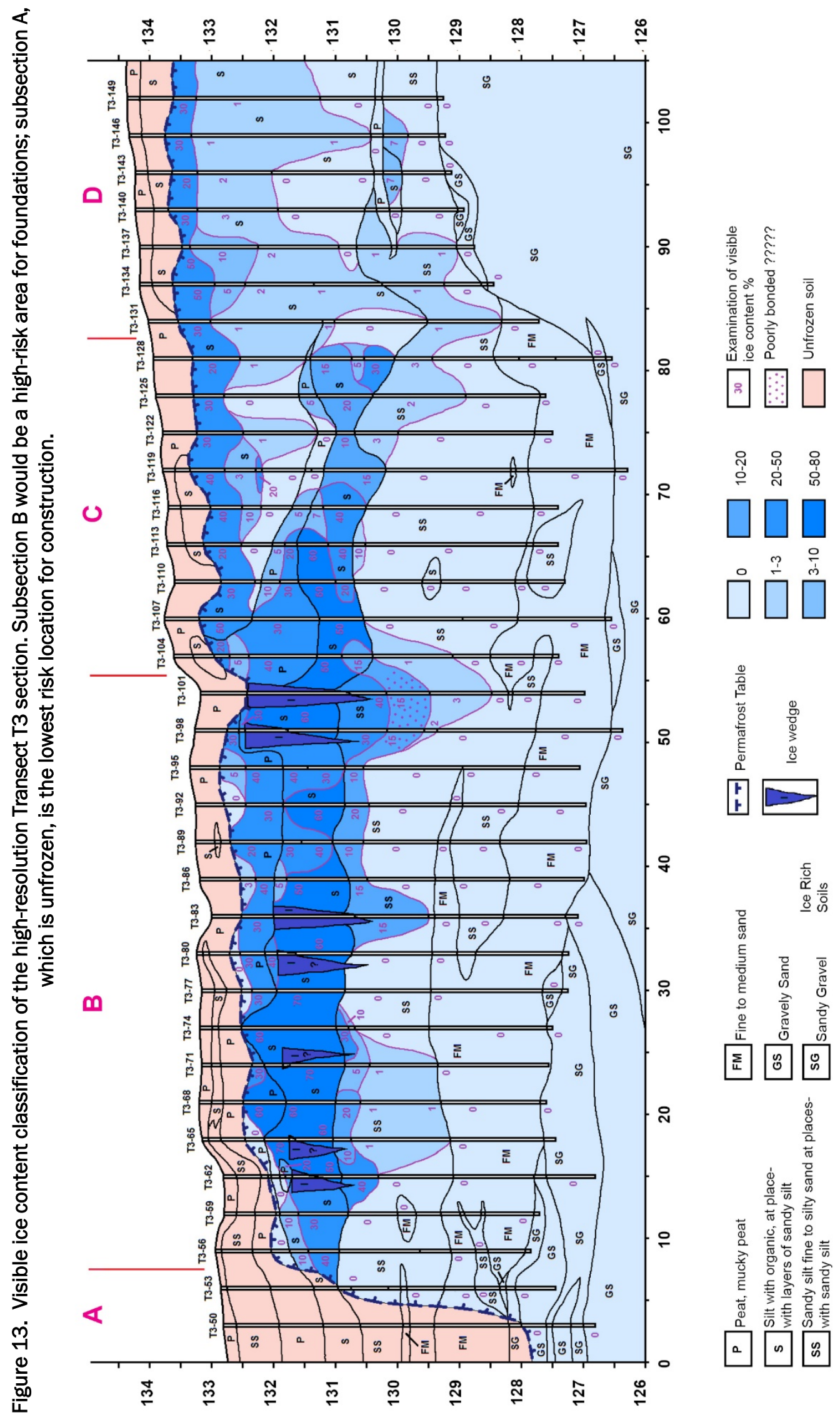


Table 2. Results of analysis using Monte Carlo method to examine effects of sampling interval on ice content based on $30 \mathrm{~cm}$ (12 in.) depth sampling scheme on high-resolution section of Transect T3 at CCHRC.

\begin{tabular}{|c|c|c|c|c|}
\hline \multirow[b]{2}{*}{ Unit } & \multirow[b]{2}{*}{ Sub-unit } & \multicolumn{3}{|c|}{ Sampling Scheme } \\
\hline & & $\begin{array}{c}\text { Every } 30 \mathrm{~cm} \text { (12 in.), } \\
100 \%\end{array}$ & $\begin{array}{c}\text { Every } 60 \mathrm{~cm}(24 \mathrm{in} .), \\
50 \%\end{array}$ & $\begin{array}{c}\text { Every } 120 \mathrm{~cm} \text { (47 in.), } \\
25 \%\end{array}$ \\
\hline \multirow{3}{*}{ 1. Active Layer, Unfrozen } & 1A. Peat & $169.0 \pm 45.0(n=23)$ & $184.4 \pm 47.3(n=5)$ & $-(n=0)$ \\
\hline & 1B. Silt, sandy silt & $39.9 \pm 13.9(n=21)$ & $32.6 \pm 3.7(n=4)$ & $-(n=0)$ \\
\hline & Total & $107.4 \pm 73.3(n=44)$ & $133.8 \pm 83.7(n=12)$ & $-(n=0)$ \\
\hline \multirow{4}{*}{ 2. Peat } & 2A. Ice-poor & $242.6 \pm 62.6(n=7)$ & $261.4 \pm 65.7(n=5)$ & $254.5(n=1)$ \\
\hline & 2B. Ice-rich & $614 \pm 266.6(n=24)$ & $640.2 \pm 293.2(n=11)$ & $700.2 \pm 115.9(n=6)$ \\
\hline & 2UF. Unfrozen & $182.7 \pm 63.6(n=5)$ & $154.9 \pm 12.4(n=2)$ & $154.9 \pm 12.4(n=2)$ \\
\hline & Total & $482.5 \pm 290.2(n=36)$ & $481.0 \pm 307.7(n=15)$ & $529.5 \pm 273.5(n=9)$ \\
\hline \multirow{4}{*}{ 3. Silt } & 3A. Ice-rich & $151.0 \pm 109.1(n=32)$ & $152.0 \pm 92.0(n=44)$ & $143.2 \pm 114.3(n=19)$ \\
\hline & 3B. Ice-poor & $41.7 \pm 11.2(n=81)$ & $42.2 \pm 13.0(n=41)$ & $43.0 \pm 10.2(n=22)$ \\
\hline & 3UF. Unfrozen & $48.6 \pm 7.8(n=3)$ & $53.1 \pm 0.4(n=2)$ & $-(n=0)$ \\
\hline & Total & $95.8 \pm 94.3(n=166)$ & $98.0 \pm 85.6(n=57)$ & $89.5 \pm 92.1(n=41)$ \\
\hline \multirow{3}{*}{ 4. Peat (Buried) } & 4A. Ice-poor & $206.4 \pm 97.4(n=7)$ & $218.7 \pm 85.4(n=3)$ & $254.7 \pm 82.7(n=2)$ \\
\hline & 4B. Ice-rich & $622.8 \pm 438.6(n=6)$ & $447.4 \pm 132.4(n=3)$ & $294.6(n=1)$ \\
\hline & Total & $398.6 \pm 362.7(n=13)$ & $333.0 \pm 160.1(n=6)$ & $268.0 \pm 62.8(n=3)$ \\
\hline \multirow{3}{*}{ 5. Silt } & 5A. Ice-rich & $121.4 \pm 82.0(n=24)$ & $125.0 \pm 97.1(n=12)$ & $186.1 \pm 128.2(n=5)$ \\
\hline & 5B. Ice-poor & $37.1 \pm 5.1(n=11)$ & $38.5 \pm 5.8(n=6)$ & $39.1 \pm 0.5(n=2)$ \\
\hline & Total & $94.9 \pm 78.3(n=35)$ & $96.2 \pm 88.7(n=18)$ & $144.1 \pm 126.9(n=7)$ \\
\hline \multirow{4}{*}{ 6. Sandy, Silt, Silty Sand } & 6A. Ice-rich & $65.3 \pm 27.4(n=26)$ & $66.6 \pm 32.4(n=14)$ & $60.6 \pm 32.9(n=11)$ \\
\hline & 6B. Ice-poor & $37.8 \pm 5.7(n=159)$ & $37.3 \pm 5.1(n=96)$ & $37.2 \pm 4.7(\mathrm{~N}-50)$ \\
\hline & 6UF. Unfrozen & $29.7 \pm 2.0(n=4)$ & $28.1 \pm 1.3(n=2)$ & $29.0(n=1)$ \\
\hline & Total & $40.9 \pm 14.0(n=219)$ & $40.8 \pm 15.6(n=112)$ & $41.2 \pm 16.7(n=62)$ \\
\hline \multirow{3}{*}{ 7. Fine to Medium Sand } & 7. Frozen & $31.2 \pm 3.3(n=110)$ & $31.7 \pm 3.6(n=33)$ & $30.8 \pm 3.7(n=26)$ \\
\hline & 7UF.Unfrozen & $22.7 \pm 5.2(n=4)$ & $20.1 \pm 6.7(n=2)$ & $24.9(n=1)$ \\
\hline & Total & $30.9 \pm 3.7(n=114)$ & $31.2 \pm 4 .(n=55)$ & $30.5 \pm 3.8(n=27)$ \\
\hline \multirow{4}{*}{ 8. Gravelly Sand, Sandy Gravel } & 8A. Frozen gravelly sand & $25.6 \pm 6.5(n=11)$ & $23.8 \pm 7.7(n=6)$ & $24.1 \pm 9.1(n=4)$ \\
\hline & 8B. Frozen sandy gravel & $13.5 \pm 7.4(n=15)$ & $13.5 \pm 7.0(n=4)$ & $16.1 \pm 10.4(n=2)$ \\
\hline & 8UF. Unfrozen sandy gravel & $10.0(n=1)$ & $10.0(n=1)$ & $10.0(n=1)$ \\
\hline & Total & $18.3 \pm 9.2(n=27)$ & $18.81 \pm 8.8(n=11)$ & $19.8 \pm 9.6(n=7)$ \\
\hline Total, All Units & Total, All Sub-Units & $90.9 \pm 148.2(n=654)$ & $91.0 \pm 140.3(n=319)$ & $88.2 \pm 143.5(n-156)$ \\
\hline
\end{tabular}

We selected a sub-site along Transect T3 (from $66 \mathrm{~m}$ to $83 \mathrm{~m} \mathrm{(216} \mathrm{ft} \mathrm{to}$ $272 \mathrm{ft}$ ) distance) within which we conducted ERT surveys of multiple and closely spaced transects to model the subsurface information in three dimensions (Figure 10). The detailed information of the subsurface are required for the proposed building site, such as assessing risk to a foundation in the short or long term where the permafrost is highly complex and ice-rich. The grid was $16 \mathrm{~m} \times 16 \mathrm{~m}(52 \mathrm{ft} \times 52 \mathrm{ft})$; electrodes are placed at nodes spaced every $2 \mathrm{~m}(7 \mathrm{ft})$, for a total of 81 data collection points using a bipole-bipole survey (Figure 10). The resistivity data are then modeled 
in three dimensions using Res2D/Res3D software (Figure 14). Ice-rich areas, including an apparent area of ice wedges in a polygonal pattern, are delineated by the modeled resistivity values.

Figure 14. Three-dimensional model of the resistivity values from the survey along Transect T3 in September 2014. Depth is $\sim 7 \mathrm{~m}(\sim 23 \mathrm{ft})$ on the $16 \mathrm{~m}^{2}$ (172 sq ft) grid, with nodes spaced every $2 \mathrm{~m}$ (7 ft). X-axis lies parallel to Transect T3; Y perpendicular to it. Highest resistivity values indicate ice-rich sediments at depth.

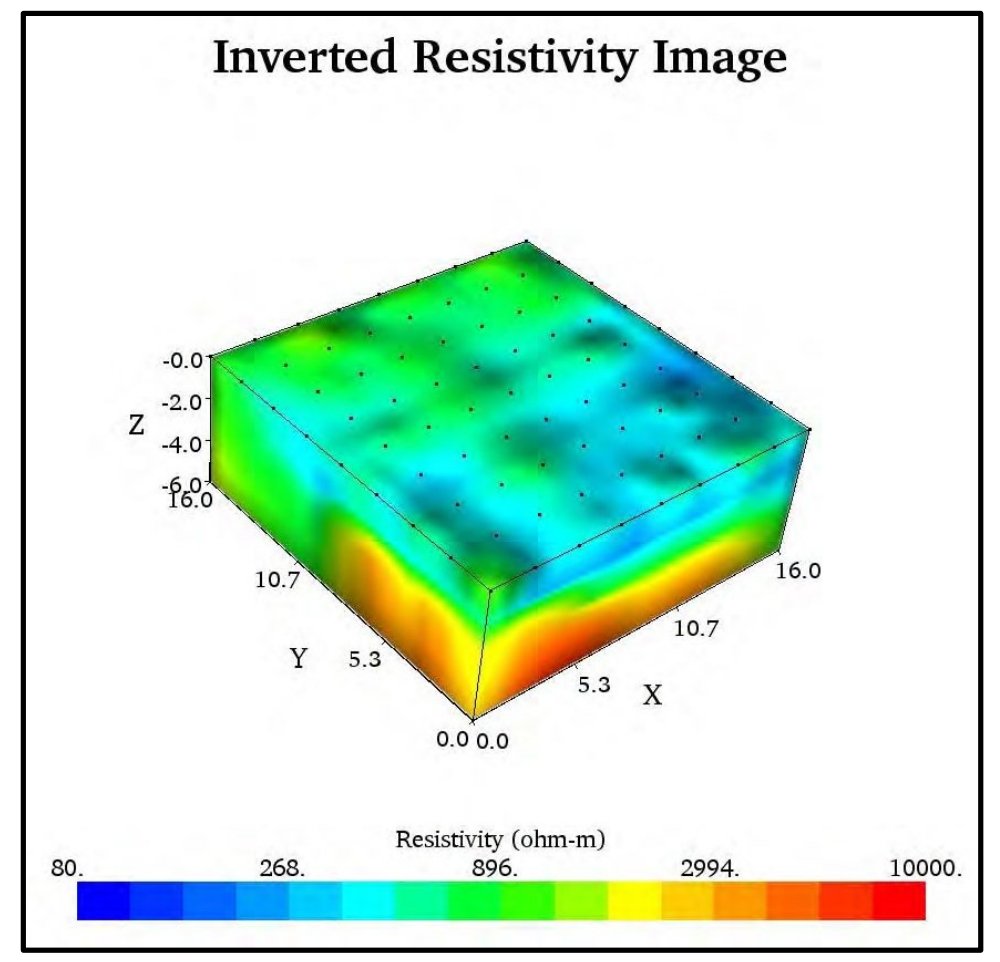

After assessing the core logging data from the boreholes and interpreting the resistivity imagery in terms of ice distribution and content on the first five transects, it was clear that the subsurface conditions beneath the former alluvial fan differed significantly. The conditions varied from those of the less ice-rich swale and slough deposits (e.g., westerly ends of Transects $\mathrm{T} 2, \mathrm{~T}_{3}, \mathrm{~T} 5 \mathrm{vs}$. their easterly sections).

Therefore, we decided that it would be useful to obtain a characterization of the western half of the CCHRC site. This allowed us to expand our knowledge and database of properties of the subsurface for use in the geostatistical analyses. We established Transects T6 to T10 for geophysical analyses with CCR and used the detailed geological data and resistivity interpretations from the previous drilling on Transects $\mathrm{T} 1$ to $\mathrm{T} 5$ and high-resolution coring on Transect $\mathrm{T} 3$ to interpret these geophysical records (Figure 15). 
Figure 15. Location of transects within the western two-thirds of the CCHRC site relative to original Transects $\mathrm{T} 1$ to $\mathrm{T} 5$ and borehole locations. This area consists of deposits of former alluvial fan; they are distinctly different in terms of sediment types and ice content than the eastern third of the site. North is to the top.

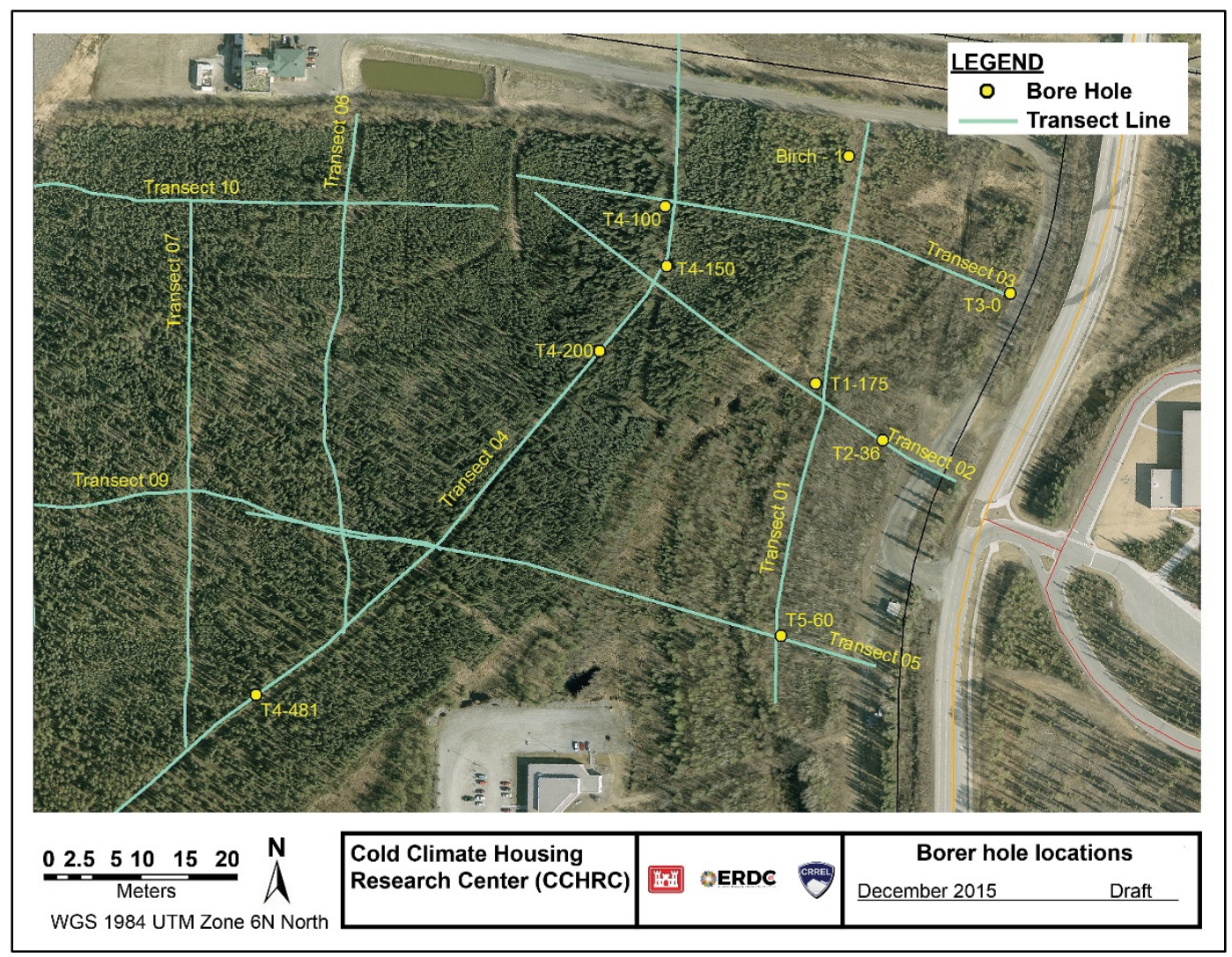

\subsubsection{Permafrost Tunnel (PT) site}

The PT site is principally a single terrain type-coalesced, gently sloping alluvial fans, but transitioning easterly upslope to a colluvium (Péwé 1958). Most of the site is poorly drained, covered by sedges and intermittent tussocks (Figure 16). Along the western edge of the vertical escarpment formed by previous placer mining operations in the Goldstream Valley, the vegetation is primarily dwarf coniferous black spruce. Images derived from the aerial photography and LiDAR imagery indicated that the site has undergone some thermokarst development; however the thermokarst development is limited to areas in and around the gullies draining from the upland terrain into the lowland formed by the placer mining (Figure 16). Extensive placer mining in the area, which hydraulically removed silt deposits overlying the gold-bearing gravels to recover the gold by dredging, has lowered the elevation near the tunnel by $\sim 12 \mathrm{~m}(\sim 39 \mathrm{ft})$. 
Figure 16. LiDAR image of the Permafrost Tunnel site obtained in May 2014. The transect illustrated was used for the initial reconnaissance data gathering using resistivity methods. The two CRREL Permafrost Tunnels are located at the western edge of the vegetated uplands. They were cut into the scarp formed by placer gold mining in the Goldstream Valley (upper left). Most of the terrain consists of poorly drained, coalesced alluvial fans, largely composed of perennially frozen silt in the Glenn Creek drainage. Thermal erosion has expanded the gullies draining into the valley. Trails are evident crisscrossing the site. North is to the top.

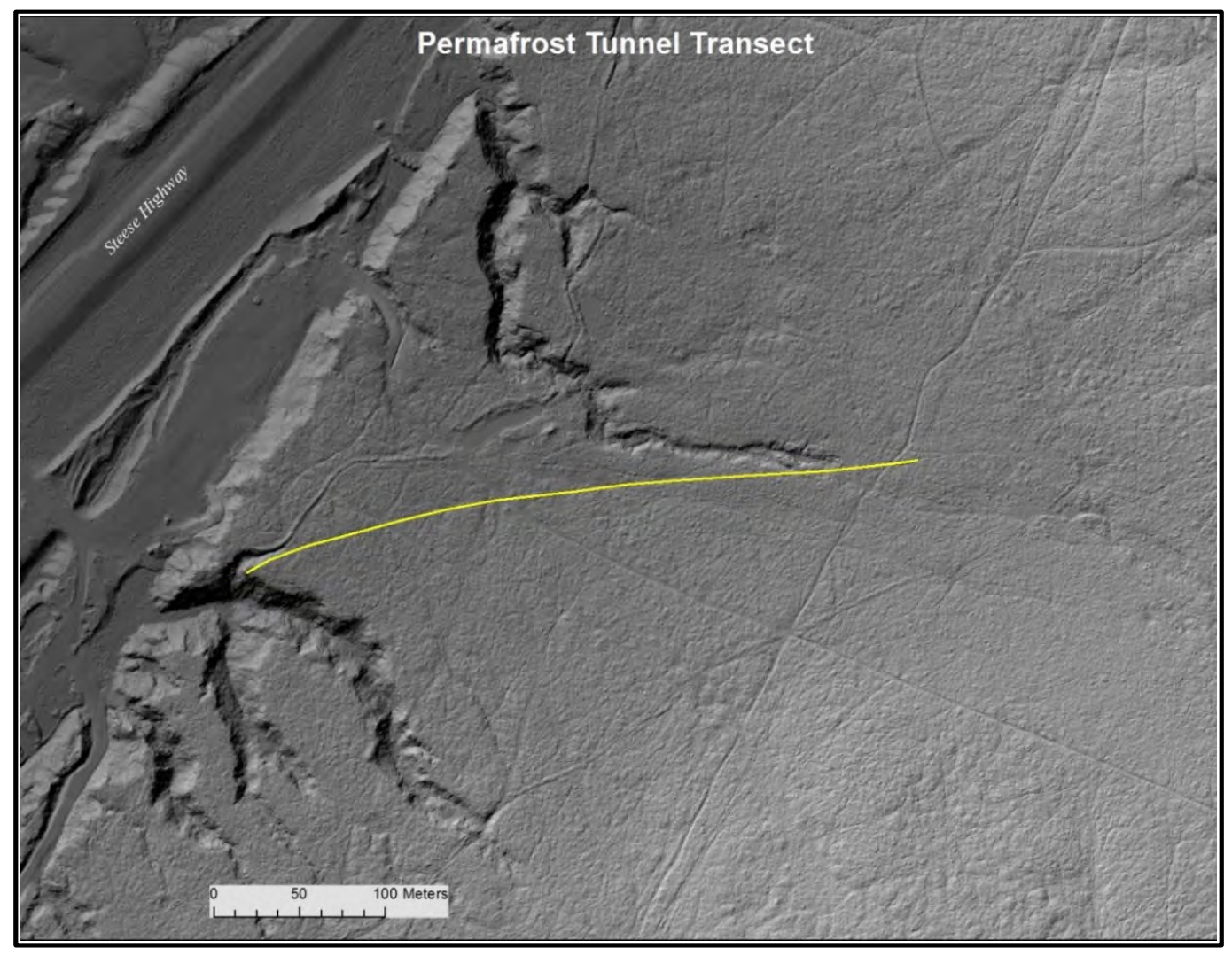

Previous geological investigations revealed that the PT site is underlain by perennially frozen, undifferentiated ice-rich silt of an average $14 \mathrm{~m}(46 \mathrm{ft})$

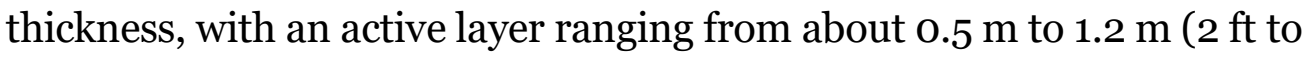
$4 \mathrm{ft}$ ) in thickness. The frozen silts overlie ice-indurated gravels of $\sim 3.5 \mathrm{~m}$ $(\sim 11 \mathrm{ft})$ thickness, which in turn lie on bedrock known as the Birch Creek Schist (Péwé 1975). The silt deposits originated as loess, wind-blown sediment from glaciers most likely located in the Alaska Range, but the deposits on this site have undergone transport and re-deposition through various slope processes within the drainage basin of Glenn Creek (Péwé 1975). Previous exploratory drilling and a seismic survey indicated the depth to bedrock of the silt ranges from $\sim 18 \mathrm{~m}(\sim 59 \mathrm{ft})$ at the western edge of the site to $\sim 9$ m upslope at the eastern edge (Figure 17, Sellmann 1967). Two stratigraphic units of different ages, Holocene and Pleistocene, were identified 
within the frozen silt deposits (Sellmann 1967, Hamilton et al. 1986), the Holocene being generally less than $5 \mathrm{~m}(16 \mathrm{ft})$ thick. More detailed analyses of the sedimentary features and ground ice relationships in section have shown these subsurface materials to be very complex (Shur 2004; Bray, French, and Shur 2006; Kanevskiy et al. 2008), a fact that could affect the ability to interpret borehole data spatially.

Figure 17. Interpretation of composite seismic refraction profiles (adapted from Sellmann, 1967) along Transect T2 at the Permafrost Tunnel site. The dashed line is the interpreted interface between Holocene and Pleistocene sediments, all of which are re-transported silts of eolian origin. Dots indicate projected depth to bedrock from the seismic information.

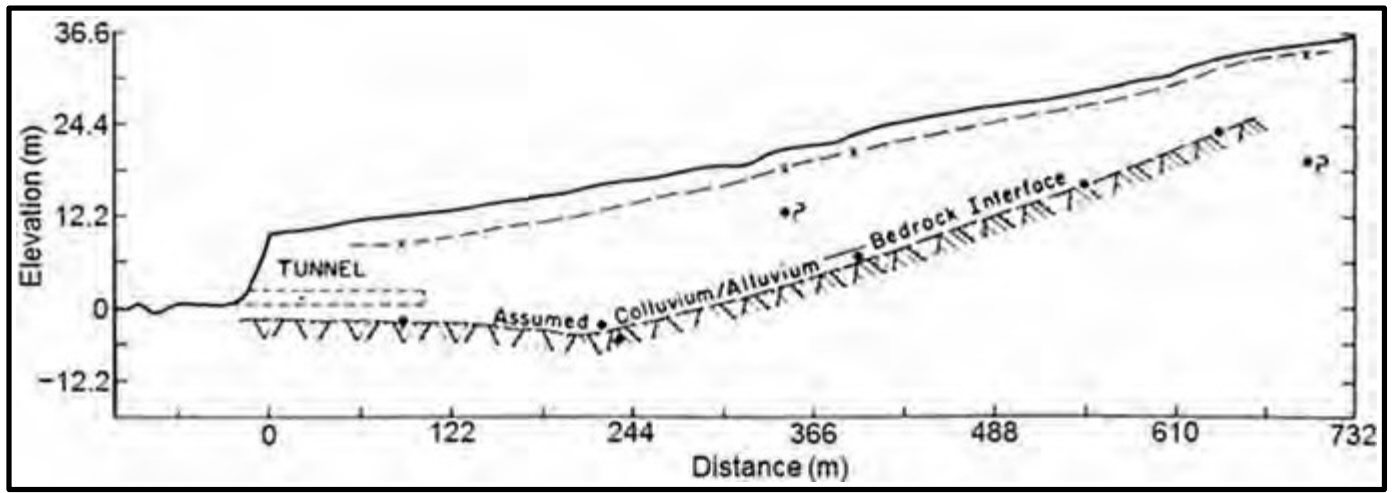

We established three transects to characterize the subsurface of the site, with two beginning near the two CRREL tunnel portals, thus allowing for a direct geo-cryostratigraphic interpretation of the subsurface data with similar observations within the tunnels (Figure 18). Transect T1 traverses about $400 \mathrm{~m}$ in a northeasterly direction from near the entrance to the new CRREL tunnel in the black spruce, crossing the poorly drained sedge area past Glenn Creek. The two additional transects are located within the central area of sedge tussocks; Transect T2 trends parallel to Glenn Creek, beginning northeast of the original Permafrost Tunnel portal; and Transect $\mathrm{T} 3$ trends $\sim \mathrm{S}$ to $\mathrm{N}$ from Glenn Creek across Transect T2 (Figure 18). 
Figure 18. Location of the three transects investigated with GPR, CCR, and ERT geophysical methods at the Permafrost Tunnel site. North is to the top.

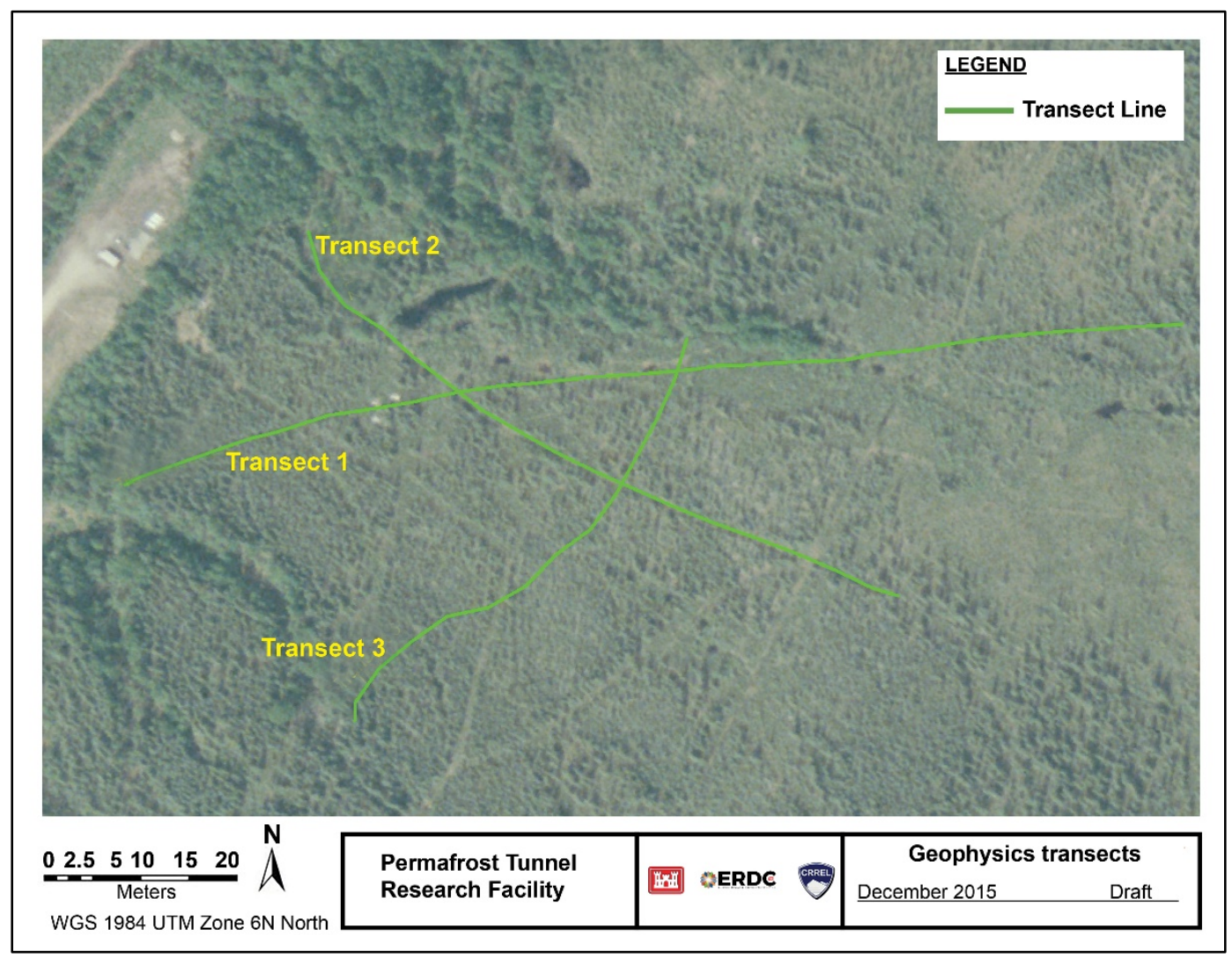

Geophysical surveys that are conducted using ERT, CCR, and GPR have proved to be distinctly different from those acquired at the CCHRC site. The resistivity data exhibited very strong values throughout the cross sections, and inverse modeling revealed that the silts underlying the site are extremely ice-rich with apparently numerous ice wedges within the upper $\sim 15 \mathrm{~m}$ ( $9 \mathrm{ft}$ ) (Figures 19 and 20). The geophysical data confirmed what was previously known of the re-transported loessal silts from the investigations of the two permafrost tunnels (Hamilton et al. 1986; Shur 2004; Bray, French, and Shur 2006; Kanevskiy et al. 2008; Bjella 2015) i.e., that ice-rich silt is contained beneath the majority of the site. 
Figure 19. Composite resistivity section for Transect T1 at Permafrost Tunnel site. The survey begins $\sim 800 \mathrm{~m}(\sim 2624 \mathrm{ft})$ uphill from the tunnel and terminates near the escarpment. The data are a composite of five surveys using multiple receivers at a spacing that changed the depth of penetration from shallow to deep ( $\max \sim 20 \mathrm{~m}[\sim 66 \mathrm{ft}]$ ). We interpret the data to show the lower ice content active layer and upper Holocene silt deposits to $\sim 2.5 \mathrm{~m}$ to $3 \mathrm{~m}$ ( $\sim \mathrm{ft}$ to $10 \mathrm{ft}$ ) depth, overlying the high ice content Pleistocene silt deposits. The very high resistivity values (deep red) may indicate the presence of ice wedges and other massive ice types; the lower resistivity values at both ends of the transect indicate reduced ice content, possibly due to previous thaw and refreezing of the deposits.

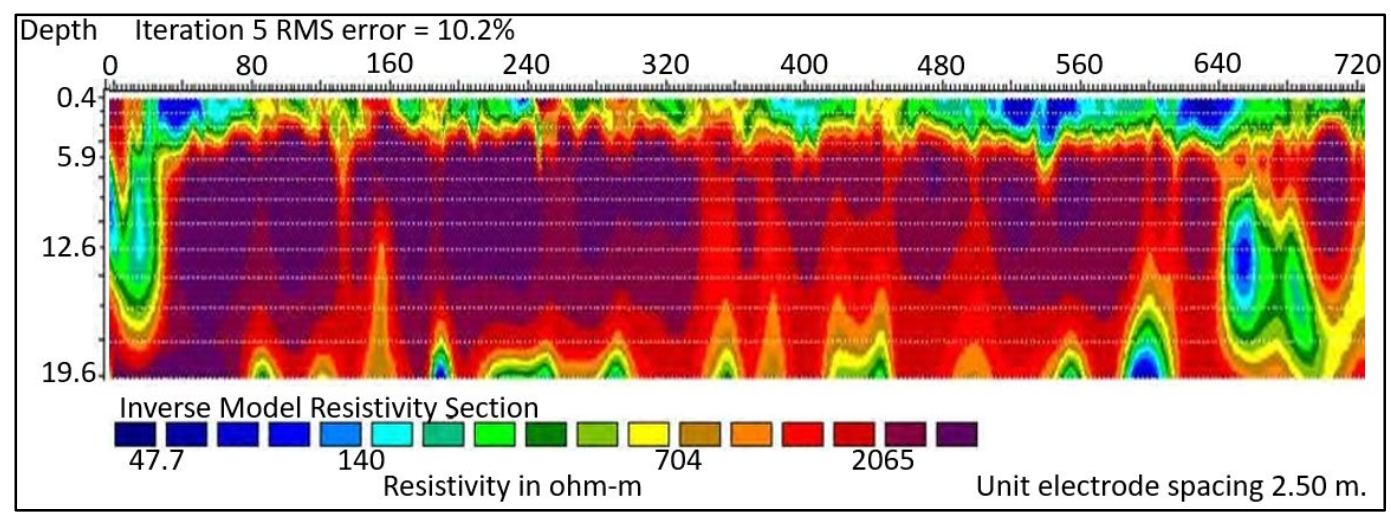


Figure 20. ERT resistivity profiles for Transect T2(A) (starts at edge of escarpment on left) and Transect T3(B) (starts at Glenn Creek on left) at the Permafrost Tunnel site. The central parts of both profiles cross the poorly drained, tussock and sedge upland terrain, and delineate ice-rich subsurface materials, but which are variable in apparent content with depth into the gravels and bedrock.

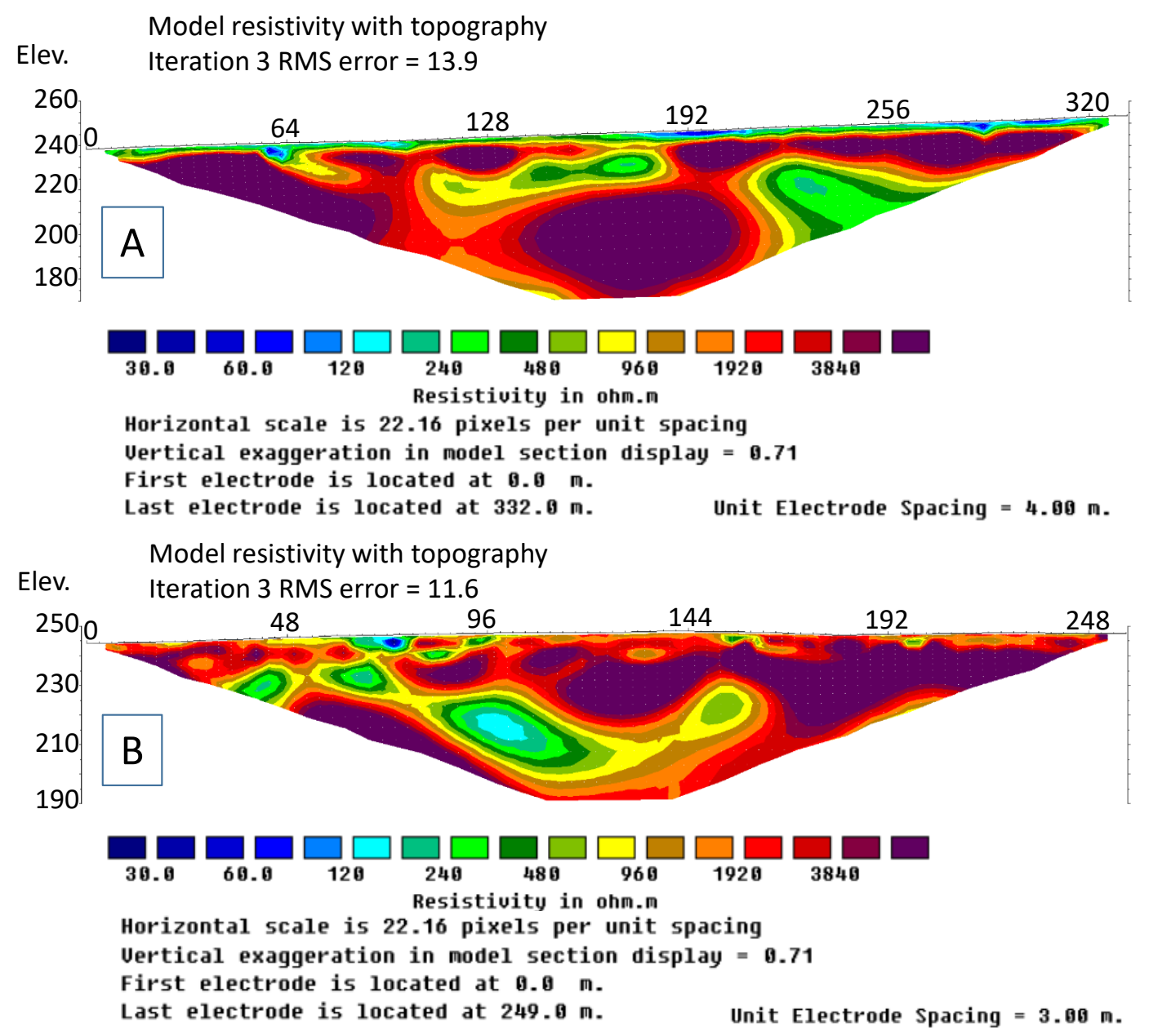

In contrast to the resistivity data, the GPR surveys were unable to detect much about the subsurface conditions because of the high attenuation of the transmitted radio waves produced by the relative permittivity of the silt soil (Arcone et al. 2008). Multiple radio wave frequencies of transmission were used, including 150,200 , and $360 \mathrm{MHz}$, to attempt improved penetration; however, depths were still limited to approximately $5 \mathrm{~m}$

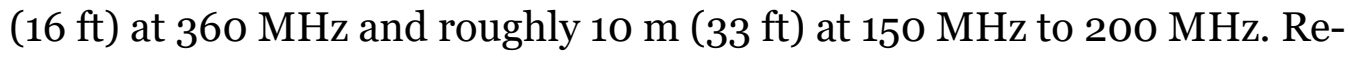
turns from the top of permafrost, which also characterized the active layer thickness, are well delineated using the $360 \mathrm{MHz}$ records (Figure 21). This response is generally confirmed when a thin layer of water lies at or just above the frozen surface. Well-defined layered returns from the upper 
Holocene silt strata are extended to a depth of approximately $2 \mathrm{~m}$ to $4 \mathrm{~m}$ ( $7 \mathrm{ft}$ to $13 \mathrm{ft}$ ) in each transect profile at $150 \mathrm{MHz}$ (Figure 22). A thawed zone is also depicted at the start of the record for Transect T2.

Figure 21. A $360 \mathrm{MHz}$ GPR profile of Transect T2 at the Permafrost Tunnel site. The profile begins $40 \mathrm{~m}$ (131 ft) before the actual start of Transect T2. The active layer, top of permafrost, and snow cover are well defined, but depth penetration is limited to several meters.

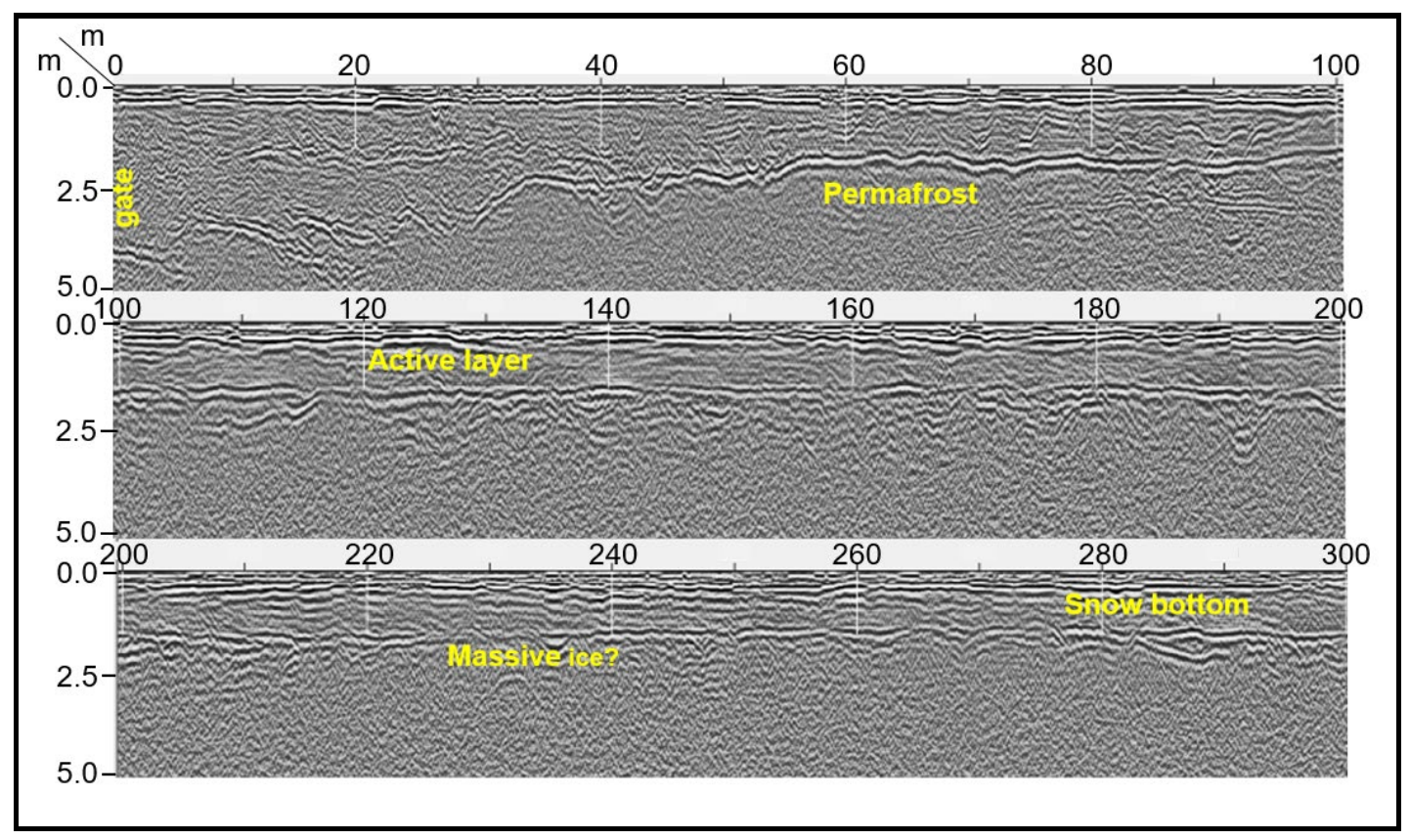


Figure 22. A $150 \mathrm{MHz}$ GPR profile beginning at Transect T1 after $100 \mathrm{~m}$. Within the first $480 \mathrm{~m}$ (1574 ft) distance, we interpret the general horizon at $2 \mathrm{~m}$ to $3 \mathrm{~m}$ ( $7 \mathrm{ft}$ to $10 \mathrm{ft}$ ) depth to be the bottom of the Holocene silt. After $480 \mathrm{~m}$ this horizon weakens and degenerates into

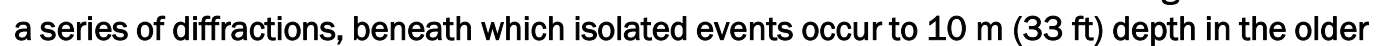
perennially frozen silts.

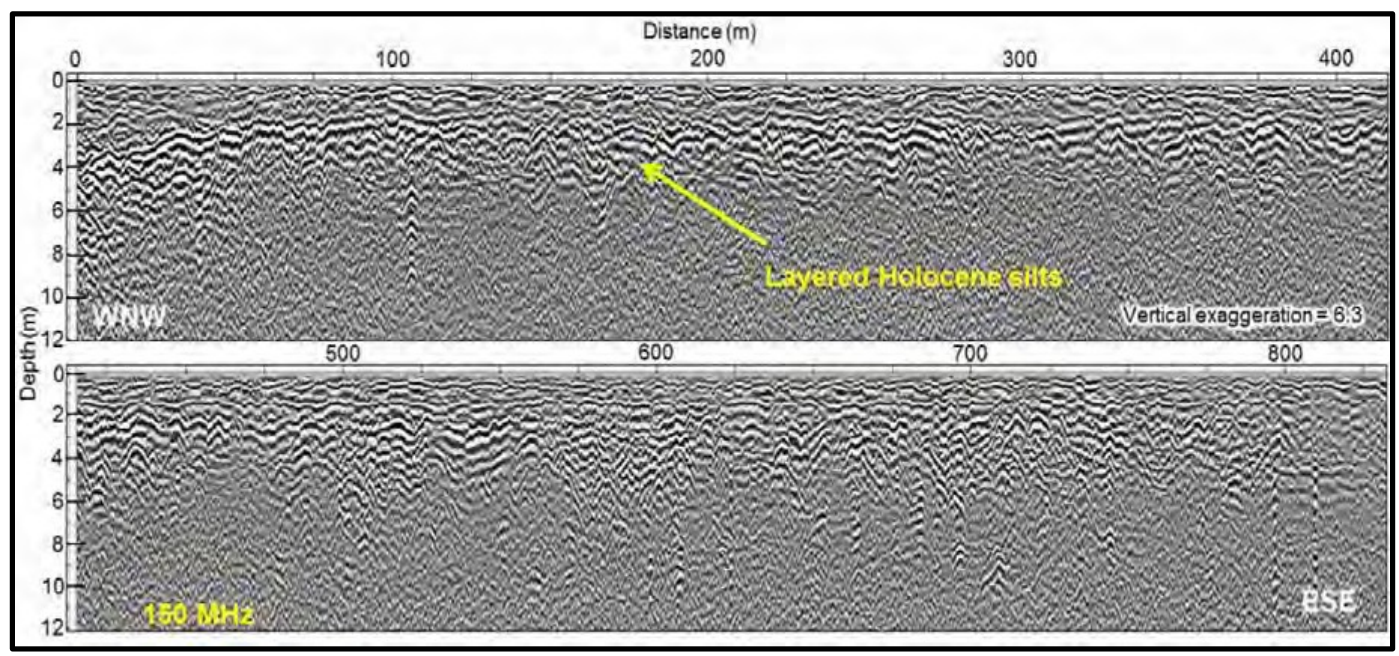

Boreholes along Transect T2 were drilled at a 6-m (20-ft) spacing, wider than the $3-\mathrm{m}$ spacing at CCHRC. However, the $6-\mathrm{m}(20-\mathrm{ft})$ interval would still be considered practical for application to Military Construction (MILCON) site characterization. The drilling began at the $148 \mathrm{~m} \mathrm{(485} \mathrm{ft}$ ) station and continued every $6 \mathrm{~m}$ to $250 \mathrm{~m}$ distance (Figure 23). Boreholes to refusal at bedrock were cored at each endpoint, while the remaining boreholes went to $\sim 8 \mathrm{~m}(\sim 26 \mathrm{ft})$ depth. Bedrock is attained at depths of

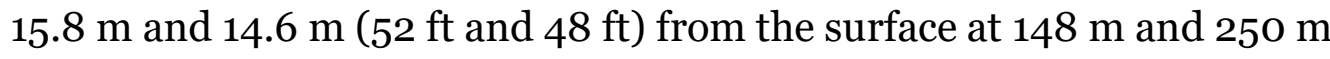
$(485 \mathrm{ft}$ and $820 \mathrm{ft}$ ) distance, respectively; this was verified with previous seismic data (Sellmann 1967, also see Figure 17). All boreholes contained extremely ice-rich silt, as well as ice wedges, particularly from $\sim 5 \mathrm{~m}$ to $7.5 \mathrm{~m}(\sim 16 \mathrm{ft}$ to $25 \mathrm{ft})$ depth. The less ice-rich silt materials are found above the $5 \mathrm{~m}$ depth including the active layer and Holocene strata, and the Pleistocene strata is overlaid with ice-rich silts below that depth. These data and preliminary field interpretations from cryostratigraphic logging of the cores are used to verify the high resistivity data and to ground truth the geophysical survey interpretation. 
Figure 23. Location of boreholes along Transect T2 at Permafrost Tunnel site (Fig. 18) with 18 boreholes every $6 \mathrm{~m}$ starting at T2-148 and ending at T2-250.

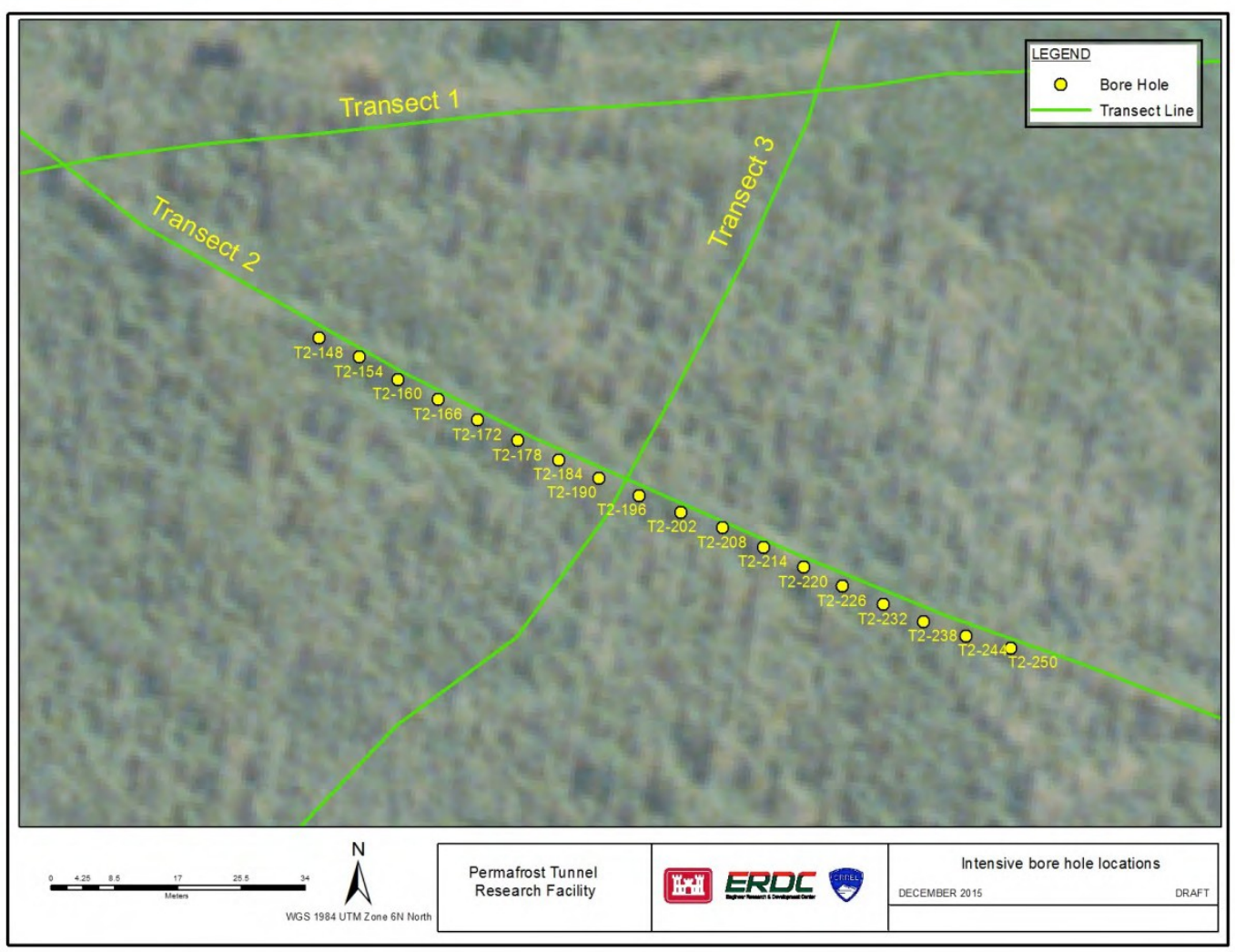

\subsubsection{Farmers Loop (FL) site}

This site is located on the eastern side of the Isabella Creek drainage (Figure 24). The terrain is situated on flat, alluvial-fan deposits composed of perennially frozen, organic-rich silt, with steep-walled, thermokarst lakes (lakes formed by melting of ground ice) and polygonal ground associated with ice wedges at depth (Péwé 1958). The site is considered to be perennially frozen to bedrock (Birch Creek Schist) at a depth of over $100 \mathrm{~m}$ (328 ft), with an

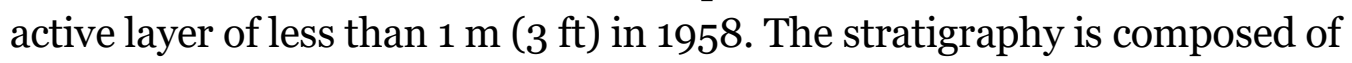
peat-rich soil overlying ice-rich, peaty silt including ice wedges to $\sim 55 \mathrm{~m}$ $(\sim 180 \mathrm{ft})$ depth and beneath it, coarse gravels ( $\sim 40 \mathrm{~m}$ to $45 \mathrm{~m}(\sim 131 \mathrm{ft}$ to $148 \mathrm{ft}$ ) thick) above the bedrock (Péwé 1958, also see Figure 25). 
Figure 24. Historic aerial photography of the Farmers Loop site. Changes in infrastructure, vegetation and physical features such as expansion of the ponds in area adjacent to the road are evident in full size images.

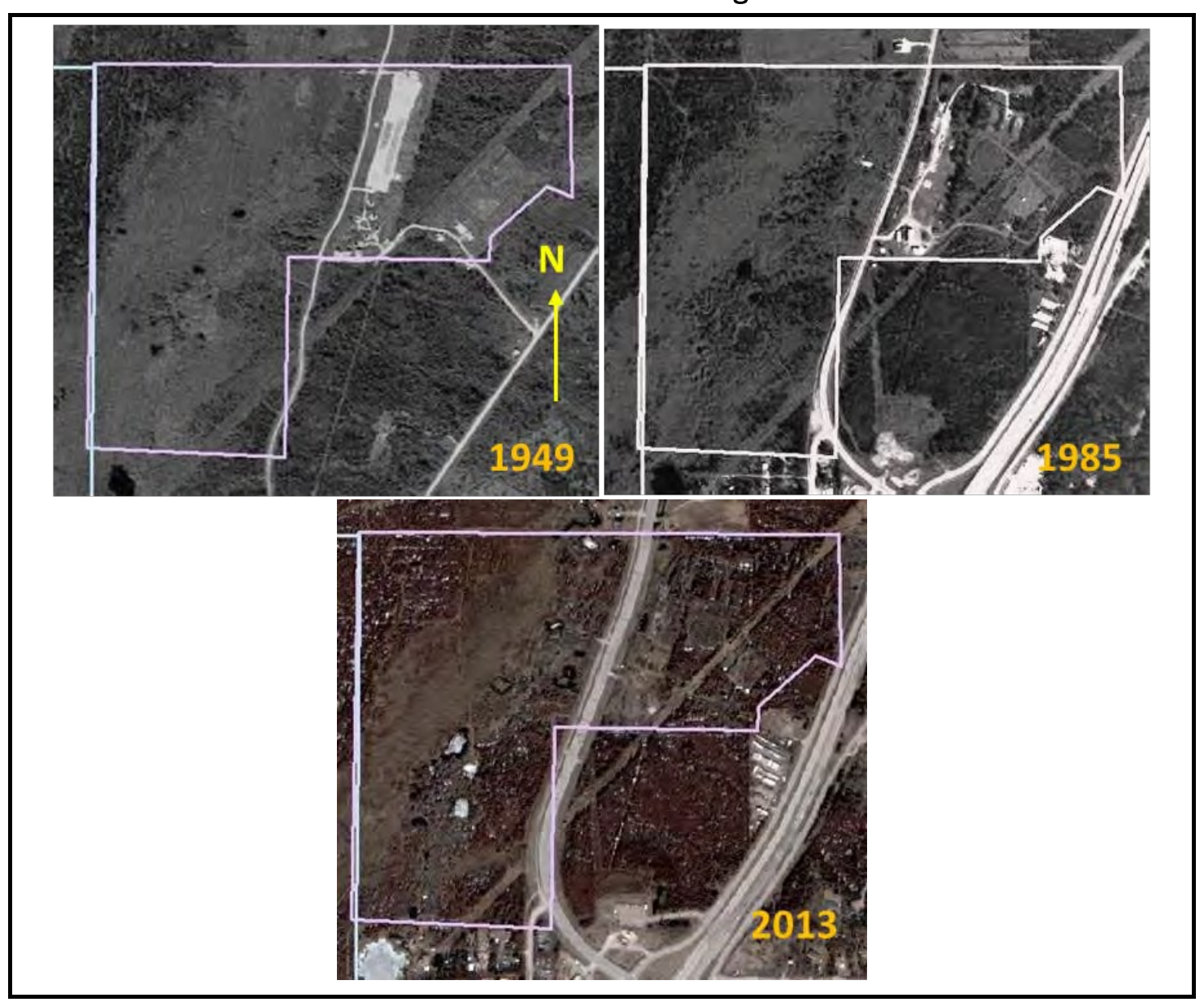


Figure 25. Geologic map of the Farmers Loop area and geologic cross-section based on logs of water wells. The cross-section trends northwest from Birch Hill across the Steese Hwy. and Farmers Loop Road.

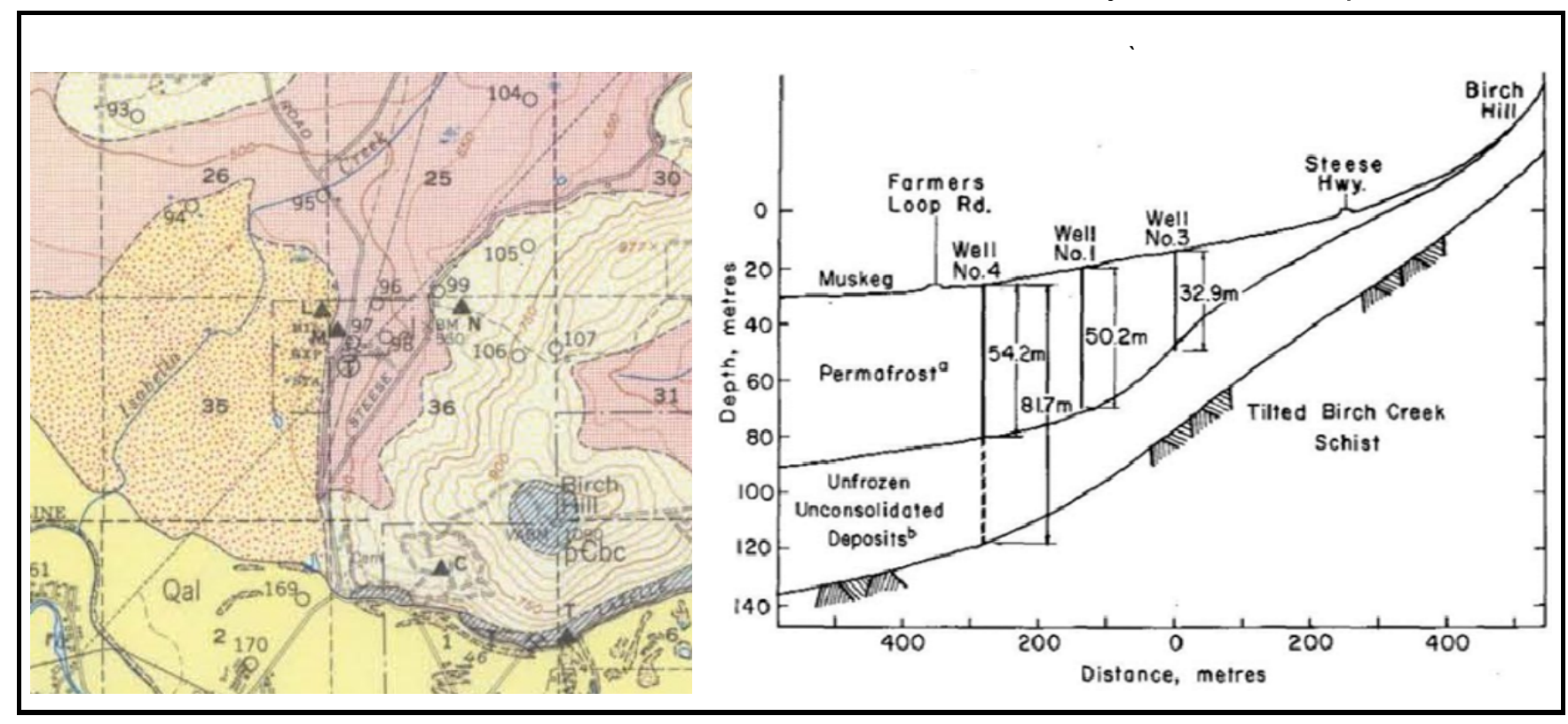

Modified from Péwé (1958).

Images drawn from historic aerial photography of the site show that some changes have occurred to the terrain and hydrology since 1949. Numerous disturbances including trails and test grids are evident on both sides of the paved Farmers Loop Road (Figure 24). Significant expansion of the thermokarst ponds west of the road have occurred over the last several decades. This expansion, along with increased thermokarst development in this area adjacent to the road, is indicated by increased thaw and melting of ground ice along the pond shore zones and within the vegetated area adjacent to them. Similarly, small pools of water within trails have developed, which are indicative of ground ice melting due to the thermal disturbance caused by the trail.

Our site visit at FL revealed significant thermokarst and wet conditions, especially west of the road, with numerous small pools of standing water within a zone of mixed deciduous and coniferous forest. Further west, the vegetation has changed to a poorly drained mix of tussocks and dwarf deciduous forest; the featureless zone, loosely classified as muskeg, runs approximately adjacent to the southwest to northeast across the site in the aerial photographs (Figure 24). In the northwest and west, the vegetation is mainly comprised of a better drained coniferous forest, principally black spruce, with sphagnum moss covering the ground. 
Research at the FL site from a previous CRREL project established two transects along which geophysical surveys were run and 10 boreholes were

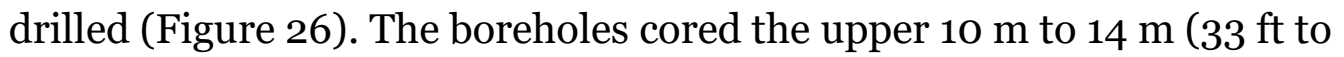
$46 \mathrm{ft}$ ) of the permafrost and the data were logged using standard geologic nomenclature. Samples for laboratory measurements of gravimetric moisture content were also taken from various depths depending on material type and visible ice content. The data provided us background on the nature of the substrate and allowed us to develop our approach to investigations for the project. However, the required description of cores following the cryostratigraphic logging methodology was not recorded with detailed information, and samples were not acquired at a fixed interval as needed for the geostatistical analyses. In addition to the drilling, geophysical surveys using CCR, ERT, and GPR were run and those data have been examined as part of the initial site appraisal.

Figure 26. Transects $\mathrm{T} 1$ and $\mathrm{T} 2$ at the Farmers Loop site. The location of these transects were previously established for an earlier CRREL project, with boreholes (yellow circles) drilled as a part of that study. The red triangle dots indicate locations for the detailed coring (every 6 meters) and analysis of the permafrost for this investigation.

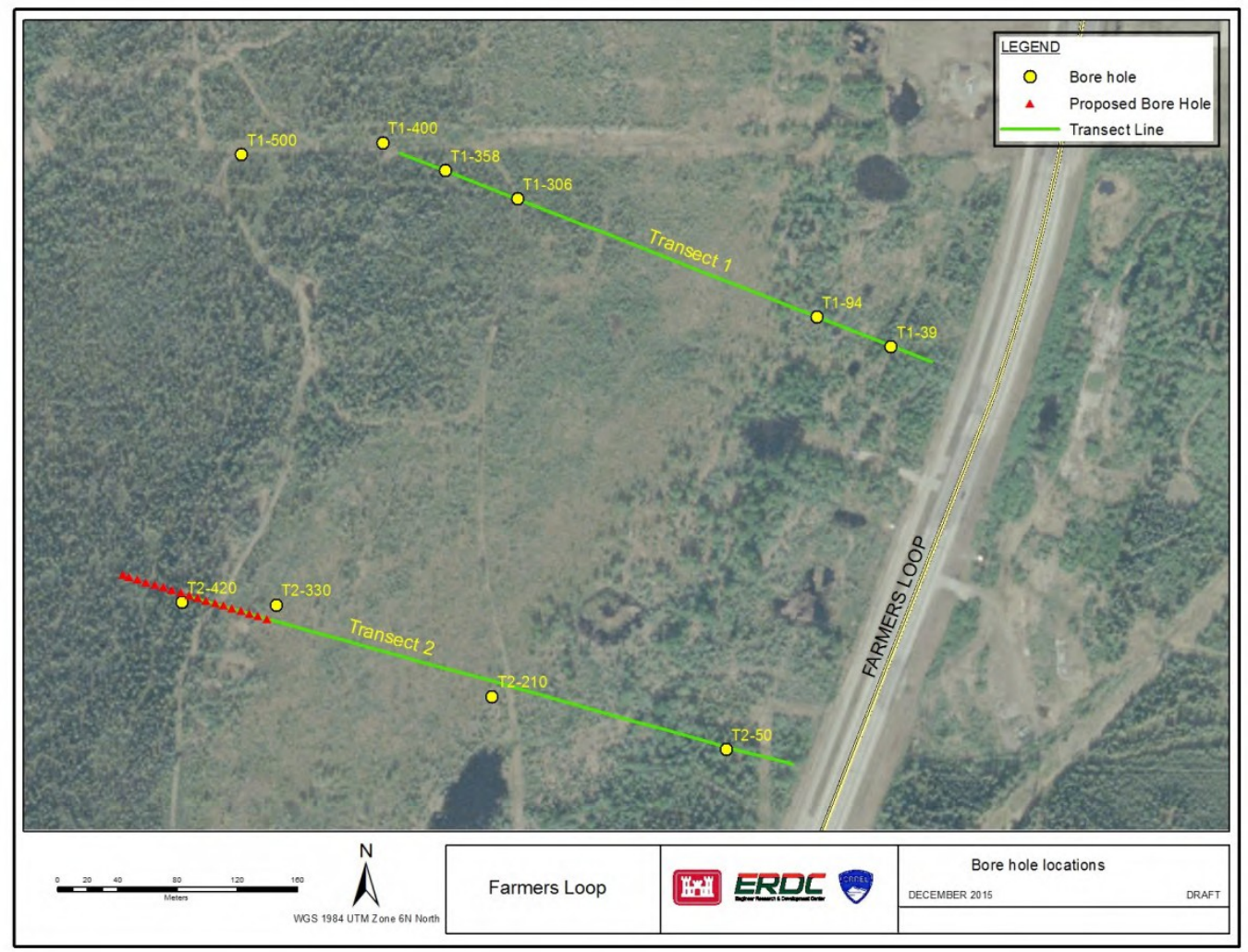


We decided to re-establish the two transects of $400 \mathrm{~m}(1,312 \mathrm{ft})$ length from this earlier study, thereby leveraging the previously acquired data on the subsurface properties. Each transect is projected approximately southeast to northwest to the west of the Farmers Loop Road, traversing the terrain features that trend $\sim \mathrm{SW}-\mathrm{NE}$ across the site (Figure 26). Based on the previous drilling results, we selected Transect $\mathrm{T} 2$ for intensive drilling with boreholes located every $6 \mathrm{~m}$ and core sampling every 30-cm (12-in.) depth (Figure 26). The section is extended to $100 \mathrm{~m}$, beginning in the tussock terrain and extending into the coniferous black spruce forest. This survey provided unique subsurface conditions to examine and evaluate with geostatistics.

CCR resistivity surveys were run on each transect with a depth of penetration of $\sim 17 \mathrm{~m}(\sim 56 \mathrm{ft})$ (Figure 27). A second survey of Transect T2 using ERT was run using a Wenner array and a dipole-to-dipole electrode configuration; the latter was used to increase the depth of penetration (Figure 27). Both sets of data revealed distinct differences in ice content along each transect, with the highest ice content and possibly presence of massive ground ice beneath the coniferous forest on the western side of the site. 
Figure 27. Resistivity profiles for Transect T1 (top) and T2 (bottom) at the Farmers Loop site. Left end is on the east end, near the road. The low resistivity values near the road indicate some areas of low ice content and/or unfrozen zones at depth, perhaps associated with thermokarst from disturbance, while the dark red indicates a high ice content beneath the western edge of the tussock and dwarf spruce area, particularly beneath the coniferous forest.

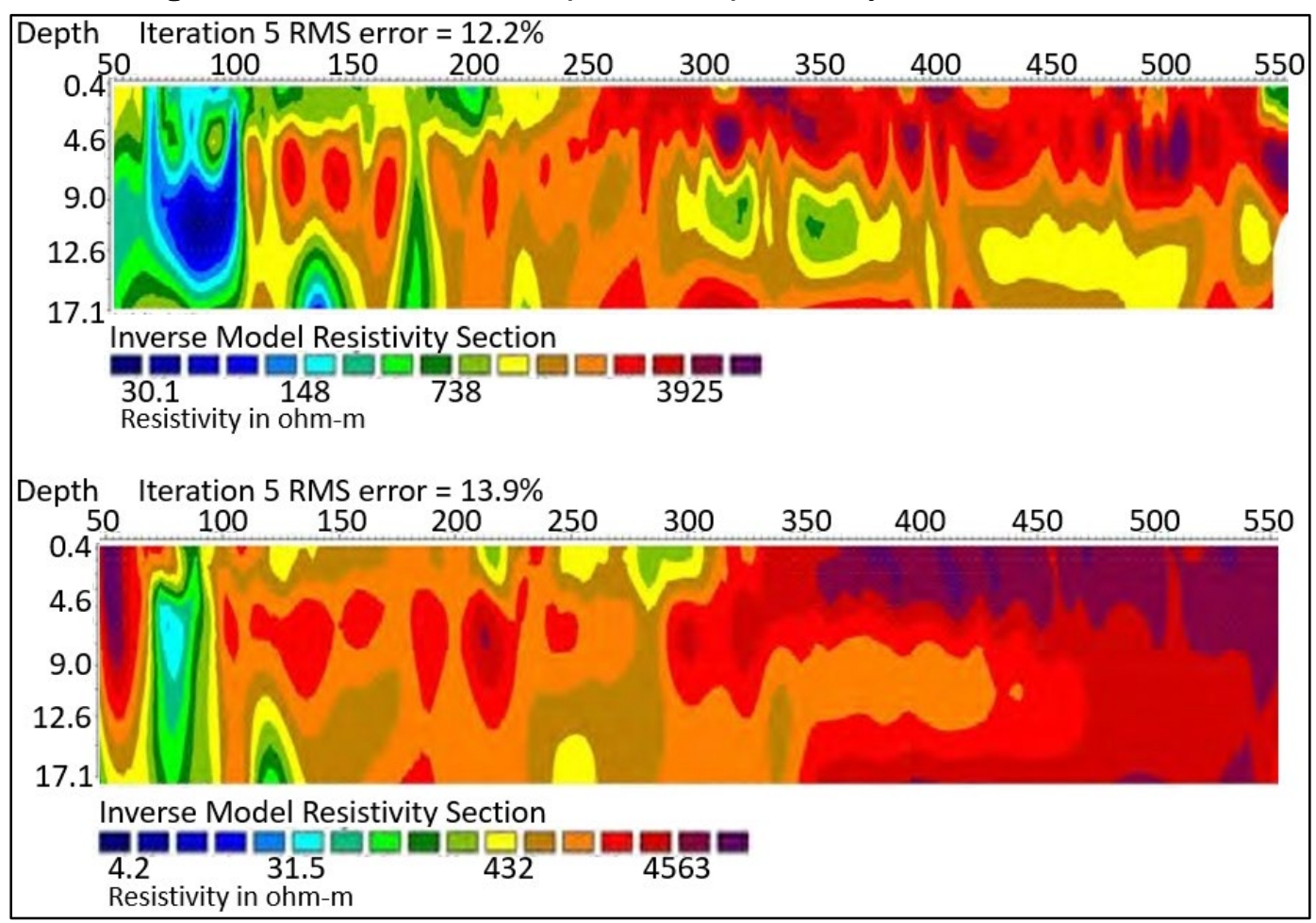

GPR surveys were also conducted on each transect; however, these provided very limited subsurface information (Figures 28 and 29). The profiles were acquired at $360 \mathrm{MHz}$ and had extremely limited depth penetration only within the active layer due to the frozen organic-rich silt beneath the site. Rough surface conditions within the tussock terrain even during the winter season had prevented antennas from maintaining contact while they were being pulled along each transect, which affected data quality. 
Figure 28. Migrated GPR profile at $360 \mathrm{MHz}$ from Transect T1 at Farmers Loop site acquired in April 2014. The 0-meter mark lies at the western end of this transect and the $400 \mathrm{~m}$ (1312 ft) mark occurs adjacent to Farmers Loop Road. The data are limited in penetration, and subsurface features shown are limited to a sporadic active layer of $1 \mathrm{~m}$ to $1.5 \mathrm{~m} \mathrm{(3 \textrm {ft } \text { to }}$ $5 \mathrm{ft}$ ) thickness (e.g., $300 \mathrm{~m}$ to $360 \mathrm{~m}$ [984 ft to 1,181 ft]), but in most cases, the base of the snow cover and top of active layer are difficult to distinguish.

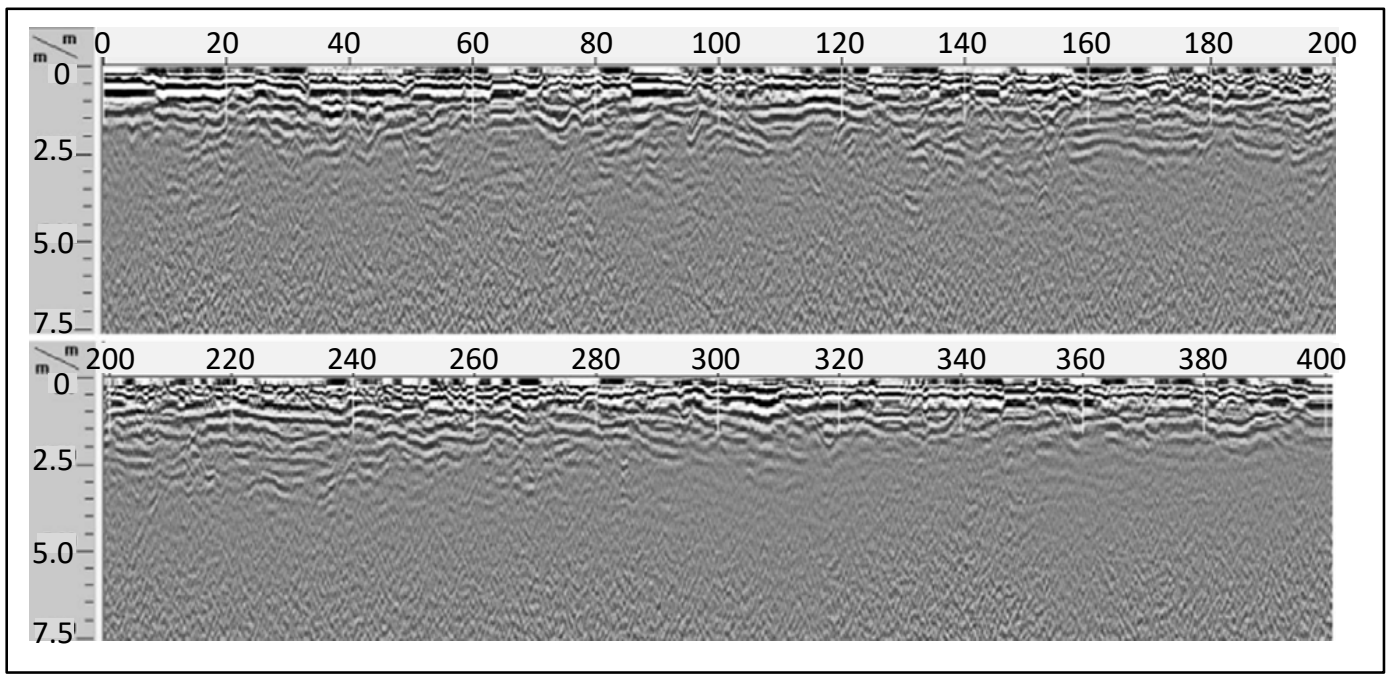

Figure 29. Migrated GPR profile at $360 \mathrm{MHz}$ of Transect T2 at Farmers Loop. Profile begins at

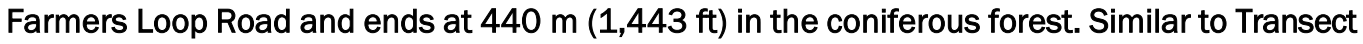
$\mathrm{T} 1$, there is only limited penetration and a sporadic active layer revealed.

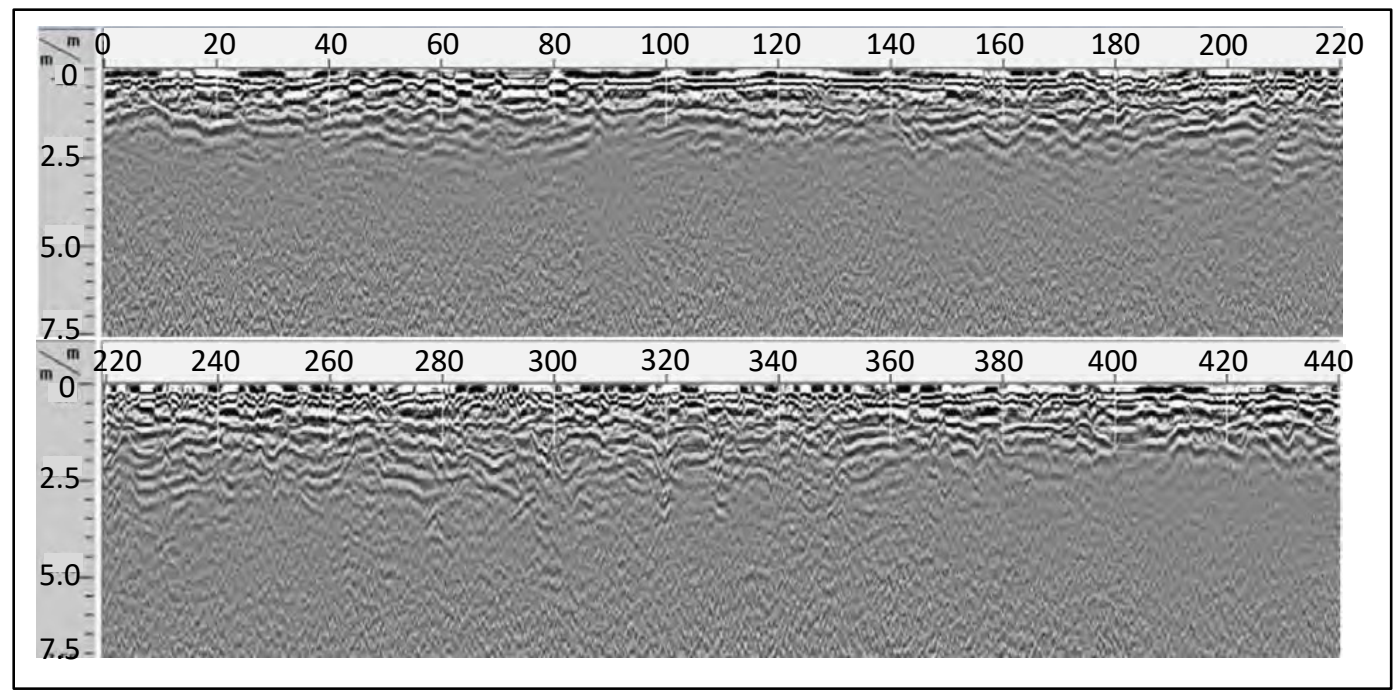




\subsection{Geostatistics analysis}

\subsubsection{Background}

Using geostatistical analysis, indirect information on subsurface ground conditions can be estimated from surface terrain feature data (Figure 30). More importantly the profiles from geophysical measurements such as electrical resistivity (Figure 31a), and the ground truth using the borehole cores can be optimized for characterizing a potential building site. Borehole cores provide the most accurate information about subsurface ground conditions including the occurrence of permafrost, presence of ground ice, soil type, and ice content of soils (Figure $31 \mathrm{~b}$ and c). However, the expense of drilling can make conducting a complete geotechnical study of a potential building site cost prohibitive. Geostatistical analysis is used to fuse these multiple data sources (e.g., surface terrain features, soil resistivity, and borehole data) for providing estimates of uncertainty. This uncertainty will be used to guide the borehole sampling scheme to minimize the number of boreholes that are drilled for a given project to optimally characterize the subsurface soil and permafrost conditions. Because the geostatistical analysis for site characterization is an integral component for the PFFDSS tool, the primary objectives are to:

- Predict subsurface conditions given some combination of information from initial assessments of surface terrain features, geophysical data (resistivity), and borehole core analysis data. The model will generally begin with initial assessments surface terrain features, then include geophysical data, and finally incorporate increasing numbers of boreholes as they are available to develop a correlation between the various data sources.

- Return some measure of uncertainty for the correlations between data sources and the predictions of subsurface soil and permafrost conditions.

- Use the measure of uncertainty to guide borehole sampling in order to minimize number of boreholes required.

- Integrate the statistical model with QGIS in order to unify the QGIS interface with the statistical model. 
Figure 30. Surface terrain features map for the CCHRC test location showing borehole sample locations and transition boundaries between terrain units. Terrain units (geology) are Qrf, Alluvial-Fan Silt (overlies floodplain alluvium); perennially frozen; Qcs, Swale and slough deposits (silt and silty sand, contains organic material); Qcs-1, perennially frozen near the surface; and Qcs-2, lowered permafrost table (after Péwé et al. 1977). Map orientation, south up, correspond to data analysis in Fig. 31.

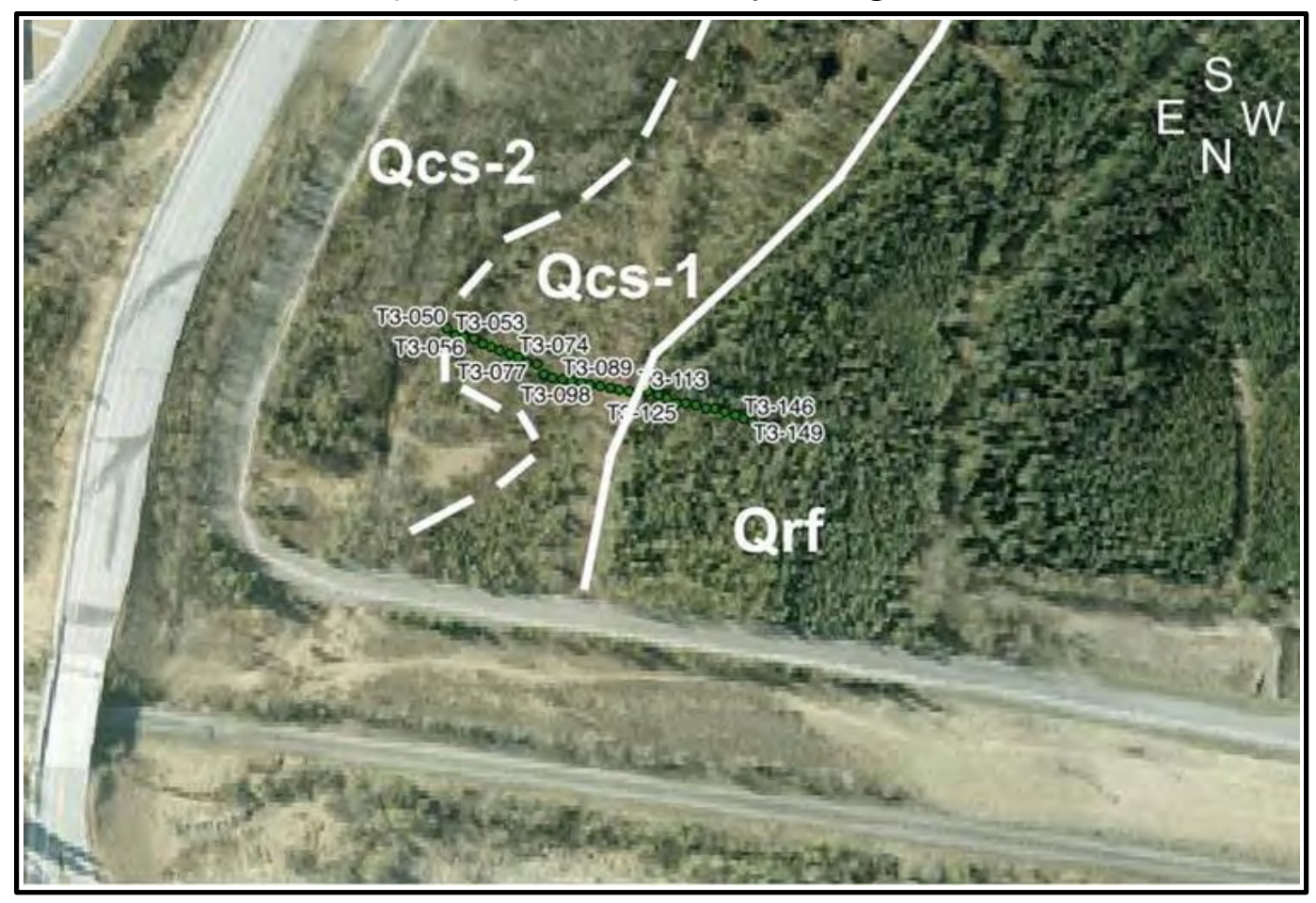


Figure 31. Charts showing: (top) CCHRC resistivity profile along the track of borehole locations, (middle) borehole core analysis derived subsurface permafrost map, and (botttom) soil conditions from interpretation of borehole core analysis from Transect T3 drilling (Fig. 46).

Borehole locations are overlaid on the permafrost and soil condition profiles with location numbers increasing from left to right. Surface terrain feature regions are shown as: A for Qcs2, B for Qcs-1, and C \& D for Qrf (Fig. 46).
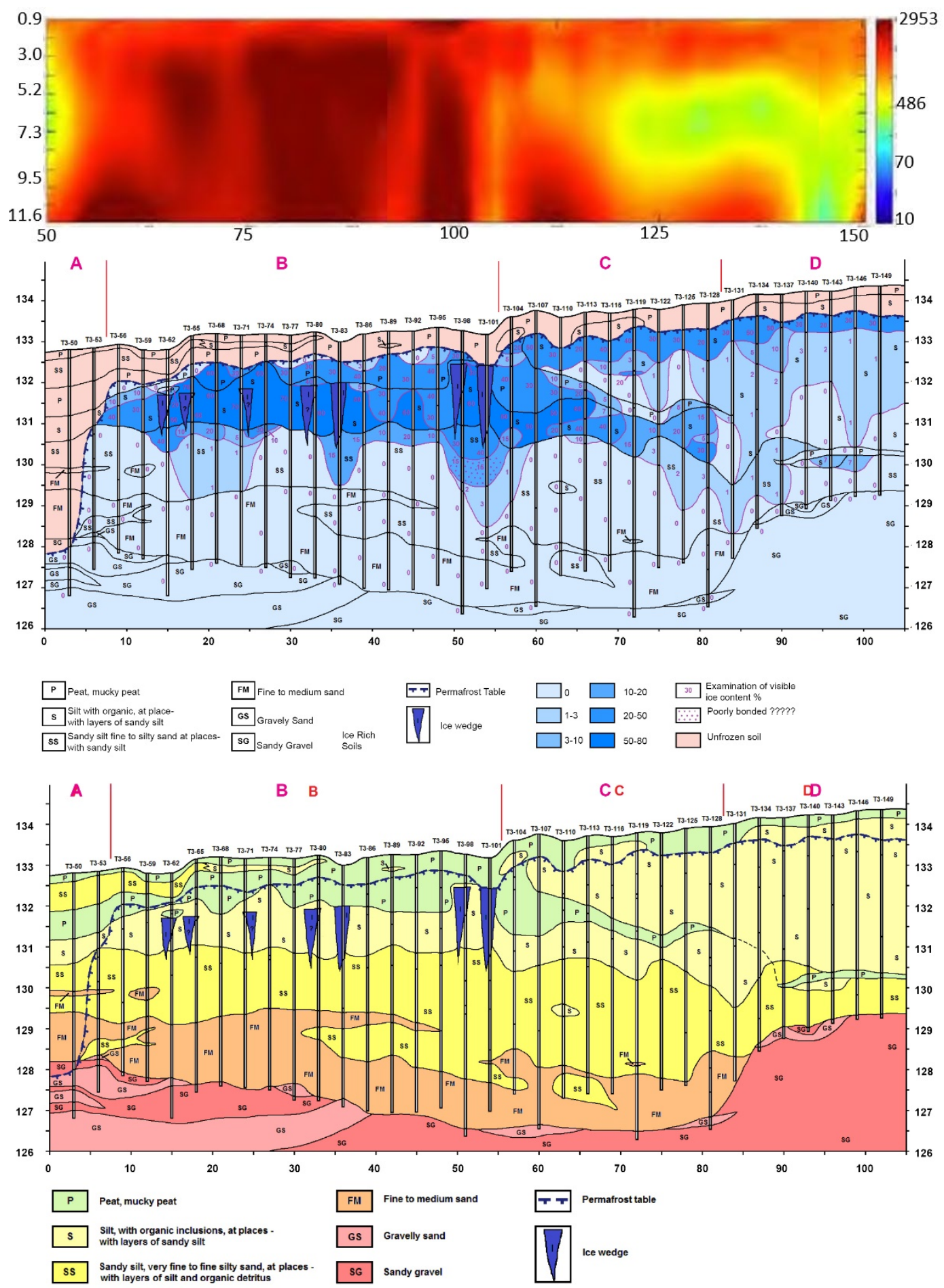
The database on subsurface conditions at CCHRC was examined using geostatistical methods to optimize the amount of geophysical, borehole, and field data required for adequate site characterization. We theorized that statistically generated results from a progressively increasing set of boreholes and surveys would attain an acceptable level of confidence adequate for the site characterization of the infrastructure of interest and would therefore determine the point at which optimal sampling density has been reached.

Geostatistics use sample locations and data values to constrain uncertainty of a given variable of interest throughout a spatial region. In our case, surface feature data, such as polygonal ground, black spruce forest, tussocks, and other features associated with the presence of permafrost, combined with ground electrical resistivity data, are used to create an initial estimate of subsurface permafrost. Review of the map then suggests where to place boreholes as ground truth for subsurface permafrost conditions at that point. New information from borehole analyses contributes to the statistical analyses, which then update permafrost subsurface estimates and reduce uncertainty. This process is repeated until an acceptable threshold of uncertainty is met.

\subsubsection{Analysis approach}

Our analysis uses Bayesian inference and Gaussian processes modeling to estimate subsurface permafrost conditions from surface terrain features, ground resistivity, and to optimize the use of borehole data. Bayesian analysis allows for the integration of prior information to quantify the statistical probability of an event and permits for an intuitive interpretation of results. This prior information would incorporate expert opinion (both sitespecific and more generally from the literature), which has always played an important role in subsurface reconstructions and decisions on where to build in permafrost terrain. Our analysis used an expert interpretation of surface terrain features to estimate the probability of the presence of subsurface permafrost (Table A-1, p 144). Surface terrain features would provide an indication that permafrost exists, or does not exist; however, surface terrain features is limited in providing information about the variation of permafrost or its ice content as a function of depth or areal extent. Ground resistivity measurements over the region of interest are used to estimate the variation of subsurface permafrost and ice using previous experience with correlating the probability occurrence of permafrost with ground resistivity (Table A-2, p 147). The correlation between the measured existence of subsurface permafrost and ground resistivity is used in 
the Bayesian prior probability estimates to recommend where to drill a borehole to collect physical information about subsurface conditions. Borehole core analysis data provide the physical information about the soil type, the frozen or unfrozen state of the ground, and moisture content that are used to improve the correlation between ground resistivity and subsurface conditions at the specific location of interest.

The goodness of fit between resistivity and borehole data will determine how many boreholes are needed to adequately characterize a given site. In this project, we assessed the goodness of correlation between subsurface conditions, resistivity, and borehole core data.

The boreholes, which were samples at $3 \mathrm{~m}$ to $6 \mathrm{~m}$ (10 ft to $20 \mathrm{ft}$ ) separation between boreholes), provided an accurate description of subsurface ground conditions. A Gaussian process is then used to estimate subsurface conditions between boreholes or across resistivity profiles based on borehole core interpretations and correlation between borehole and resistivity data. A Gaussian process is a semi-parametric model for fitting a surface (or curve) to data in geostatistics, which is a normal distribution to every point along the surface. The overall shape of the surface could be primarily based on the data and is unrestricted in this model. This includes data points for which we have no direct observation of discrete or continuous predictor variable descriptions (for covariate measurements) to use for prediction.

Also, the Gaussian process model can use the spatial dependence of the variation of conditions between measured points to predict soil conditions at new locations. Generally, measured data points that are collected in close proximity are more similar to each other than are data points that are farther apart. The Gaussian process accounts for dependence of data points on each other as a function of distance using a covariance function. Covariance determines the effect of nearby points on a point's predicted value. The specific parameterization of the covariance function determines how much a fitted surface will change on different length scales and how smooth those changes will be. The parameterization of the covariance functions is where variogram (sometimes called semi-variogram) methods are typically used. A variogram is a function describing the correlation of measurements with nearby data as a function of distance; it is based on the idea that nearby observations will be more similar than those that are more distant. 


\subsubsection{Data processing}

The spatial coordinates along each transect were taken to be the distance along the transect and the elevation above sea level (both in meters). The coordinates of a location within our spatial domain of interest is a vector of length two, and will be denoted by s, with potential sub- or superscripts. Elevation was calculated by subtracting sample depth from surface elevation, as measured by GPS. Where surface elevation was not available (at locations between boreholes), quadratic interpolation was used as an approximation. All surface elevation measurements were used even when not all boreholes were used, under the assumption that these would be available or could be taken during an initial site survey with minimal effort. Resistivity measurements were inverted using Res2D. This gave an irregular grid of resistivity values from a $0.85-\mathrm{m}(2.79-\mathrm{ft})$ depth to below a $10 \mathrm{~m}$ (33-ft) depth. Resistivity values must be available at all points within the domain of interest to be used in the spatial model. Consequently, the spatial domain of analysis was restricted to depths below 0.85-m (2.79-ft) along the resistivity transects. Resistivity values can range over two orders of magnitude, so the natural logarithm of each value was taken. Linear interpolation was used to retrieve the log-resistivity values anywhere within the spatial domain. For convenience, the log-resistivity at location is denoted as R(s). Each borehole sample had a soil type recorded. These were based on a simplified Unified Soils Classification System (USCS) code (Table 3), so that we had about six distinct soil types per transect. If massive ice was included in the sample, this was recorded as the soil type, sometimes along with another present soil type.

Table 3. Soil types used and their abbreviations. Based on a simplified USCS code.

\begin{tabular}{|c|l|}
\hline USCS code & Description \\
\hline Pt & Organic soil (peat) \\
\hline OL & Organic-mineral soil (organic silt, silty peat, silty with peat layers) \\
\hline ML & Silt \\
\hline SM & Sandy silt or silty sand, very fine to fine \\
\hline SP & Fine to medium sand \\
\hline SW & Gravelly sand, fine to very coarse \\
\hline GW & Sandy gravel \\
\hline (ICE) & Massive ice \\
\hline
\end{tabular}


Because estimating the amount of thaw settlement that might occur at a construction site is a primary goal of characterizing the subsurface soil conditions and ice has the potential to undergo 100\% thaw settlement, observations of ice as a soil type were removed. If a second soil type was recorded, it was used as the soil type for that sample. Because gravimetric moisture content was only measured every $30 \mathrm{~cm}$ (12 in.), there were many instances of missing measurements. Observations of ice as a soil type were used as information about the water content of that soil. Where these locations had no measured gravimetric moisture content, the gravimetric moisture content was imputed to be $2000 \%$. In this way, areas of massive ice are recorded not as a separate soil type, but as an area of very high soil moisture. Because gravimetric moisture content spans multiple orders of magnitude, these measurements were converted to water content, where the value represents the fraction of the mass of the original sample that was water. For a measured gravimetric moisture content at location $\mathrm{s}, w_{G M C}(\mathrm{~s})$, the corresponding water content $w_{w c}(\mathrm{~s})$ is given by

$$
w_{w C}(\mathbf{s})=0.01 w_{G M C}(\mathbf{s}) /\left(1+0.01 w_{G M C}(\mathbf{s})\right)
$$

This moves the measurements from a range of $[0, \infty)$ to a range of $[0,1]$. It is advantageous for statistical models to deal with observations on an unconstrained scale. The standard transformation for statistical modeling of data in $[0,1]$ is the logistic transform, so

$$
w(\mathrm{~s})=\ln \left(w_{w c}(\mathbf{s}) / 1-w_{w c}(\mathbf{s})\right) .
$$

Note that these are all one-to-one transforms, so the results can be backtransformed to gravimetric moisture content without loss of information.

\subsubsection{Spatial dependence}

When making statistical predictions about spatial phenomena, it is important to account for spatial dependence. Spatial dependence occurs because we expect that the closer two locations are, the more similar their condition will be. This complicates the modeling process, but also allows us to use the information in each observation more effectively. For example, if we observe permafrost at a $2 \mathrm{~m}(7 \mathrm{ft})$ depth in a borehole, we could reasonably expect that if we drilled a borehole $30 \mathrm{~cm}(12 \mathrm{in}$.) to the side, we would also observe permafrost at a $2 \mathrm{~m}$ (7ft) depth. In this way, we can "spread" borehole observations. 
These models use a variety of latent processes to model subsurface conditions. A latent process is one that is not directly observable, but that can be linked to those conditions in some way. For the two-dimensional case we are dealing with, the latent processes may be thought of as a third dimension where the value ("height" so to speak) of the process is related to the subsurface condition of interest. The latent process we are using to account for our spatial dependence is represented by a process convolution. Computationally, this is much more efficient than standard methods for accounting for spatial dependence (Higdon 2001).

A process convolution uses a set of $n$ knots at locations $s_{1}{ }^{*}, \ldots, S_{n}{ }^{*}$ within the spatial domain of interest. Each of these knots has a value $x_{1}, \ldots, x_{n}$. The term "knots" is used as shorthand to refer to these locations, which control the value of the process everywhere within the spatial domain.

The value of the latent process at a location within this domain is then determined by the convolution of the knots with a kernel. A kernel is a function that provides weights based on the distance from a given point. This means that the value of the latent process at a given location is a weighted sum of the knot values. The weights (and thus level of spatial dependence) are determined by the distance from location of interest to a given knot. The kernel for all spatial components is Gaussian, so for a location of interest $s_{o}$, a knot location $s^{*}$, and a scale matrix $V$, the weight given to that knot is

$$
k\left(s_{0} ; s^{\star}, V\right)=\exp \left(\left(s_{0}-s^{*}\right) V\left(s_{0}-s^{*}\right)\right) .
$$

Because we are dealing with generally horizontal layers of soil, we use an anisotropic kernel, where the dependence extends horizontally farther than it does vertically. We define the matrix representing this relationship as

$$
\mathrm{V}=\left[\begin{array}{cc}
14 & 0 \\
0 & 1
\end{array}\right]
$$

Thus, the dependence of two points separated by $1 \mathrm{~m}$ vertically is the same as two points separated by $\sqrt{14 \mathrm{~m}}(\sqrt{46 f t})(\approx 3.74 \mathrm{~m}[12 \mathrm{ft}])$ horizontally. Then, the value of the spatial latent process $Z_{\text {spat }}$ at location s is given by

$$
Z(\mathrm{~s})=\sum_{i=1}^{n} x_{i} k\left(\mathrm{~s}, s_{i}^{*} ; \mathrm{V}\right) .
$$


Multiple latent processes may be used to predict subsurface conditions. One example would be to incorporate geophysical information such as resistivity. These processes are added together for a final latent process that is finally linked to the condition of interest.

\subsubsection{Model fitting process}

Each of the models described below depends on a number of parameter values. The process of "fitting" the model uses information from the observations to find likely values for these parameters. In the Bayesian data analysis paradigm, these parameters are taken to be random variables. The distributions of the parameters may be approached using Bayes' theorem, so for a set of parameters $\theta$ and a set of observations $Y$

$$
\mathrm{P}(\theta \mid Y)=\mathrm{P}(\theta) \mathrm{P}(Y \mid \theta) / \mathrm{P}(Y) \text {. }
$$

In equation 2-6, $\mathrm{P}(\theta \mid Y)$ is known as the posterior. This is the term that we are ultimately interested in for the probability of a set of parameter values given the observations. $\mathrm{P}(\theta)$ is the prior. This term allows us to include our beliefs in possible parameter values before we have collected these data. The denominator, $\mathrm{P}(Y)$, is a normalizing constant. This would ensure that the posterior probability density integrates to one. Finding $P(Y)$ is difficult, as it involves integrating over all possible parameter values. Because of this, the distributions of parameter values can be found analytically only for very simple models. Standard quadrature rules are not effective for the high dimensional integrals typically encountered, so other techniques are typically used. The standard method for fitting these models is known as Markov Chain Monte Carlo (MCMC). This effectively performs the required integration and only requires specifying the model up to a constant of proportionality. A Markov chain is a random process where the value at each time is dependent on only a finite set of previous values, and typically only the value immediately preceding it.

The MCMC algorithm used in this study is the Metropolis-within-Gibbs algorithm. From a set of initial parameter values $\theta^{(0)}$, a parameter $\theta_{i}$ is chosen at random to perturb. A random perturbation is added to this parameter, giving a set of proposed parameter values $\theta^{(*)}$. The Metropolis ratio is then calculated as

$$
\begin{aligned}
M & =P\left(\theta^{(*)} \mid Y\right) / P\left(\theta^{(0)} \mid Y\right) \\
& =\left(P\left(\theta^{(*)}\right) P\left(Y \mid \theta^{(0)}\right)\right) /\left(P\left(\theta^{(0)}\right) P\left(Y \mid \theta^{(0)}\right)\right) .
\end{aligned}
$$


Note that the computationally difficult normalizing constant does not play a part in this calculation.

For $\mathrm{M}>1$, the proposed parameter value is accepted, so $\theta_{i}^{(1)}$ is set to $\theta_{i}{ }^{(*)}$. For $\mathrm{M}<1$, the proposed parameter value is accepted with probability $\mathrm{M}$. If it is not accepted, then that parameter value is the same in $\theta^{(1)}$ and $\theta^{(0)}$. In this way, parameter values tend toward the regions that more closely match the observed data. This is repeated for each parameter, using the current state of $\theta^{(1)}$ until at least one perturbation has been proposed for each parameter value. This is considered one iteration. Each subsequent iteration is based on the previous. Over many iterations, the distribution of these sampled parameter values has been shown to converge to the posterior distribution. The Bayesian analysis program was written and run using the Julia language (Bezanson et al. 2012, 2014).

\subsubsection{Permafrost model}

Permafrost was the initial subsurface condition to be modeled. The amount of prior information available and the simple binary representation made this a natural choice. It is also important to note that, if a volume of subsurface soil is not frozen, it is not susceptible to melting and so thaw strain is not a concern. Binary classification is typically accomplished using a logistic regression model, where each location is given a probability of a given label (in this case, permafrost or thawed soil). In a spatial setting such as this, this leads to an implicit assumption that the true state could change over arbitrarily short distances, even if the probabilities of the labels are constant. This is contrary to expectations; we generally would expect that permafrost would occur in large, contiguous areas.

Earlier work has shown that in this situation it is more effective to model the border between the two states. This is accomplished by modeling a latent process and setting the border to be the contour of some cutoff value. The obvious choice for this cutoff is zero. Thus, anywhere the latent process is positive is considered to be permafrost, and anywhere it is negative is thawed soil. 
The latent process $Z_{\mathrm{PF}}$ was modeled as the sum of two other latent processes. The first considers the relationship between the latent surface and the interpolated log-resistivity to be linear. Thus, we define

$$
Z_{\text {Res }}(s)=\beta_{0}+\beta_{1} R(s) \text {. }
$$

Our first two parameters are then $\beta_{\mathrm{o}}$ and $\beta_{1}$. We gave them prior distributions of

$$
\begin{gathered}
\beta_{0} \sim \operatorname{Normal}(-3,0.5), \\
\beta_{1} \sim \operatorname{Normal}(0.45,0.25) .
\end{gathered}
$$

The specific values for these distributions were determined in consultation with local experts. The experts first provided their expected probability of permafrost given ranges of measured resistivity. Random values were generated from each distribution, which were then used to calculate $Z_{\text {Res }}$ for $\log$-resistivity values up to $10 \ln \Omega \mathrm{m}$. This was done 10,000 times. The proportion of samples where $Z_{\text {Res }}$ was positive represented the probability of frozen soil at a given resistivity value. The distributions of $\beta_{0}$ and $\beta_{1}$ were adjusted until these probabilities matched those presented by the subject matter experts.

The second latent process used a process convolution to account for the spatial dependence of the permafrost process, $Z_{\text {spat. }}$ A regular grid of knots

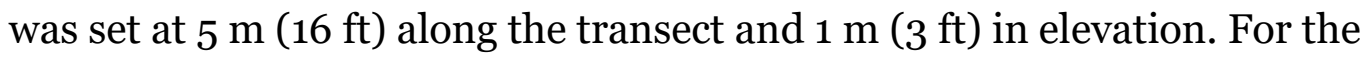
$\mathrm{CCHRC}$ transect, this resulted in 253 additional parameters. These were each given $\operatorname{Normal}(0,1)$ prior distributions. This served to regularize the knot values and prevent them from increasing in magnitude arbitrary. We then have

$$
Z^{\star}{ }_{P F}(\mathrm{~s})=Z_{R e s}(\mathrm{~s})+Z_{\text {spat }}(\mathrm{s}) .
$$

Our predictive process $Z_{P F}^{*}$ for a cutoff value $c$ (o in this case), is then

$$
Z_{P F}^{*}=\left\{\begin{array}{l}
1 \text { if } Z P F(\mathrm{~s}) \text { ge } 0, \\
0 \text { if } Z P F(\mathrm{~s}) \text { lt } 0 .
\end{array}\right.
$$

These predictions can then be compared to borehole observations, and a likelihood of the observations given the predicted states. A misclassification occurs when the model predicts thawed soil in a location where frozen soil was observed, or vice versa. If no misclassification is allowed for, any set of parameter values that provided a single incorrect prediction would 
have the same likelihood as a set of parameter values that provided 100 incorrect predictions - that is, zero. Thus, to fit the model, we must allow for some amount of misclassification so that it can move toward parameter values with more correct classifications. In this case, we use a misclassification rate of $1 / 1000$.

In this way, during the MCMC process, the values of the parameters controlling the latent process are adjusted toward more favorable states. Parameter values that provide additional correct classifications are kept while those that increase the number of misclassified observations are generally rejected. Once most of the observations are correctly classified, the parameter values will be adjusted many times as part of the MCMC process.

The border between states will generally occur between two observations of differing labels, so that each is correctly classified. A range of parameter values will preserve these correct classifications though any given point between these two observations may change label. Any point within the transect may be classified using the parameters sampled during MCMC. The proportion of classifications as permafrost then corresponds to the probability that the location is permafrost.

As a simple example, consider a transect where only two observations were made, one permafrost and one thawed soil. Given a sufficient number of initial iterations, these two observations would be correctly classified. The point halfway between them would change often, and probably have a predicted $50 / 50$ chance of permafrost. On the other hand, a point very close to the permafrost observation would have a much higher probability of permafrost.

It is important to have some measure of confidence in our predictions for each point on the transect. Areas where we have less information would be expected to have a higher measure of variance. Maps of a measure of variance for each model are important so that we can see where we have adequate information, and where additional information will provide the most benefit. The variance maps for these permafrost classifications use the variance of the Bernoulli distribution for each point; for a probability of permafrost $p, \operatorname{Var}(p)$ $=p(1-p)$. This reflects the fact that locations where we have the least information (highest variance) occur when the probability of permafrost is $50 \%$. 
Mapping areas of permafrost was done using a single-process model. Resistivity information was used, and a process convolution was used to account for the spatial component and to "spread" the borehole observations.

\subsubsection{Soil type model}

The model used to predict soil types is similar to the permafrost model. It uses the same basic idea of latent processes where larger values of the process provide some measure of evidence for a physical condition. Because we are classifying areas of the transect into $\{5,6\}$ categories, a simple cutoff value will not be effective. In this case, we fit a separate process convolution for each soil type we are predicting. At any given point on the transect, the process with maximum value provides the predicted soil type. Then for location s in the transect, a set of knot values for soil type $j \mathrm{Xj}$, our predicted soil type $Z_{\text {soil, is }}^{*}$

$$
\mathrm{Z}^{*}{ }_{\text {soil }}(\mathrm{s})=\arg \max _{\mathrm{j}} \sum_{i=1}^{n}(\mathrm{Xj}) i k(s, s * i ; V) .
$$

Over many MCMC iterations, the proportion of predictions made for each soil type provides the probability of each soil type's presence at that location. The MCMC simulation was run for 100,000 iterations because this model is much more computationally expensive. Every tenth sample of the model was saved.

\subsubsection{Water content model}

The ultimate goal of these models is to predict the water content of frozen ground. In frozen ground, we expect higher resistivity in areas with higher water (i.e., ice) content, as shown in Figure 32. The relationship between log-resistivity and logistic water content is clearly dependent on soil type. All of the soil types demonstrate a linear relationship. For sandy gravel, sandy silt, fine to medium sand, and gravelly sand (GW, SM, SP, and SW), knowing the soil type basically determines the water content. Silt and peat (ML and Pt) show a clear positive relationship, as expected. 
Figure 32. The relationship between log-resistivity and logistic water content is linear, but dependent on soil type.

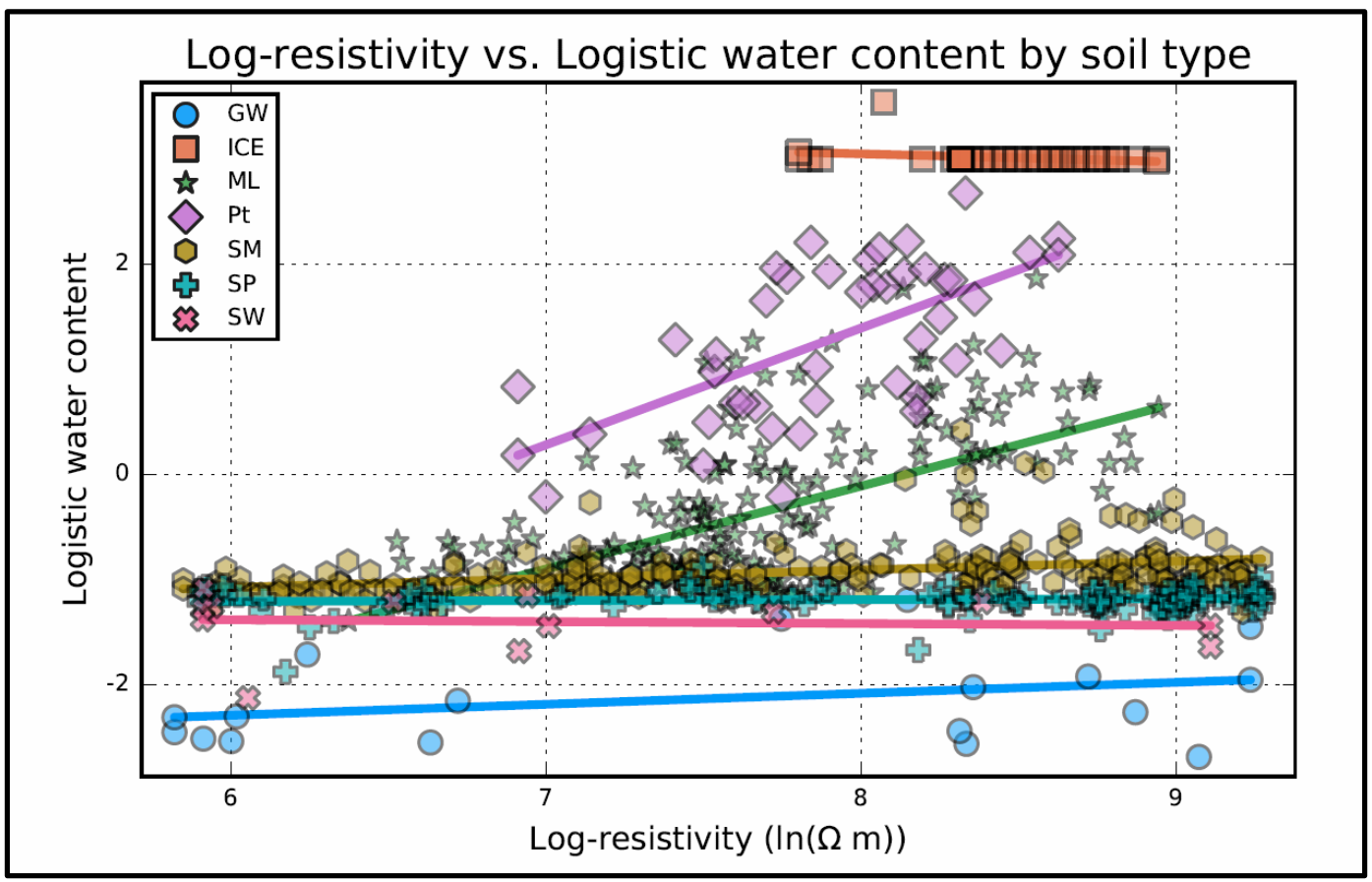

Note that we populated the output from the soil type model over to the water content model. The most likely soil type at a given location is assumed, and then the linear relationships with log-resistivity are then fit for the water content model. The spread of the observations around the linear fits is different based on the soil type. This necessitated the use of a separate variance parameter for each soil type. The final model for a location $s$ with predicted soil type $j$ is then

$$
Z_{w c}(S)=\operatorname{logit}\left[\beta_{0 j}+\beta_{1 j} R(s)+\varepsilon_{j}\right] .
$$

where

$$
\varepsilon_{j} \sim \operatorname{Normal}\left(\mathrm{o}, \sigma^{2} j\right) .
$$

This model was also run for 1,000,000 iterations, of which every 10oth was saved.

\subsubsection{QGIS}

QGIS is an open source software for spatial data management and geostatistical analysis that it is being used to store and display data to assist in 
the development of the statistical methods for interpreting surface features, soil electrical resistivity, and borehole data. There are two main types of data in QGIS, the vector layers (everything that can be geo-located: points, lines, and polygons) and raster layers (everything composed by pixels, for example maps). The main interface is organized by layers and a map canvas (Figure 33). For the CCHRC site, the map accommodates surficial data such as the location of boreholes, resistivity measurements, and polygons representing surface terrain features.

Figure 33. QGIS Main Interface with the layer page on the left for displaying the feature data (cores, topography, vegetation, geology, resistivity, etc.) and a map on the right.

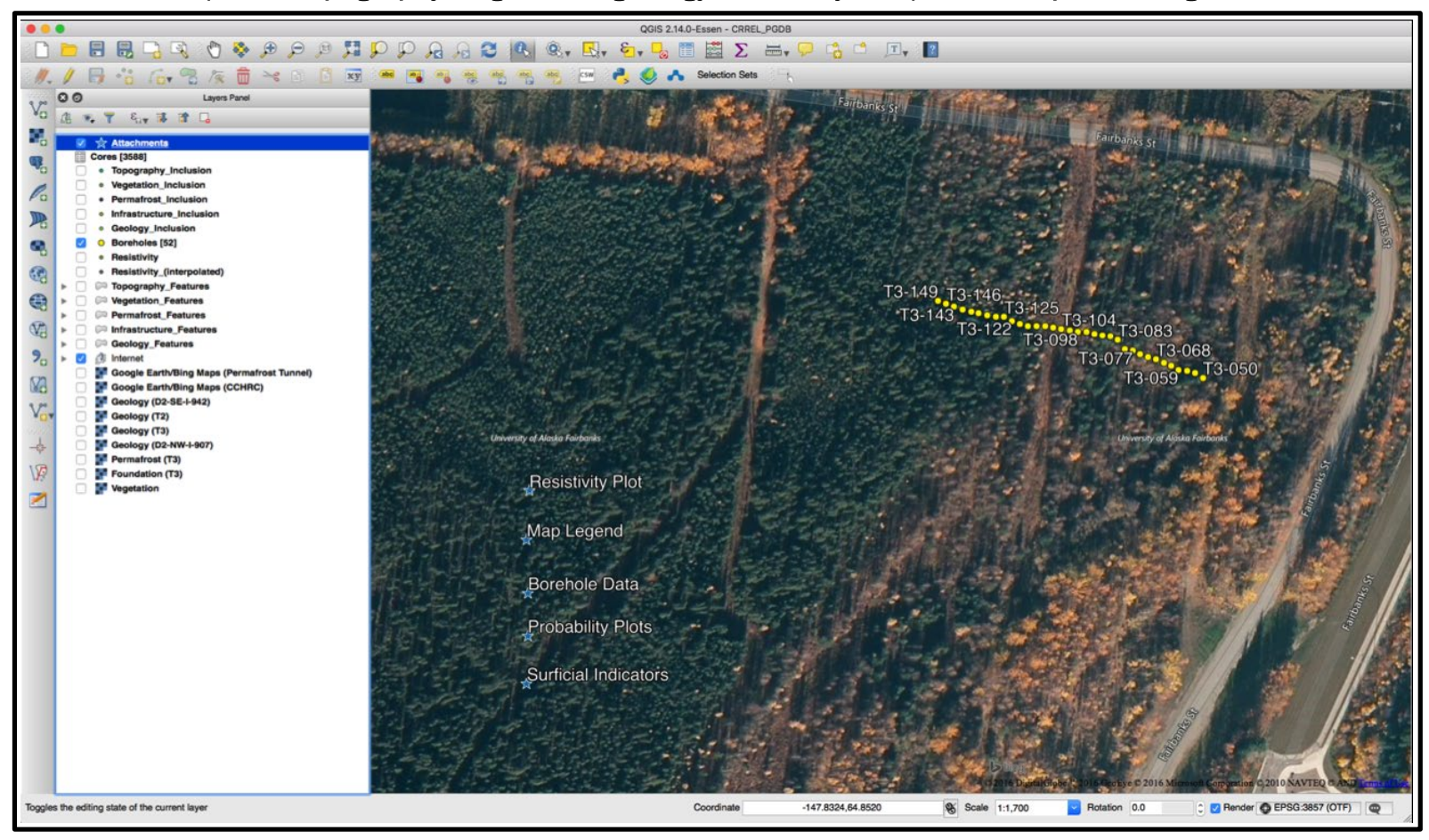

The QGIS data have resided in a Postgres open source relational database, which is at the same time accessed by the statistical model written in Julia code. The statistical model can access the data both from the local network and through the internet and uses embedded SQL (Structured Query Language) code to query the data at the database. Two web services are being provided for external systems, (Open Geospatial Consortium) Web Map Service (WMS) for map images and Web Feature Service (WFS) for tables (Figure 34). 
Figure 34. QGIS System

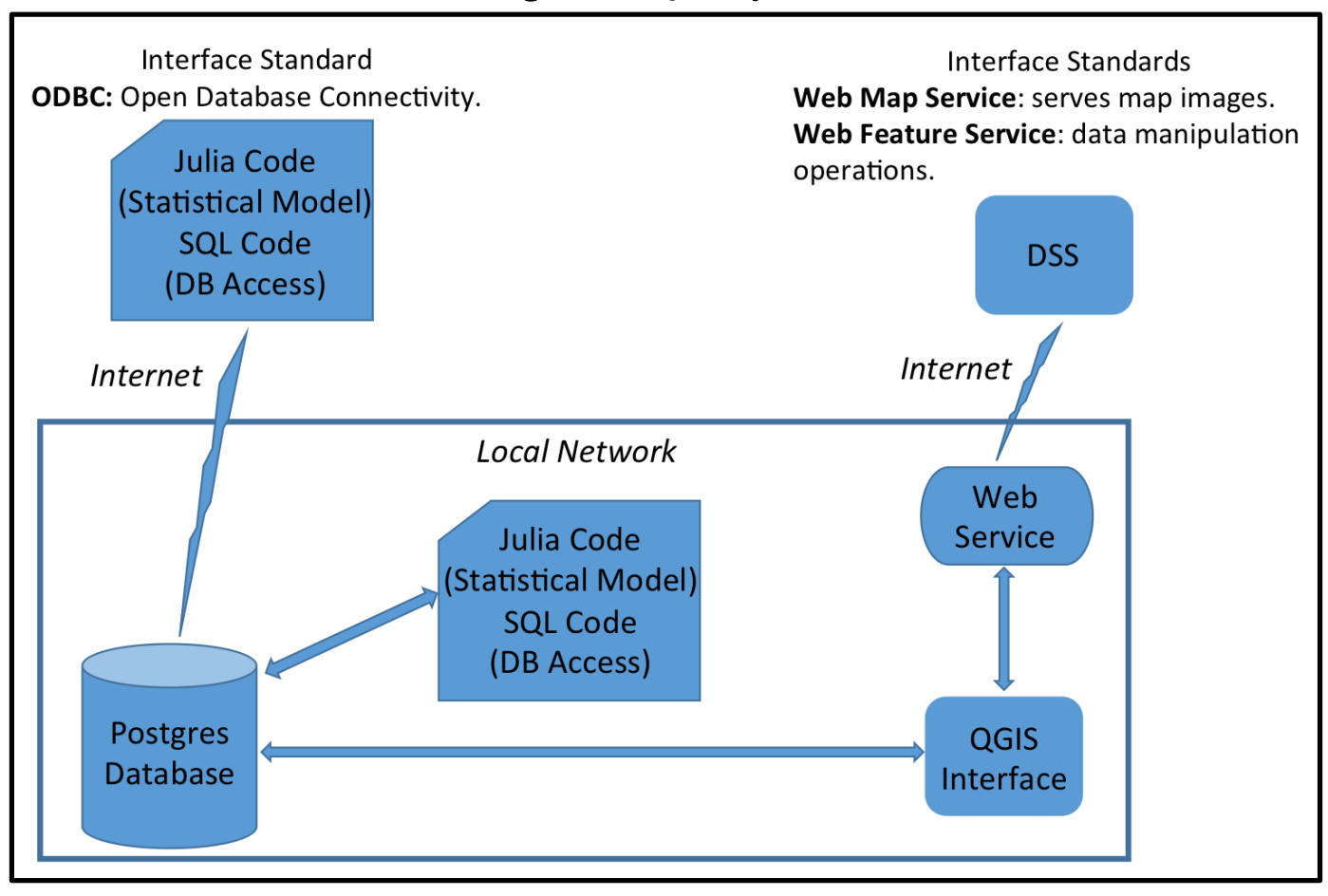

Figure 35 shows the QGIS data structure at the Postgres database. For each of the four sites, there is one transect. The following tables are defined for all sites:

- boreholes

- cores

- features

- resistivity

- attachments.

Two raster layers provide different sources of internet maps and maps authored by Troy Lewis Péwé (available at https://pubs.er.usgs.gov/search?q=geologic+map\&contributor=pewe). 
Figure 35. QGIS/Postgres Database

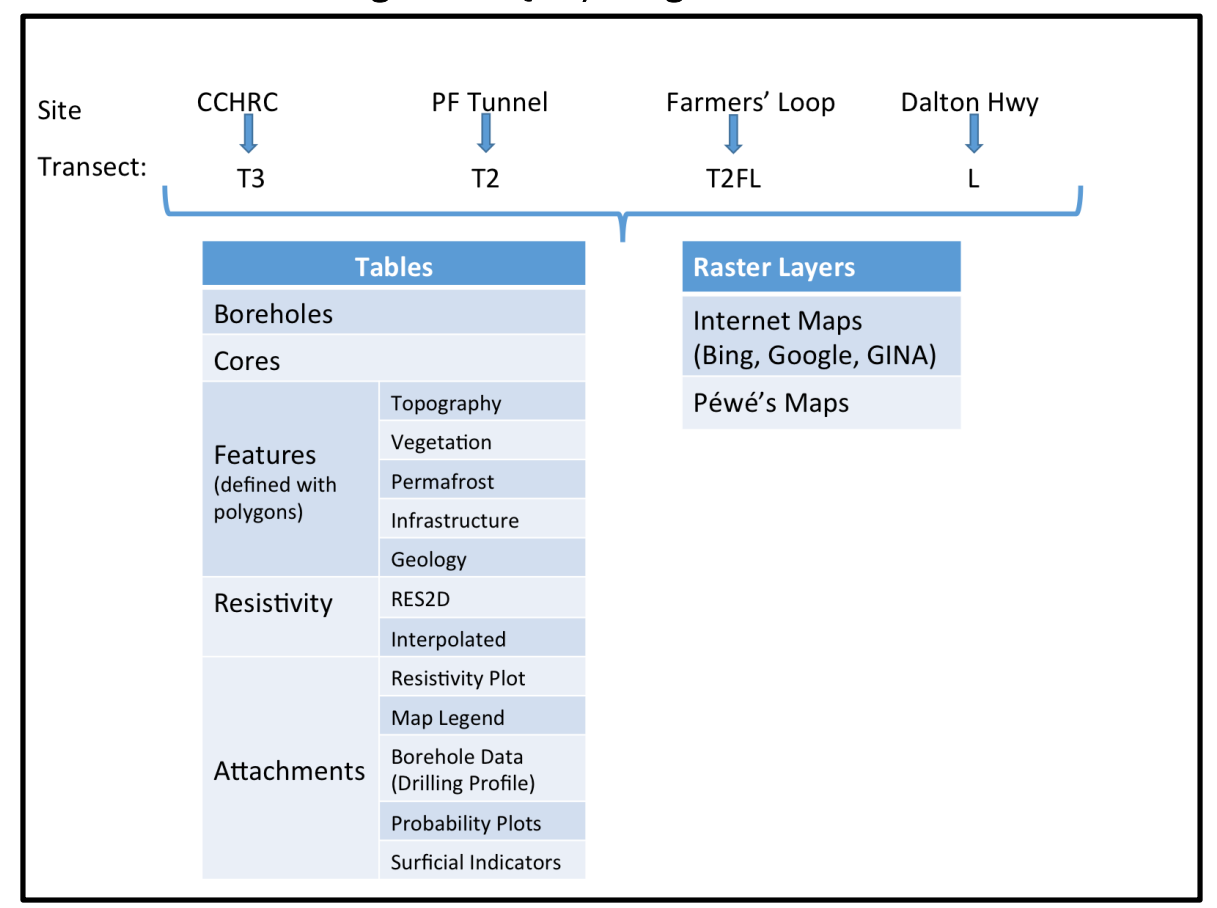

The borehole and resistivity data have both surface location and depth data that are stored in tables that can be accessed for analysis and display (Figure 36). For each borehole, the table listed the borehole name, the location (Northing, Easting, Elevation) and distance along the transect. Each borehole is then linked to the borehole cores table. For each borehole, the core depth, soil type, presence of permafrost, and the gravimetric moisture content are all registered. The separation distance between analyzed increments of the cores is $10 \mathrm{~cm}$ ( 4 in.) and the soil is classified according to the USCS categories (ASTM 1993).

Multiple types of data files can be stored at QGIS as attachments. For example, Figure 37 shows the resistivity profile and drilling profile plots for the transect at CCHRC site. The resistivity profile has been interpolated with Matlab from the output obtained from RES2D software. This is then used to improve the resolution of the geostatistical analysis compared to the original data. 
Figure 36. Format of QGIS Tables.

\begin{tabular}{|c|c|c|c|c|c|c|c|c|c|c|c|c|}
\hline & \multicolumn{12}{|c|}{$\begin{array}{l}\text { Partial borehole location table showing location information for } \\
\text { transect T3 boreholes. }\end{array}$} \\
\hline & \multicolumn{2}{|c|}{ Point $\nabla$} & \multirow{2}{*}{\multicolumn{2}{|c|}{$\begin{array}{c}\text { Northing } \\
7192288.724 \ldots\end{array}$}} & \multirow{2}{*}{\multicolumn{2}{|c|}{$\begin{array}{c}\text { Easting } \\
460650.3449 \ldots\end{array}$}} & \multirow{2}{*}{\multicolumn{2}{|c|}{\begin{tabular}{|c|} 
Elevation \\
$132.7849999 .$. \\
\end{tabular}}} & \multirow{2}{*}{\multicolumn{2}{|c|}{$\begin{array}{l}\text { Document } \\
\text { /Documents/... }\end{array}$}} & \multirow{2}{*}{$\begin{array}{l}\text { Notes } \\
\text { NULL }\end{array}$} & \multirow{2}{*}{\begin{tabular}{|c} 
Distance \\
$50.00000000 \ldots$
\end{tabular}} \\
\hline 0 & \multicolumn{2}{|c|}{$13-050$} & & & & & & & & & & \\
\hline 1 & \multicolumn{2}{|l|}{ T3-053 } & \multicolumn{2}{|c|}{$7192290.562 \ldots$} & \multicolumn{2}{|c|}{$460647.6840 \ldots$} & \multicolumn{2}{|c|}{$132.8350000 \ldots$} & \multicolumn{2}{|c|}{ Documents/... } & NULL & $53.00000000 \ldots$ \\
\hline 2 & T3-056 & & 7192291.3 & $315 \ldots$ & \multicolumn{2}{|c|}{$460644.8040 \ldots$} & \multicolumn{2}{|c|}{$132.9269999 \ldots$} & \multicolumn{2}{|c|}{ Documents/... } & NULL & $56.00000000 \ldots$ \\
\hline 3 & \multicolumn{2}{|l|}{ T3-059 } & \multicolumn{2}{|c|}{$7192291.688 \ldots$} & \multicolumn{2}{|c|}{$460641.7489 \ldots$} & \multicolumn{2}{|c|}{$132.7669999 \ldots$} & \multicolumn{2}{|c|}{ Documents/... } & NULL & $59.00000000 \ldots$ \\
\hline 4 & \multicolumn{2}{|c|}{ Т3-062 } & \multicolumn{2}{|c|}{$7192293.112 \ldots$} & \multicolumn{2}{|c|}{$460639.3210 \ldots$} & \multicolumn{2}{|c|}{$132.8100000 \ldots$} & \multicolumn{2}{|c|}{ Documents/... } & NULL & $62.00000000 \ldots$ \\
\hline 5 & \multicolumn{2}{|c|}{ T3-065 } & \multicolumn{2}{|c|}{$7192294.247 \ldots$} & \multicolumn{2}{|c|}{$460636.6560 \ldots$} & \multicolumn{2}{|c|}{$133.1409999 \ldots$} & Docur & ents/... & NULL & $65.00000000 \ldots$ \\
\hline 6 & T3-068 & & 7192295. & $432 \ldots$ & 460633.8 & $3499 \ldots$ & 133.19 & $9999 \ldots$ & /Docur & nents/... & NULL & $68.00000000 \ldots$ \\
\hline & $\begin{array}{l}\text { Parti } \\
\text { analy }\end{array}$ & & $\begin{array}{l}\text { borehol } \\
\text { d samp }\end{array}$ & & ores tak & le sh & lowin & $\begin{array}{l}\text { g bore } \\
\text { moist }\end{array}$ & ehole & $\begin{array}{l}\text { ID nu } \\
\text { ontent }\end{array}$ & $\begin{array}{l}\text { Imber } \\
\text { and } \mathrm{r}\end{array}$ & $\begin{array}{l}\text {, depth of } \\
\text { remarks. }\end{array}$ \\
\hline & & & oint & & Depth & usc & S_code & PF_ & code & GM & & Notes \\
\hline & 0 & T3-0: & & 10.000 & $000000 \ldots$ & $\mathrm{Pt}$ & & 0 & & & NULL & PF table $480 \ldots$ \\
\hline & 1 & T3-05 & & 20.000 & $000000 \ldots$ & $\mathrm{Pt}$ & & 0 & & & NULL & NULL \\
\hline & 2 & T3-05 & & 30.000 & $000000 \ldots$ & SM & & 0 & & 29.1000 & $0000 \ldots$ & NULL \\
\hline & 3 & T3-05 & & 40.000 & $000000 \ldots$ & SM & & 0 & & & NULL & NULL \\
\hline & 4 & T3-05 & & 50.000 & $000000 \ldots$ & SM & & 0 & & & NULL & NULL \\
\hline & 5 & T3-05 & & 60.000 & $000000 \ldots$ & SM & & 0 & & 31.0000 & $0000 \ldots$ & NULL \\
\hline & 6 & T3-05 & & 70.000 & $000000 \ldots$ & SM & & 0 & & & NULL & NULL \\
\hline & 7 & T3-05 & & 80.000 & $000000 \ldots$ & SM & & 0 & & & NULL & NULL \\
\hline & 8 & T3-05 & & 90.000 & $000000 \ldots$ & SM & & 0 & & 39.3999 & 19999... & NULL \\
\hline & 9 & T3-05 & & 100.00 & $000000 \ldots$ & $\mathrm{Pt}$ & & 0 & & & NULL & NULL \\
\hline
\end{tabular}




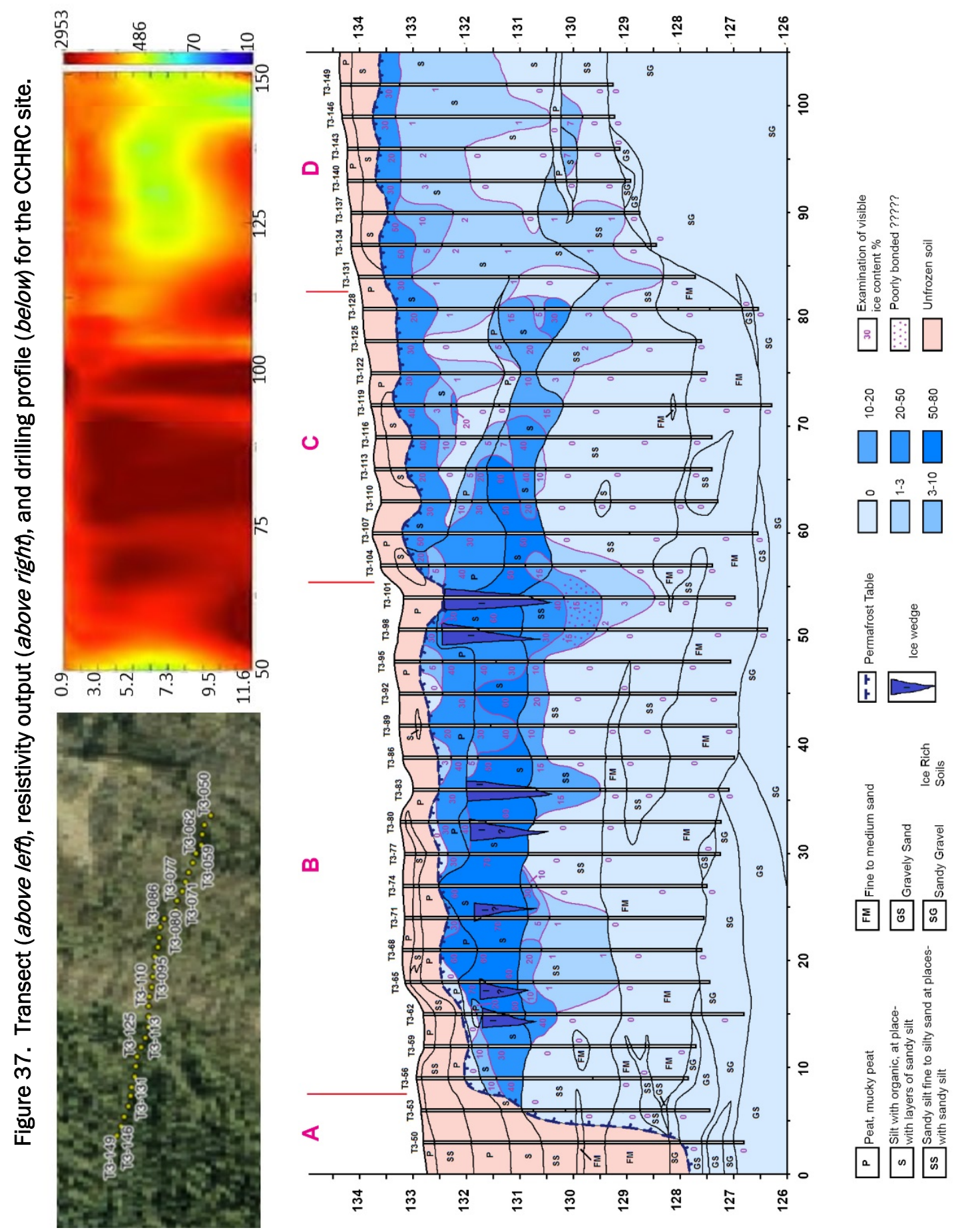


Surface terrain features can be displayed on the QGIS map as polygons with associated surface feature labels. The surface features were characterized over the CCHRC site by means of polygons that represent

- Surficial geology (alluvial silt fans, young slough deposits, and old slough deposits),

- Engineered infrastructures (adjacent infrastructure-permafrost engineered),

- Permafrost features (ice-wedge troughs with high-centered polygons),

- Vegetation (spruce forest and mixed forest), and

- Topography (valley bottom).

Figure 38 shows the geology characterization of the site in three polygons: alluvial silt fan, old slough deposits, and young slough deposits.

Figure 38. QGIS surface features definition with polygons.

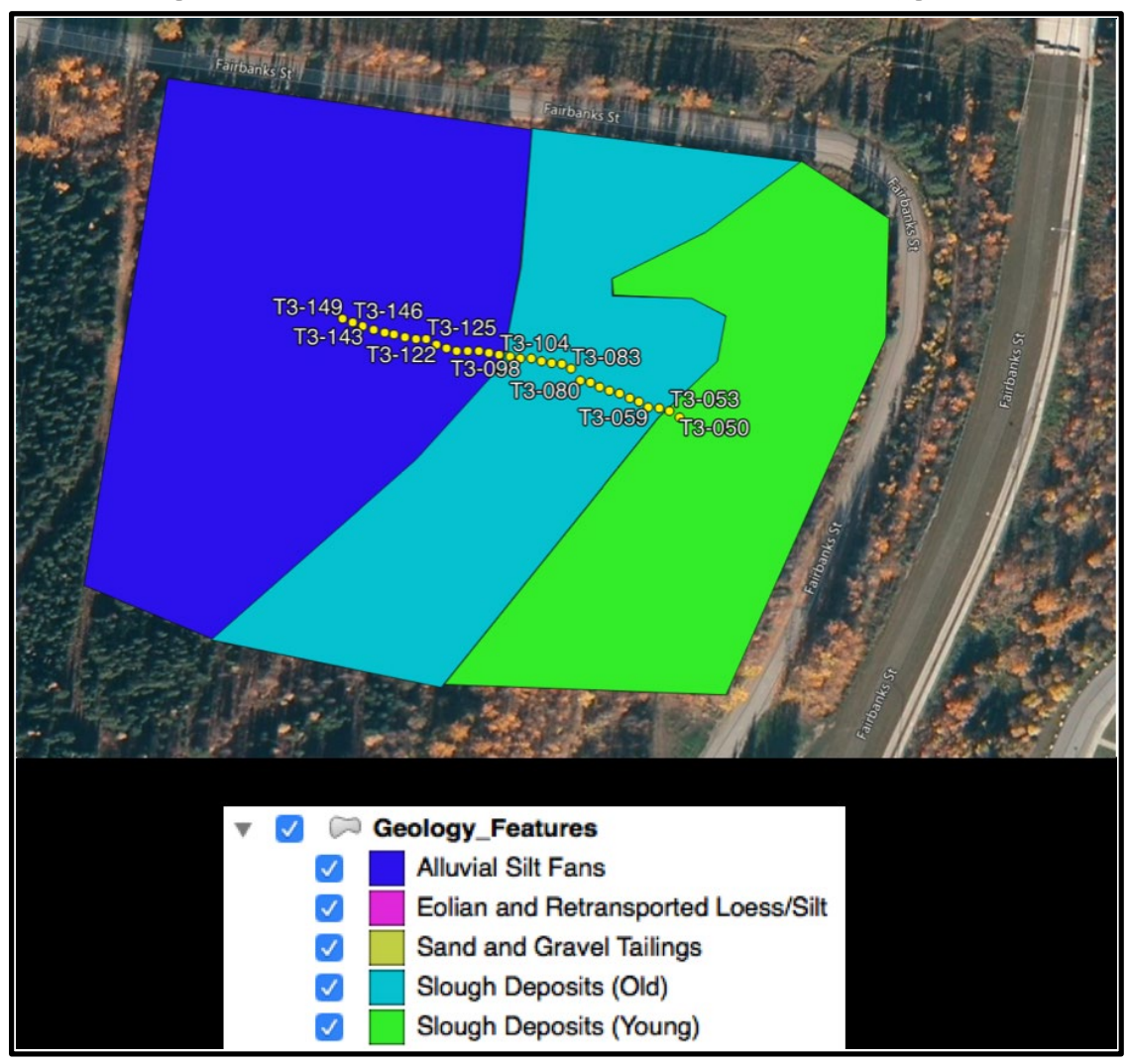

A basic version of the QGIS interface is accessible over the internet from any browser. Figure 39 shows the example polygon used to characterize the vegetation features: spruce forest with moss cover and mixed forest. 
Figure 39. Basic QGIS web interface showing vegetation for spruce forests with moss cover (green polygon), mixed forest (purple polygon) and destroyed vegetation (not shown).

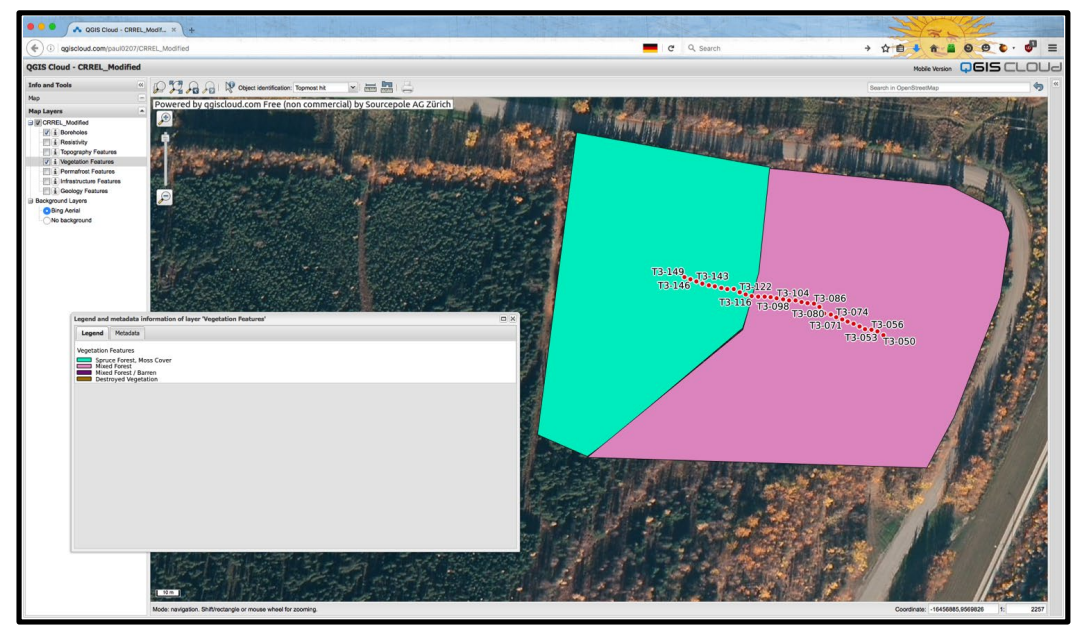

\subsection{Discussion}

\subsubsection{Probability of permafrost maps}

The engineering objective of using geostatistics analysis based on ground resistivity soil type and water content data derived from borehole cores (Figures 40 to 49) is to minimize the number of boreholes needed to suitably characterize a potential building site. The Bayesian approach first uses surface terrain and vegetation features (Figure 38) as a prior probability that a location may have subsurface permafrost (see Table B-1, p 157). This provides an estimate of the presence of permafrost and its type near the ground surface, but does not provide information about the spatial variation of permafrost or its water content (Figure 8). To estimate the spatial variability of the subsurface permafrost, a ground resistivity geophysical survey is conducted and the prior probability correlation between the magnitude of ground resistivity and permafrost (see Table A-2, p 147) is used to create a prior probability map of permafrost and type based on resistivity.

The prior probability maps of permafrost and its type based on resistivity provide the initial estimate about the variation of subsurface permafrost based on expert opinion developed from previous work. To characterize a specific site, the prior probability maps need to be updated using data from borehole core data analysis for soil type and water content at specific location that can be correlated to the resistance measurements. The prior probability, which is a map based on resistivity data, is used to guide 
placement of the boreholes to investigate regions of transition and uncertainty, and to confirm interpretations based on prior probability information (Figure 10). With this new information, an updated probability map of permafrost spatial variation can be generated (Figure 50) and its entropy (Figure 51). In comparing the prior probability map of permafrost (Figure 8) with the borehole data updated probability map (Figure 50), it is apparent that the prior probability map did a reasonable job of predicting permafrost spatial variability in general. Data from the three boreholes confirmed the existence of permafrost in the region centered around $80 \mathrm{~m}$, raising the probability of permafrost from a probability or 0.8 or higher for the prior probability map to more than 0.9 for the updated probability map. In the region centered around $50 \mathrm{~m}$, the prior probability ranged from about 0.7 to 0.8 , while the updated probability map based on borehole data lowered the probability of permafrost to less than 0.15 and to 0 right at the borehole. In the region centered around $140 \mathrm{~m}$ (459 ft), the prior probability map indicated probabilities of from about 0.7 to 0.8 , while the updated map showed probabilities from around 0.75 to over 0.9.

Figure 40. Most likely soil type using boreholes at $40 \mathrm{~m}, 80 \mathrm{~m}$, and $140 \mathrm{~m}$ (131 ft, $262 \mathrm{ft}$ and $459 \mathrm{ft})$.

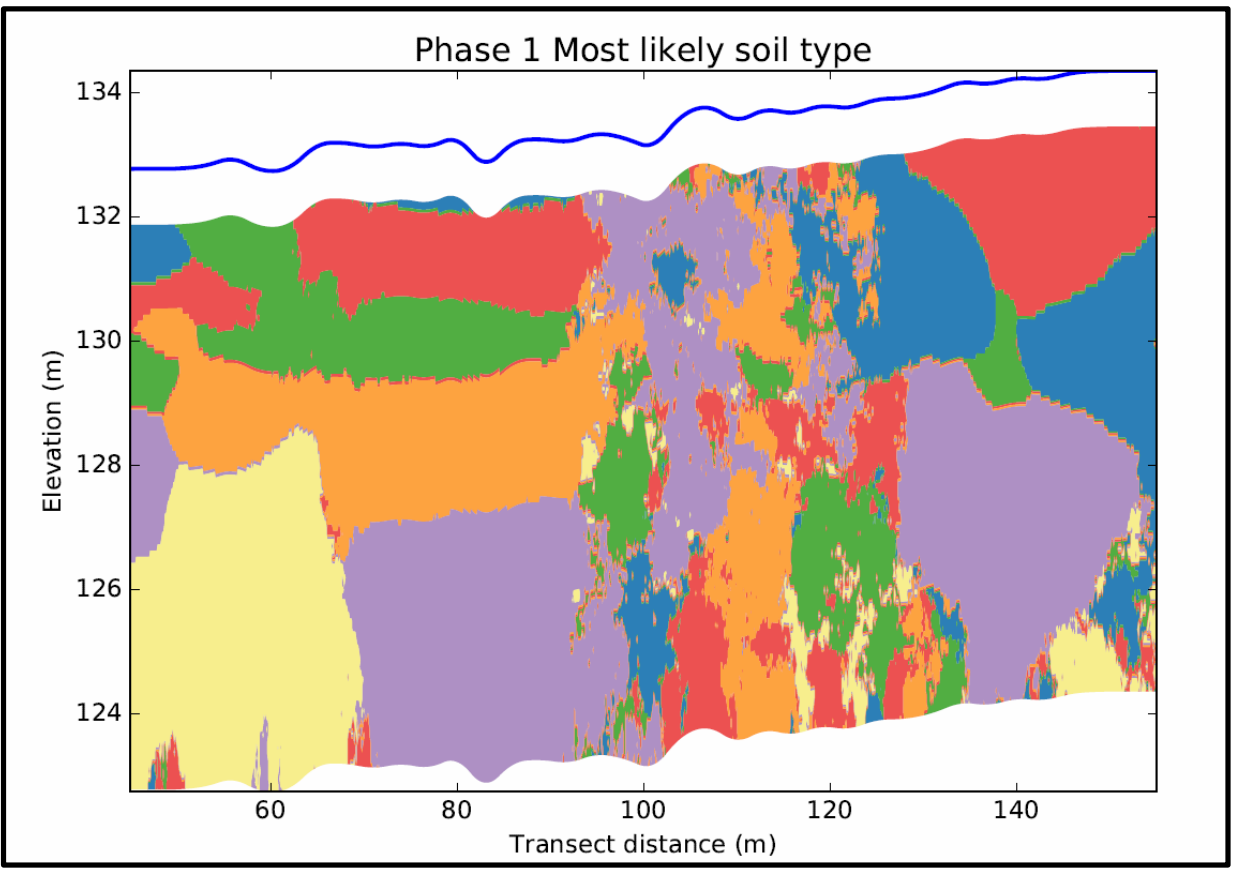




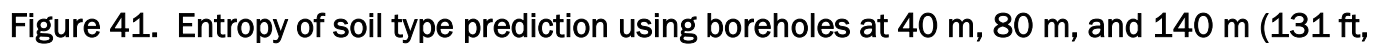
$262 \mathrm{ft}$ and $459 \mathrm{ft}$ ). Entropy is highest far from boreholes and at the border between two observed soil types.

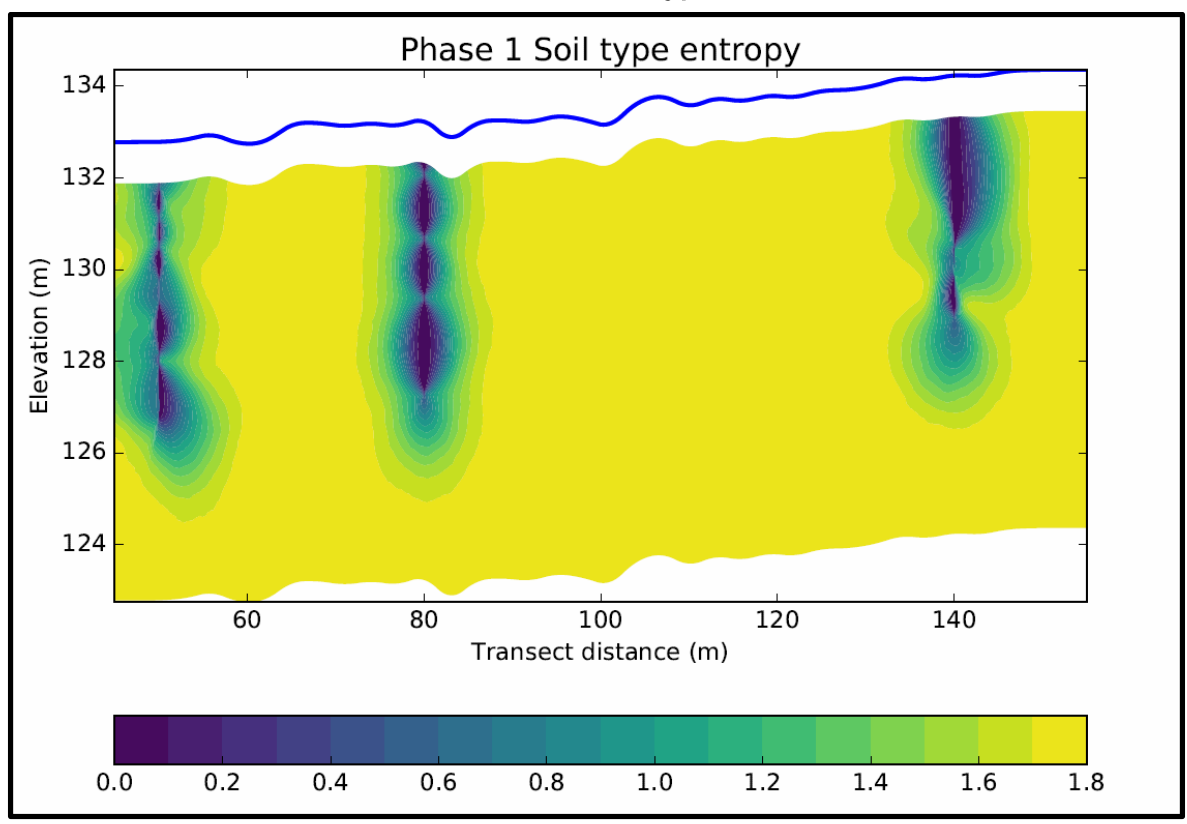

Figure 42. Predicted water content using resistivity and boreholes at $40 \mathrm{~m}, 80 \mathrm{~m}$, and $140 \mathrm{~m}$ (131 ft, $262 \mathrm{ft}$ and $459 \mathrm{ft})$.

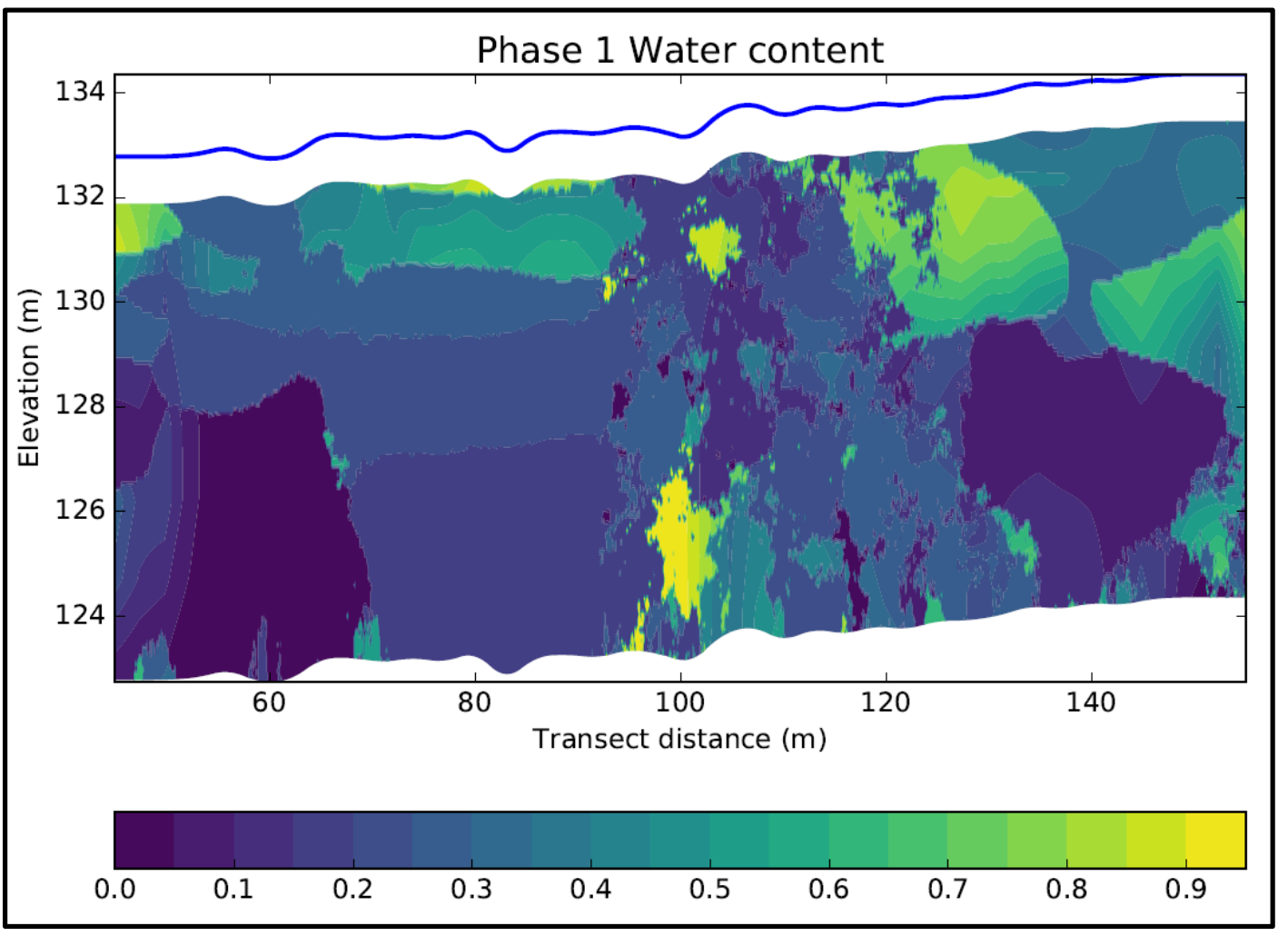


Figure 43 . Width of the $80 \%$ credible interval for water content. A wider interval represents higher uncertainty.

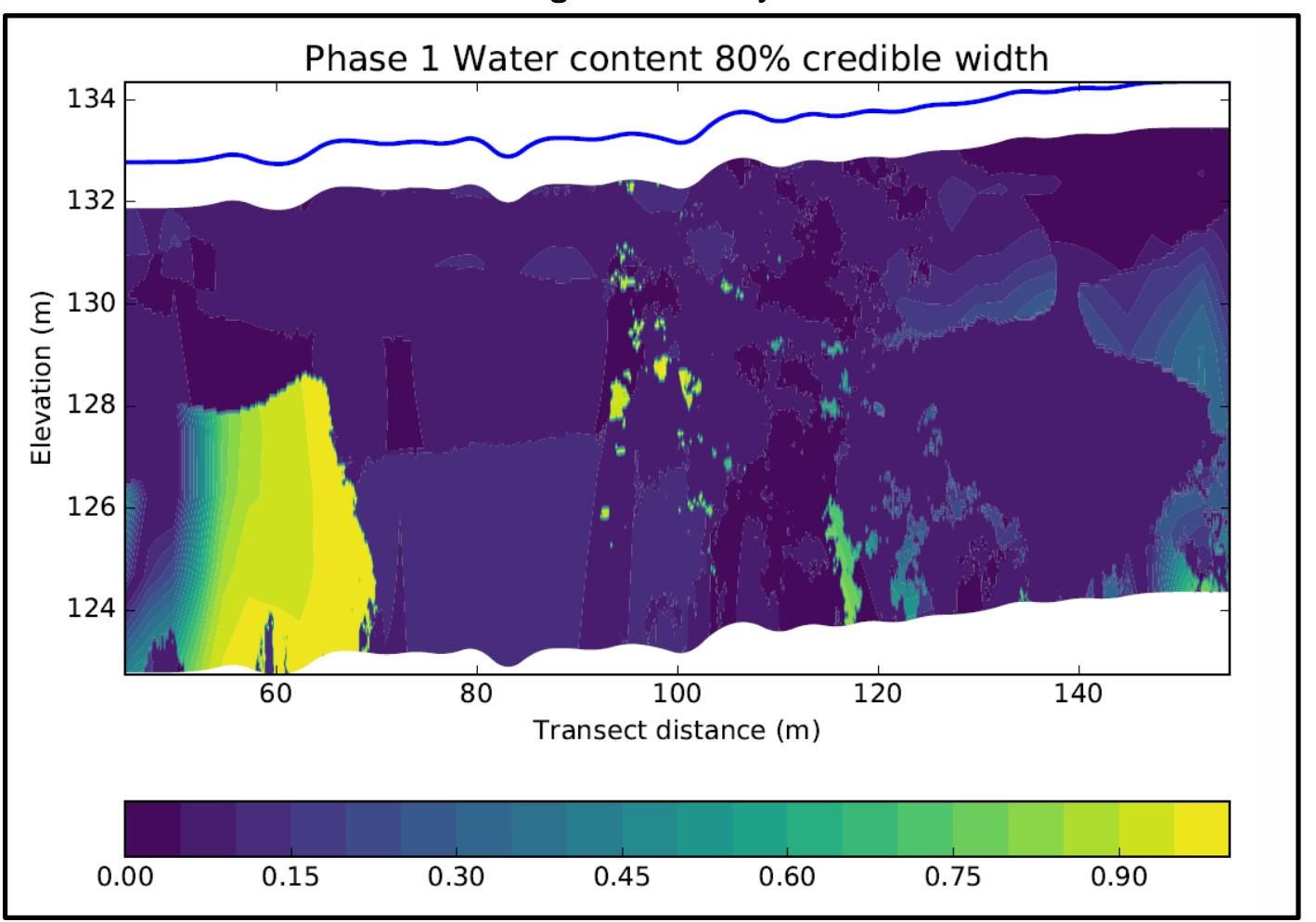

Figure 44. Calculated probability of permafrost using resistivity and boreholes at $50 \mathrm{~m}, 62 \mathrm{~m}$, $80 \mathrm{~m}, 104 \mathrm{~m}, 125 \mathrm{~m}$, and $140 \mathrm{~m}$ (164 ft, $203 \mathrm{ft}, 262 \mathrm{ft}, 341 \mathrm{ft}, 410 \mathrm{ft}$, and $459 \mathrm{ft}$ ). The blue line represents the surface elevation. Note that the vast majority of points where we have resistivity measurements are permafrost.

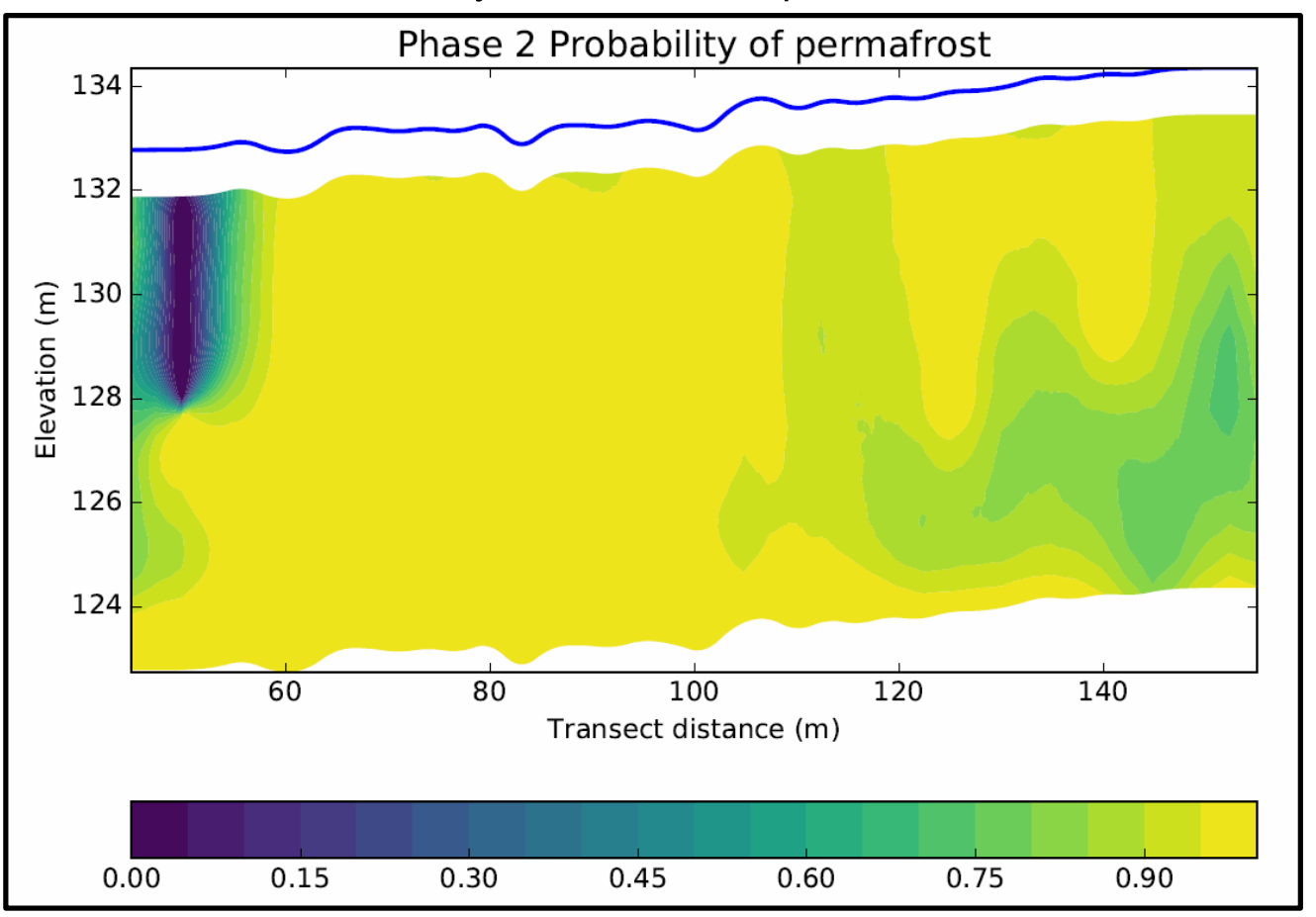


Figure 45. Entropy of predicted permafrost using resistivity and boreholes at $50 \mathrm{~m}, 62 \mathrm{~m}$, $80 \mathrm{~m}, 104 \mathrm{~m}, 125 \mathrm{~m}$, and $140 \mathrm{~m}$ (164 ft, $203 \mathrm{ft}, 262 \mathrm{ft}, 341 \mathrm{ft}, 410 \mathrm{ft}$, and $459 \mathrm{ft}$ ). Higher values represent greater uncertainty. The areas of low uncertainty surround the locations of the boreholes. Highest uncertainty occurs in the area between observations of permafrost and thawed soils.

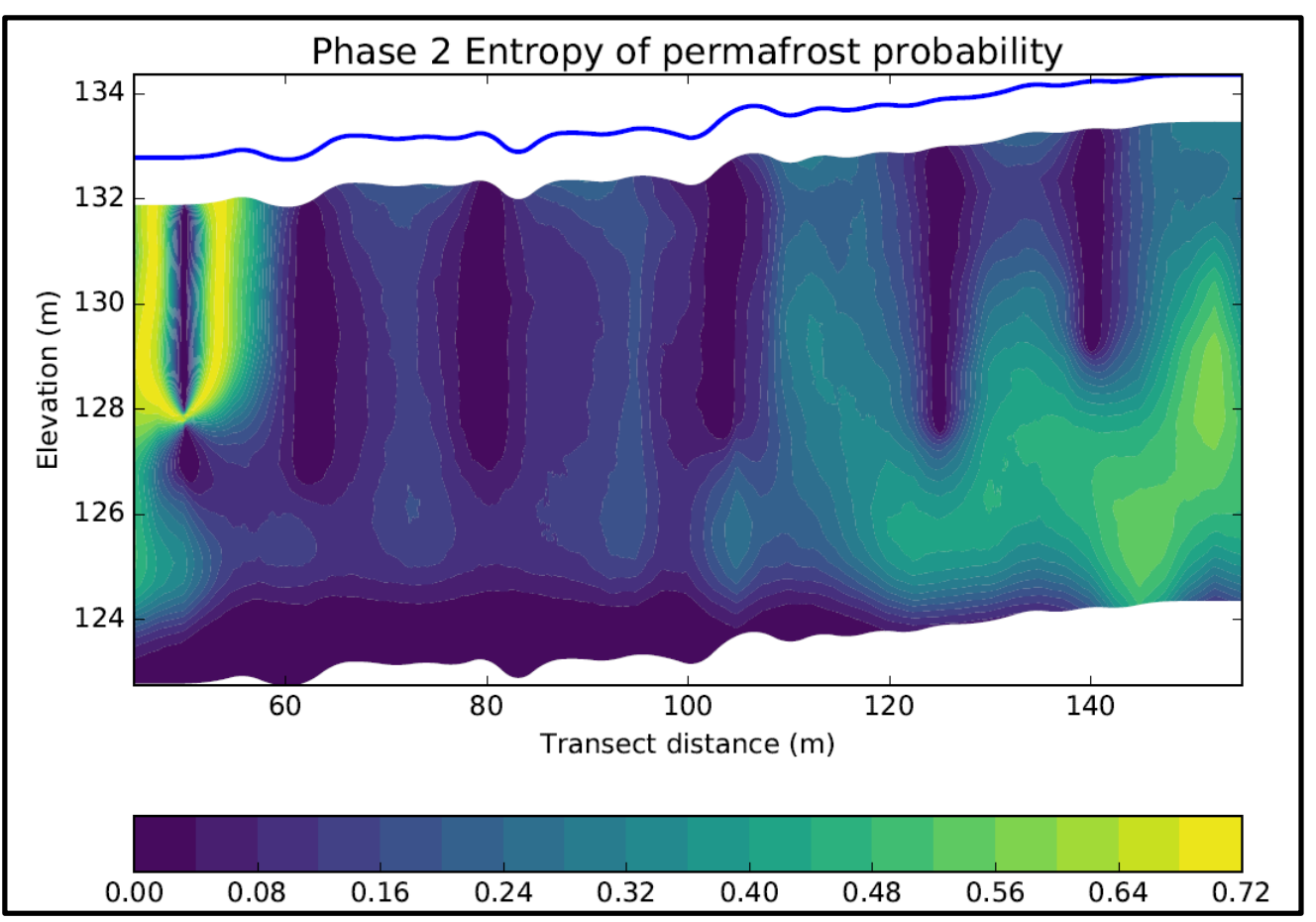

Figure 46. Most likely soil type using boreholes at $40 \mathrm{~m}, 62 \mathrm{~m}, 80 \mathrm{~m}$, and $104 \mathrm{~m}$ (131 ft, $203 \mathrm{ft}, 262 \mathrm{ft}$, and $341 \mathrm{ft}$ ).

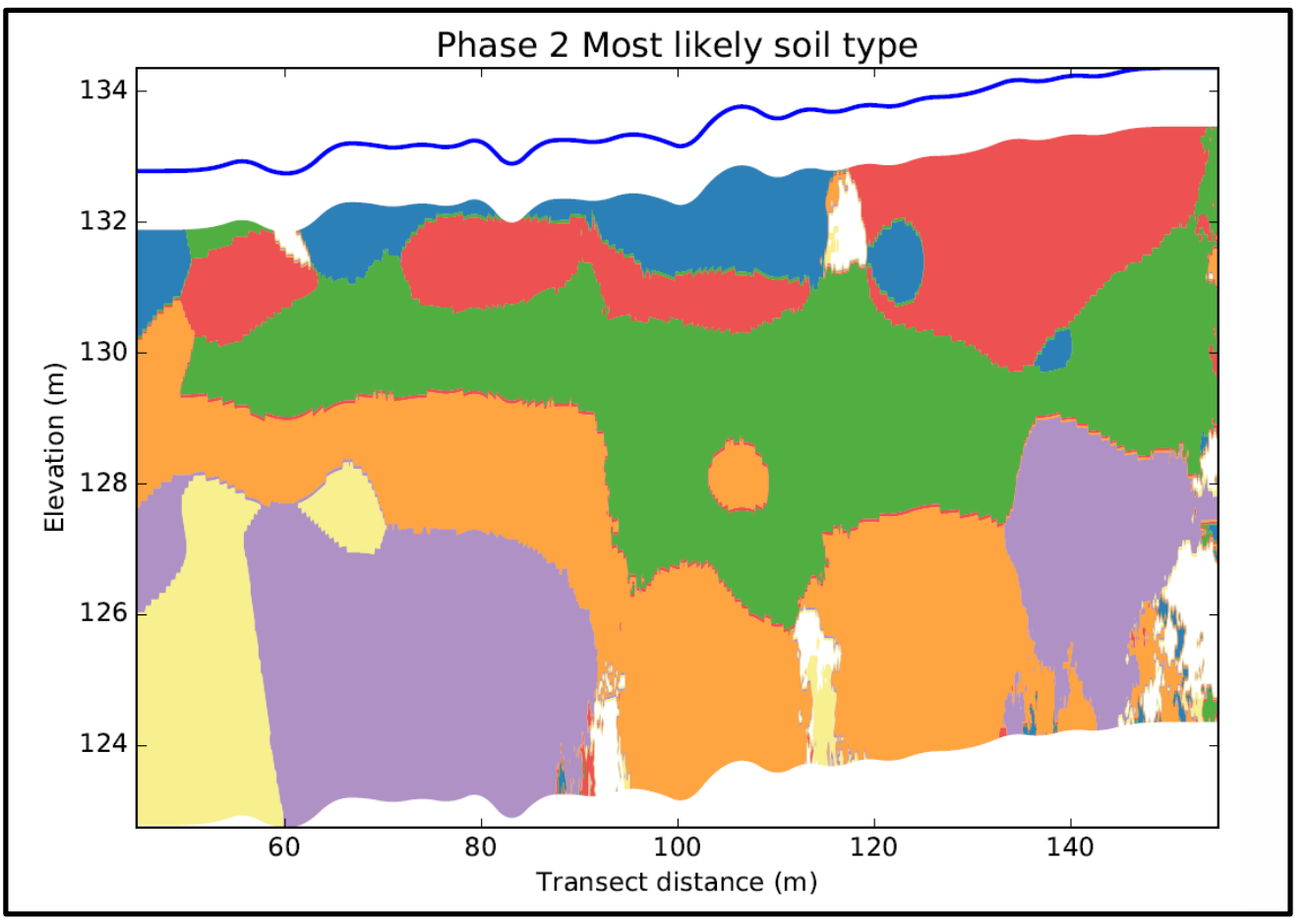


Figure 47. Entropy of soil type prediction using boreholes at $50 \mathrm{~m}, 62 \mathrm{~m}, 80 \mathrm{~m}, 104 \mathrm{~m}$, $125 \mathrm{~m}$, and $140 \mathrm{~m}$ (164 ft, $203 \mathrm{ft}, 262 \mathrm{ft}, 341 \mathrm{ft}, 410 \mathrm{ft}$, and $459 \mathrm{ft}$ ). Entropy is highest far from boreholes and at the border between two observed soil types.

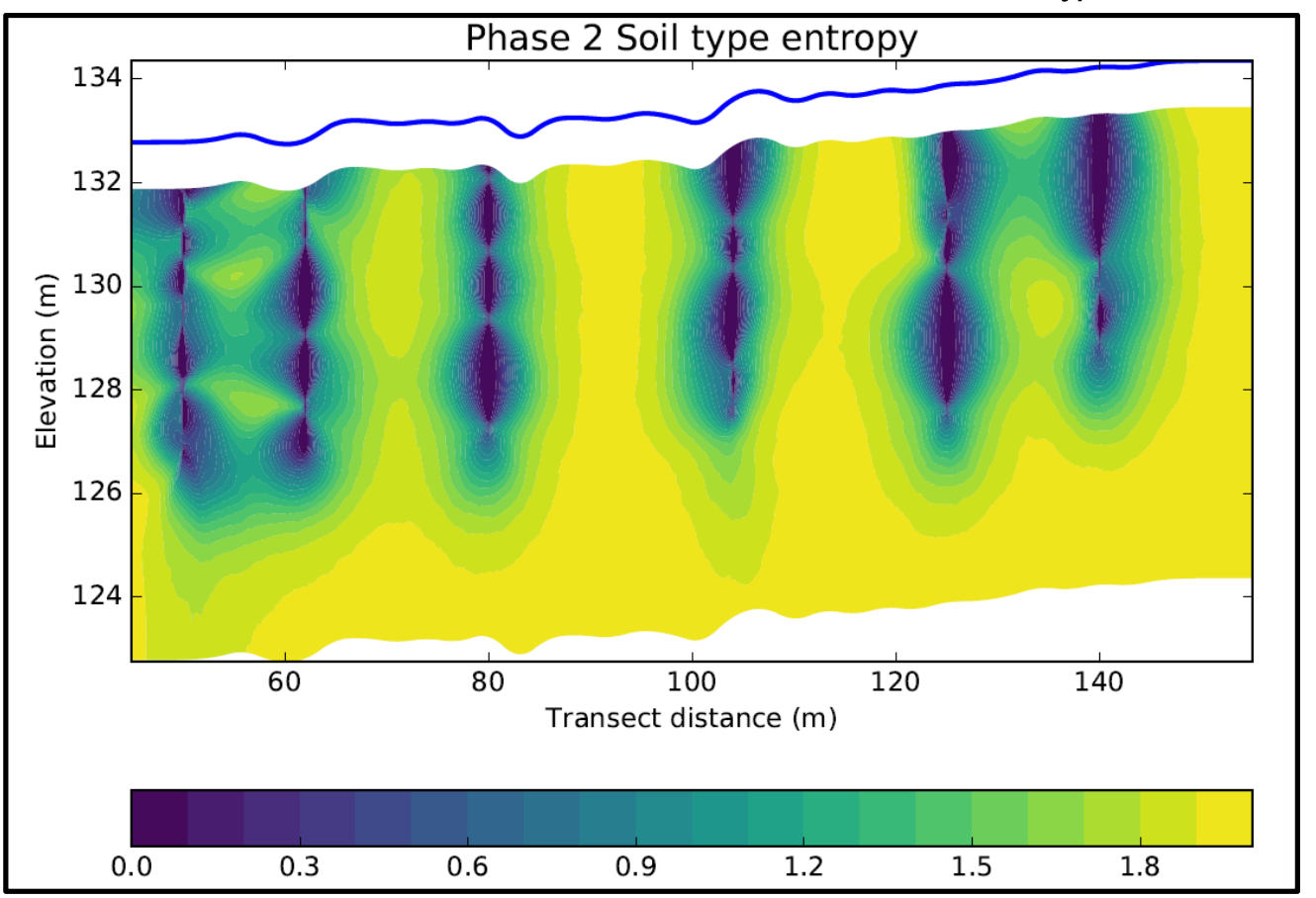

Figure 48. Predicted water content using resistivity and boreholes at $40 \mathrm{~m}$ (131 ft).

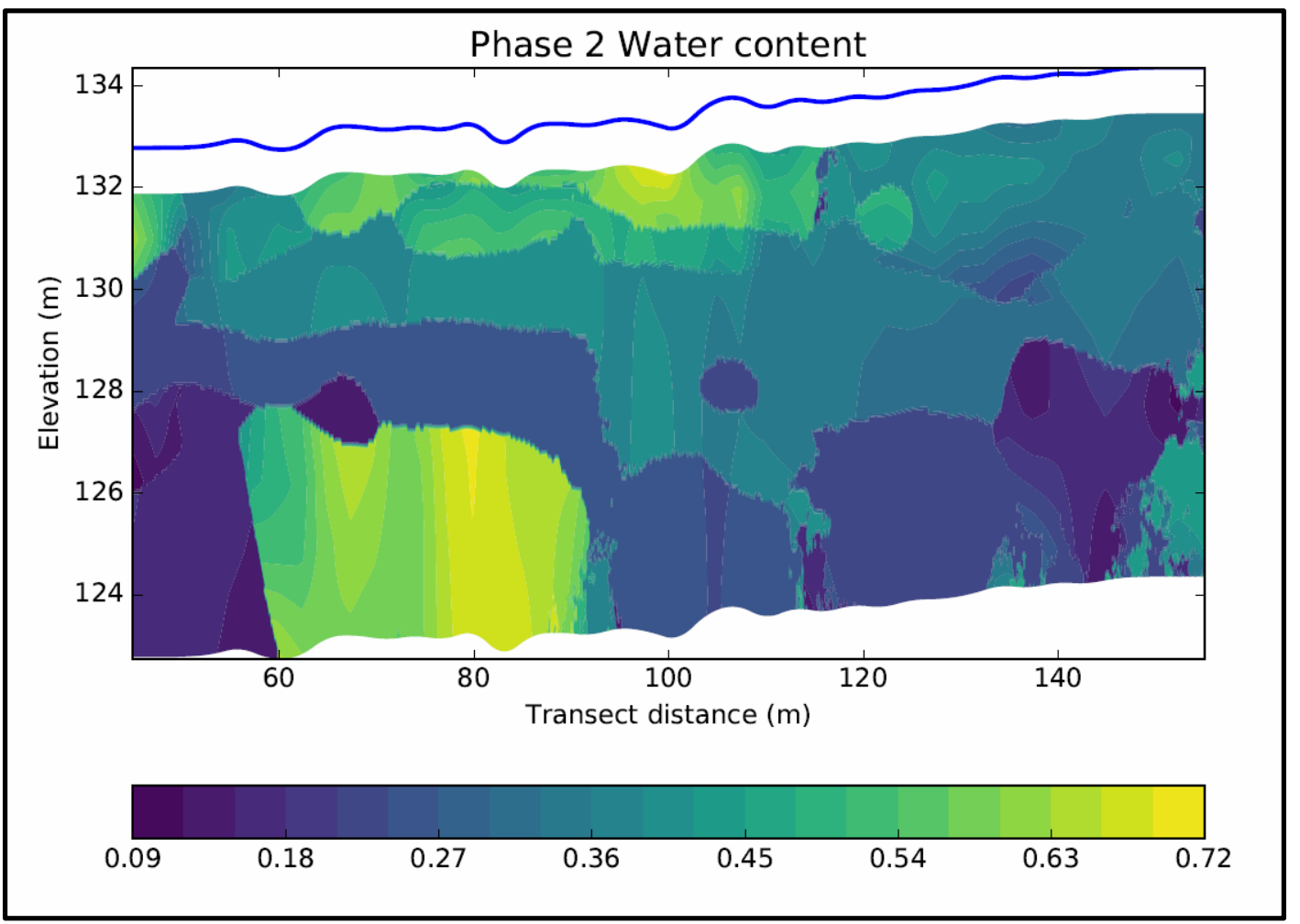


Figure 49 . Width of the $80 \%$ credible interval for water content. A wider interval represents higher uncertainty.

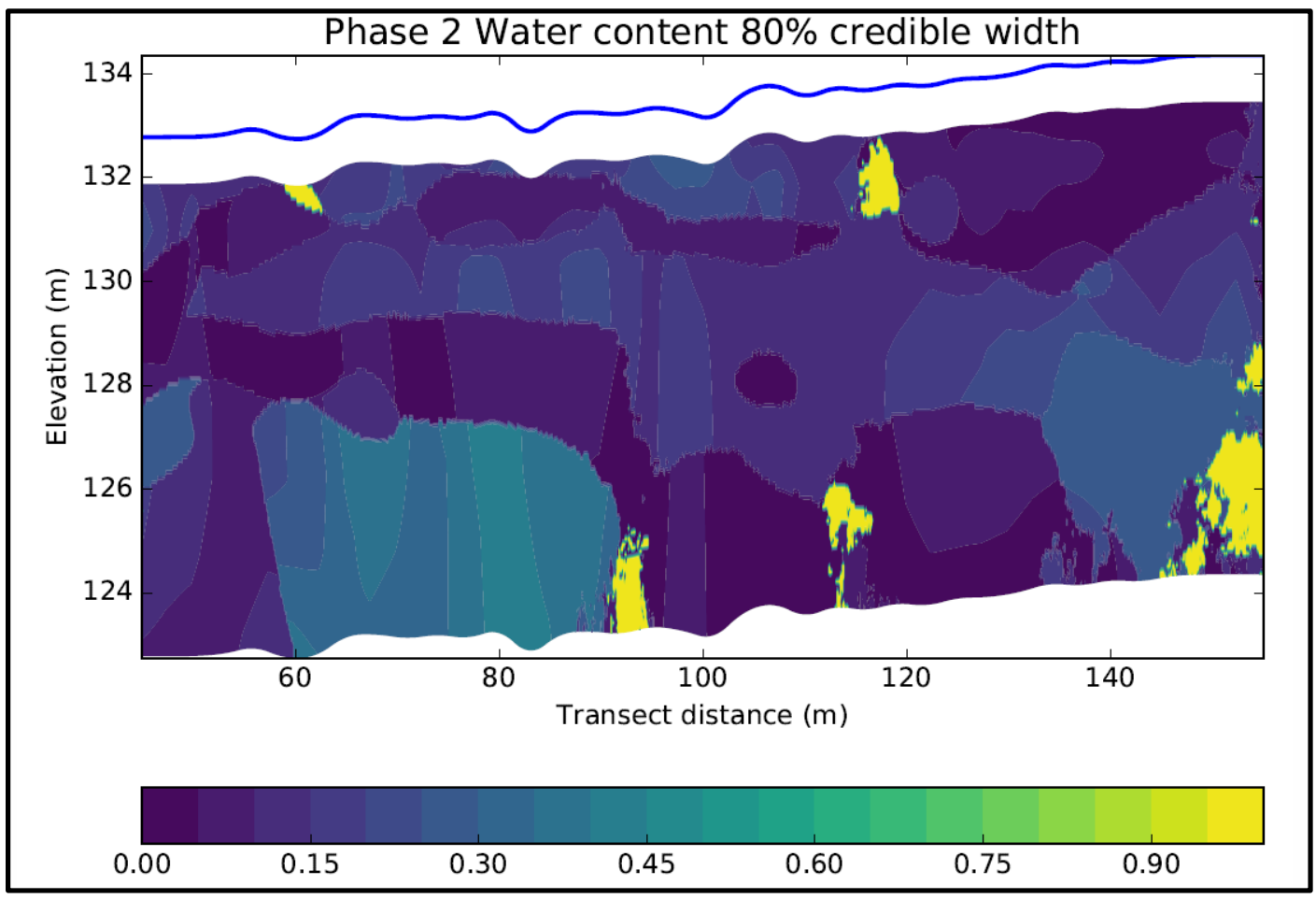

Figure 50. Calculated probability of permafrost using resistivity and boreholes at $50 \mathrm{~m}, 80 \mathrm{~m}$,

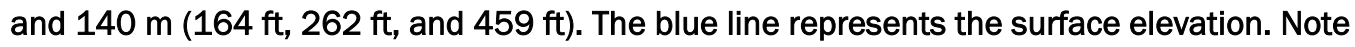
that the vast majority of points where we have resistivity measurements are permafrost.

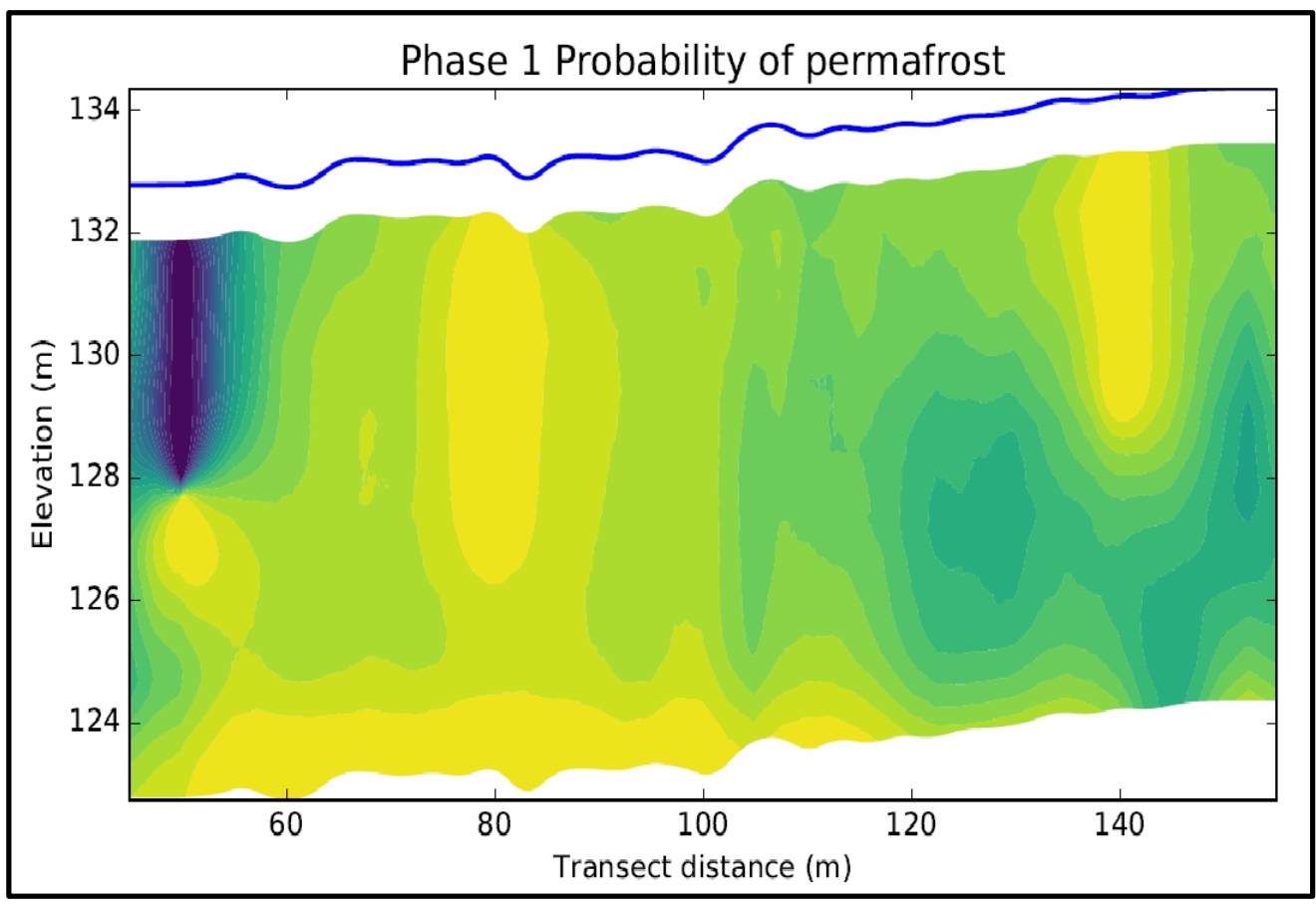


Figure 51. Entropy of predicted permafrost using resistivity and boreholes at $50 \mathrm{~m}, 80 \mathrm{~m}$, and $140 \mathrm{~m}$ (164 ft, $262 \mathrm{ft}$, and $459 \mathrm{ft}$ ). Higher values represent greater uncertainty. The areas of low uncertainty surround the locations of the boreholes. Highest uncertainty occurs in the area between observations of permafrost and thawed soils.

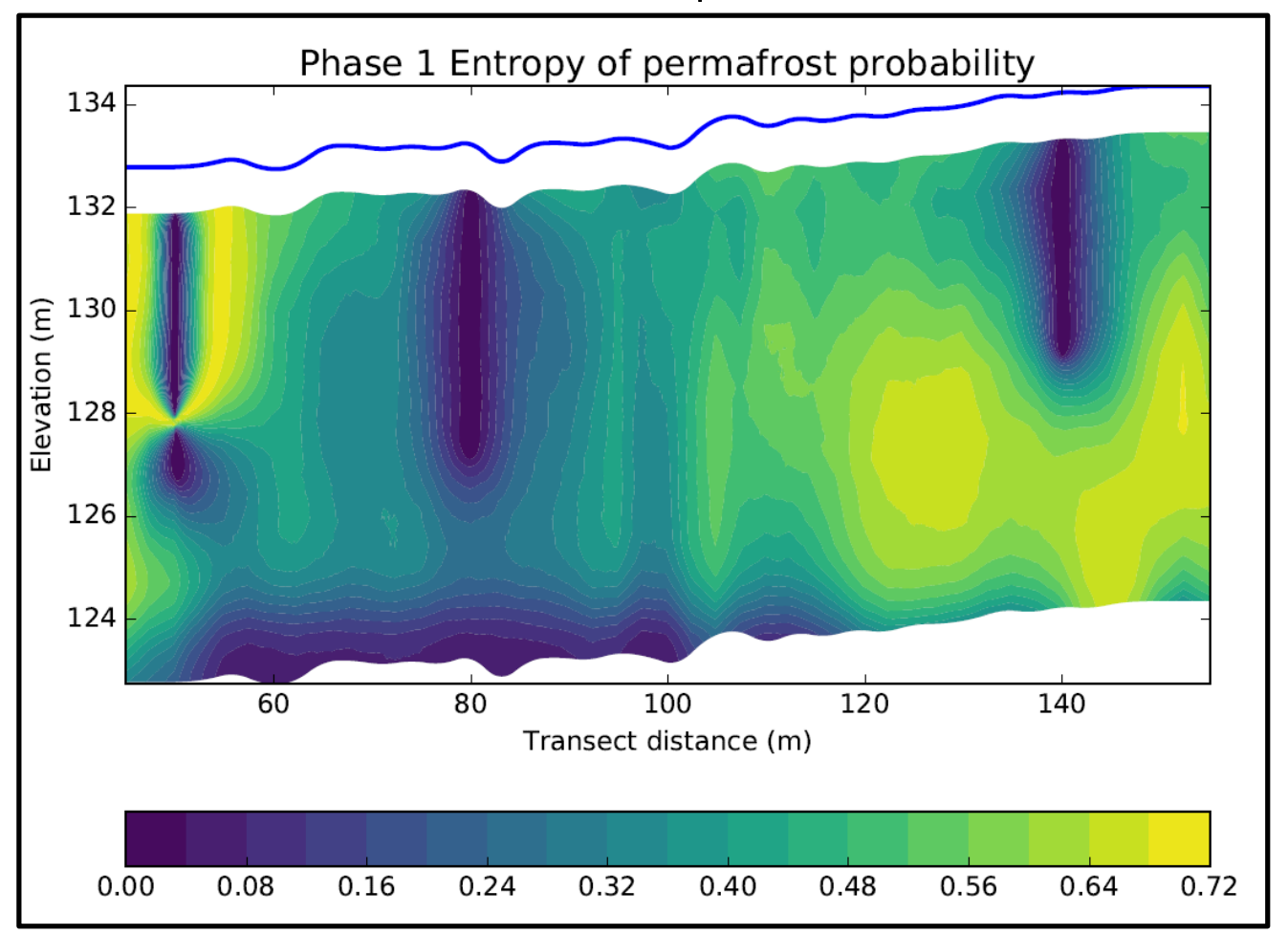

The prior probability map indicated a relatively high likelihood of permafrost all across the resistivity transect. The lowest prior probability was for

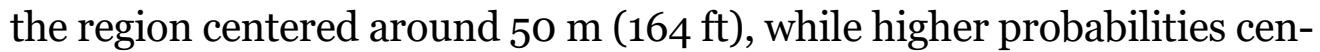
tered around $80 \mathrm{~m}$ and $140 \mathrm{~m}$ ( $262 \mathrm{ft}$ and $459 \mathrm{ft})$. However, the probability of permafrost at $50 \mathrm{~m}(164 \mathrm{ft})$ was still relatively high at 0.7 to 0.8 , which might lead one to conclude that there was permafrost at this location. The updated probability map using data from the three boreholes confirmed the findings for the regions centered around $80 \mathrm{~m}$ and $140 \mathrm{~m}$ ( $262 \mathrm{ft}$ and $459 \mathrm{ft}$ ) and produced probability values of permafrost that were significantly higher than were predicted by the prior probability analysis. The updated probability of permafrost in the region centered around $50 \mathrm{~m}(164 \mathrm{ft})$ indicated that soil was thawed with no permafrost while the prior probability map predicted a probability of over 0.7 that permafrost would be present.

These results demonstrate the value of using a prior probability map to initially estimate the probability of permafrost zones and to strategically select drill hole locations to further test the reliability of the estimated probabilities. Placing a drill hole around $50 \mathrm{~m}(164 \mathrm{ft})$ is reasonable considering that this is a region of strong gradients in resistivity measurements, 
and considering the nature of resistivity measurements, i.e., that they are the result of the volume averaged resistivity of the ground. As a result, a region without permafrost next to the edge of a permafrost region produces a transition zone that can be masked by averaging the resistivity of thawed and frozen soil. The borehole data at $50 \mathrm{~m}(164 \mathrm{ft})$ provide direct evidence to establish the approximate edge of the transition from permafrost to non-permafrost ground.

The entropy map shown in Figure 51 illustrates a measure of uncertainty associated with the geostatistical prediction of permafrost. High values of entropy indicate more uncertainty in the geostatistical predictions. The entropy in and around the boreholes is very low since direct measurements are available at those locations. Entropy increases with distance away from the boreholes. The gradient of change in entropy and its magnitude is related to the gradient of change in the resistivity measurements, such that the region centered on $50 \mathrm{~m}(164 \mathrm{ft}$ ) has high entropy near the borehole because of the high gradient in resistivity values, which is another indication that the location is in a transition zone from permafrost to non-permafrost soil. The entropy map provides useful information to evaluate where one might want to place additional boreholes to further improve the geostatistical predictions.

Regions of highest entropy in the updated map using three boreholes are

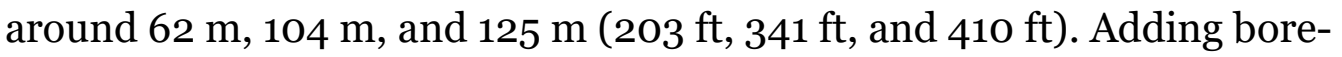
holes at those locations and updating the probability map results in a map that shows high probability for permafrost everywhere but in the zone

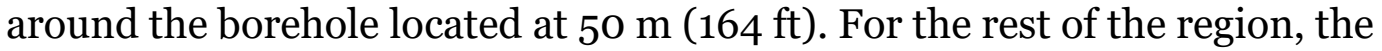
probability of permafrost ranges from about 0.7 to near 1 with the majority of the region having a probability of permafrost near 1 (Figure 44). The en-

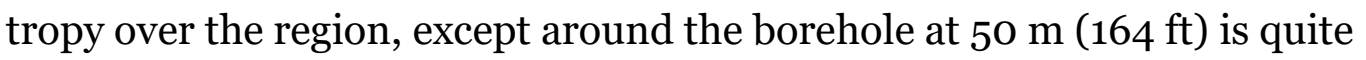
low, giving high confidence in the interpretation that permafrost exists everywhere in the region at distance greater than $\sim 55 \mathrm{~m}$ to $60 \mathrm{~m}(\sim 180 \mathrm{ft}$ to $197 \mathrm{ft}$ ). With these results, it is unlikely that additional borehole data would improve the probability maps. The question is whether we needed the six boreholes to adequately characterize the site, or whether fewer boreholes would have been sufficient.

The permafrost map based on three boreholes indicates that the probability of permafrost is greater than about 0.8 everywhere except $\sim 125 \mathrm{~m}$ $(\sim 410 \mathrm{ft}$ ) (and $\sim 150 \mathrm{~m}[\sim 492 \mathrm{ft}])$. Had the initial drilling used four bore- 
holes instead of three, then the additional borehole data may have produced a map with probabilities permafrost of greater than 0.8 over the

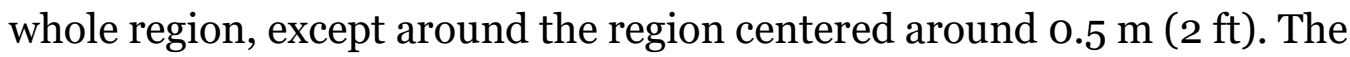
four-borehole probability map of permafrost may have provided sufficiently high probabilities of permafrost to satisfy building site planners.

Because the goal is to reduce drilling costs, it is important to investigate ways to only have to bring a drill rig in once to drill the necessary boreholes to produce an accurate updated probability map. The characterization scheme that was presented above requires mobilizing a drilling rig twice. It is possible, by examining the prior probability maps (Figures 9 and 10), to locate the areas of lowest probability of permafrost to refine the selection of potential locations for drilling boreholes. The lowest probabil-

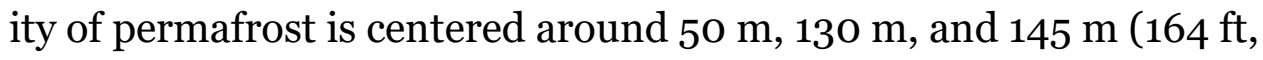
$426 \mathrm{ft}$, and $476 \mathrm{ft}$ ). The region centered around $80 \mathrm{~m}$ ( $262 \mathrm{ft}$ ) has high probability of permafrost but needs to be drilled to provide ground truth data to calibrate the resistivity-probability of permafrost relationship. With this analysis, a single four-borehole drilling campaign might provide sufficient information to provide a probability of permafrost map of sufficient accuracy to characterize the site.

\subsubsection{Probability of soil type and water content maps}

Once borehole cores have been analyzed to determine soil type and water content, probability maps of the variability of soil type and water content are developed along with their associated entropies (Figures 15 to 22). The soil type distribution map based on analysis of the cores of three boreholes (Figure 40) is compared to the soil type map developed from analysis of cores from six boreholes (Figure 46). The most notable difference is that, for the soil type map based on cores from three boreholes, there is much more differentiation of soil type distributed in small volume segments than there is in the core data from six boreholes. The results from entropy plots for soil type have exhibited relatively higher uncertainty in identifying soil types for points farther away from the boreholes for both the three-borehole and six-borehole locations. The reason for the variations of soil type represented in the region between the $80 \mathrm{~m}$ and $140 \mathrm{~m}(262 \mathrm{ft}$ and $459 \mathrm{ft}$ ) boreholes is unclear; further effort is needed to determine the possible sources of these variations. The additional information provided by the six-borehole analysis appeared to smooth out soil type information. 
However, a possible explanation for why there is so much variation be-

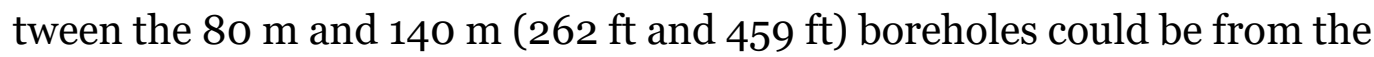
geostatistical analysis in distributing the soil core data (Table 2) between two boreholes with significantly different soil type depth profiles. The aggregation could potentially produce the high variability in soil type identification. When additional soil type information is available from adjacent boreholes in the six-borehole case, the geostatistical distribution algorithm can use the denser information to distribute soil types more smoothly.

Water content maps are of most interest to engineers as they provide the information needed to estimate the potential amount of thaw settlement that infrastructure foundation can experience. Water content is correlated with log-resistivity (Figure 32) by soil type, which resulted in water content maps that exhibited similar distribution patterns as the soil type maps. The water content map derived from the analysis of three boreholes (Figure 42) shows the high variability between boreholes at $80 \mathrm{~m}$ and $140 \mathrm{~m}$ (262 ft and $459 \mathrm{ft}$ ) as was also observed for the soil type map. The spatial variation of water content is shown to have smoother distribution for mapping the soil water content derived from an analysis of cores from six boreholes than for a map derived from an analysis of cores from only three boreholes.

Figures 43 and 49 illustrate the uncertainty associated with the water content maps; these plots display the width of $80 \%$ credible interval for water content, where a wider interval represents more uncertainty. Both the three-borehole analysis map and six-hole borehole analysis map show relatively low uncertainties (excepting the region between $60 \mathrm{~m}$ and $80 \mathrm{~m}$ [197 ft and $262 \mathrm{ft}]$ ), which may be a reflection of the correlation of water content with the different soil types.

From both the three-borehole and six-borehole derived water content maps, water content appears to be relatively high near the surface and lower at depth. The region of uncertain water content at depth for the three-borehole analysis case in the region from 60 to $80 \mathrm{~m}(197 \mathrm{ft}$ to $262 \mathrm{ft}$ ) appears warranted given that water content was indicated as low for the three-borehole analysis case and relatively high with more information from the six-borehole analysis. For the three-borehole analysis, there was no information about soil type from drilling in the 60 to $80 \mathrm{~m}$ ( $197 \mathrm{ft}$ to $262 \mathrm{ft}$ ) region; and the six-borehole investigation filled that information gap to significantly change the result. 


\subsection{Geostatistical analysis summary}

The Bayesian geostatistical analysis was used for integrating the surface terrain features, ground resistivity measurements, and limited borehole data. The analysis produced maps of probability for subsurface permafrost, soil type, and soil water content to characterize potential building sites. Surface terrain feature-derived probability of permafrost based on expert opinion (terrain prior) is applied to identify where and what type of permafrost might be present. A preliminary probability of permafrost map based on expert opinion of the probability relationship between ground resistivity and permafrost (resistivity prior) is incorporated to predict the variation of probabilities of permafrost. The preliminary probability of permafrost map is then created to identify regions of variation in the probability of permafrost, which are applied for selecting locations to drill boreholes; the actual boreholes information is then applied to ground truth and improve the accuracy of permafrost maps. Results from the resistivity prior with a resistivity-permafrost probability are substituted with the data from borehole core analysis representing the descriptions on the presence of ice, soil type, and water content based on local measurements. Calibrated relationships between resistivity and soil, and resistivity and water content are developed using core data from boreholes; these data are then used to create probability of soil type and water content.

Permafrost, soil type, and water content probability map accuracy are improved as more borehole core data from drilling become available. The optimal number of boreholes needed to characterize a potential building site is dependent on the purpose of the survey and required accuracy of the maps. For the CCHRC test site, the preliminary probability permafrost map derived from resistivity prior probability estimates produced probability of permafrost greater than 0.65 for most regions that were later determined to be permafrost. A region near the transition from permafrost to non-permafrost was predicted to have a probability of approximately 0.67 , which was later determined to be unfrozen.

Two drilling patterns (three-borehole pattern and six-borehole pattern) were used to improve the probability of permafrost-resistivity calibration, and to obtain data on soil type and water content. The resolution and accuracy of permafrost, soil type, and water content maps are improved as more boreholes are drilled along the survey transect. The three-borehole investigation of probability of permafrost produced a probability of permafrost map with probabilities greater than 0.6 to 0.7 for most regions that 
drilling later confirmed as permafrost. Two boreholes were drilled in regions where probabilities of permafrost changed rapidly with distance; and a third borehole was drilled in a region with relatively high, constant probabilities of permafrost (greater than 0.9). These data were used to confirm the probability of permafrost map calibration over the region. The six-borehole analysis produced a probability of permafrost map with probabilities in excess of 0.9 over most of the transect region and captured the majority of permafrost features. Note that probability maps for soil type and water content cannot be constructed until borehole core data are available. The resolution and accuracy borehole core data are directly related to the resolution and accuracy of the probability of permafrost maps.

The primary permafrost map based on resistivity priors is probably adequate to map where permafrost exists or is not present. Transition regions between permafrost and non-permafrost regions may be missed due to the volume averaging of resistivity from both permafrost and non-permafrost data. The probability of permafrost map based on three boreholes (approximately $50 \mathrm{~m}[164 \mathrm{ft}]$ between drill holes) is adequate to predict the spatial variation of permafrost and to identify the transition between permafrost and non-permafrost regions. A fourth borehole (approximately $33 \mathrm{~m}$ [108 ft] between boreholes) would significantly improve the resolution of probability of permafrost, soil type, and water content maps. This is demonstrated by the significant improvement in data for soil type and water content from using six boreholes (approximately $25 \mathrm{~m}[82 \mathrm{ft}$ ] between boreholes) as compared to three boreholes to provide data to the geostatistical analysis. Given the high probabilities of permafrost and the resolution for soil type and water content probability maps, additional boreholes would likely not provide enough additional data to significantly improve probability maps of permafrost, soil type, and water content.

The following recommended factors for determining how many boreholes are needed to provide adequate probability maps for permafrost, soil type, and water content

1. The variability in ground resistivity measurements across the site. Low variability in the preliminary probability of permafrost map may require data from only one or two boreholes. The number of boreholes, and their spacing, which are needed to develop adequate probability maps for permafrost, soil type, and water content, will need to be increased as the variability of ground resistivity measurements increases. 
2. The purpose of the characterization work. If the purpose is to only identify the extent of permafrost, then a preliminary probability of permafrost map may be adequate; however, the use of one or two boreholes may be sufficient to increase the level of confidence. For sites where it is important to define the water content, then the number of boreholes should be selected to provide probabilities of permafrost greater than about 0.7 .

Several improvements to the Bayesian geostatistical approach to characterize subsurface conditions of permafrost terrain are needed to make the technique practical for the majority of engineers. Increasing the algorithmic efficiency of Monte Carlo simulations will reduce the computational resources needed to calculate probability maps. Improving methods to interpret the preliminary probability of permafrost maps to select the number and location of boreholes needed to provide data to generate the second-generation probability maps will reduce characterization costs. If the optimal number of boreholes can be selected to define the first drilling program, then the cost of remobilizing a drilling crew to obtain additional data can be avoided. Finally, updating the terrain and resistivity priors using the results of previous characterization efforts can produce more accurate preliminary probability of permafrost maps. 


\section{Foundation Alternatives Investigation}

\subsection{Objectives}

Investigation of foundation alternatives is one of the parallel efforts under this SERDP project. The CCHRC has partnered with CRREL through the SERDP program to improve our overall understanding of, and capacity to respond to potential climate change impacts on DoD built infrastructure in Alaska and similar climates. Effective foundation design in cold regions requires a comprehensive knowledge of design options, Arctic and Subarctic environmental and terrain conditions. These include an understanding of frozen and unfrozen ground characteristics and properties, as well as thermal effects of heated and unheated structures on cold ground. Complex thermal interactions between infrastructure and permafrost requires an effective capacity to monitor and to detect shifts early enough so that problems on permafrost thaw can be mitigated before infrastructure becomes compromised.

Our objectives for monitoring and modeling under this effort are to

1. Use thermal modeling that draws on empirical temperature sensor data to inform SERDP on lessons learned from existing systems and to apply these lessons to thermal modeling guidance, and

2. Define, and scope a better guidance on an EWDS for building foundations in permafrost-affected locations.

We analyzed up to 8 years of existing subsurface thermal data on novel foundation performance for five structures situated on epigenetic permafrost in Fairbanks, AK. Analyzing the data for these foundations helped this effort to

1. Achieve a better understanding of the ground and foundation response in permafrost and

2. Identify deficiencies in the instrumentation installed on these foundations so that existing instrumentation can be augmented, and to ensure that data are sufficient to answer foundation performance questions.

These analyzed data were used to develop an EWDS for new construction or with existing buildings for evaluating the impact of subsurface warming on the building foundation. An early warning of melting permafrost will enable building managers to initiate foundation protection measures before major movement occurs. 


\subsection{Background}

CCHRC's Research and Testing Facility (RTF) and the neighboring student housing complex at the University of Alaska at Fairbanks (UAF) Sustainable Village were constructed on permafrost terrain of varying ice content. The site included four light residential buildings and one heavy commercial building that have been constructed with instrumented foundations. Before this SERDP project, these instruments have produced a wealth of data that have been analyzed to examine the performance of several innovative foundation designs. Additionally, the effectiveness of the sensor system design was studied to form empirical recommendations for an EWDS for structures built on frozen ground.

The data have been collected by CCHRC since 2007. These data are primarily temperature profiles adjacent to and underlying CCHRC's RTF, a $1400 \mathrm{~m}^{2}$ (15,064 sq ft) light-commercial building constructed with an adjustable concrete foundation over warm, moderately ice-rich permafrost. Figure 52 shows the RTF just after completion. More recent additions to the facility included four residential buildings, two with conventional permafrost foundations (driven piles) and two with experimental thermal raft foundations at UAF's Sustainable Village (Figure 53).

CCHRC also built an addition to the RTF with in-floor heat and sub-slab hydronic heat recovery systems as a further experiment in innovative foundations (Figure 54). The adjustable foundation at the RTF and the novel thermal raft foundation system provide the benefit of appearing like traditional foundations when complete. The system as a whole allows the installation of traditional features such as heated floors, and in the case of the RTF, a basement to house utilities. Cold climate vertical infrastructure that is directly coupled to the ground surface is many factors more energy efficient for heating and less costly to construct than raised construction. These characteristics are considered more functional by building designers, owners, managers, and funding sources. 
Figure 52. The CCHRC RTF as built in 2007.

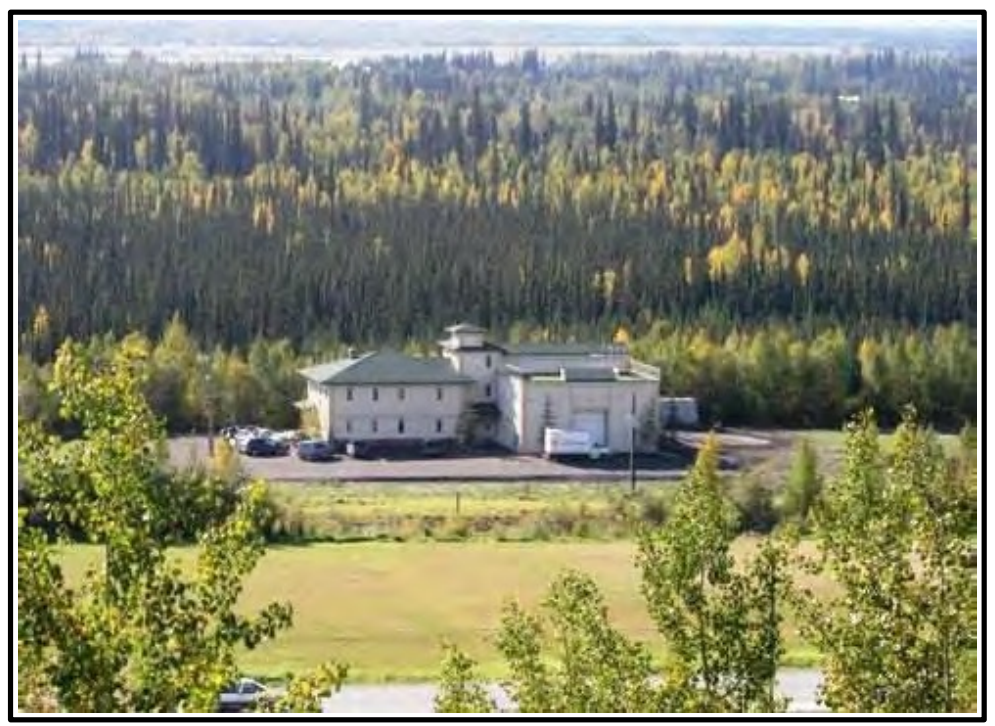

Figure 53. The four residential buildings in the Sustainable Village built in 2012. (Photo J. Fiely)

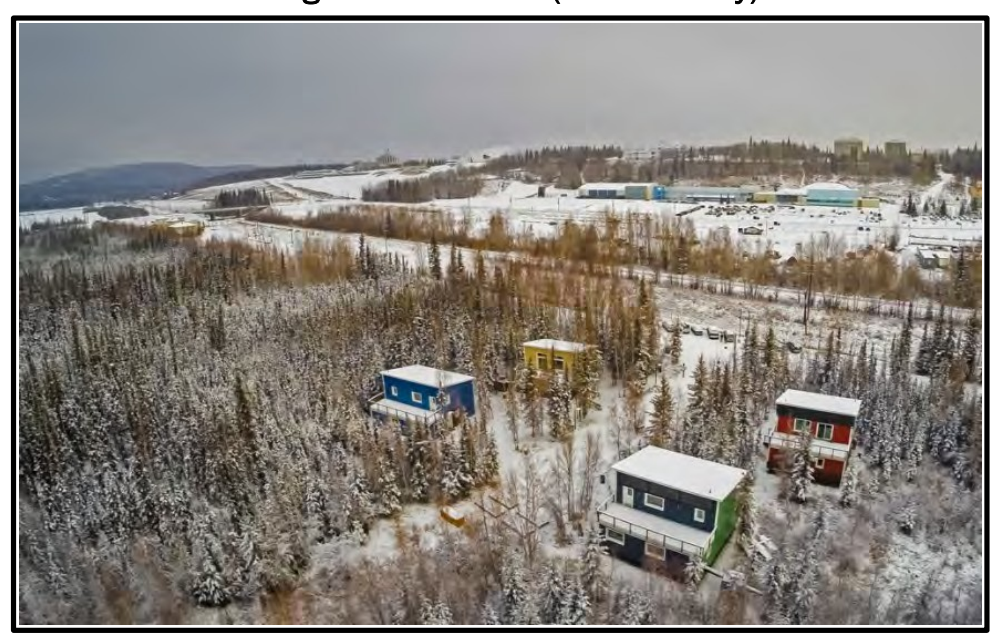

Figure 54. CCHRC RTF with the addition built in 2013.

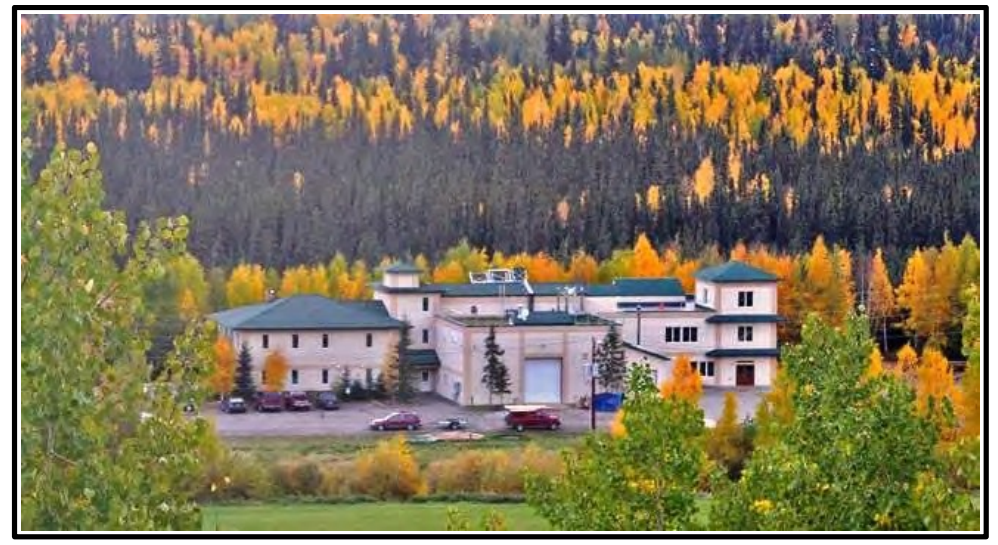


The collection of substantial amounts of subsurface thermal data on all of these foundations helped this study assess the effects of the buildings on the underlying permafrost. Also, lessons have been learned regarding measurement and collection of soil temperature data under infrastructure. Adding these data to the literature contributes substantially to the body of knowledge because there are only few sources of in situ data that characterize this type of novel foundations.

\subsubsection{General design approach}

The approach to foundation design in cold regions is to first determine whether the bearing soils are thaw-stable or thaw-unstable, which involves determining the soil type and properties for each subsurface layer beneath the structure. Thaw-stable means that the bearing capacity of the frozen ground is not compromised when thawed. The type of soils that are thaw-stable is usually clean granular soils or rock without any ground ice. In this case, conventional temperate-zone foundation design approaches may be used.

If the ground is considered to be thaw-unstable, then the soil will consolidate when thawed, resulting in damage to supported structures. In thawunstable soils, three general approaches may be considered:

1. The foundation is designed to maintain the pre-construction (existing) ground thermal regime using pilings, spread footings, posts and pads, ventilation ducts, artificial refrigeration, or designing a rigid structural base.

2. The foundation is designed using end-bearing piles or footings that are extended into the ground on stable bearing layer to accept the changes in the ground thermal regime caused by the building/road construction and operation.

3. The foundation material conditions is modified before construction by prethawing, pre-consolidating, or replacing unfavorable materials and using designs applicable for these conditions.

The next step is to determine the depth of thaw of soils supporting the structure; this could be using equations such as the Stefan and modified Berggren formulas, or by using thermal modeling. Once the depth of thaw is calculated, the required depth of footing can be determined. If the foundation is bearing on permafrost soils, then the temperature distribution with respect to the structure bearing mechanism (i.e., footing) can be calculated. Based on the permafrost temperature, the bearing capacity of the 
soils, which in turn is used to design the foundation geometry (such as footing size), can be determined.

Once the foundation bearing surface has been sized, a settlement analysis should be performed by first determining the distribution of the imposed vertical stress of the bearing soils beneath the foundation and then by determining the deformation of the frozen soil through creep.

The last step involves determining whether the estimated settlement is within acceptable limits. If so, then the design is complete. If not, then the foundation geometry or size must be modified; and the design approach is repeated. An example of this design approach is shown as a flow diagram in Figure 87 (p 126), which was created based on Unified Facilities Criteria (UFC) 3-130-04, Foundations for Structures: Arctic and Subarctic Construction (HQUSACE 2004) for the design of footings, rafts, and piers.

\subsubsection{Thermal modeling}

In permafrost regions, the primary enemies to stable foundations are frost heave, thaw consolidation, and thermokarst degradation. As described above, a critical step for foundation design is to determine the depth of thaw of the soils supporting the structure. One method involves using the modified Berggren equation, which is best suited for soils much colder than $\mathrm{O}^{\circ} \mathrm{C}\left(32^{\circ} \mathrm{F}\right)$

$$
x=\lambda \sqrt{\frac{48 k_{\text {avg } n T I}}{L}} .
$$

where

$$
\begin{aligned}
\mathrm{x}= & \text { depth of freeze or thaw }(\mathrm{ft}) \\
\lambda= & \text { dimensionless coefficient that takes into consideration the } \\
& \text { effect of temperature changes in the soil mass (i.e., a fudge } \\
& \text { factor) and corrects the Stefan formula for the neglected effects } \\
& \text { of volumetric heats (accounts for "sensible heat" changes) } \\
\mathrm{k}_{\mathrm{avg}}= & \text { thermal conductivity of soil, average of frozen and unfrozen } \\
& \left(\mathrm{BTU} / \mathrm{hr} \cdot \mathrm{ft} \cdot{ }^{\circ} \mathrm{F}\right) \\
\mathrm{n}= & \text { conversion factor for air freezing (or thawing) index to surface } \\
& \text { freezing (or thawing) index } \\
\mathrm{TI}= & \text { air thawing index }\left({ }^{\circ} \mathrm{F} \cdot\right. \text { days) } \\
\mathrm{L}= & \text { latent heat }(\mathrm{BTU} / \mathrm{ft} 3) .
\end{aligned}
$$


Similar to the modified Berggren equation, the Steffan equation is also used to determine the depth of thaw and is best suited for soils near the phase change point (near $\mathrm{O}^{\circ} \mathrm{C}\left[32^{\circ} \mathrm{F}\right]$ ). While either equation can be modified to account for the effects of insulation and can be used to estimate depth of thaw and/or depth of freeze, neither can be used for ground beneath the building because the equations cannot account for the edge effects of buildings. In this condition, more heat is lost to the edges of buildings than in the center of the building.

Another approach to accommodate these situations is the application of finite-element thermal modeling. As a multi-dimensional solution, thermal modeling is a useful tool that provides feedback to the foundation designer to better account for the thermal impacts of their structure on frozen ground. In regions with permafrost, it is paramount that the designers understand subsurface heat flows and the impacts of their intended structure on the supporting ground. In foundation design, this method would permit modeling of various configurations for soil, insulation, and building geometries. The modeling would also account for complex considerations of properties such as the latent heat of soil, unfrozen water content of soil, varying air temperatures, $n$-factors, and variability of ground thermal conductivity, as a function of temperature. This modeling process would allow for more accurate calculations and would accommodate more complex geometries than would be possible using a one-dimensional analysis.

The basic steps for creating a model begin by defining the problem and type of analysis. Using the graphical user interface (GUI) capabilities of modern thermal modeling programs, the problem geometry is defined and divided into regions. At this point, the user defines material properties for each region, initial temperatures, and boundary conditions such as temperature and geothermal heat flux. The model is then divided into smaller parts (called finite elements) by a process called meshing. When the analysis is performed, temperature and heat equations are applied to each finite element. The thermal conditions are computed for each element. The model output can be evaluated by temperature plots, heat flow calculations, contour maps, or other means.

Note that this report is not intended to teach the user how to build a thermal model or how to provide an analysis of results. Those skills must be obtained through training and experience. The scope of this work is to provide a consolidated resource for sometimes hard-to-find pertinent thermal 
modeling parameters used in defining material properties and pertinent boundary conditions in cold climates.

\subsection{CCHRC foundations: Designs and thermal monitoring}

\subsubsection{CCHRC-RTF}

The RTF is a $2,046 \mathrm{~m}^{2}(22,000 \mathrm{sq} \mathrm{ft})$ building located on the UAF campus in Fairbanks, AK. Its original 1,395 $\mathrm{m}^{2}(15,000 \mathrm{sq} \mathrm{ft})$ portion of the building was completed in 2006. A $744 \mathrm{~m}^{2}$ (8,000 sq ft) addition was completed in 2013. The entire building sits above degrading permafrost, which has continued to degrade in the 10 years since the original building was constructed. The top of the permafrost has fallen from $10 \mathrm{~m}(34 \mathrm{ft})$ below

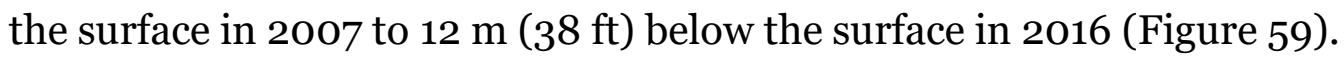

\subsubsection{Foundation}

The RTF has three distinct types of foundations: basement, slab-on-grade, and heated slab-on-grade. All three foundations (Figure 55) were designed using an adjustable spread footer that can account for ground movement due to permafrost degradation and that spreads the weight of the building out so that the pressure does not exceed the bearing capacity of the soil as the permafrost melts (Figure 56). In the original building, the below-grade foundation has R-30 insulation in the walls, and R-20 insulation underneath the floor, and under the slab-on-grade foundations. The building addition has R-48 insulation under its heated slab.

The building walls rest on the grade beam. If the bearing surface sinks due to permafrost degradation, a hydraulic jack can be used to raise the grade beam away from the spread footer until the building is level. Structural foam can be injected in the interstitial space between the grade beam and spread footer. Additionally, heat extraction coils of plastic pipe were installed beneath the foam insulation in the building addition that could be connected to a ground source heat pump if active cooling is required to stabilize the ground. To date none of these foundation-leveling techniques have been used. 
Figure 55. The RTF foundations. The green shows the original building, and the blue is the building addition.

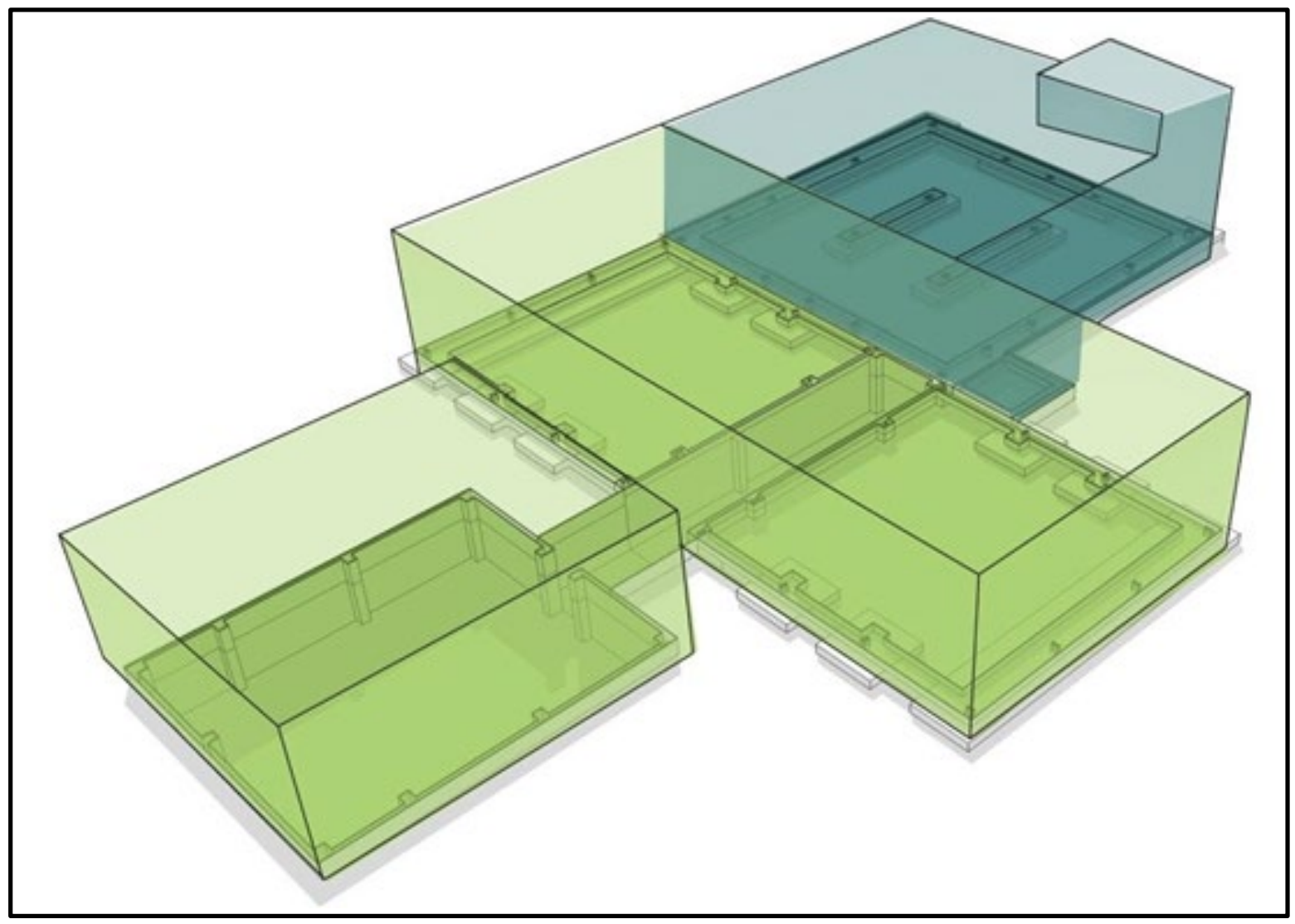

Figure 56. Adjustable spread footer design in the RTF Building addition. Left: The jacking plate is attached at the column and a hydraulic jack is placed between the jacking plate and the jacking column. Middle: The hydraulic jack is expanded to raise the grade beam away from the spread footing. Right: Structural foam is injected into the void between the grade beam and spread footing.

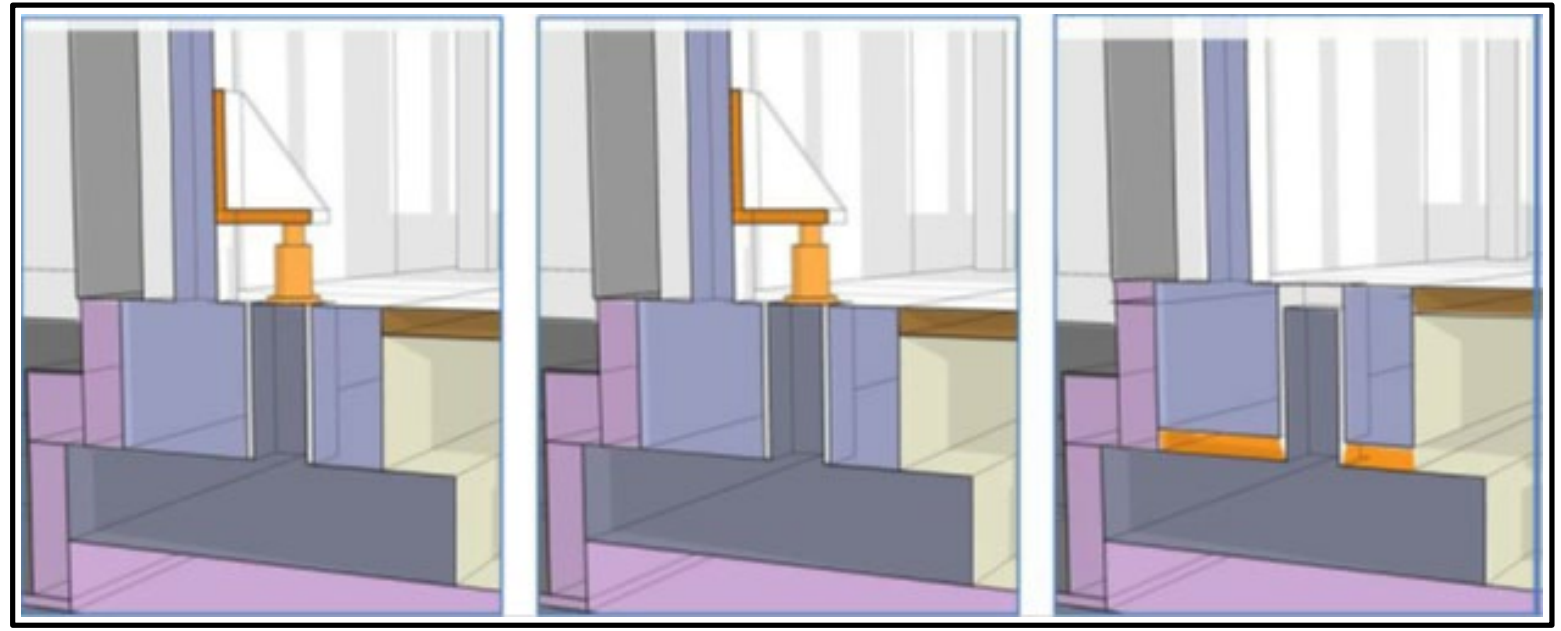




\subsubsection{Data collection systems}

When original RTF construction began in 2005, CCHRC worked with GW Scientific on instrumentation to monitor the subsurface and permafrost under the foundation and surrounding area. Several questions lead to the design of the data system:

1. Will the building cause permafrost to melt?

2. Will the building cause permafrost to form?

3. Will soil compaction cause the building foundation to settle?

4. Will groundwater level variation affect the foundation performance?

To answer these questions, a system of temperature and soil moisture sensors were deployed in and around the foundation as it was laid. The system was developed and installed under a very fast timeline. About 250 sensors were installed in and around the foundation in about 110 locations (many sensors were installed in triplicate). Table 4 describes the sensor placement in the RTF.

Table 4. Sensor location in the original RTF.

\begin{tabular}{|l|l|c|}
\hline Location & Number of Temperature Sensors & $\begin{array}{c}\text { Number of Moisture } \\
\text { Content Sensors }\end{array}$ \\
\hline Basement & 22 locations (66 sensors; 3/location) & 13 \\
\hline South Lab (slab-on-grade) & 9 locations (18 sensors; 3/location) & 4 \\
\hline North Lab (slab-on-grade) & 28 locations (84; 3/location) & 4 \\
\hline Basement Wall (ICF) & 9 locations (18 sensors; 3/location) & 0 \\
\hline Outside foundation & $\begin{array}{l}\text { 48 (12 vertically southwest, } \\
36 \text { vertically east of building) }\end{array}$ & 0 \\
\hline
\end{tabular}

The temperature sensors are NTC thermistors (YSI model 44033) wired along directly buried cable. Unfrozen soil water content, on a volumetric basis, is monitored by Campbell Scientific CS616 TDR type sensors. All of the sensors are attached to Campbell Scientific CR10oo data collection devices, which have logging programs recording the data points at varying intervals.

In 2012, during the foundation installation for the building addition, five thermistor strings were installed under the new foundation. Four of these strings were installed in conduit to $5 \mathrm{~m}(16.3 \mathrm{ft})$ below the floor surface, and one string was installed in conduit to $4 \mathrm{~m}$ (14.3 ft) below the surface. The location of these sensors was determined by evaluating existing temperature strings to find the permafrost table depth. These sensors all report back to a Campbell Scientific CR10oo that records daily average temperatures. These 
sensors were installed to allow CCHRC to watch the temperatures under the foundation so that they can deploy the foundation stabilization system if it becomes necessary. Figure 57 shows the locations for the thermistor strings.

Figure 57. Temperature string installed beneath the RTF Building addition.

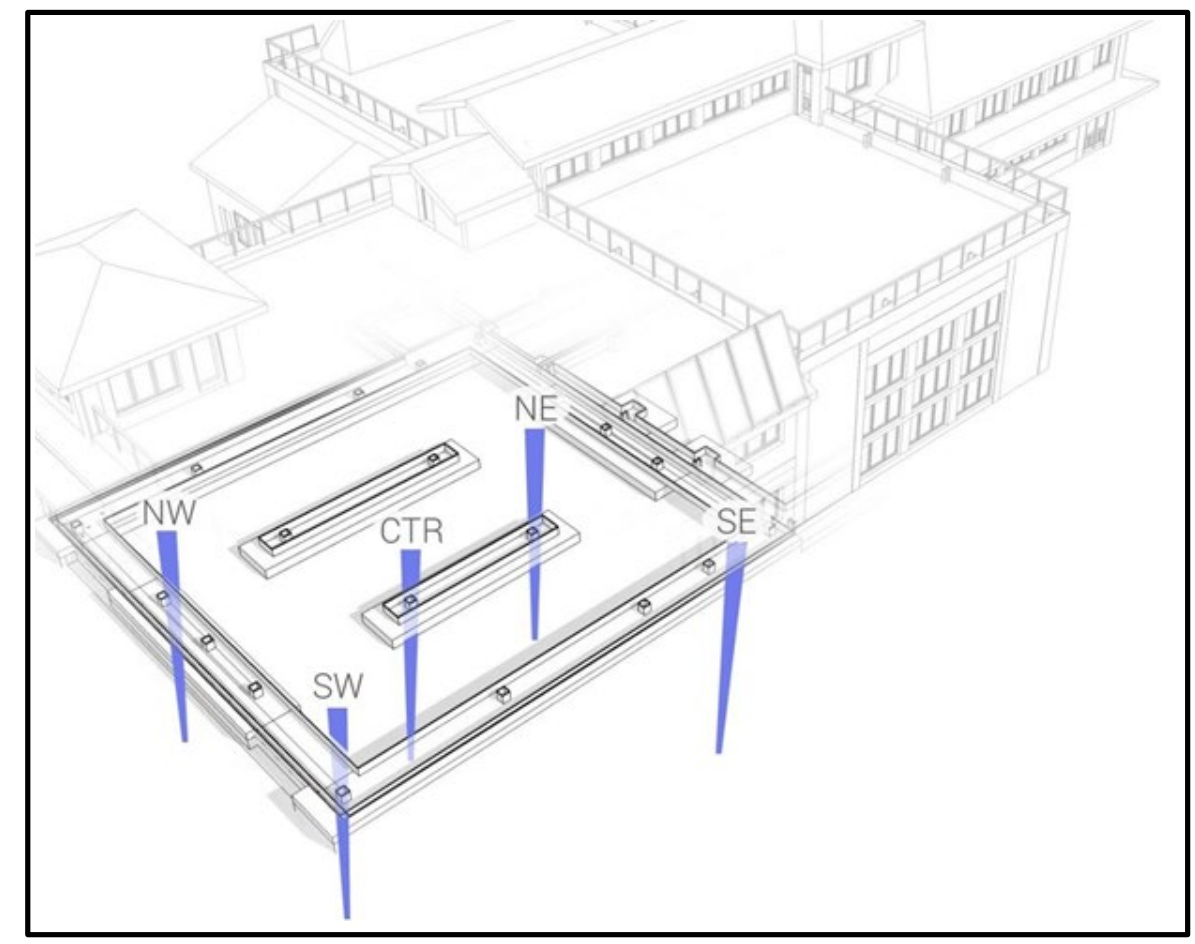

\subsubsection{Data analysis}

CCHRC has been reviewing the data from all of the locations under the RTF. Of the 237 temperature sensors installed in and around the foundation, 88 are still recording reasonable temperatures, with a $63 \%$ failure rate. Of the 88 sensors still working, 21 lack adequate location data so their values are not useful. Therefore, there are approximately 67 temperature sensors left in the foundation that are providing useful data. Figure 58 shows an example of temperature sensor drift over time; sensor placement is grouped by color (the grey line is the air temperature). The data charted in Figure 58 were taken from the north lab foundation from 2007 to 2012; some of these sensors are still working, but many are not. Because the sensors were installed in triplicate at each location, under ideal conditions, the three sensors would show identical or closely similar readings over time. The diverging lines show when an individual sensor failed. 
Figure 58. Subsurface temperature data under the north lab foundation in the RTF. The data show temperature sensor drift over time; sensor placement is grouped by color. The grey line is the air temperature.

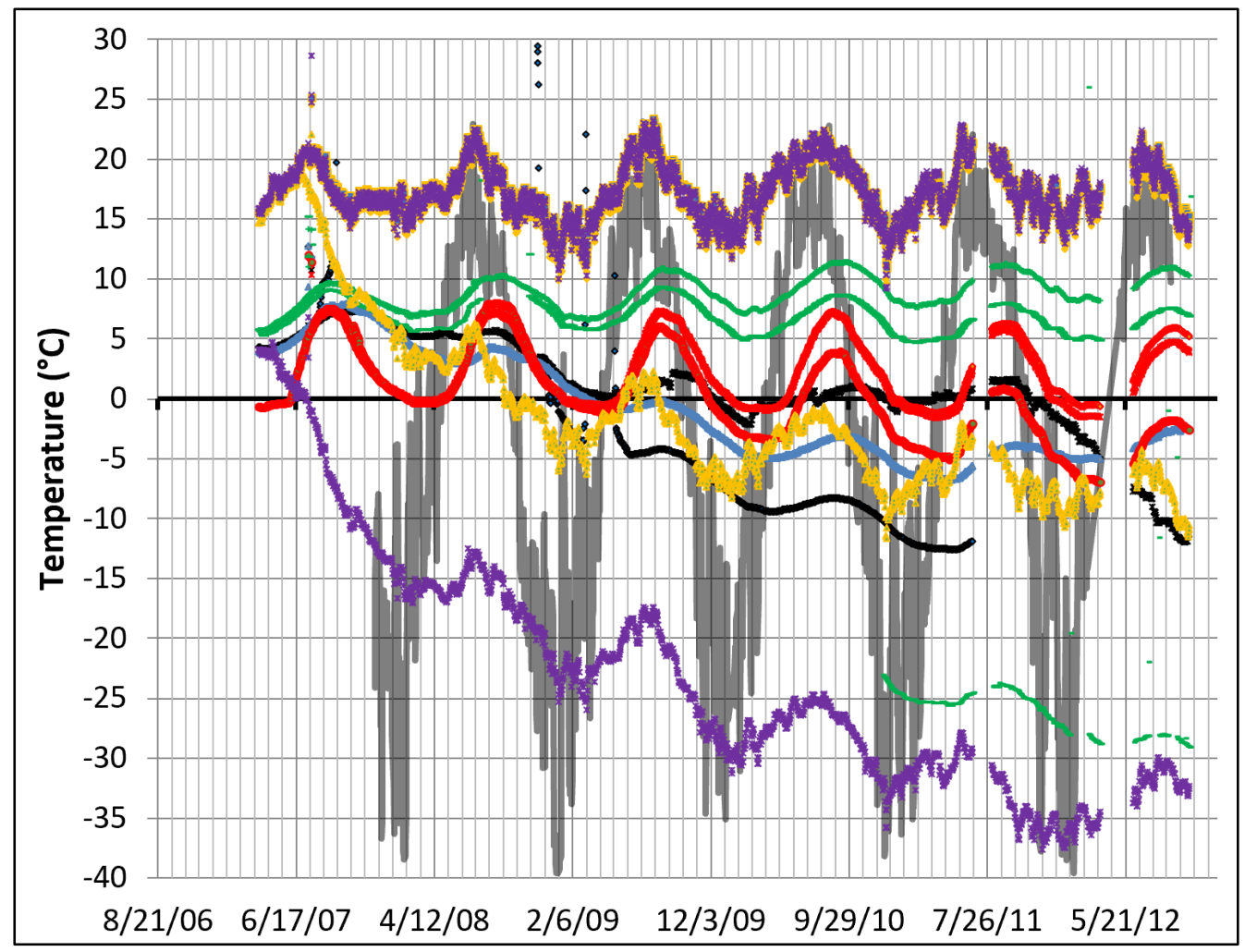

The best data under the original RTF come from the two temperature strings that were placed outside of the foundation. Originally, there was one string placed $1 \mathrm{~m}(4 \mathrm{ft})$ to the east of the building and one to the west. The wire to the west string in 2012 was cut when construction of the building addition began. Figure 59 shows a comparison of the trumpet curves for 2008 and 2016 from the temperature string to the east of the basement. From the data shown in Figure 59, it can be determined that the permafrost table depth has increased (or degraded) by approximately $1 \mathrm{~m}$ $(4 \mathrm{ft})$ over the 8 years that the data were monitored.

In addition to denoting where the permafrost is, Figure 59 also shows that there is a sensor failure in this temperature string. The sensor at $1 \mathrm{~m}$ (3.5 ft) started to fail in 2015 and is no longer working at the end of 2016. 
Figure 59. Subsurface temperature data shown as trumpet curves under the RTF from 2008 (left) and 2016 (right). The comparative graphs indicate the permafrost table depth has increased by approximately $1 \mathrm{~m}(4 \mathrm{ft})$.

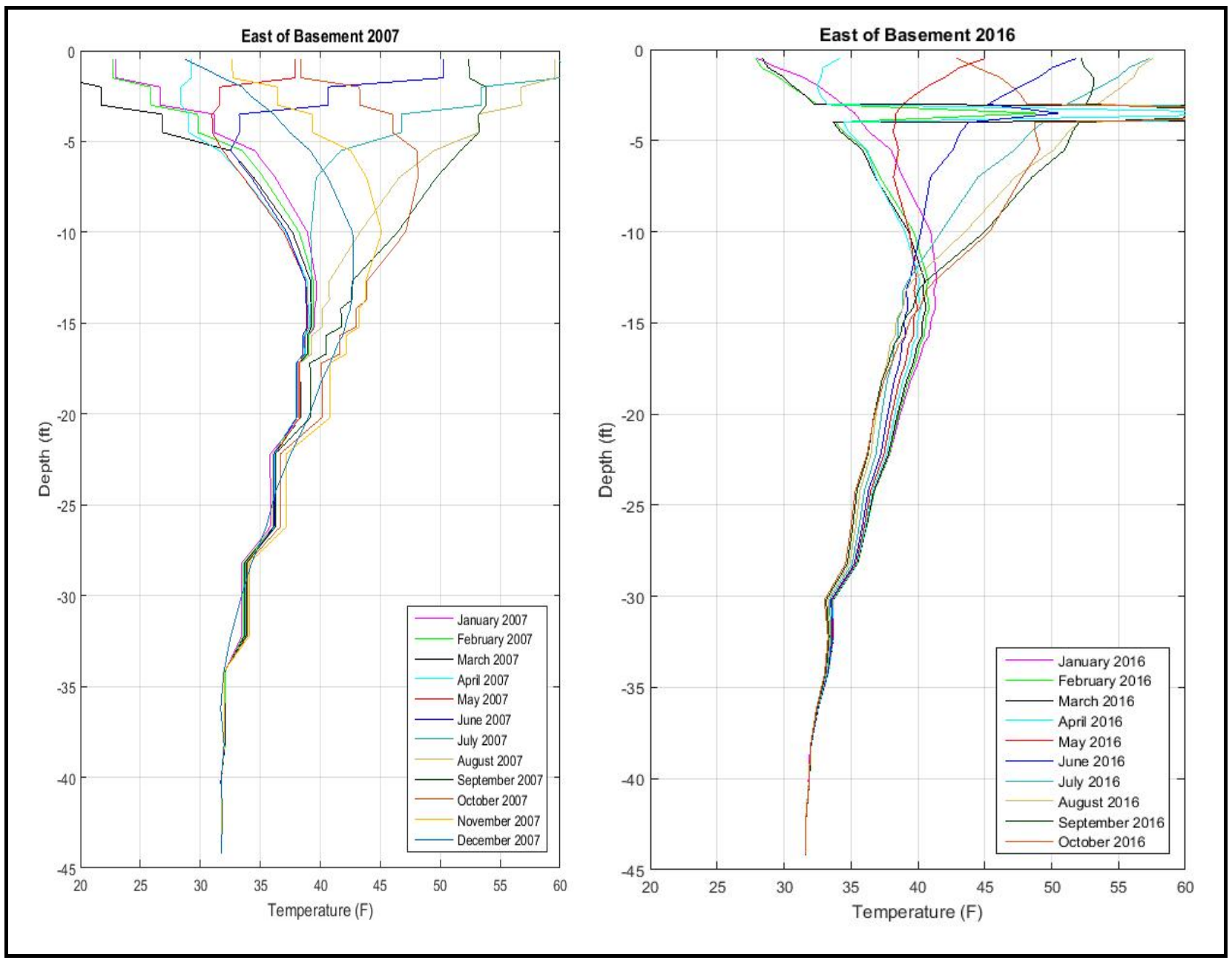

The sensors under the building addition have been returning accurate data thus far. Figure 60 shows a sample of the temperature data under the building addition. A distinct warming trend is depicted in the soil over time down

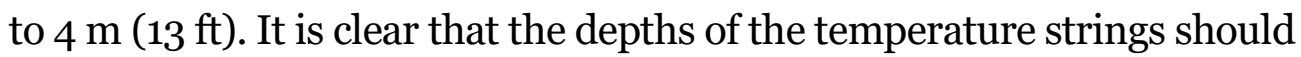
have been greater because the permafrost table (shown where the temperature is less than $\mathrm{o}^{\circ} \mathrm{C}\left[32^{\circ} \mathrm{F}\right]$ ) has moved below the greatest measured depth ( $4.8 \mathrm{~m}[16 \mathrm{ft}]$ below the surface). In this case, a time trend line was used since there were only a few sensors; the time-based graph makes it easier to show the trend. Figure 61 shows the temperatures under the addition. 
Figure 60 . The change in subsurface temperatures in the building addition.

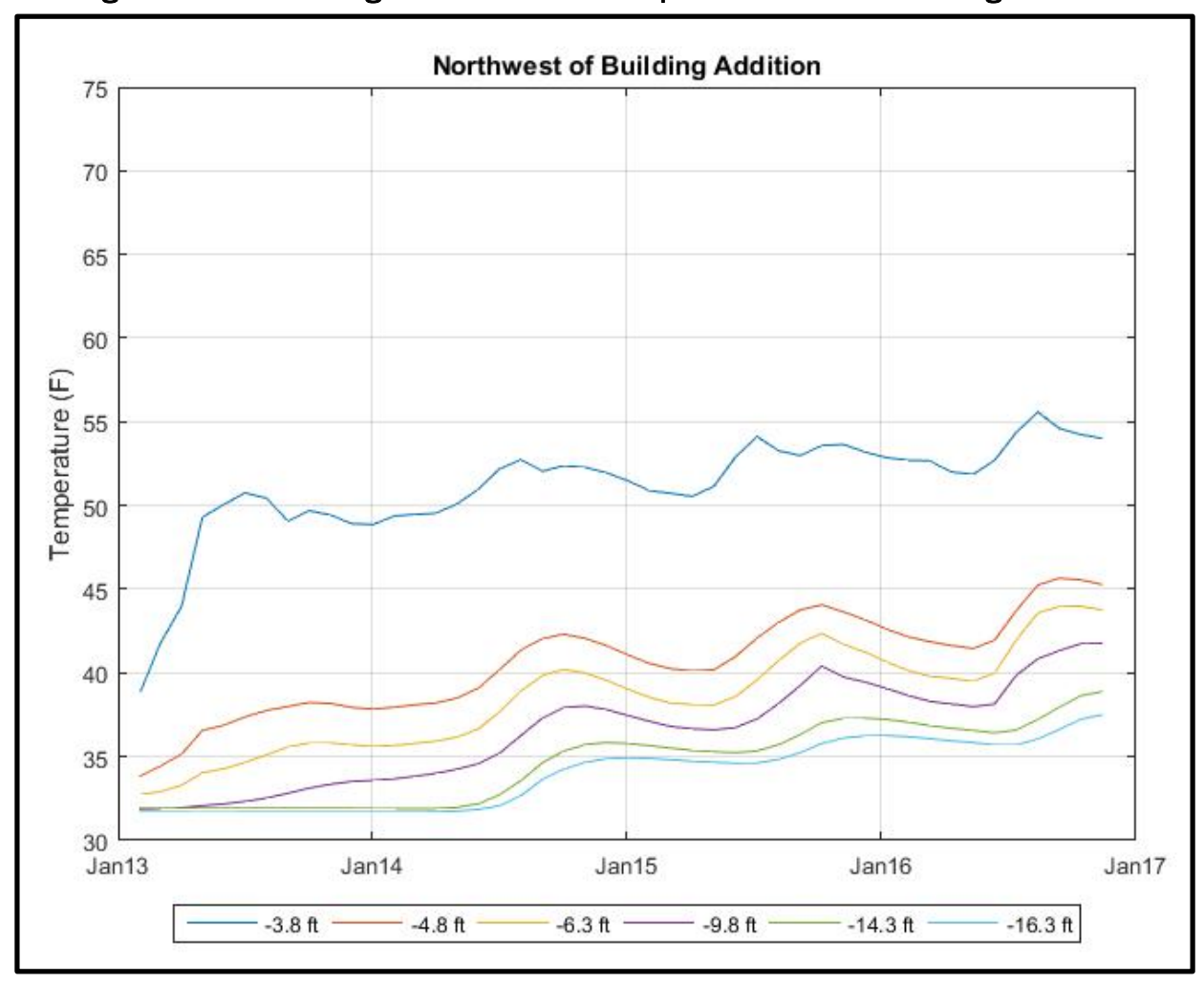

Figure 61. Trumpet curves under the building addition.
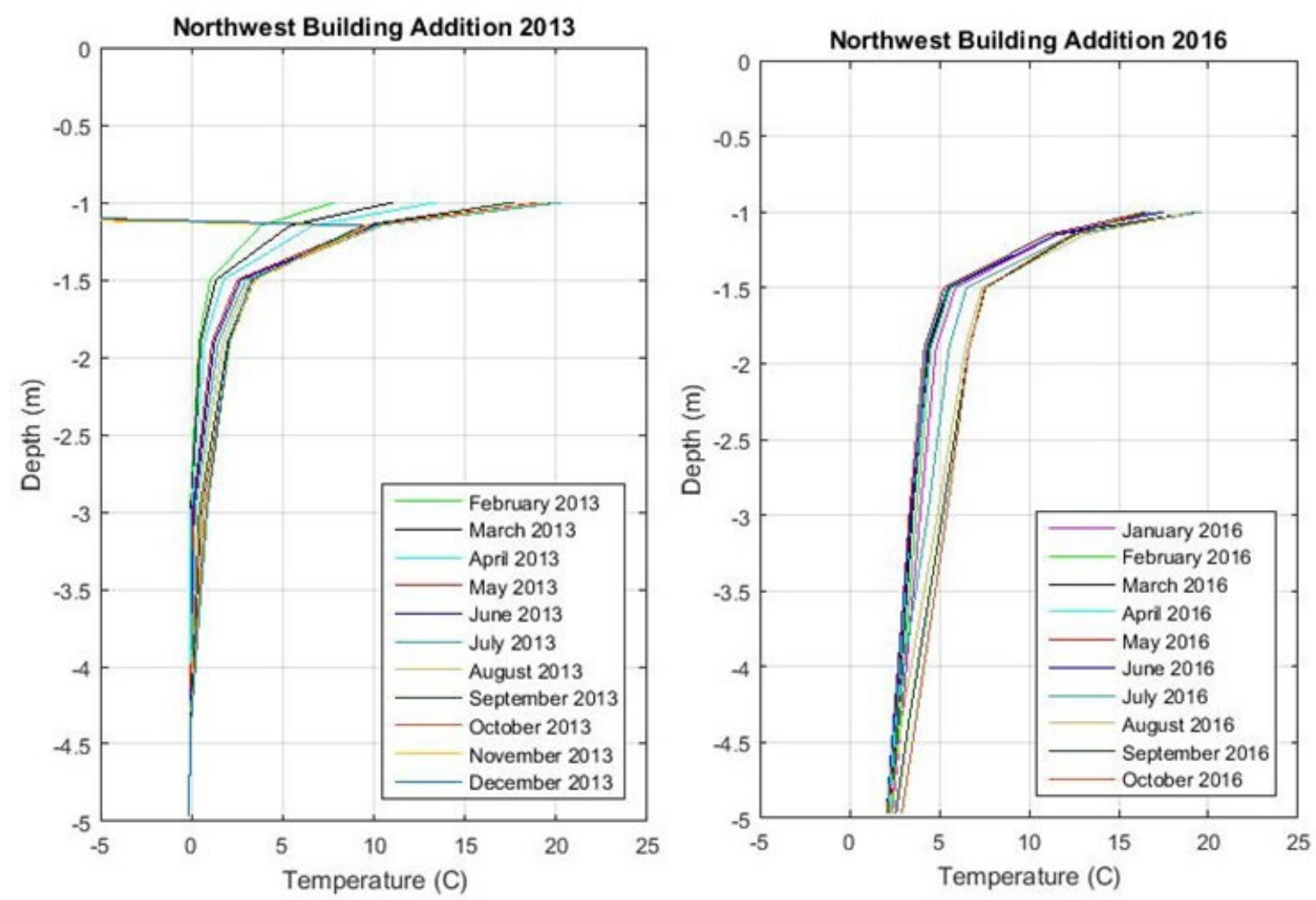


\subsubsection{Lessons learned from RTF sensors}

The first iterations of subfoundation data collection at the CCHRC RTF have had mixed outcomes. The lack of a clear plan for the data from the start caused some of the difficulties. A clear plan would have ensured that sensors were installed in critical spots and that they extended into the permafrost. Additionally, a plan would have involved a schedule for review of the data instead of allowing error-prone data points to continue to collect erroneous data.

There are many sensors under the original building, but none under the foundation are providing information on the temperatures below the foundation. This is partly due to sensor failures as well as to the lack of location information on these sensors. It is unknown if any of the temperature sensors under the basement were even installed near the permafrost.

Many of the sensors under the RTF have failed while the ones outside of the foundation footprint continue to function. CCHRC assumed that the sensors under the foundation have failed due to water infiltration into the wiring of the sensors. The baseline sensors outside of the footprint seemed to be better protected from moisture infiltration.

\subsubsection{Sustainable Village at UAF}

The first phase of the Sustainable Village was built in 2012. It consists of four residential homes of $1600 \mathrm{sq} \mathrm{ft}$ that each house four university students. The homes were deliberately built on poor soils to test foundations in these conditions.

Test boreholes were dug on the east and west portions of the site before construction. The initial boring found that the east portion has ice-rich silt

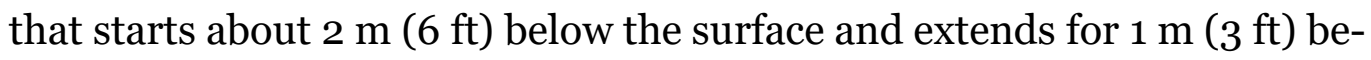
fore turning to thawed silty sand, while the west portion is thawed silt and sand. However, boreholes drilled to install the sensor strings under the houses in 2014 found frozen layers of silt and sand under the west houses. This demonstrated the importance of not relying on one test hole when constructing on permafrost. 


\subsubsection{Foundation}

The two east homes are built on steel piles that extend $9 \mathrm{~m}$ (30 ft) into the soil (Figure 62). The floors in these homes have heated concrete slabs with 10 in. of open cell spray foam between the floor joists (R 65). Each house sits on an array of nine driven piles with smaller diameter helical piles supporting the porches.

The west two homes are built on polyurethane spray foam raft foundations, directly on the ground (Figure 63). Figure 64 shows the raft foundation as it was being installed. The raft foundation is directly on a layer of gravel, which was placed on a geomembrane that is directly on the vegetative mat of the site. There are tubes embedded in the gravel that can be opened to the cold air in winter to cool the foundation; fans have had to be used to introduce more cold air. The spray foam for these foundations is also $254 \mathrm{~mm}$ (10 in.) thick.

Figure 62. One of the two Sustainable Village homes on pile foundations installed on permafrost ground.

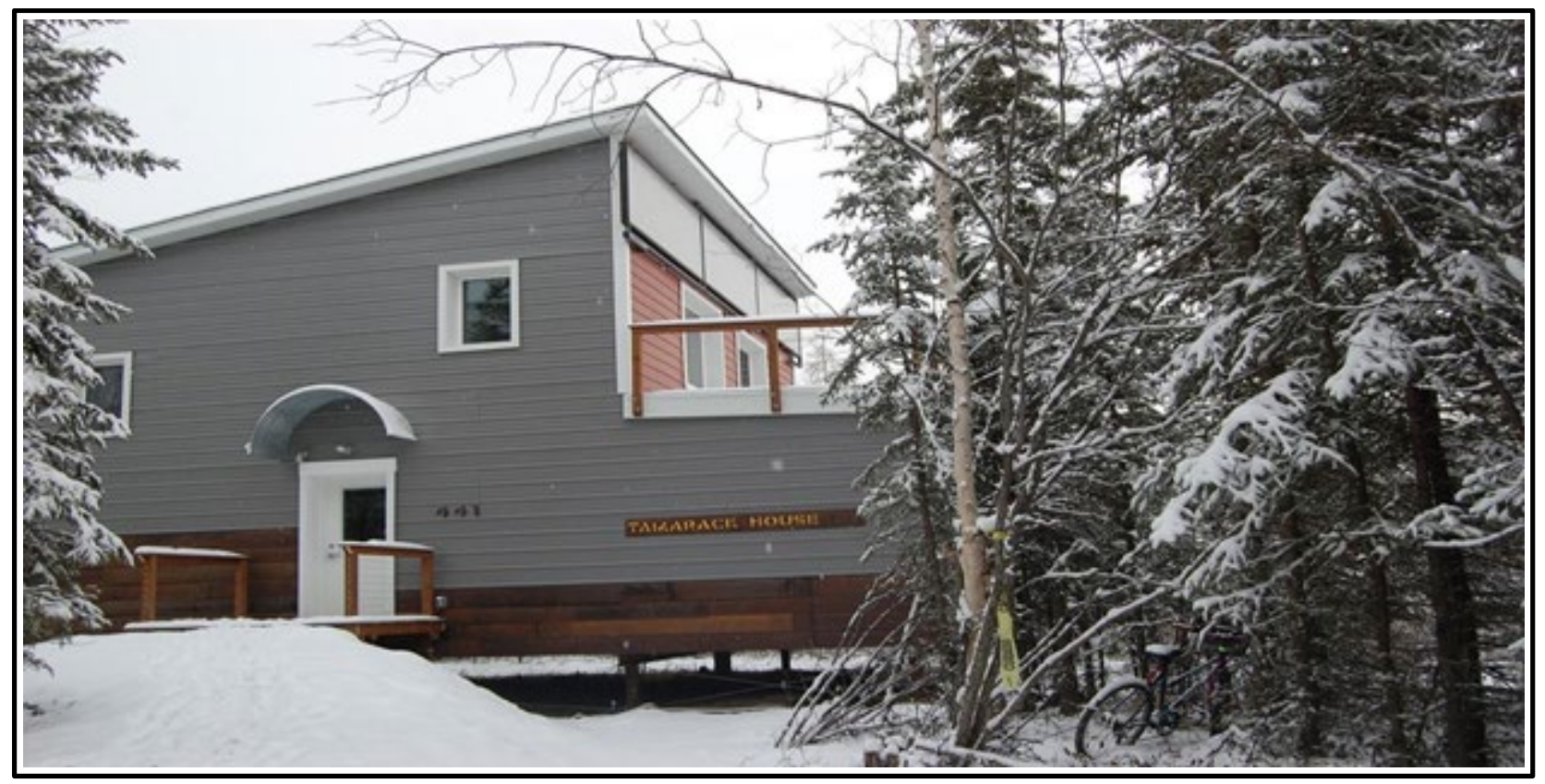


Figure 63. The two Sustainable Village homes on the insulated raft foundations installed on the ground.

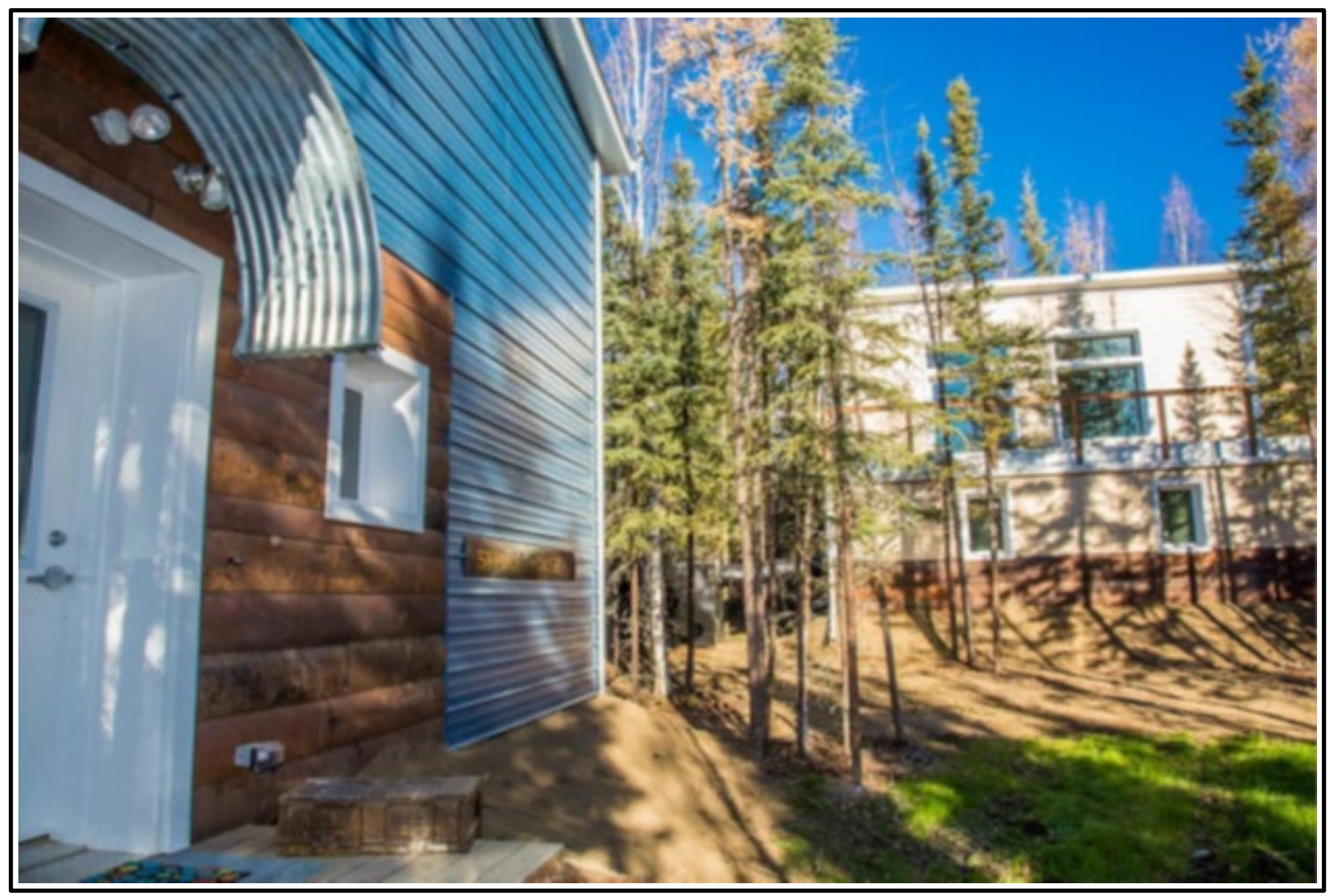

Figure 64. Raft foundation as it was being installed under one of the two Sustainable Village homes.

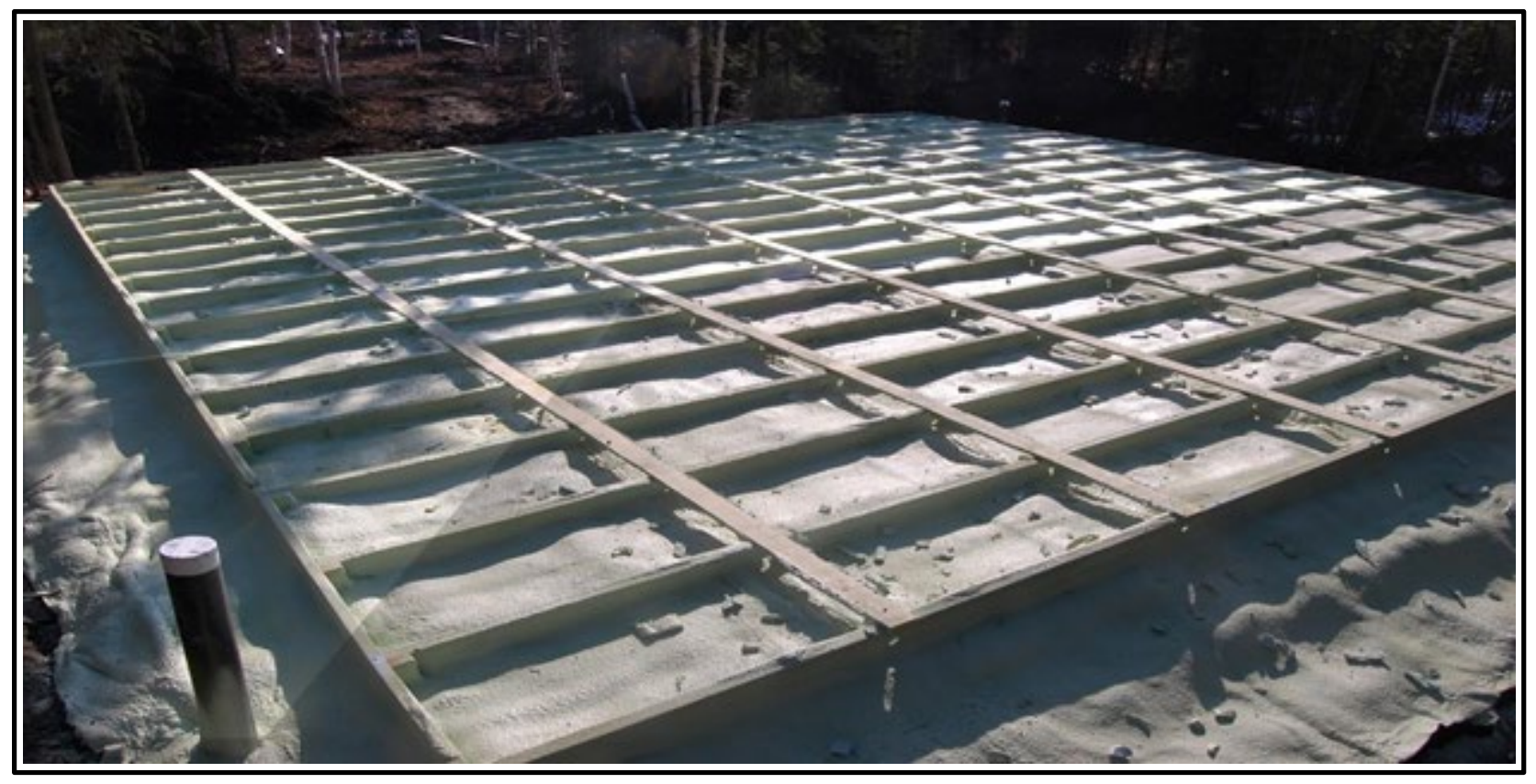




\subsubsection{Data collection systems}

CCHRC installed temperature sensors under the west houses in 2012 during construction. The NTC thermistor strings were under the center of each house in conduit. They were connected to a LabJack UE9 (Ethernet DAQ device) running data collection software. These sensor strings began to fail in their first year (Figure 65); it is assumed that they failed due to a combination of moisture infiltration and power irregularities. These sensors were not accessible and could not be replaced. New sensors and loggers were installed in October 2014 in new holes drilled from outside the houses. Figure 66 shows a timeline of sensor changes.

Figure 65. Subsurface temperatures directly under the northwestern Sustainable Village house that used the insulated raft foundation. Sensor failure occurred over time starting in December 2012.

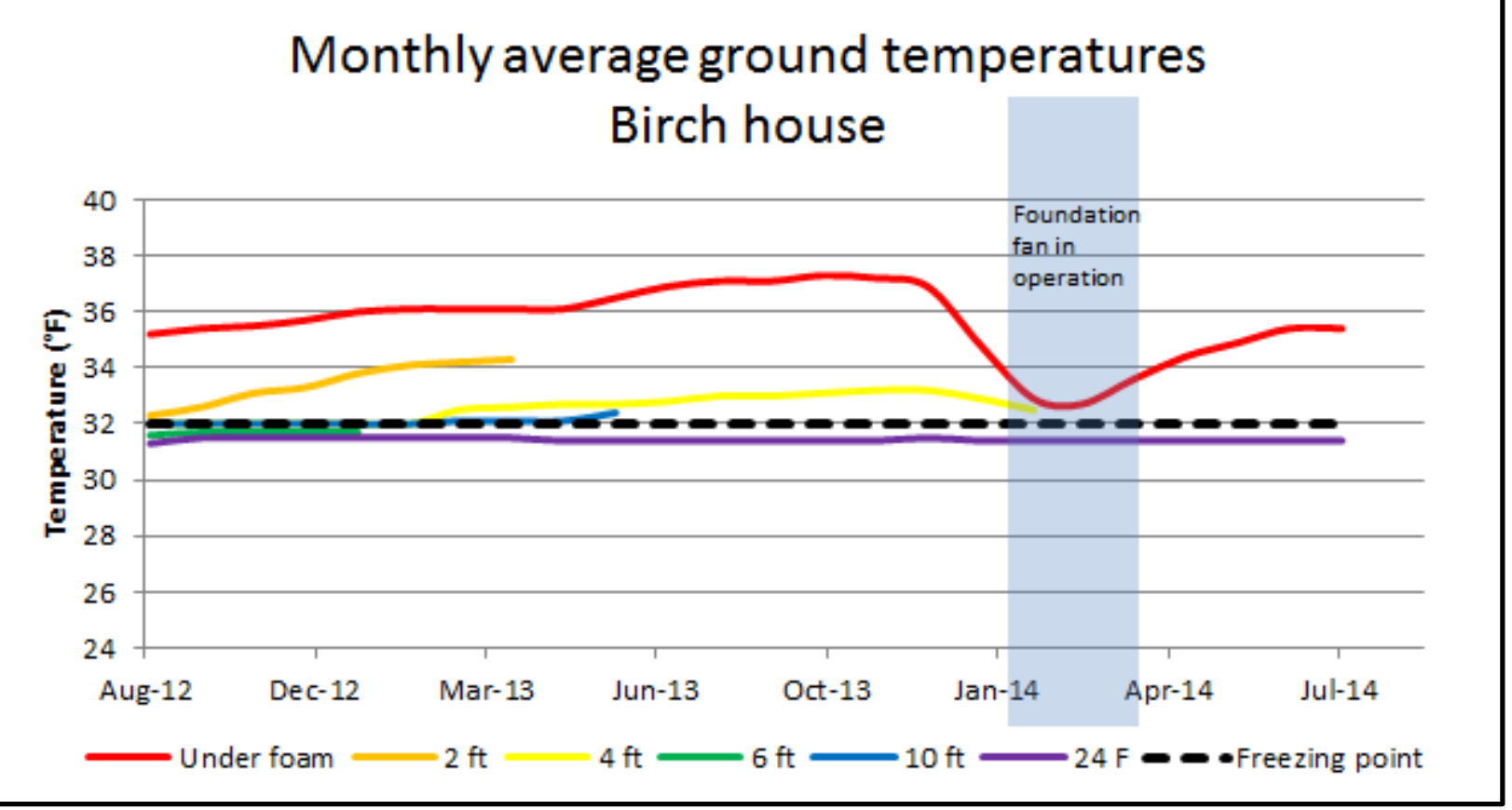


Figure 66. A timeline of data collection changes under the UAF Sustainable Village houses.

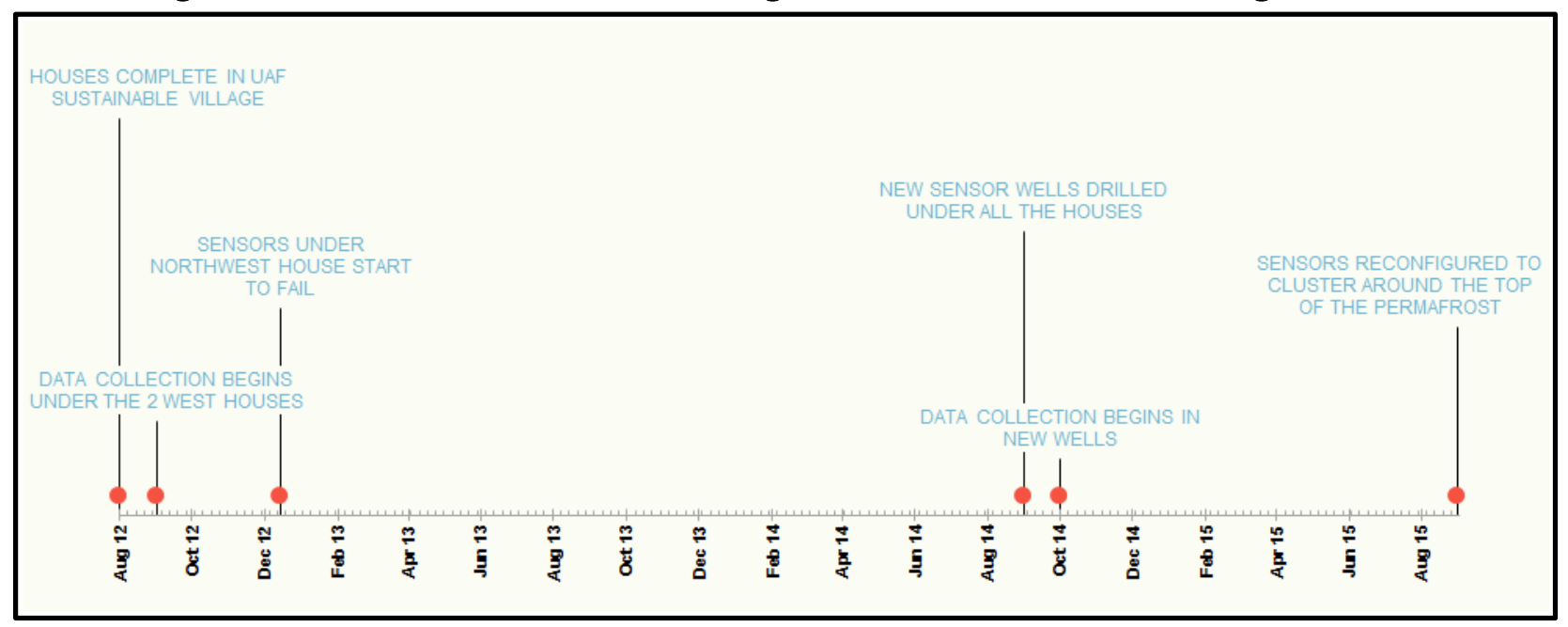

The new data system used Onset temperature sensors (TCM50-HD) and loggers (UX160-006M and U12-001). A single string of temperature sensors was also installed under each house and two baseline strings between the houses (Figure 67). The thermowells was extended approximately $8 \mathrm{~m}$ $(25 \mathrm{ft})$ below grade and the holes are lined with 25-mm (1-in.) diameter PVC pipe so that sensors can be removed or replaced. The probes were inserted in the holes drilled by the soil drilling rig that is used for the geotechnical soil analysis. The annular space between the borehole wall and the casing was backfilled with cuttings produced during the drilling. Each assembly contains one four-channel battery-operated data logger (HOBO U12-006). Each temperature logger sampled and recorded the ground temperature on an hourly basis. The data were downloaded directly from each logger and include a time stamp and measured temperature point (units in degrees Fahrenheit). Figures 68 and 69 show the temperature strings installation under each of the two foundation types for the Sustainable Village houses. Additional temperature sensors were also installed on the ground surface adjacent to the piles of the southeast house and in an additional hole directly under the house. Over the course of the SERDP project, the data have been analyzed regularly and some of the sensors have been reconfigured to look more closely at the permafrost movement with respect to the foundation. 
Figure 67. The thermistor string locations under the homes of the Sustainable Village.

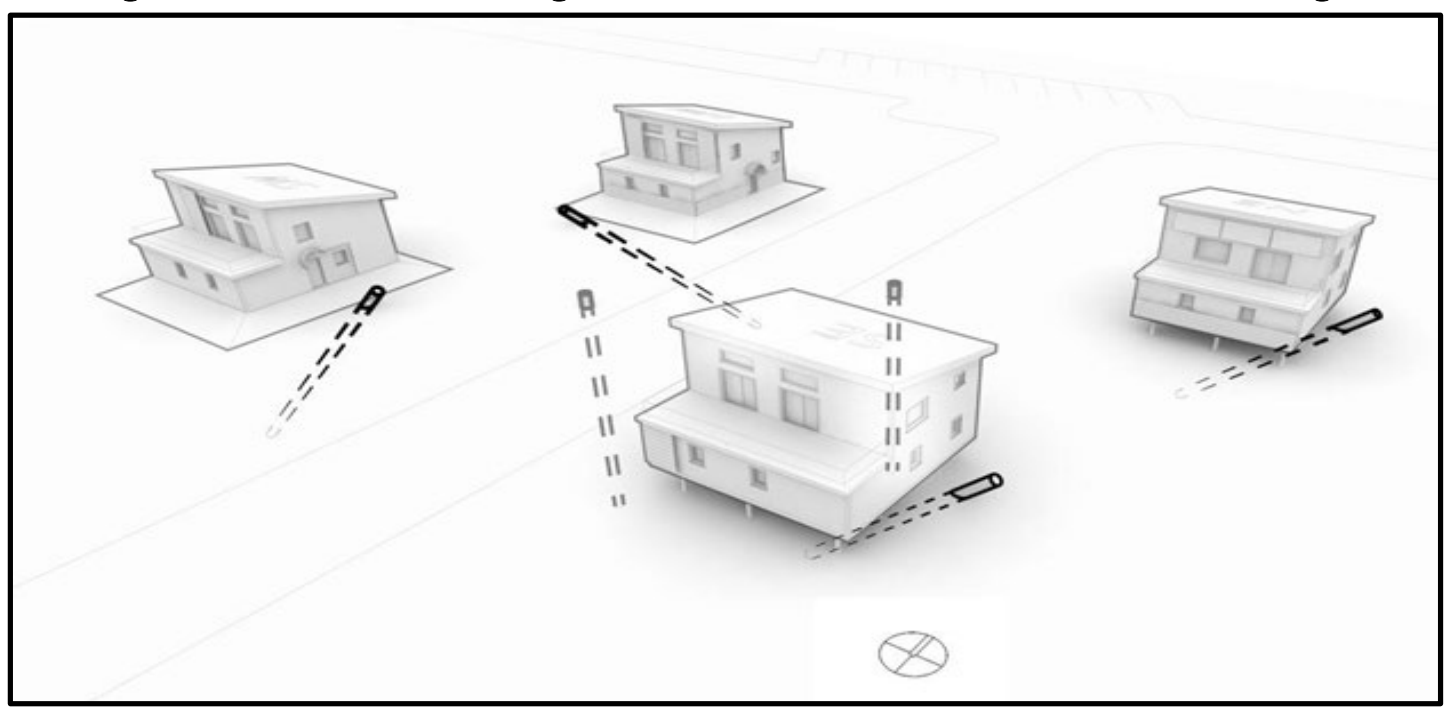

Figure 68. The thermistor string installation under the piling foundation under a Sustainable Village Home

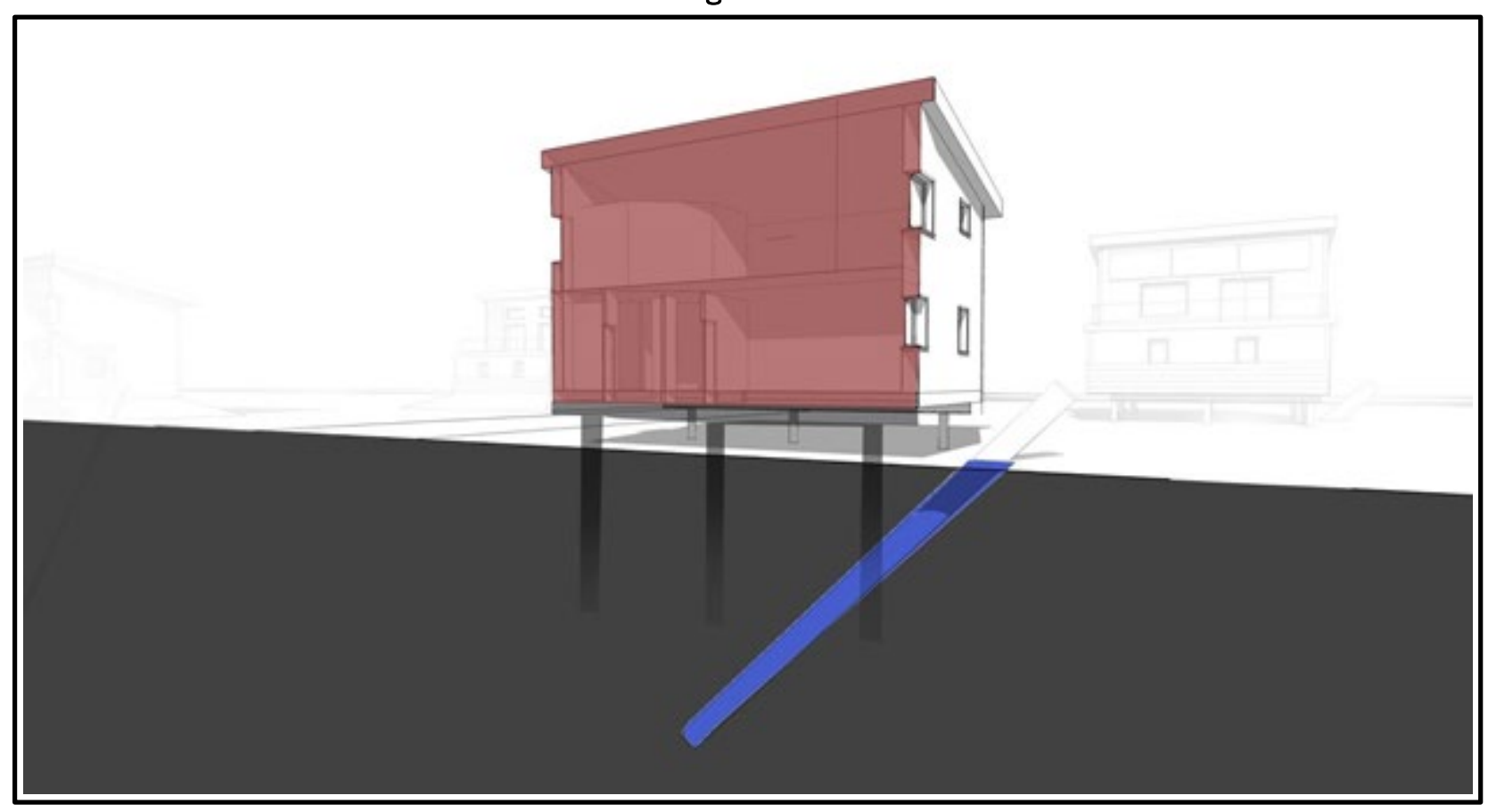


Figure 69. The thermistor string installation under the insulated raft foundation under a Sustainable Village Home

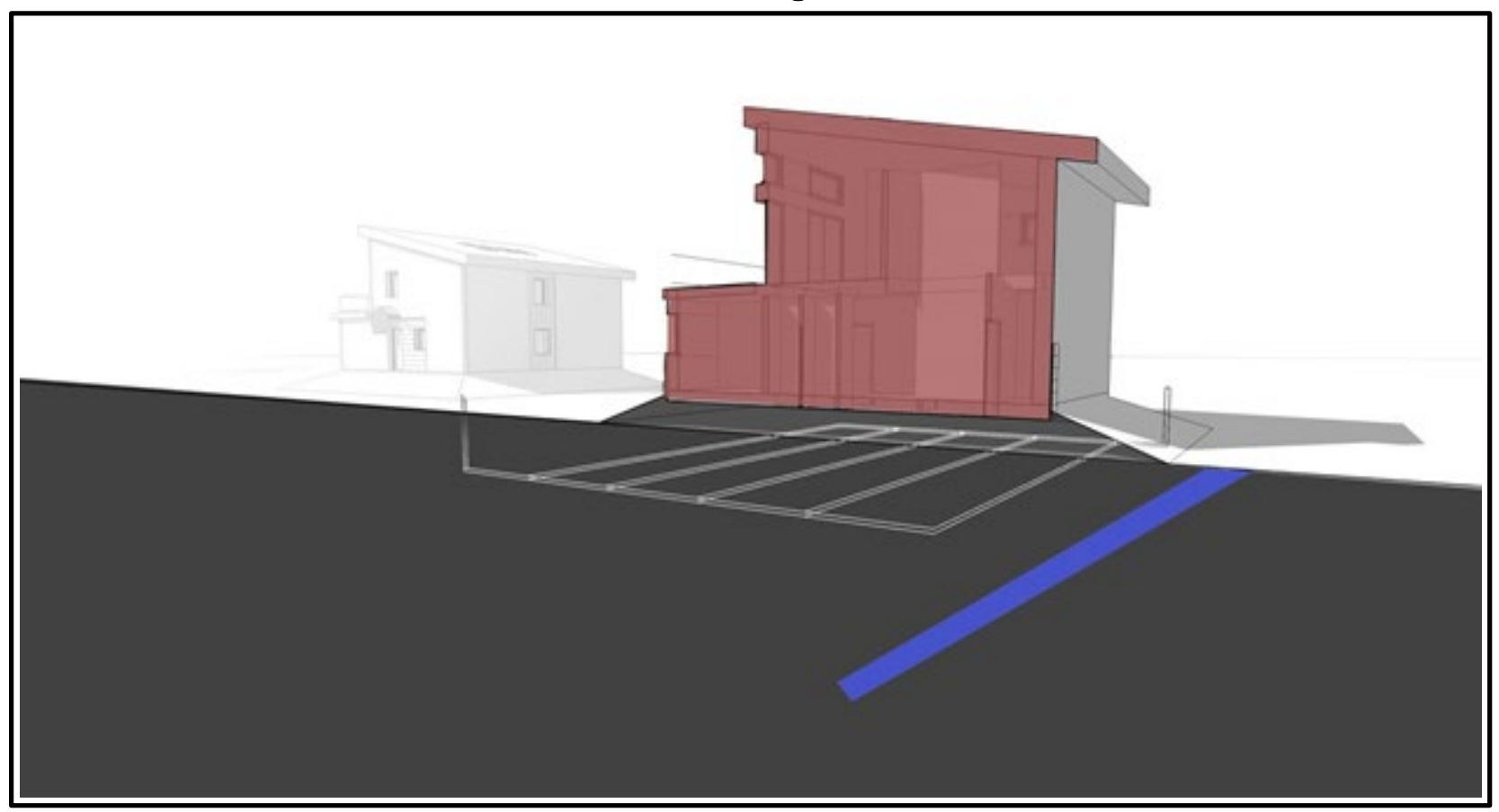

\subsubsection{Data analysis}

The original data collection system in the west houses provided enough data to produce the chart shown in Figure 70. By 2014, there were too few remaining sensors to make detailed graphs (Figure 71). 
Figure 70. Temperatures under the center of the northwest house.

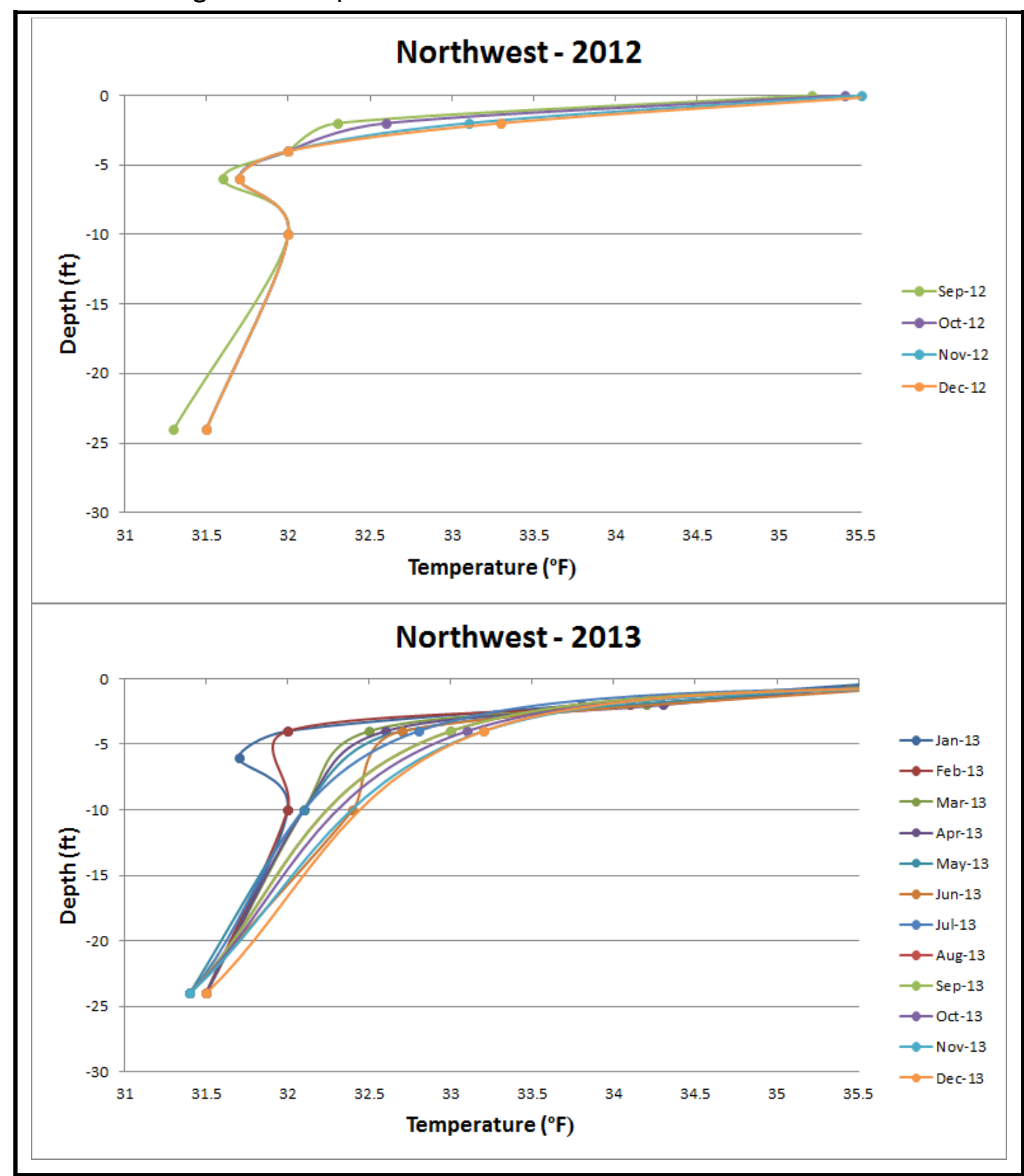


Figure 71. Transition from the failing thermistors to the new data system. The thermistors failed too much to create meaningful whiplash curves.

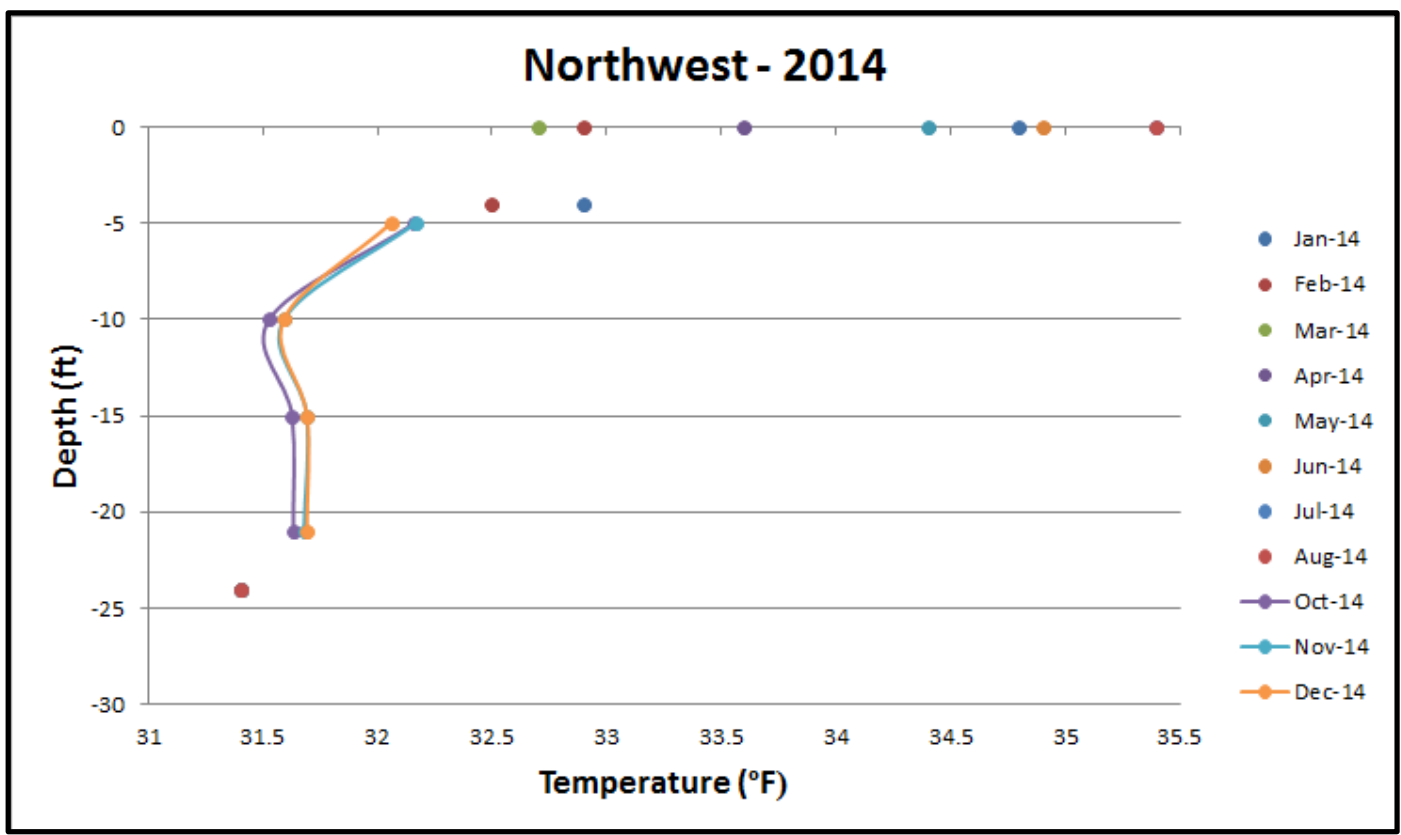

New sensors were installed in October 2014. These were installed under all of the existing buildings using a directional drill rig set up to angle under the foundation (Figure 72). After a year of collecting data from the new loggers, in September 2015, the sensors were moved in the conduit to be more concentrated around the top of the permafrost. Each temperature string has four sensors (Figure 73) so clustering them around the top of the permafrost will help discern changes in the permafrost on a finer scale.

There are 2 years of data for the northeast houses (Figures 74 and 75). These houses are on piles and therefore have colder temperatures than west houses. 
Figure 72. New data system data from the Northwest house. The temperature sensors were moved in September 2015 to be closer together.

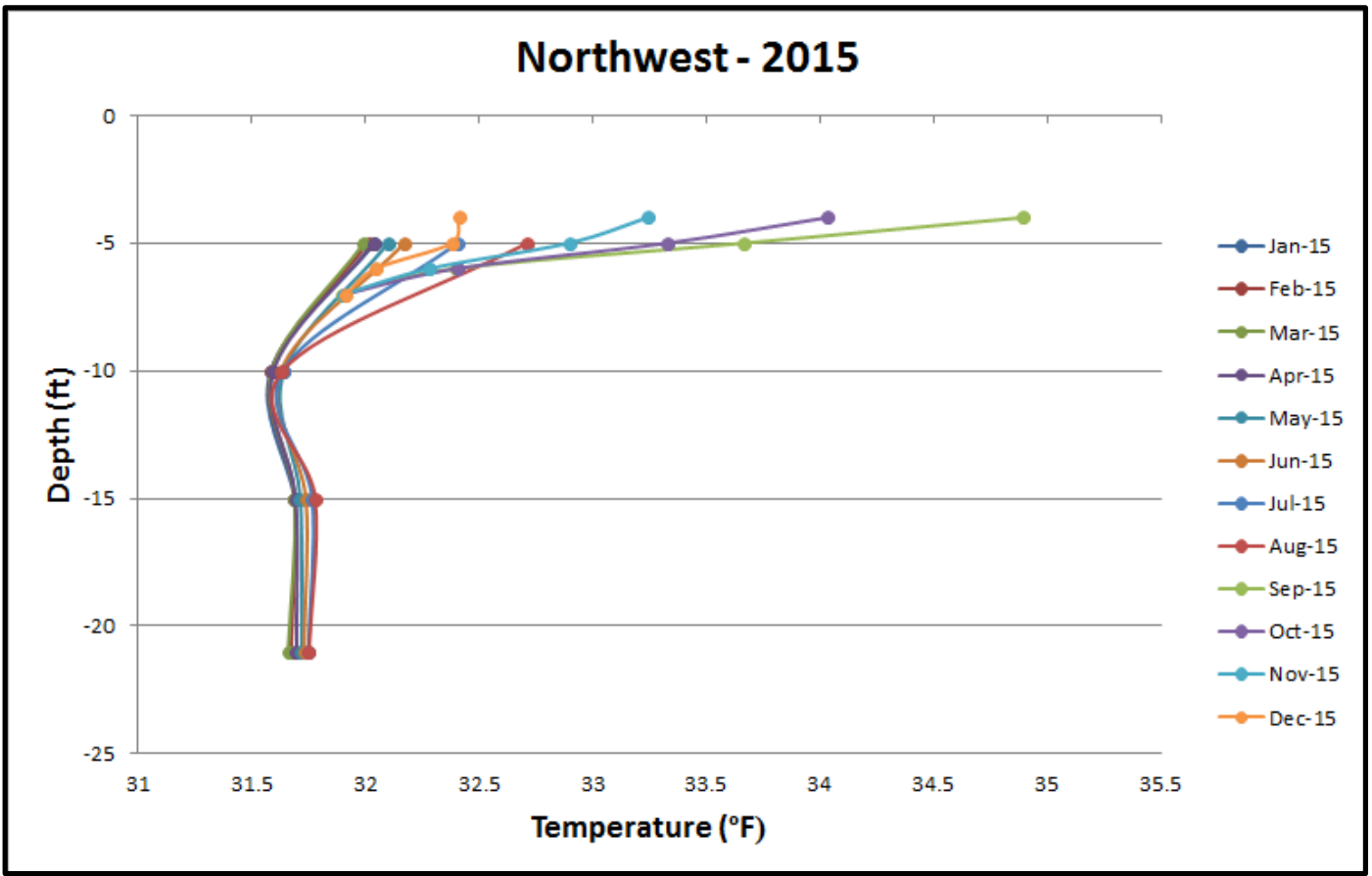

Figure 73. The new locations of the temperature sensors under the northwest house. Notice the large difference in the $y$-axis to enlarge the interface near the top of the permafrost.

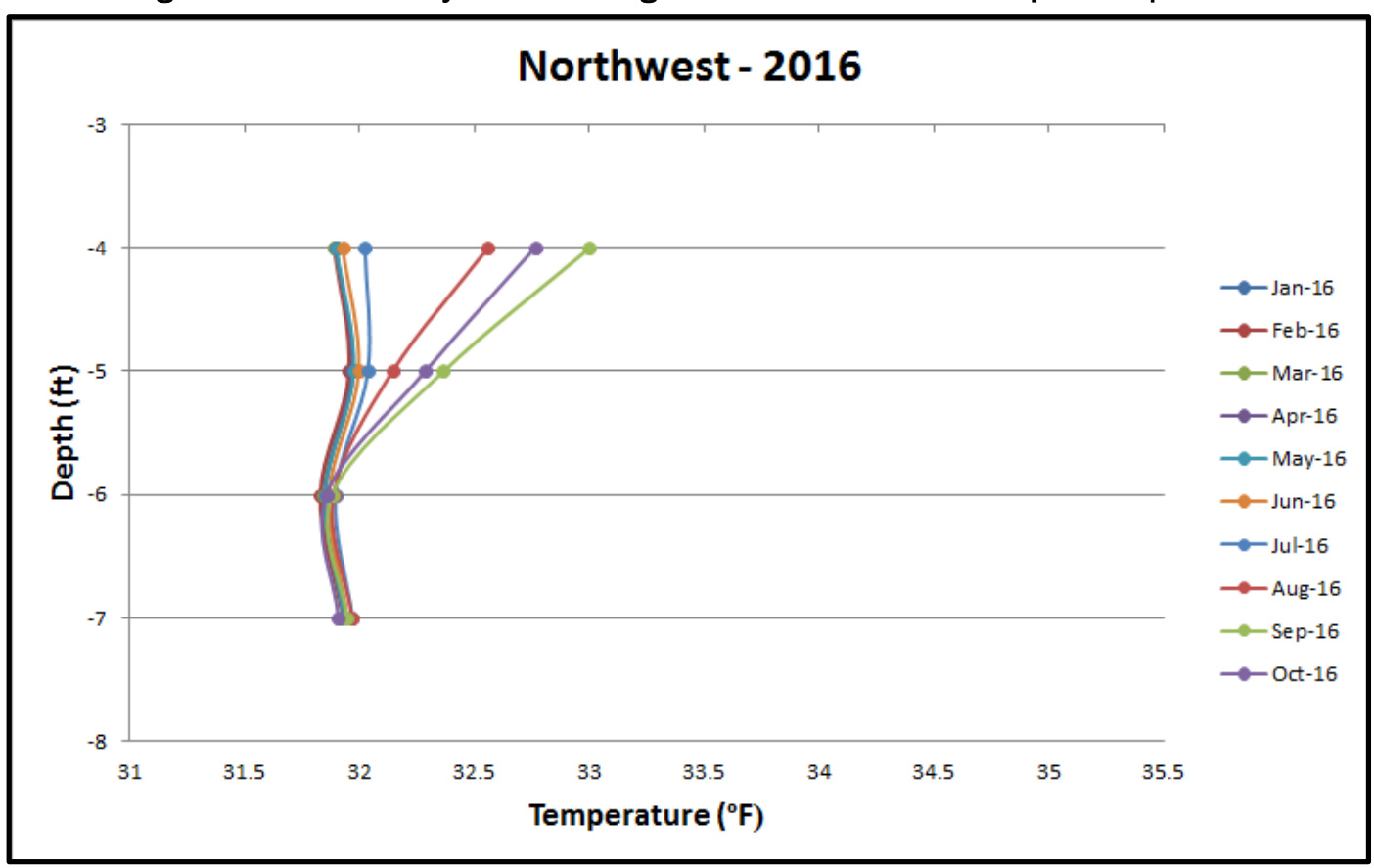


Figure 74. Temperature data under the northeast house. There are no data under this house before 2015. The sensors were moved in September 2015.

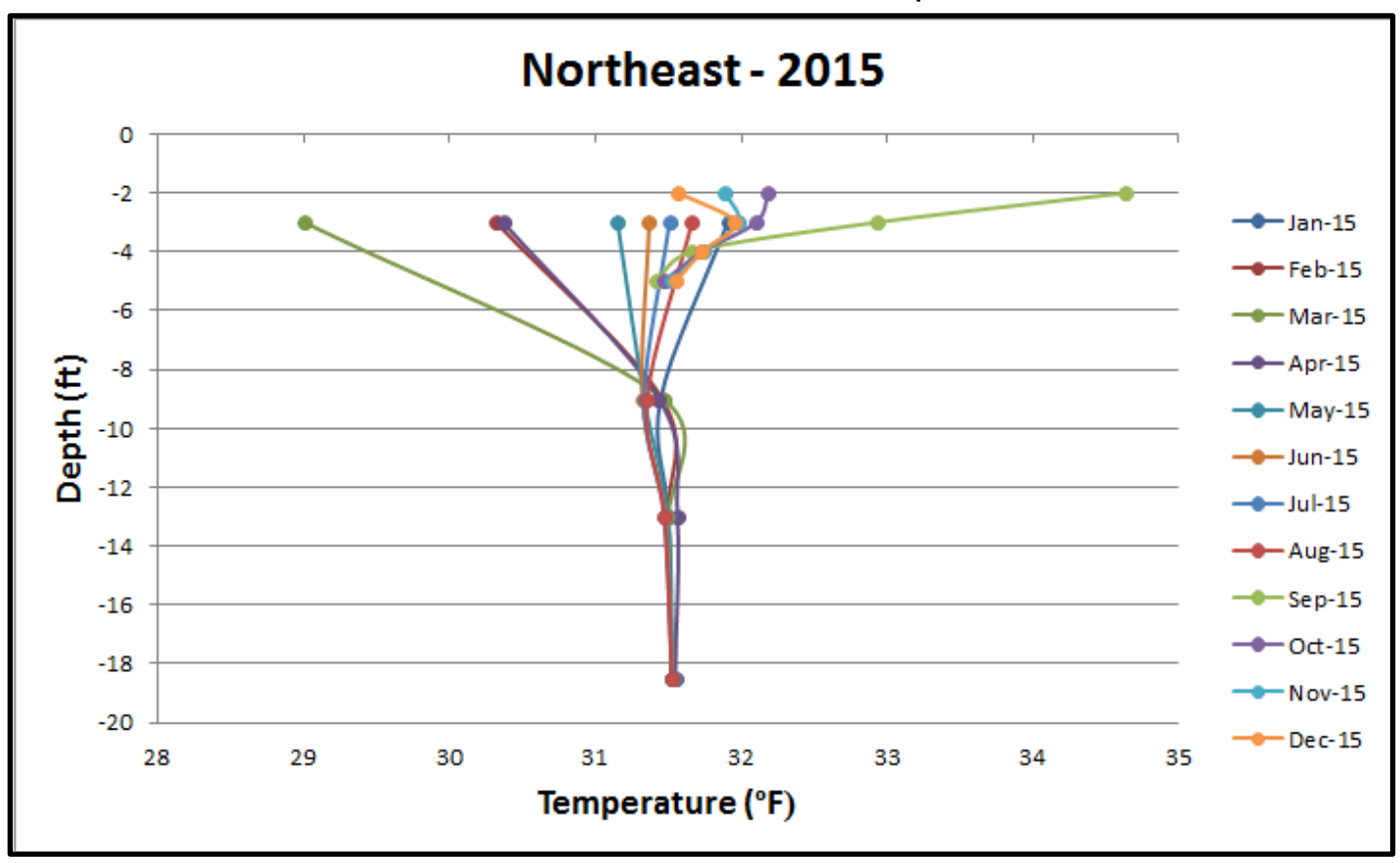

Figure 75. Temperature under the northeast house. The sensors are in a new location; notice the change in the y-axis.

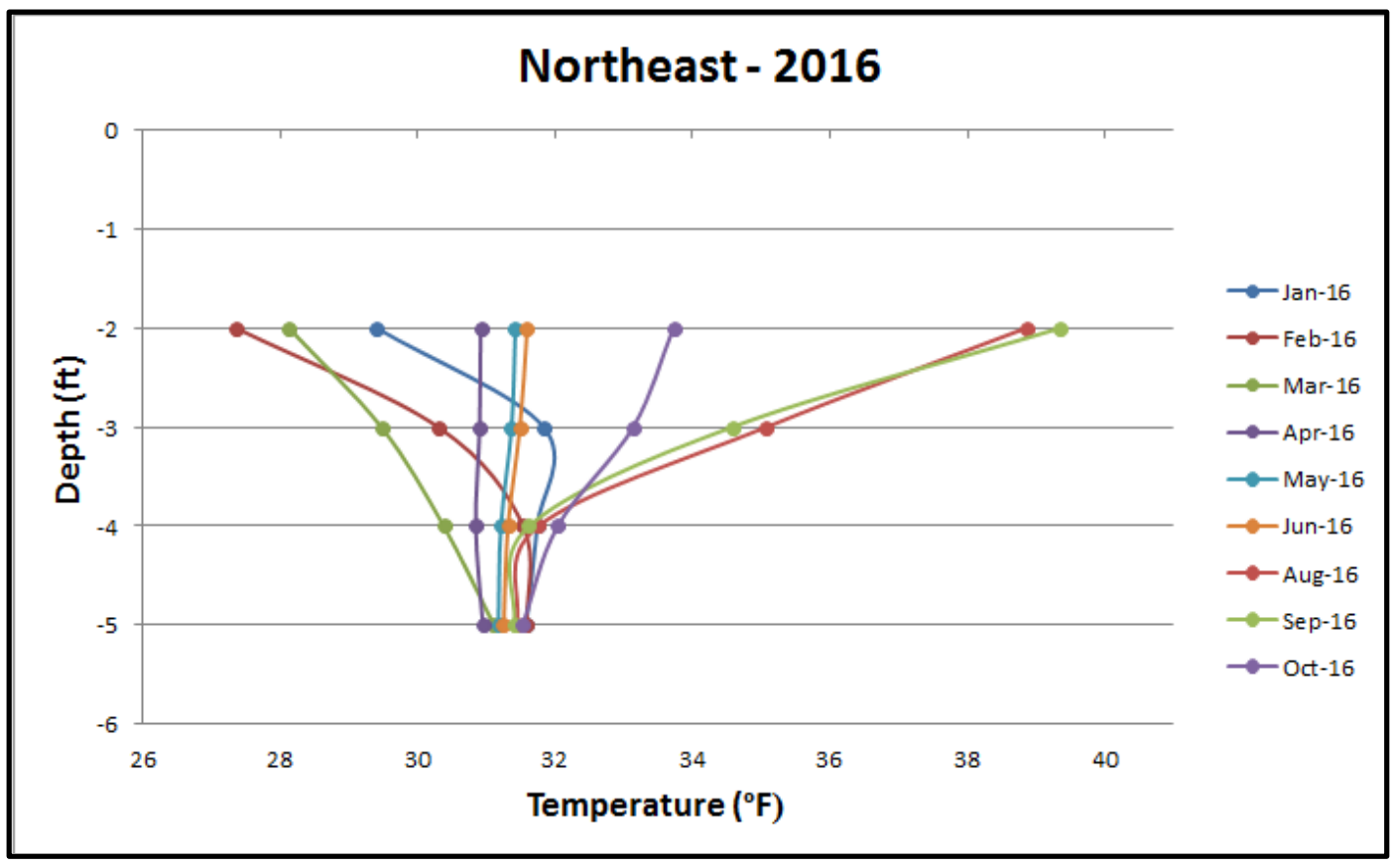




\subsubsection{Lessons learned from Sustainable Village sensors}

The information gleaned from the original RTF data system has informed the process of installing sensors under the building addition and the Sustainable Village at UAF. Each of those projects started with a set plan. Additionally, each project has a data management plan that lays out all the details about the project and the sensor layout in one document. The data management plan also specifies who is responsible for checking on the data and making adjustments, as necessary. The largest hurdle facing a building sensor system is not only the placement of sensors or the datalogging equipment, but also the time required for data management, and reliability in data collection.

Based on the experience of the systems installed at the RTF, the building addition, and at the Sustainable Village, subsurface temperature strings seemed to be the most informative and useful means to determine subsurface thawing conditions in permafrost. The initial placement and location of these sensors can best be determined through modeling efforts. The ability to move and replace sensors is also important for long-term monitoring.

\subsection{Early Warning Detection System (EWDS)}

The stability of permafrost, and the design of structures constructed on permafrost would always be predicated on the phase change from water to ice at temperatures closely approaching, and at $\mathrm{o}^{\circ} \mathrm{C}$. Soil temperature measurement conducted at critical locations of a structure (load bearing points, heating source proximity, and building geometry) would provide one measure of performance of the sub-grade founding soils. To consider the possible effects of climate change on structures built on "warm" $\left(>5{ }^{\circ} \mathrm{C}\right)$ permafrost, temperature measurement would offer an EWDS to alert building managers and/or engineers of changing conditions that could lead to foundation damage. If such conditions are imminent, predetermined actions may be taken to mitigate the structural threat.

Pioneers in basic permafrost research such as Péwé (1982), Ferrians et al. (1969) and Johnston (1981) have provided examples of the difficulties of building structures on permafrost. Factors such as varying ground/surface temperatures, $\mathrm{n}$-factors, soil moisture, soil type, vegetation, and thermal dynamics from different foundation geometries have precluded simple solutions or a "one-size-fits-all" approach to building on permafrost. An EWDS would account for complex, and possibly unanticipated, shifts in 
thermal regime surrounding foundations in the context of unprecedented effects of climate change.

Several iterations of EWDSs have been developed for the three sites studies at CCHRC: the RTF, RTF Building addition, and the Sustainable Village, to monitor effects and interactions between buildings and permafrost, and to alert researchers to changing conditions posing a threat to structural integrity. The earliest of these was built for the RTF. Experience gained from such as system provided refined guidance for the placement and design of monitoring systems for the RTF Building addition and the Sustainable Village. The system developed for the RTF addition and Sustainable Village have been through the most advanced iterations of development to date; this formed the basis for the iteration of system design recommendations presented in this report.

Systems for ground temperature measurement and monitoring in permafrost have evolved steadily since the mid-twentieth century. Early ground temperature measurement systems involving thermocouples (temperature-sensitive bi-metallic strips) and a battery-powered electric clock that turns a rotating metal disk with a pointer and wax coated paper (Johnston et al. 1966) yielded to more robust and detailed systems. Currently, a North American Permafrost Monitoring Network sets the base standard for monitoring the state of permafrost in Arctic settings (Smith et al. 2010). This sophisticated system is comprised of multi-thermistor cables that are connected to data loggers, examples of which are currently implemented throughout the Arctic.

Buildings built in permafrost areas are usually built with the mantra, "if it's frozen keep it frozen." However, with the climate changing and permafrost melting, "keeping it frozen" is an increasingly difficult task. An EWDS for building foundations will provide building managers with a tool to know ahead of time if the permafrost is melting so that mitigation efforts can be put in place before the building starts to move or fail.

\subsubsection{EWDS evaluation and processes}

The proposed EWDS is a temperature-based system. Temperature was chosen as it is easier to detect changes in permafrost early just by knowing the subterranean temperatures. A displacement-based system will set off the alarm when it is too late to do anything. In addition, temperature sensors are simple and rather inexpensive to deploy. Table 5 describes the 


\section{overall approaches and suggestions for the EWDS process that are essen- tial for monitoring.}

Table 5. Overall approaches and suggestions for EWDS.

\begin{tabular}{|c|c|c|}
\hline Process & Importance & Steps and Considerations \\
\hline $\begin{array}{l}\text { Site } \\
\text { Evaluation }\end{array}$ & $\begin{array}{l}\text { The site evaluation data are important for design, } \\
\text { and to help determine how the building will behave } \\
\text { in the future. Site data can be extensive and costly; } \\
\text { thus, the data should be saved for future and } \\
\text { building administrators use. Knowing the makeup } \\
\text { of the soils is essential to developing a plan for } \\
\text { melting permafrost mitigation strategies. }\end{array}$ & $\begin{array}{l}\text { - Leverage existing site conditions data that have } \\
\text { been reliably catalogued and interpreted } \\
\text { - Use pre-construction site evaluation documents if } \\
\text { readily available. } \\
\text { - Search for documents pertaining to buildings in } \\
\text { close proximity to use as a rough survey of the area } \\
\text { if site evaluation documents are not available. }\end{array}$ \\
\hline $\begin{array}{l}\text { Foundation } \\
\text { Type }\end{array}$ & $\begin{array}{l}\text { The design of the foundation will be imperative to } \\
\text { helping determine the location of the EWDS. } \\
\text { Understanding the design of the foundation of an } \\
\text { existing building is important to laying out the } \\
\text { EWDS. }\end{array}$ & $\begin{array}{l}\text { - Assess the variety of designs for permafrost } \\
\text { foundations. } \\
\text { - Learn about the existing foundation through } \\
\text { inspection. } \\
\text { - Use original drawings for existing buildings. }\end{array}$ \\
\hline $\begin{array}{l}\text { Sensor } \\
\text { Location }\end{array}$ & $\begin{array}{l}\text { Choosing strategic locations require careful } \\
\text { thought. A few properly installed sensors in } \\
\text { appropriate locations are more likely to provide the } \\
\text { proper information and attention than with many } \\
\text { sensors placed in less than optimum locations. It is } \\
\text { important to protect the sensors from water } \\
\text { intrusion to ensure their long-term life. Ideally, the } \\
\text { top of the conduit will be accessible to allow for } \\
\text { sensor replacements in the future. }\end{array}$ & $\begin{array}{l}\text { - Place temperature sensors around the interface of } \\
\text { permafrost and non-permafrost soils and in } \\
\text { strategic locations based on the foundation } \\
\text { configuration. } \\
\text { - Use a soil drill to reach strategic locations. } \\
\text { - Line the drill holes with plastic conduit, with a } \\
\text { diameter less than } 1 / 2 \text { in., place a cap the end of } \\
\text { each pipe, and glue all joints. }\end{array}$ \\
\hline New & $\begin{array}{l}\text { New buildings on permafrost should be designed to } \\
\text { accommodate the installation of long-term } \\
\text { foundation monitoring systems. As the foundation } \\
\text { design develops, the designers and engineers } \\
\text { should indicate locations where permafrost } \\
\text { monitoring sensors should be installed. The sensor } \\
\text { locations for the new building will be based on } \\
\text { foundation design, the type of soil, and the location } \\
\text { and temperature of the permafrost. Accessing an } \\
\text { empty site for sensor installation should be } \\
\text { coordinated before the construction of the new } \\
\text { foundation. }\end{array}$ & $\begin{array}{l}\text { - Install temperature sensors above and below the } \\
\text { top edge of the frozen layer for indication of } \\
\text { thawing or if permafrost is changing. } \\
\text { - Install temperature sensors for long-term } \\
\text { foundation monitoring in in appropriate locations } \\
\text { before the new foundation. } \\
\text { - Protect from construction activities. }\end{array}$ \\
\hline $\begin{array}{l}\text { Existing } \\
\text { Building }\end{array}$ & $\begin{array}{l}\text { The sensor locations for the new building will be } \\
\text { based on foundation design, the type of soil, and } \\
\text { the location and temperature of the permafrost. Be } \\
\text { careful to avoid any subsurface utilities while doing } \\
\text { this drilling. The location for these drillings should } \\
\text { be at critical areas of the foundation (e.g., an ice- } \\
\text { wedge area or a location near outgoing wastewater } \\
\text { pipes). }\end{array}$ & $\begin{array}{l}\text { - Use existing information on the foundation, the } \\
\text { type of soil, and the permafrost if readily available, } \\
\text { otherwise use other sources of subsurface } \\
\text { information available from nearby locations. } \\
\text { - Determine the locations of the permafrost and the } \\
\text { type of soils underlying the building. } \\
\text { - Place sensors around the outside of the } \\
\text { foundation. }\end{array}$ \\
\hline Metadata & $\begin{array}{l}\text { The metadata about the early warning system is the } \\
\text { most important part of the system. Without } \\
\text { accurate metadata, it is almost impossible to figure } \\
\text { out the location of subsurface temperature sensor } \\
\text { after there is a building on top of them. A map of } \\
\text { sensor locations with foundation information is } \\
\text { absolutely necessary for the EWDS to function. }\end{array}$ & $\begin{array}{l}\text { - Create a map of sensor and foundation } \\
\text { information. } \\
\text { - Ensure that the map is available and } \\
\text { understandable to the building manager } 20 \text { or } 30 \\
\text { years down the road } \\
\text { - Use the map as an underlay in a digital data } \\
\text { display for soil temperatures and ensure that } \\
\text { important location data are documented with } \\
\text { details. }\end{array}$ \\
\hline
\end{tabular}


Ideally, the sensors should indicate thawing around the edge of the frozen layer to provide an early warning that the permafrost is changing. For new construction, the sensors should be installed in conjunction with the new foundation. It is simpler for a drill rig to access an empty site than to work around an existing foundation and other equipment. However, sensors can be fragile, so once installed, they must be protected from construction activities (Figure 76).

Figure 76. Preparing the foundation for concrete pouring. The white buckets are full of sensor wires. The sensors are already in the conduit in the ground. The wires are in 1-in. Loctite conduit running back to the buckets. The buckets make the wiring more visible to the building crew.

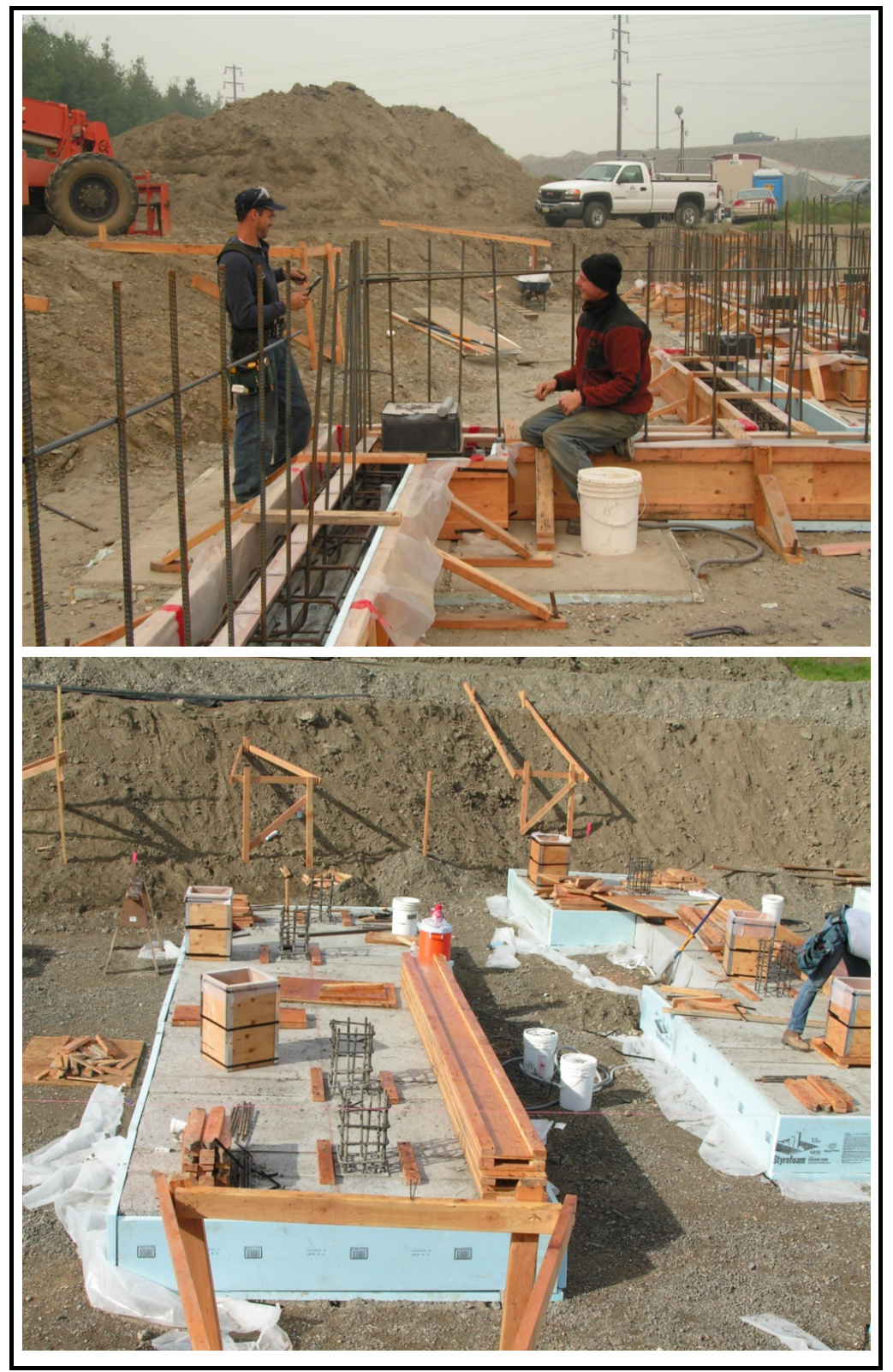


For an existing building, the sensors can be placed around the outside of the foundation. They can also be put under the foundation using a directional drill rig (Figure 77) with caution to avoid any disturbance to existing subsurface utilities while doing the drilling.

Figure 77. A directional drilling rig. Drilling a sensor tube hole under an existing house at the Sustainable Village at UAF.

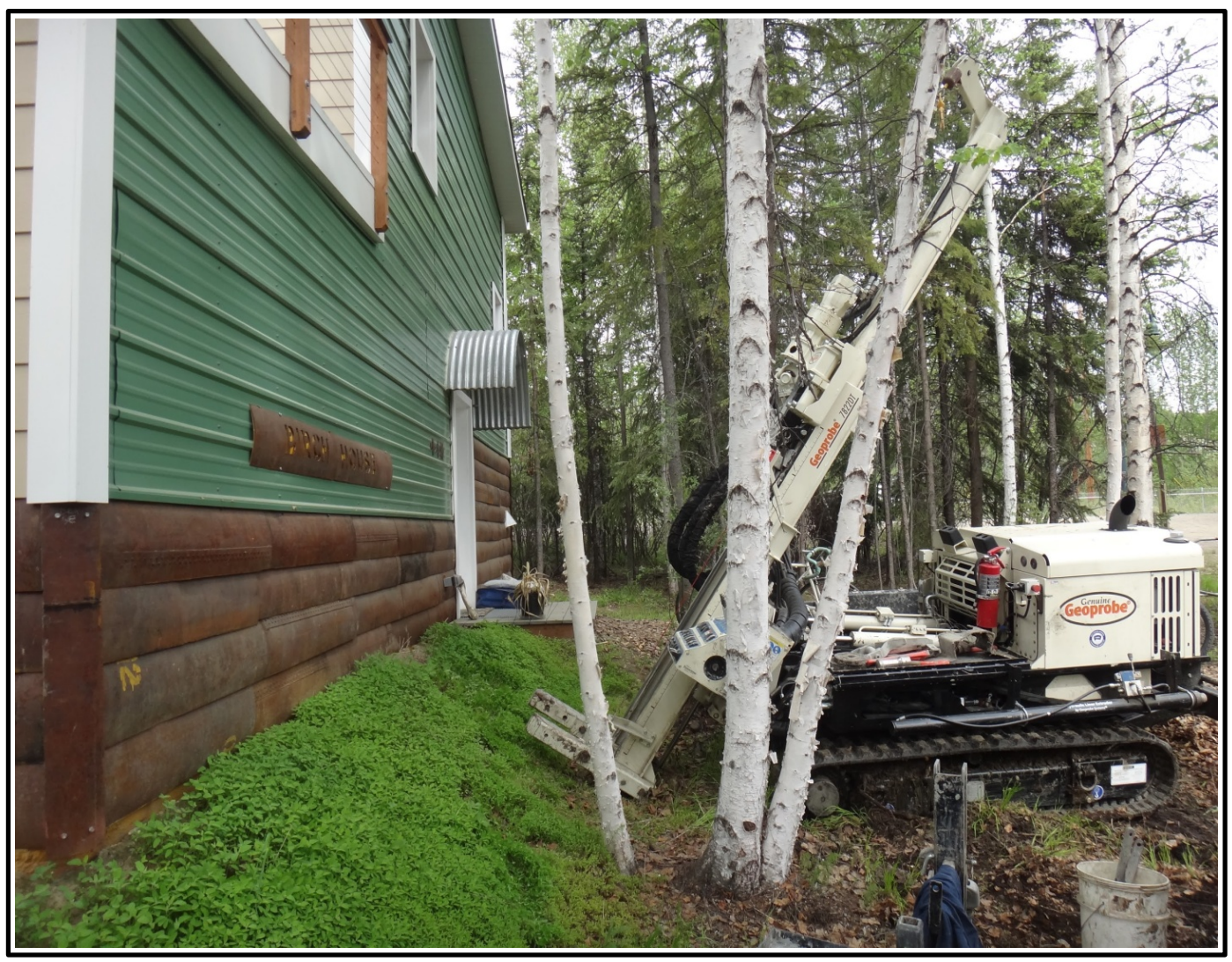

\subsubsection{Data acquisition for EWDS}

\subsubsection{Sensors}

There are a variety of temperature sensors. Table 6 lists the advantages and disadvantages of each generic type. Often, the best choice of sensor is the one that will work with the building automation system (BAS) over the long term. In long-term foundation monitoring, accuracy (i.e., absolute temperature measurements) is not as important as are measurements of changes in temperature. Nevertheless, reliability over time is very important when analyzing changes in temperature. 
Table 6. Temperature sensor types.

\begin{tabular}{|c|c|c|c|c|}
\hline & Accuracy & Reliability & $\begin{array}{c}\text { Power } \\
\text { Requirements }\end{array}$ & $\begin{array}{c}\text { Other } \\
\text { Considerations }\end{array}$ \\
\hline Thermocouples & $\begin{array}{l}\text { Least accurate unless } \\
\text { a specialty type }\end{array}$ & Drift over time & & $\begin{array}{l}\text { Require special wire } \\
\text { that runs all the way } \\
\text { back to the data } \\
\text { collection system }\end{array}$ \\
\hline Thermistors & & Drift over time & $\begin{array}{l}\text { Need a small voltage to } \\
\text { operate }\end{array}$ & $\begin{array}{l}\text { Create heat } \\
\text { Fragile }\end{array}$ \\
\hline $\begin{array}{l}\text { (Resistance } \\
\text { Temperature Device } \\
\text { (RTD) }\end{array}$ & $\begin{array}{l}\text { More accurate than } \\
\text { thermistors and } \\
\text { thermocouples }\end{array}$ & More stable over time & $\begin{array}{l}\text { Need a small voltage to } \\
\text { operate }\end{array}$ & \\
\hline Digital & $\begin{array}{l}\text { Very dependent on } \\
\text { sensors }\end{array}$ & More stable over time & $\begin{array}{l}\text { Often need a small } \\
\text { voltage to operate }\end{array}$ & Can be expensive \\
\hline Fiber Optic & & & & $\begin{array}{l}\text { Expensive data reading } \\
\text { system }\end{array}$ \\
\hline Wireless & \multicolumn{4}{|c|}{ Rely on Batteries to communicate, they are not very useful when buried } \\
\hline
\end{tabular}

Sensors need to be waterproofed in some way, even if the ground is currently frozen or if the string of sensors is housed in a PVC casing. Putting temperature strings in $1 / 2-i n$. PVC casing is helpful in keeping the sensors dry. Broken sensors will be easier to replace if the PVC pipe terminates in an accessible place in the building. However, condensation can be a problem even within a PVC casing, so the sensors should still be waterproofed.

Several companies package waterproofed digital sensor strings that are accurate and have low drift over time. Beaded Streams in Anchorage, AK, sells a customizable digital temperature cable that is designed for installation in harsh climates. Campbell Scientific out of Logan, UT, sells a similar digital sensor string in its CS225-L.

\subsubsection{Data acquisition system}

A temperature collection system that ties into a computer-based BAS has the most potential to be used in the long term. A BAS usually has the capacity to create graphs and deliver trends to a building manager. In addition, the BAS can have an alarm system that alerts the building manager when certain criteria are met. Programming the BAS to alert the building manager when the subsurface temperatures rise to a danger point allows the temperature system to remain running in the background in the long term so that it will still be useful when needed.

In the absence of a useable BAS, a standalone data acquisition system (DAQ) is needed. The DAQ will require quite a bit of thought. It will need a 
consistent power source. Batteries are not an option as a primary power source because they do not last over the long term without an external power source; however, they are useful as a backup power system. The selected DAQ should be simple enough so that a special installer and operator (or at the very least a special operator) is not required. It should also have a simple interface with useable output. Long-term stability is also important.

Both Campbell Scientific and Beaded Streams provide DAQ systems for their sensor strings, both these suppliers have methods to interface their sensors with a BAS.

An ideal system would operate in the background and send trends to a building manager once every 6 months. The trends should be in a graph format that accumulates over time, so that the first delivery would contain data for just 6 months, the next for 1 year, and the next for 18 months, and so on. This will allow the building manager to monitor changes in subsurface temperature over time.

\subsubsection{Data management and analysis}

It is imperative to set up a data management plan for a long-term data collection system before the sensors are installed. The plan will lay out how the system works and who is responsible for it. All of the metadata on the sensors should be included in the data management plan. The plan will help a foundation EWDS serve its purpose in the long term.

Data collection is the simple part of any data project. The analysis and use of the data are important parts of the project. A careful plan for data analysis is needed that lays out when data will be reviewed and who will review the data. A building located on permafrost can affect change to the frozen ground quickly initially. Ideally, data analysis will occur once a month for the first 2 years of building occupation. Depending on the results of the first 2 years' data, a yearly review may be all that is necessary after that.

Additionally, a plan on how the data will be reviewed is necessary. It is important to have an assigned individual to assess data or examine any alarming trends. Because the EWDS is looking for warming trends, a graph that shows changes in temperature over time will probably be the most helpful. Depending on the systems, a BAS could output graphs di- 
rectly; other systems may need programming to output graphs; some systems may only be capable of outputting raw data that someone will have to put into useful graphs.

\subsubsection{Personnel responsible}

Since this is a long-term project with very few tasks to be performed over the course of the year, it is imperative to the program's success to name the person responsible, and to schedule the tasks. The local building manager is probably the best person to perform scheduled data checks because they are normally on site, and they are already familiar with the building's operations and problems. It is likely that the building manager will need some training to perform the analysis. Also, the building manager should have a list of individuals to contact if there are changes to ground temperature that need to be addressed.

\subsubsection{When to act}

The decision to act on changes in ground temperature will be based on the foundation, the permafrost, and changes in temperatures. If the foundation is designed to maintain integrity with some loss of permafrost, or if the permafrost is quite cold to start with, the changes may have to be large to justify action. However, if the permafrost is heavily saturated with near freezing temperatures, then swift, early action may be necessary. The criteria for this decision should be developed during the design phase of a new building. For an existing building, the mitigation criteria should be established before monitoring begins.

If the initial criteria of the EWDS indicates that action is required, the interested stakeholders should convene to review the data. Input from the building manager and the EWDS system should be used to develop an intervention strategy.

Ideally, an intervention strategy will have been created when the foundation was designed; however, there are potentially simple interventions that can help protect the foundation. Planting plants close to the foundation that offer shade to the permafrost in the summer or removing snow from around the foundation in the winter are both simple strategies that might be effective depending on the foundation and the permafrost. Changing surface drainage paths to keep water away from the foundation is another effective strategy. 
If simple strategies are not acceptable, an active cooling system may be necessary. If a cooling system were installed during construction, the next course of action would be to turn the system on and monitor it for changes. It will need to be monitored. The cooling system may not need to run all the time. It would be efficient to run it on a schedule that maintains the permafrost but does not use extra energy to extract excess heat. If there is no installed cooling system, an engineer should study the problem and develop a retrofit cooling system. 


\section{Permafrost Foundation Decision Support System (PFFDSS)}

\subsection{Overview}

The development of the PFFDSS is another task done under this SERDP project. This effort outlines a design guidance for determining or selecting the most applicable foundation for warming and degrading permafrost. The PFFDSS (also referred as DSS) is a web-based tool that allows engineers to harness the expertise developed through our site characterization, geostatistical analyses, and evaluation of foundations to make better-informed selections of foundation types for vertical and horizontal infrastructure on permafrost landscapes.

The tool is intended to be open to all audiences. It will initially lead users through what is called a desktop assessment and then through a field assessment. In the desktop assessment, the user can get an idea of which types of foundations will work for his project, as well as their suitability, risk, and cost based primarily on an initial visit to the site and background information from previous studies relevant to the site location. This desktop assessment will then lead to a field assessment, which consists of data collection through borehole drilling and geophysical surveys (e.g., ERT, CCR, GPR). As the user progresses through the desktop assessment and into the field assessment, data will be progressively added on the building sites. Based on these data inputs, the resulting foundation recommendations will become more precise.

The desktop assessment is broken into First Glance and Detailed Assessments sections. The first glance assessment is intended for users who have not visited the intended location where the structure will be built. Users will indicate the type of structure they would like to build and a general location for the structure. Using this information, the PFFDSS will query geospatial layers that cover the Arctic region to discover terrain type, vegetation type, permafrost extent, and ice content in the site selected. These layers are currently available as GIS data that we have collected over the course of the project, which will be converted to map services that the tool uses.

In addition to GIS sources, the tool leverages permafrost foundation (PF) knowledge-based information, and an "expert" database, all of which are 
implemented in the PFFDSS for this project. Essentially, the expert database contains tables that describe conditions that could be present within the site. Examples of conditions include terrain features, vegetation type, massive ground ice, and subsurface properties such as moisture content or texture of sediments.

By tapping into GIS sources and inputting responses to the questionnaires developed and reviewed by PF experts, the tool seeks to establish the site's relevant conditions. The user can then establish the site's relevant conditions. Once this is established, the tool provides an assessment of difficulty of development using a Development Difficulty Factor (DDF), which we have formulated for the PFFDSS tool.

To assess the appropriate foundation type, the user must complete both the field assessment and desktop assessment. The field assessment includes both planning surveys and an interpretation of the results. Users first upload any survey or other data they already have and determine the sufficiency of those data for determining the appropriate foundation type(s). If insufficient, users can plan where transects for geophysical surveys and boreholes should be done to ensure data sufficiency. Once they have collected these additional data, users upload it to the system and interpret it, indicating graphically where permafrost, ground ice, and various geologic materials (such as unfrozen gravel layers) occur that lend well to foundation development. The tool creates a virtual picture of the subsurface using these data and links the site analyses to the conditions in the expert database. With the field data interpreted, the tool provides a foundation type assessment, evaluating the suitability, risk, and cost of each of several foundation types for the infrastructure and intended site.

The PFFDSS is aimed at multiple users:

- Engineers new to permafrost conditions. Students and engineers new to design atop permafrost can use the tool to learn about issues unique to building on permafrost and better frame and inform their approach to site assessment and foundation design selection.

- Experienced Engineers. Experienced engineers will find the data integration capabilities of the PFFDSS useful for quick, efficient, and highly visual assessments of proposed sites.

- Engineering/Research Offices. The PFFDSS provides a stable, central location for long-term storage and archiving of baseline data for use in further studies and future design work. 


\subsection{PFFDSS technological design}

The DSS facilitates a desktop assessment, field data assessment, and a foundation type assessment in each site assessment project. The user is lead through these assessments step-by-step. The DSS includes several algorithms that integrate the data provided by the user and online data to estimate the stability of the subsurface and potential thaw settlement. Furthermore, the DSS uses the conditions provided for the site to run the foundation type assessment, by estimating risk and cost for multiple foundation types. Appendix $\mathrm{C}$ illustrates and describes the structure of the interface and the general system architecture, and includes the user guide and instructions. The following sections describe the algorithms the DSS runs to accomplish these tasks.

\subsubsection{Desktop assessment process}

Figure 78 shows the desktop assessment process. The algorithm first requires the user to specify the area of assessment by sketching on the map. Then, the algorithm asks the user to provide information on the intended structure and on observed conditions on the site related to topography, vegetation, warning signs of permafrost presence and thawing, and the presence and condition of existing structures.

The algorithm adjusts the five-part DDF based on answers to the desktop assessment questions. The intent of the DDF is to point out the factors that typically contribute to any issues in construction of structures on permafrost and to roughly estimate the difficulty that each of these factors will present given the information the user provided in the DSS. The five factors are material type, ice content, vegetation, cost, and resiliency.

Each member of the DDF has a score that is set up to range between $o$ and 10, with an uncertainty bar that narrows as more information is provided about the site. The PFFDSS reference foundation type is a slab-on-grade foundation that supports a heated structure. The DDF is set up to have a score of 5 in all members for this foundation type given no information is known about the site. As the user answers more questions, the scores for the five members would either increase, indicating a higher difficulty, or decrease, representing a lower difficulty value. For example, the cost factor is reduced by 1 if a user identifies an unheated structure. 
Thus, the uncertainty bar reflects how much is known about the site. Whether the user answers yes or no to wanting a heated structure, for example, results in a reduction of the uncertainty bar for the cost factor by o.1. Each answer the user provides leads to a similar narrowing of the uncertainty bar. At the end of an assessment, the bars still have some width, indicating that it is impossible to know the exact difficulty to be expected.

Figure 79 shows how answering each question in the desktop questionnaire influences the DDF. The team of permafrost experts developing this project have reviewed and agreed upon these adjustments. 
Figure 78. Conceptual model of PFFDSS Desktop Assessment Algorithm.

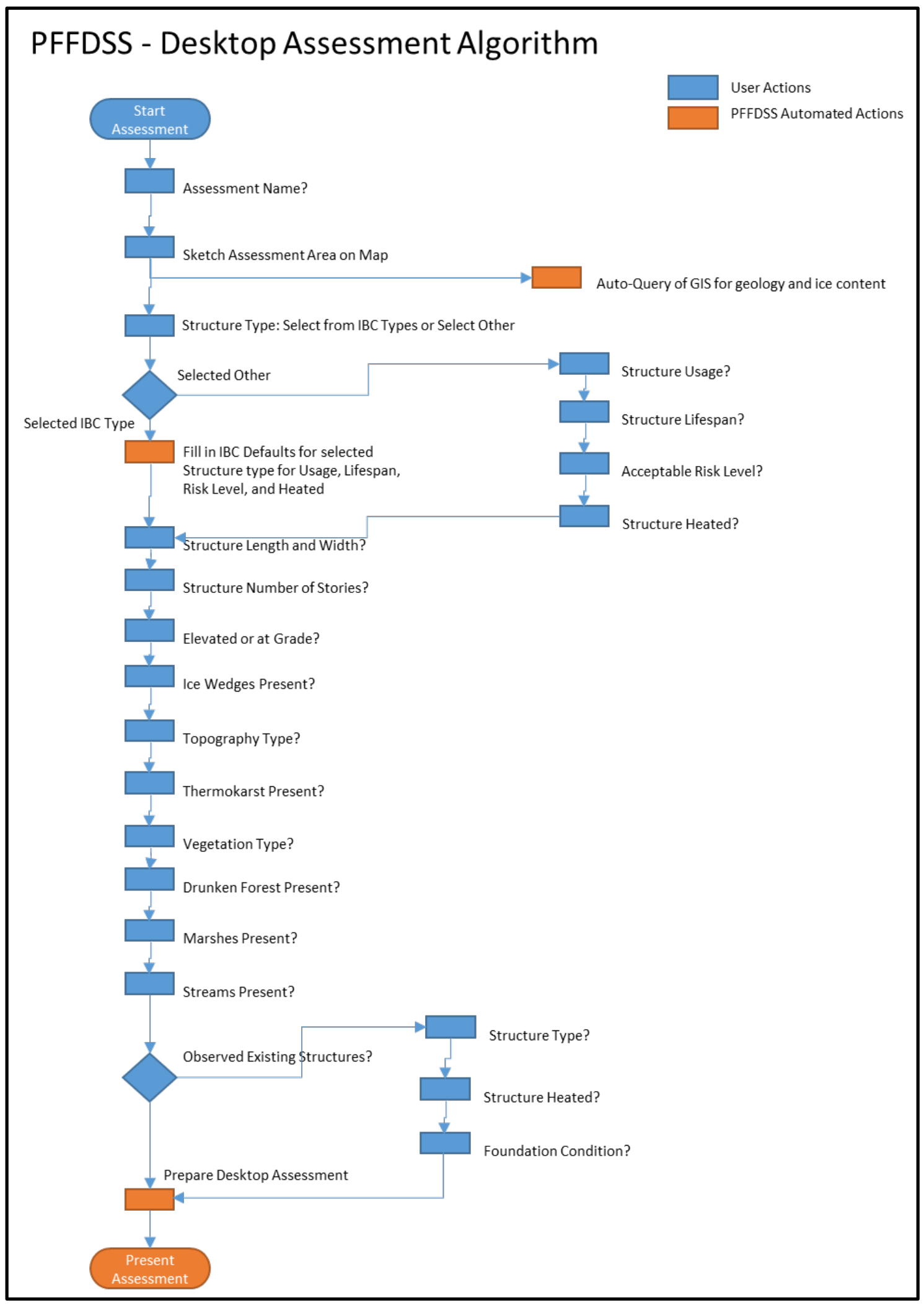


Figure 79. Variables used in estimating the DDF.

\section{PFFDSS - Development Difficulty Factor Influencers}

\begin{tabular}{|c|c|c|c|c|c|c|}
\hline Influencer & Condition & $\begin{array}{l}\text { Material } \\
\text { Type }\end{array}$ & $\begin{array}{l}\text { Ice } \\
\text { Content }\end{array}$ & Vegetation & Cost & Resiliency \\
\hline Structure Usage & Warehouse & No effect & No effect & No effect & +1 & No effect \\
\hline Structure Usage & Residential & No effect & No effect & No effect & +2 & -2 \\
\hline Structure Usage & Offices & No effect & No effect & No effect & +1 & -2 \\
\hline Structure Type & Heavy & No effect & No effect & No effect & No effect & +2 \\
\hline Structure Usage & Hospital & No effect & No effect & No effect & +4 & +4 \\
\hline Structure Usage & Power Plant & No effect & No effect & No effect & +3 & +4 \\
\hline Lifespan & $>30$ years & No effect & No effect & No effect & +2 & +2 \\
\hline Number of Stories & $>2$ stories & No effect & No effect & No effect & +2 & +2 \\
\hline Foundation Elevated & Raised & No effect & No effect & No effect & +1 & +1 \\
\hline Foundation on Grade & Raised & No effect & No effect & No effect & +3 & +3 \\
\hline Acceptable Risk of Failure & High & No effect & No effect & No effect & -1 & -1 \\
\hline Acceptable Risk of Failure & Medium & No effect & No effect & No effect & +2 & +2 \\
\hline Acceptable Risk of Failure & Low & No effect & No effect & No effect & +4 & +4 \\
\hline Heated & Structure is Heated & No effect & No effect & No effect & +3 & +3 \\
\hline Heated & Structure not Heated & No effect & No effect & No effect & -1 & No effect \\
\hline Ice Wedges & Present & No effect & No effect & No effect & +2 & +2 \\
\hline Topography & Flat & No effect & No effect & No effect & +1 & No effect \\
\hline Topography & Steep & No effect & No effect & No effect & +1 & No effect \\
\hline Thermokarst & Present & No effect & No effect & No effect & +4 & No effect \\
\hline Drunken Forest & Present & +3 & +3 & +4 & +3 & +3 \\
\hline Vegetation Type & $\begin{array}{l}\text { Low elevation Black } \\
\text { Spruce }\end{array}$ & +3 & +3 & +4 & +3 & +3 \\
\hline Vegetation Type & $\begin{array}{l}\text { High elevation Black } \\
\text { Spruce }\end{array}$ & -2 & No effect & No effect & No effect & No effect \\
\hline Vegetation Type & White Spruce & -1 & +2 & +1 & +2 & +3 \\
\hline Vegetation Type & Deciduous & -1 & No effect & No effect & -1 & -1 \\
\hline Vegetation Type & Tussock & +4 & +4 & +4 & +4 & +4 \\
\hline Vegetation Type & $\begin{array}{l}\text { Early Succession } \\
\text { Boreal Forest }\end{array}$ & No effect & No effect & No effect & +2 & +1 \\
\hline Marshes/Standing Water & Present & +2 & +2 & +3 & +1 & +2 \\
\hline Streams & Present & No effect & No effect & No effect & +1 & +1 \\
\hline Existing Structure & Light Structure & No effect & No effect & No effect & -1 & -1 \\
\hline Existing Structure & Heavy Structure & No effect & No effect & No effect & +1 & +1 \\
\hline Existing Structure & Heated & No effect & No effect & No effect & +1 & +1 \\
\hline Existing Structure & Failing Condition & +3 & +3 & No effect & +4 & +3 \\
\hline Existing Structure & Failed Condition & +4 & +4 & No effect & +4 & +3 \\
\hline
\end{tabular}




\subsubsection{Field assessment process}

The PFFDSS recommends in all cases that at least some field data be collected to establish the subsurface conditions of the site. The field assessment process integrates the data collected. Figure 80 shows the algorithm that the DSS uses to guide the user through the field assessment process.

Figure 80. Conceptual model of PFFDSS Field Assessment Algorithm.

\section{PFFDSS - Field Assessment Algorithm}

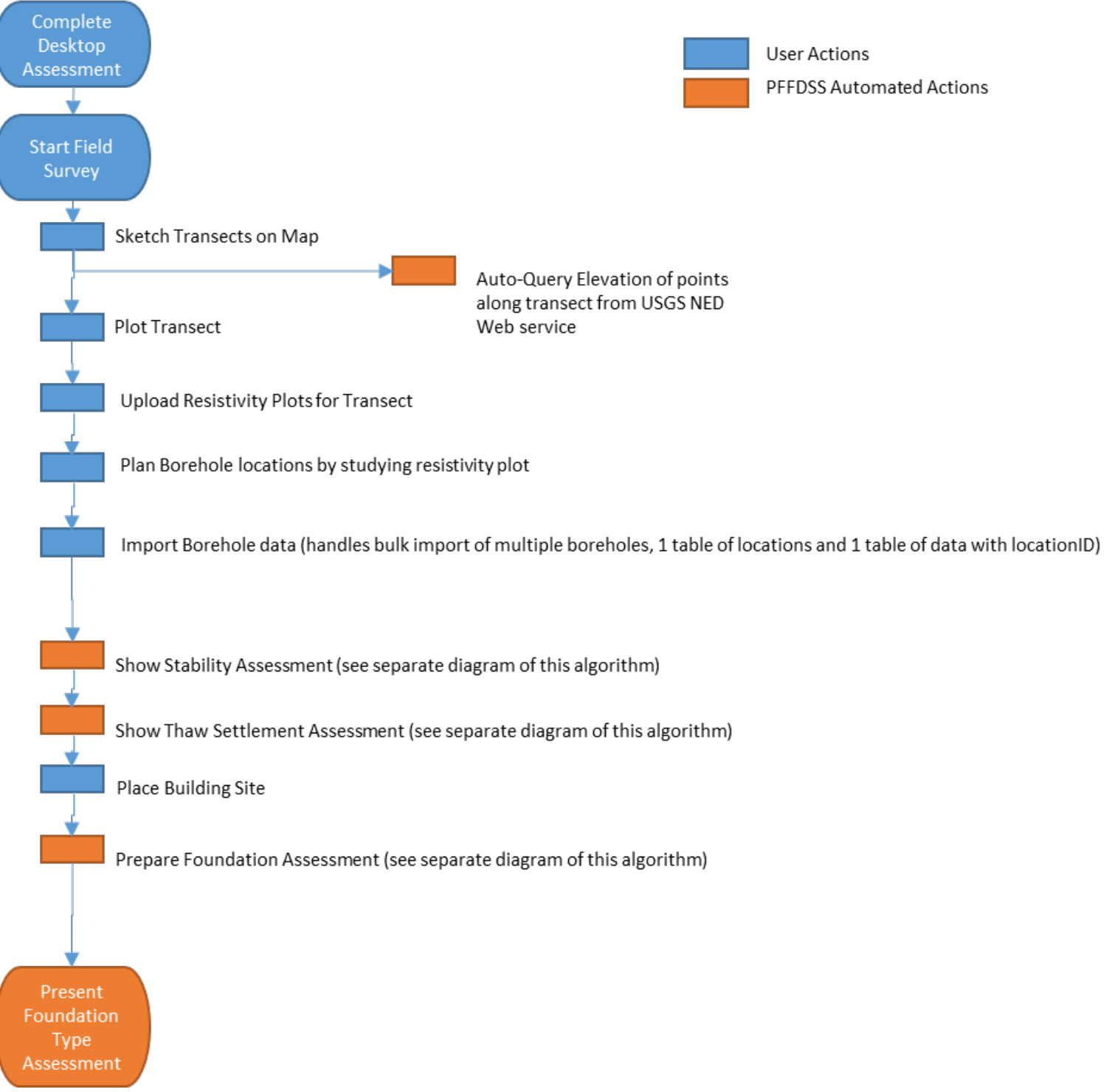


Many of the steps in the process are user-driven (e.g., drawing transects, planning borehole locations, and importing and assessing resistivity plots). The DSS completes one query and three automated assessments in the process: elevation query, stability assessment, thaw settlement assessment, and foundation type assessment. The following sections describe the algorithms for these automated methods.

\subsubsection{Elevation query}

Much of the field survey process is driven by the specification of transects along which resistivity data and borehole samples are collected. As the field assessment diagram shows, when the user sketches a new transect, the DSS queries the U.S. Geological Survey (USGS) National Mapper web service for elevations of points along the transect. Figure 81 shows the sketched transect and the resulting elevation profile. It is important to note that the USGS

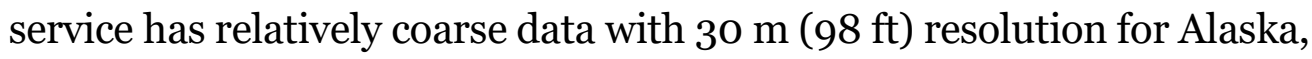
which of course should be superseded when elevation data from either the resistivity plots or borehole data assessments are collected.

\subsubsection{Stability assessment algorithm}

When borehole data have been uploaded, the DSS can do a stability assessment. This includes two main steps:

\section{Estimating the stability of each sample layer in the borehole}

core data. This process uses three parameters (whether the sample is frozen, soil type, and gravimetric moisture content) to estimate the potential stability index (PSI) based on a lookup table developed by the project team. Appendix A includes the lookup table.

2. Creating a swath on the map to show stability. This process uses the depth to stable layer information at each borehole to create an estimated swath of stable area along the transect. The width of the swath is based on the homogeneity of the stable depth of the layers. For example, if the stable depth for all boreholes in a borehole neighborhood is approximately the same, then the swath will be a maximum width of $50 \mathrm{~m}$ (164 ft). If the stable depth is highly heterogeneous from borehole to borehole, then the width may be reduced to a minimum of $2 \mathrm{~m}(7 \mathrm{ft})$. The flowchart for stability assessment algorithm (Figure 82) details the conditions for swath width. 
Figure 81. PFFDSS field assessment survey planning.

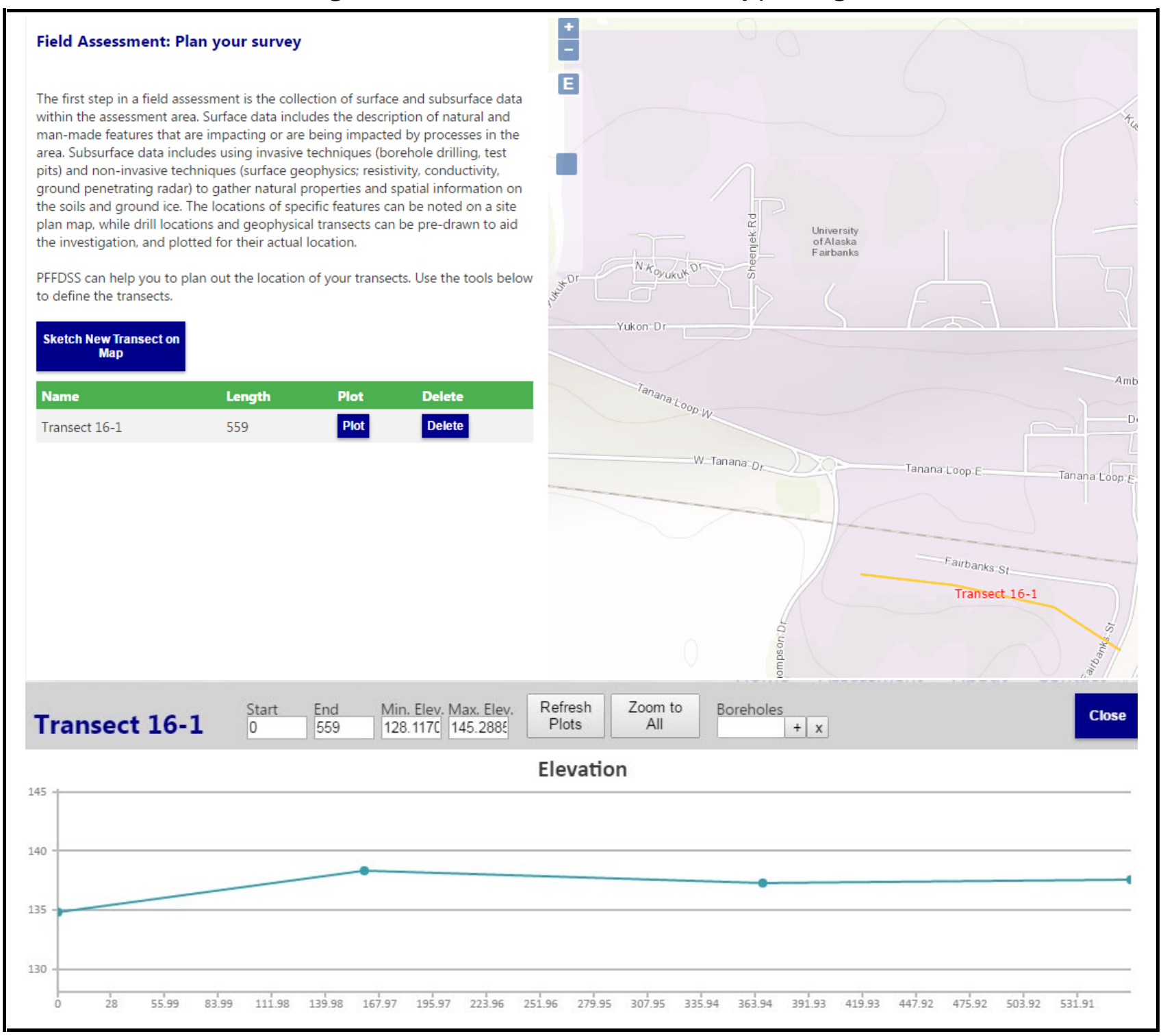


Figure 82. Conceptual model of PFFDSS Stability Assessment Algorithm.

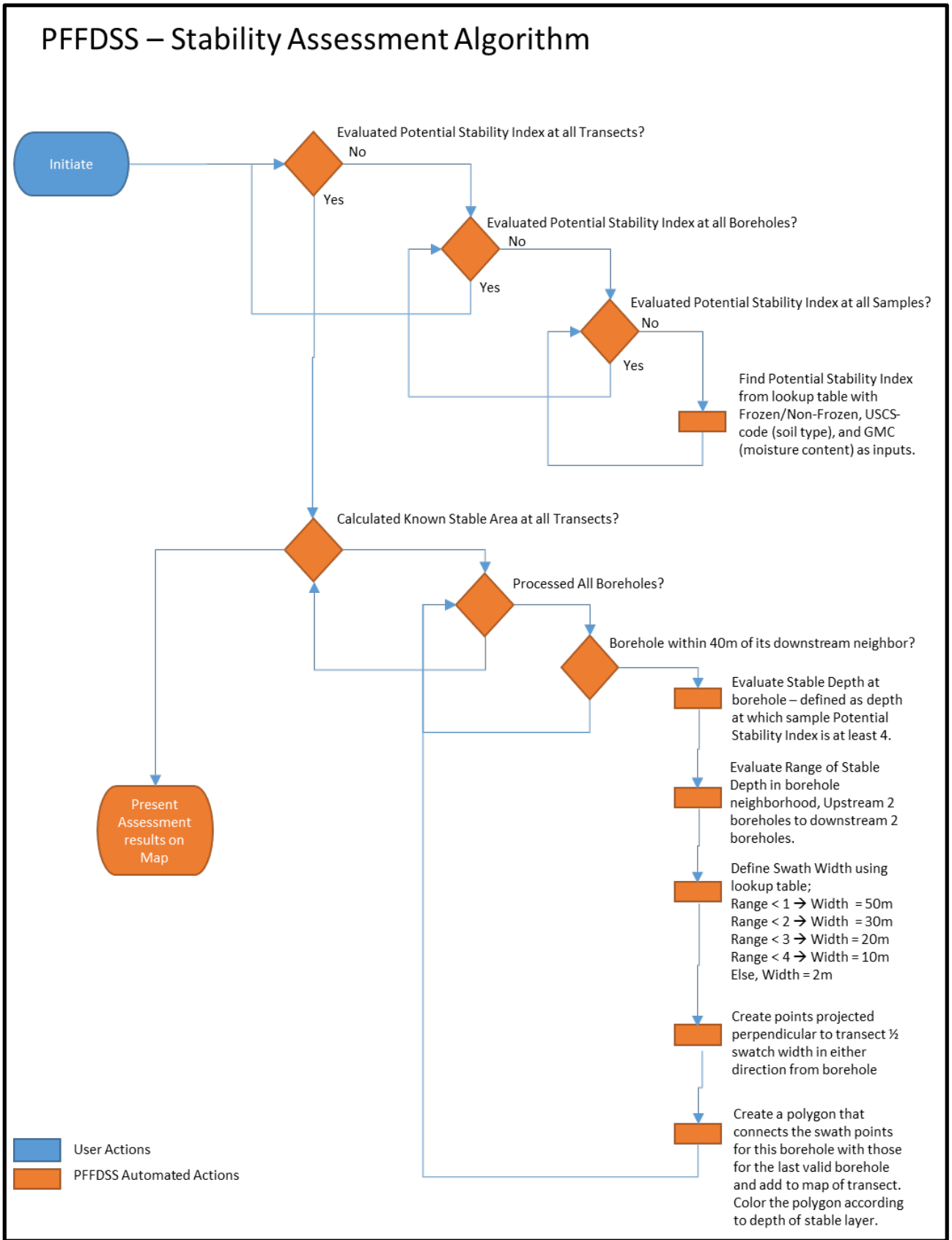

The swath is only created in areas where the boreholes are a close enough together to give enough confidence to interpolate the stability from borehole to borehole. The criterion for "closeness" is a maximum of $40 \mathrm{~m}$ $(131 \mathrm{ft})$ between boreholes.

Figure 83 details an example of a set of boreholes along a transect. The stable depth is shown for each borehole. The left four boreholes are valid for swath determination as they are within the $40 \mathrm{~m}(131 \mathrm{ft})$ criteria. 
Figure 83. Borehole stability indices (composited) along a transect.

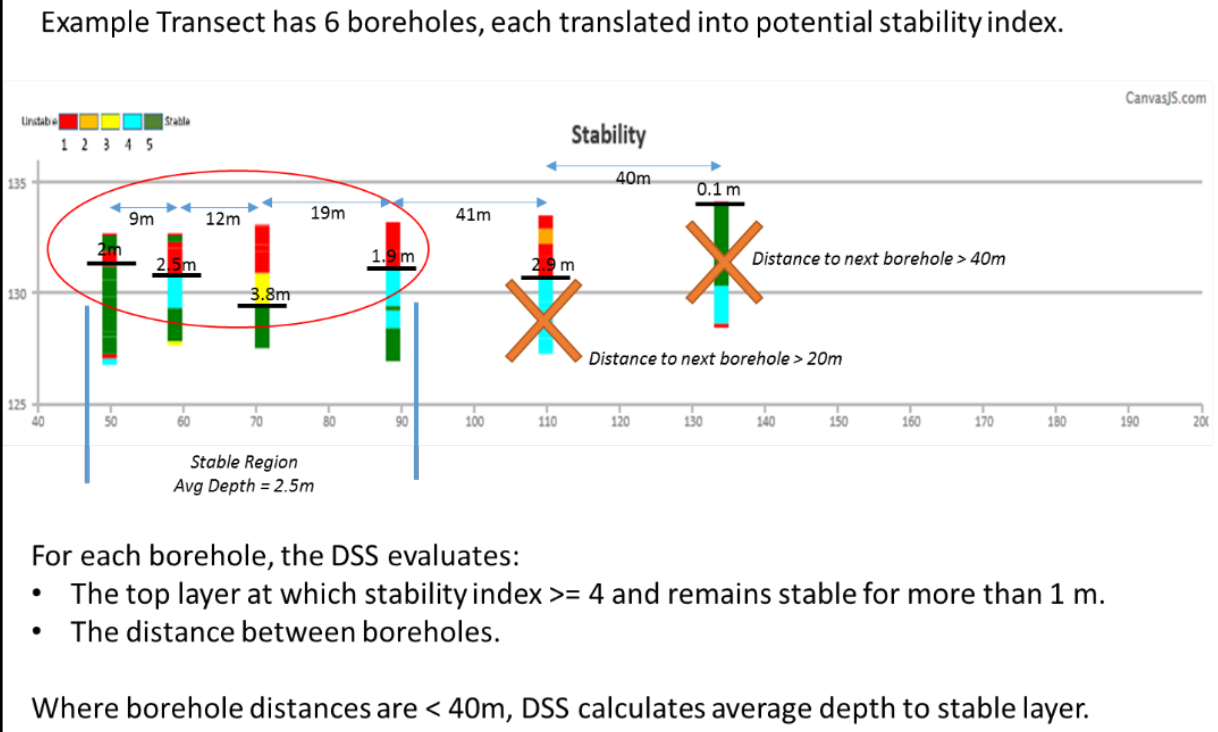

Figure 84 shows a complete stability assessment on the map. This case uses the boreholes from our CCHRC study; they are approximately $3 \mathrm{~m}$ (10 ft) apart and therefore are all considered valid by the algorithm. Note that the swatch width gets wide in areas where the stable depth is consistent from borehole to borehole and narrows where the stable depth changes rapidly from borehole to borehole.

\subsubsection{Potential borehole thaw settlement algorithm}

Potential thaw settlement estimates the subsidence the land surrounding a borehole would experience if the specified building were constructed at that spot. The diagram shown in Figure 85 describes the process for estimating potential thaw settlement. The process works through all boreholes in the assessment, estimating subsidence for each sample layer in the borehole. Subsidence is defined as

$$
\text { Subsidence }_{\text {Total }}=\text { Subsidence }_{\text {Material }}+\text { Subsidence }_{\text {Thaw }} \text {. }
$$

The material subsidence component is defined as the sample layer depth multiplied by a compression factor, which is a function of the soil type.

The thaw subsidence component is evaluated based on a decision tree described in the flow chart. If the sample is all ice, then thaw subsidence is the full depth of the sample layer. If the sample is not frozen, then the thaw subsidence is zero. Otherwise, the thaw subsidence is calculated as the sample layer depth divided by the moisture content. 
Figure 84. Depth to stable layer, depicted in swaths. Swath width is calculated based on subsurface data and variability among borehole samples.

\section{Stable Area Swath}

$<1.0 \mathrm{~m}$ to Stable Layer

$1-2 m$ to Stable Layer

$2-3 m$ to Stable Layer

$3-4 m$ to Stable Layer

4-5m to Stable Layer

$>5 \mathrm{~m}$ to Stable Layer

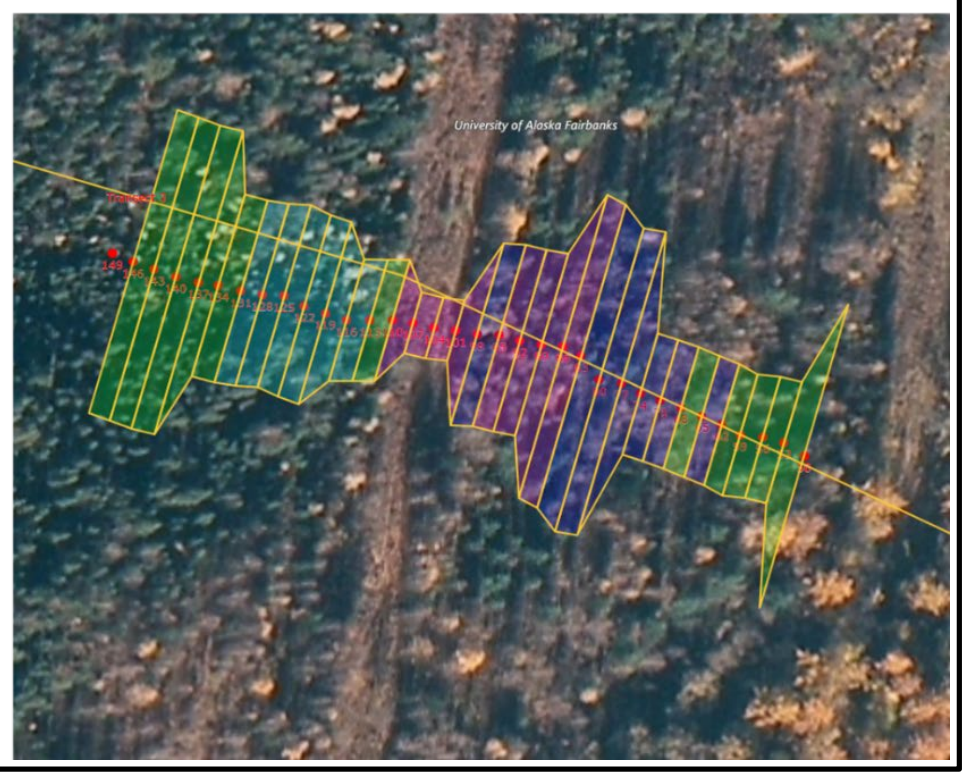


Figure 85. Conceptual model of the PFFDSS Potential Borehole Thaw Settlement Algorithm.

\section{PFFDSS - Potential Borehole Thaw Settlement Algorithm}

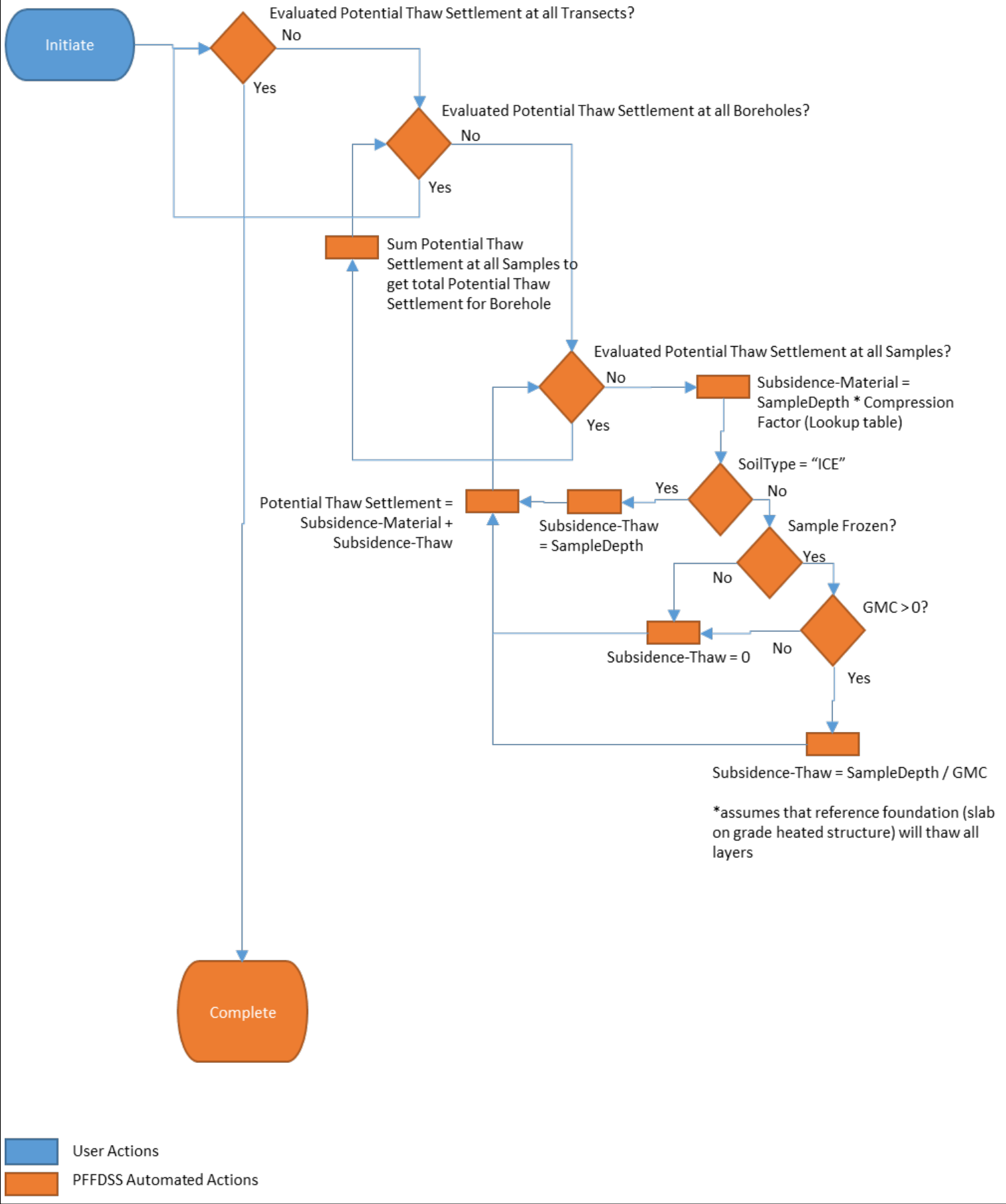




\subsubsection{Potential thaw settlement area assessment algorithm}

The thaw settlement algorithm described above estimates potential settlement on a borehole-by-borehole basis. The flowchart in Figure 86 shows how these data are used to estimate a swath of potential thaw settlement similar to the stability assessment described above. The algorithm works very similarly to the stable area algorithm, with the stable depth being replaced by the potential thaw settlement metric.

Note that this assessment is run before the user specifies a foundation type that they would like so the reference foundation type (slab-on-grade with heated structure) is used. It is assumed that this foundation type will effectively thaw all layers in the borehole.

\subsubsection{Value of swath analysis}

The thaw settlement and stability assessments help the user to understand the regions in their assessment area that are mostly likely stable and those that are likely to require significant foundation work. The value of the swath analysis is that it places these estimates right on the map, so that the user can conduct the following step of placing the proposed building on the map with as much information as possible. If the user has freedom in choosing the building's location, the swath analysis can help them save significantly on foundation costs simply by avoiding unstable areas.

\subsubsection{Foundation type risk and cost assessment process}

Once the user has placed the building on the map, a foundation type assessment is possible. The foundation type assessment evaluates the following foundation types:

- Slab-on-Grade

- End-Bearing Piles

- AdFreeze Piles

- Over-Excavation

- Refrigeration.

The assessment evaluates the risk and cost associated with the placement of the intended building in the intended location with the foundation type in question. The flowchart shown on Figure 87 describes the algorithm for evaluating risk and cost. 
Figure 86. Conceptual model of the PFFDSS Potential Thaw Settlement Area Assessment Algorithm.

\section{PFFDSS - Potential Thaw Settlement Area Assessment Algorithm}

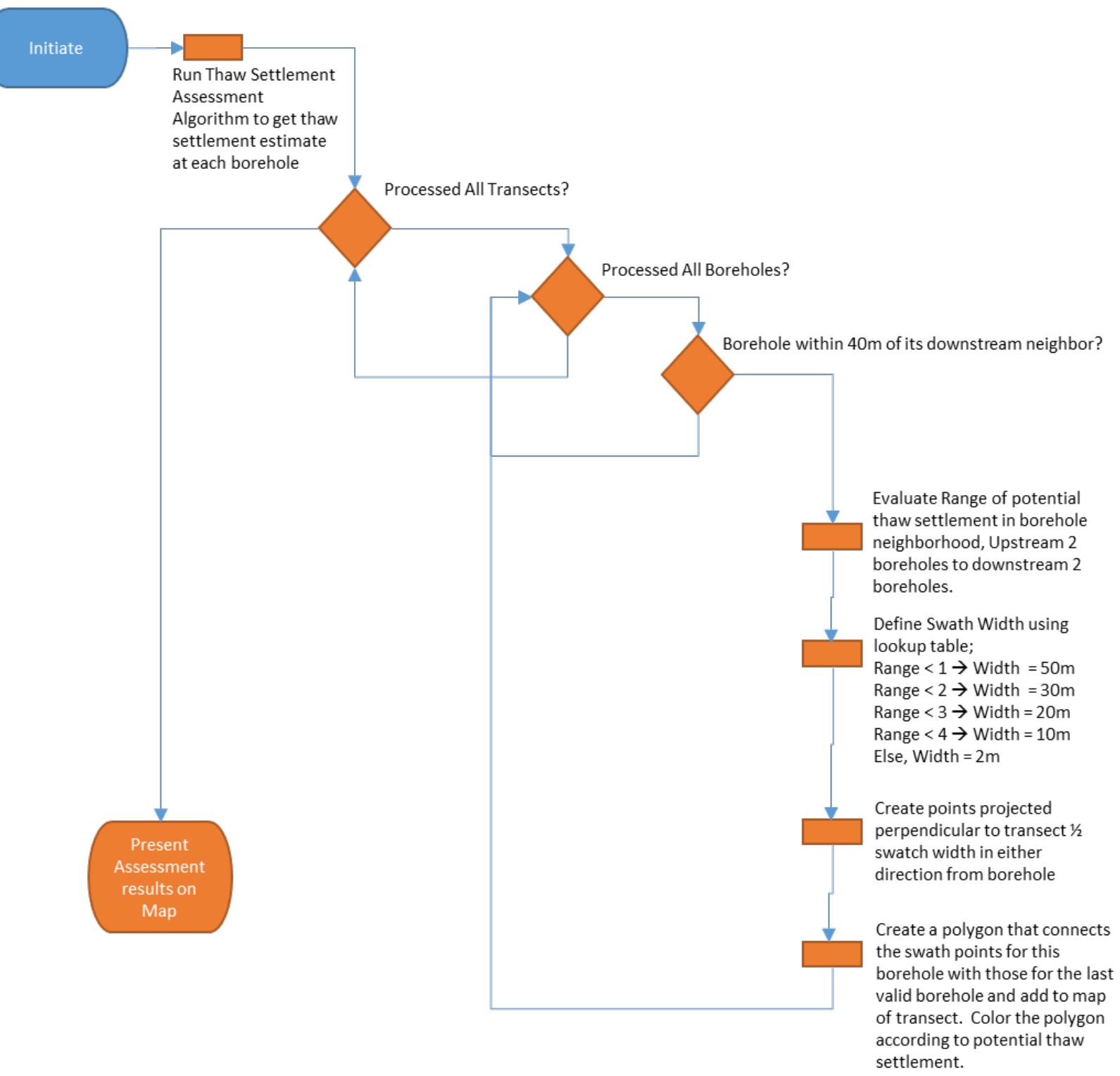


Figure 87. Conceptual model of PFFDSS Foundation Type Risk and Cost Assessment Algorithm.

\section{PFFDSS - Foundation Type Risk and Cost Assessment Algorithm}

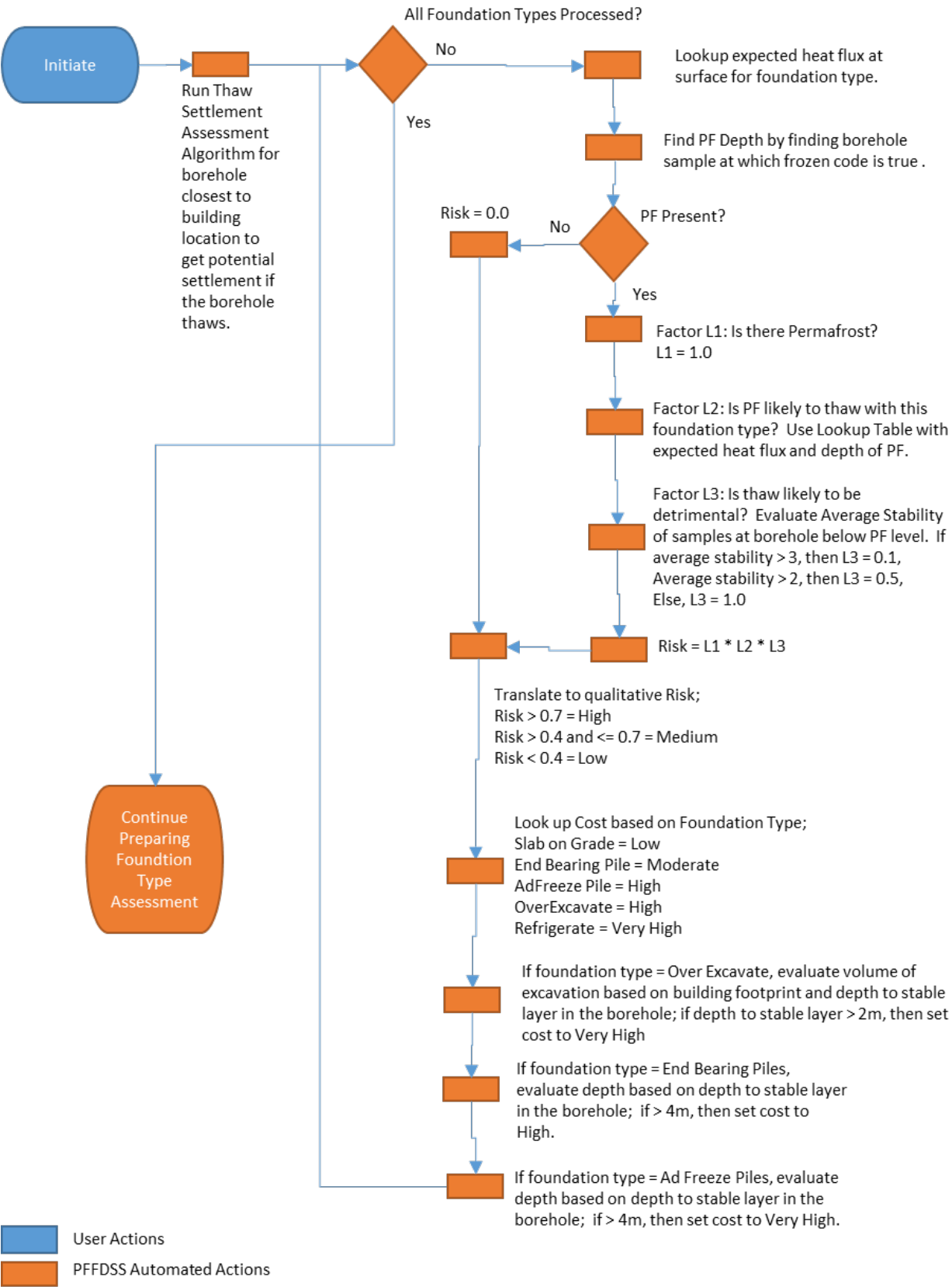




\subsubsection{Risk assessment algorithm}

Risk is defined as

$$
\text { Risk }=\mathrm{L} 1 \text { * L2 * L3, }
$$

in which

- L1: Is permafrost present at the intended site? - this is determined by evaluating the samples from the borehole data. If one is frozen, then L1 $=1.0$. Otherwise $\mathrm{L} 1=0.0$.

- L2: If present, is the permafrost likely to thaw?-this is determined through a lookup table that considers the depth of the permafrost and the heat flux generated by the foundation type. L2 is numeric and ranges between 0 and 1 , where 1 indicates very likely to thaw while 0 indicates not very likely to thaw.

- L3: If the permafrost thaws, will it be detrimental to the building?-this is determined currently by evaluating the average stability of the layers of soil at and below the ground ice level. The algorithm evaluates the average stability in the borehole for all samples that are frozen. If the average is above 3 , then L3 = 0.1 (low risk); if the average is between 2 and 3 , then L3 $=0.5$; If the average is below 2, then L3 $=1.0$ (high risk).

In a final step, the risk value is converted to a qualitative scale as follows:

- If Risk > 0.7, Risk Score = High;

- If Risk $>0.4$ and Risk <= 0.7, Risk Score = Medium;

- Otherwise, Risk Score = Low.

\subsubsection{Cost assessment algorithm}

The cost estimate is a categorical scale of low, moderate, high, and very high. The assessment is based on foundation type as follows:

- Slab-on-Grade-Low.

- End-Bearing Pile-Moderate; if the depth to the stable layer in the

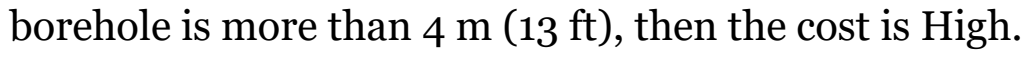

- AdFreeze Pile-High; if the depth to the stable layer in the borehole

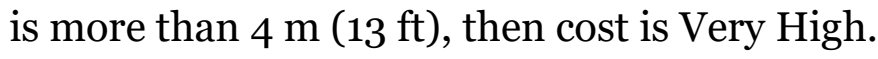

- OverExcavate-High; if the depth to the stable layer in the borehole is more than $2 \mathrm{~m}$ ( $7 \mathrm{ft}$ ), then cost is Very High. The tool evaluates the total volume of excavation for this foundation type during the assessment, defined as

Excavated Volume $=$ Length ${ }^{*}$ Width ${ }^{*}$ Depth to Stable Layer.

- Refrigerate: Very High. 


\subsection{Current implementation (2017)}

As of 2017, the PFFDSS is currently a fully constructed and functioning prototype, in which all three assessment phases are in place and logically linked. The system is considered to be an affirmative proof-of-concept and a solid foundation with room for continued refinement and expansion. The complex nature of the analysis of permafrost conditions, coupled with the pure novelty of the approach, have led us to believe that the prototype PFFDSS is not yet suitable for fully vetted site assessments. A reliable, practical utility for a broad user base will come as a result of iterative, long-term testing, refinement, and expansion, leveraging progressive feedback from willing testers and beta-users.

The PFFDSS currently facilitates an overall prototype site assessment with steps and algorithms for Desktop Assessment, Field Survey, and Foundation Type Assessment modules. Algorithms are incorporated that evaluate the DDF, stability of soil layers at the site, and potential thaw settlement at the building site if a "reference foundation" is used. Our reference foundation is based on a slab-on-grade, heated structure. The algorithm for Foundation Type Assessment is implemented to compare five foundation types against the data from the site depicting permafrost conditions, and to estimate cost and risk for each option. Algorithms were developed in consultation with the entire project team, which reached an expert consensus on all analytical methods and logical results.

The PFFDSS is designed to accept both geophysical transect and borehole sample datasets by integrating and displaying the information in a vertically-aligned transect chart of elevation/topography data. The system is designed to provide maps of spatially explicit resistivity values and of interpreted soil type and stability, and an analysis of potential thaw settlement. A benefit of this approach is that users can aggregate all of their data in a single location and keep track of multiple sites as they evaluate foundation types in the design process.

This web-based tool included the GIS data sources that inform the desktop assessment such as surficial geologic features and ground ice content. The geologic features layer is comprised of digitized U.S. Geological Survey (USGS) quad maps covering much of the region around Fairbanks, AK. These data are compiled from the product of surveys conducted by Péwé (1975), which contain a moderate level of detail. Detailed, reliable surficial geology data are largely unavailable throughout permafrost-affected parts of 
Alaska. As a result, Desktop Assessments must be undertaken without the benefit of these data in most areas. The ground ice content dataset does cover the entire region, but these rough estimates are at coarse resolution for a parameter that is markedly variable spatially. Also, the ground ice content dataset is highly critical for effective site assessment and is extremely difficult to estimate with accuracy using surface proxies, as this dataset has. These GIS-based ground ice data should therefore only be used as a rough guide within the Desktop Assessment. The DSS makes this clear to the user.

The strengths of the current version of the PFFDSS are

- A simple step-by-step interface to introduce engineers without permafrost experience to the important factors and considerations in PF design.

- A partitioning of the assessment process into desktop and field surveys, which allows the user to refine the list of specific locations within the site, and to focus costly field data collection transects after a walking survey of the site.

- A central location for users to aggregate and integrate their data.

- Assessment algorithms that reflect the consensus of the expert team and, as such, that offer a theoretically-sound, technically valid point of embarkation for future development and refinement.

- Innovative methods for presenting results that help the user understand their data. (An example is swath analysis, which interprets the borehole sample data into a map-based surface of depth to a stable layer in the subsurface and a map-based surface of potential thaw settlement if a reference foundation type [slab-on-grade heated structure] were built there.) 


\section{Conclusions, Recommendations, and Future Work}

\subsection{Conclusions}

\subsubsection{Site characterization}

This project has advanced a formal geostatistical methodology to analyze site characterization data. In this effort, we developed a methodology for storing geospatial field data in such a way that it can be displayed in a GIS format and remotely accessed for geostatistical analysis by using the open source software "QGIS" (OSGeo 2018). Geospatial data for surface terrain features, ground resistivity, and borehole data used in characterizing permafrost conditions are stored within QGIS and accessed by the statistical package " $R$ " (The R foundation 2018) for analysis.

This methodology uses a Bayesian Gaussian process model approach to create a map of subsurface permafrost conditions and to optimize the use of borehole core data. Unique surface terrain features associated with permafrost are applied to make an initial estimate of subsurface permafrost conditions. Variations in ground resistivity data correlated with the surface terrain feature estimates of subsurface permafrost conditions, combined with past experience, are incorporated to update the subsurface permafrost map. We then used the subsurface permafrost map to select the most promising locations for a borehole to update the subsurface permafrost map and to reduce the uncertainty in mapping subsurface conditions. The newly updated map would provide the information necessary to select the next borehole location to further improve the subsurface permafrost map until uncertainty levels in the map are within acceptable limits.

Data from the CCHRC measurement site (pertaining to surface terrain features, ground resistivity, and borehole core analysis) were uploaded into QGIS. A preliminary geostatistical analysis of the data was completed to estimate the depth to permafrost using the Bayesian Gaussian process model. From this analysis, it became evident that estimates of uncertainty that we derived from the Gaussian process model could be used to determine whether it is worth the cost to drill additional boreholes. This relationship advanced the investigation toward its ultimate goal of providing sound technical guidance for the optimized investigation of permafrost 
ground ice, which was critical to ensure sound, cost-effective design and construction in a warming climate.

\subsubsection{Foundations}

The first iterations of subfoundation data collection at the CCHRC RTF experienced some difficulties that resulted in mixed outcomes. We concluded that these difficulties could have been resolved if there had been a clear plan for the data from the start before the instruments were installed. A clear plan would have made certain that sensors were installed in critical spots, and that they extended into the permafrost. This plan would have also involved a schedule for data review that would have corrected (or eliminated) error-prone data points, thereby disallowing continued error in data collection.

Specifically, while there are many sensors under the building, none under the structure were providing information on the temperatures below the foundation. This was partly due to sensor failures, but more importantly, was due to the lack of location information on these sensors. It is unknown if any of the temperature sensors under the basement were even installed near the permafrost. It was found that many of the sensors under the RTF had failed while the ones outside of the foundation footprint continued to function. Furthermore, the baseline sensors outside of the footprint were installed in a conduit casing, which likely protected the sensors from water infiltration, whereas the sensors under the foundation were placed directly in the ground. Since water presumably infiltrated into the sensors' wiring, causing the sensors under the foundation to fail, we concluded that installation in conduit protected the sensor wiring better than does installation directly in the ground.

The information gleaned from the original RTF data system informed the process of installing sensors under the building addition and the Sustainable Village at UAF. Each of those projects started with a set plan and a data management plan designed with explicit project details and the sensor layout in one document. The data management plan specified a responsible individual who checks the data and arranges for adjustments, as necessary. We have concluded that the greatest challenge facing a building sensor system is not the placement of sensors or the data-logging equipment, but the management of data over time. 
Based on the experience with the systems installed at the RTF, at the building addition, and at the Sustainable Village, the use of subsurface temperature strings seemed to be the most informative and useful way to determine subsurface thawing conditions in permafrost. The initial placement and location of these sensors can best be determined through modeling efforts.

Developing an EWDS has been in progress at CCHRC since 2006 when the RTF was originally built. This project has afforded researchers an opportunity to explore the progress of this EWDS development. This accumulated experience has led to the current system for collecting and archiving the temperature data into a context that provides the building manager/engineer useful with information. A distributed temperature sensor, which was not originally part of the proposal for this project, was also deployed under one of the structures at the Sustainable Village. This sensor was tested during the winter of 2015 - 2016 for its effectiveness in identifying locations of thermal bridging, and for determining the optimal placement of an EWDS. Lastly, as the EWDS was being developed, the system incorporated a process that would provide an end product, with reliable information that would adequately detect subsurface thermal conditions that may pose a threat to structures. Finite-element thermal modeling should be employed to understand where critical locations exist for early warning detection installation.

\subsubsection{Decision support system}

The current PFFDSS is operational. The following tool components continue to be developed:

- The data model and database have been created and populated with an initial case study using the CCHRC test site data.

- The GIS data sources have been identified that identify terrain type, ice content, permafrost extent, and vegetation type.

- The user interface is designed to help the user navigate the system. Appendix C illustrates the structure of the interface.

- The site characterization data are loaded to the DSS expert database and uploaded in tandem with the user interface development to assess the navigation process.

- The tools are implemented for uploading survey and borehole data.

- The geostatistical algorithms are added to the user interface when completed to aid in interpreting new survey data from users. 
- Case studies two and three are implemented as site data are acquired and used to validate the DSS.

Review and assessment of related Russian literature was compiled for this study into an annotated bibliography (Appendix B). These included lessons learned and protective measures that are helpful for the design of foundations in permafrost areas. Information derived from this literature are incorporated into the DSS as best practices for selection of foundation type. For example, ventilated foundations (which use a separation between bottom floor and ground surface) are found to have good application for marginally frozen locations (warm permafrost $>0.5{ }^{\circ} \mathrm{C}\left[>33^{\circ} \mathrm{F}\right]$ ) such as the discontinuous permafrost areas. Augmentation of these ventilated spaces has demonstrated some success in aggrading the permafrost table.

\subsection{Lessons learned}

As with any large project, this project encountered complications and some delays. Field work in the summer of 2015 at our Farmers Loop site plan was impeded by very wet conditions and an arson. These incidents postponed all efforts for the project and set the field work at FL back until the fall of 2015, after freeze-up conditions. However, damages and security were assessed, rehabilitation completed, and contracts established to remedy the delays. These events reinforced the need to be adaptable and to be prepared to make necessary schedule adjustments to complete the project.

Also, while moving the drill rig to the site in November 2015, the drill broke through a floating ice cover. We extricated the unit, applied advanced-mechanical techniques to ascertain the damage (and to prevent further mechanical damage), and placed the apparatus in operational condition. This significant setback delayed drilling until late spring of 2016. The fieldwork was eventually completed with success, and we learned that these setbacks are part of the dynamic environment in cold regions, particularly in permafrost areas and in remote locations.

\subsection{Recommendations for future efforts}

We and the broader community of practice in permafrost believe that there is a critical need to develop the guidance for engineers and designers in the following areas: 
- Guidance for engineers who perform finite-element thermal analysis for infrastructure projects on permafrost. Thermal modeling is a complex, yet useful tool that provides feedback to the foundation designer to better account for the thermal impacts of their structure on frozen ground. In regions with permafrost, it is paramount that the designers understand subsurface heat flows and the impacts of their intended structure on the supporting ground. Based on the findings of this project, information is lacking on the best parameters to use. These parameters include suitable values for thermal properties, limits of boundary conditions, and types of boundary conditions. This guidance could be implemented as supplementary information in the PFFDSS tool.

- A tool to assist engineers or designers in planning for long-term performance of infrastructure that may be affected by climate warming. By examining mean annual air temperature (MAAT) values, this tool would formulate temperature projections, which may indicate potential changes to permafrost conditions. This tool would be implementable as an additional module within the "Foundation Alternatives and Selection" section that will allow the user to examine predicted MAAT values and to apply these warmer air temperature values back into the DSS thermal modeling. This will be done by linking the DSS to the Scenarios Network for Alaska and Arctic Planning (SNAP) Regional Climate Projection webpage (SNAP 2018). This interactive map allows for display of 10-year increments (2010 up to 2099) of predicted averaged air temperature, based on the top five climate models from each Intergovernmental Panel on Climate Change (IPCC) Assessment Reports, and the Coupled Model Intercomparison Project (CMIP), which are most accurate for Alaska and the Arctic. 


\section{References}

American Society for Testing and Materials (ASTM). 2000. Standard Practice for Classification of Soils for Engineering Purposes (Unified Soil Classification System) ASTM Standard D2487. West Conshohocken, PA: ASTM International, doi:10.1520/D2487-00.

Andersland, O. B., and B. Ladanyi. 2013. An Introduction to Frozen-Ground Engineering. Springer Science \& Business Media.

Arcone, S., S. Grant, G. Boitnott, and B. Bostick. 2008. "Complex Permittivity and Clay Mineralogy of Grain-Size Fractions in a Wet Silt Soil.” Geophysics. 73(3):J1-J13.

Bezanson, J., S. Karpinski, V.B. Shah, and A. Edelman. 2012. "Julia: A Fast Dynamic Language for Technical Computing." Cambridge, MA: Massachusetts Institute of Technology. https://arxiv.org/pdf/1209.5145.pdf.

Bezanson, J., J. Chen, S. Karpinski, V. Shah, and A. Edelman. 2014. "Array Operators Using Multiple Dispatch: a Design Methodology for Array Implementations in Dynamic Languages." Proceedings of ACM SIGPLAN International Workshop on Libraries, Languages, and Compilers for Array Programming, pp. 56-61. https://dl.acm.org/doi/abs/10.1145/2627373.2627383.

Bjella, K., S. Arcone, and T. Douglas. 2015. Imaging of Ground Ice with Surface-Based Geophysics. ERDC/CRREL TR-15-14. Hanover, NH: Engineer Research and Development Center, Cold Regions Research and Engineering Laboratory (ERDC-CRREL).

Bray, M. T., H. M. French, and Y. Shur. 2006. "Further Cryostratigraphic Observations in the CRREL Permafrost Tunnel, Fox, Alaska." Permafrost and Periglacial Processes 17(3):233-243, doi:10.1002/p.558.

Ferrians, O. J., R. Kachadoorian, and G. W. Greene. 1969. Permafrost and Related Engineering Problems in Alaska. Vol. 678. Washington, DC: Government Printing Office.

Hamilton, T. D., K. M. Reed, and R. M. Thorson (eds). 1986. Glaciation in Alaska - The Geologic Record. Anchorage, AK: Alaska Geological Society.

Higdon, D. 2002. "Space and Space-Time Modeling Using Process Convolutions." Quantitative Methods for Current Environmental Issues, pp. 37-56. London, UK: Springer.

Hinkel, K. M., and F. E. Nelson. 2003. "Spatial and Temporal Patterns of Active Layer Thickness at Circumpolar Active Layer Monitoring (CALM) Sites in Northern Alaska, 1995-2000.” Journal of Geophysical Research: Atmospheres 108(D2).

HQDA (Headquarters, Department of the Army). 1954. Arctic and Subarctic Construction: Runway and Road Design. Army Technical Manual TM-5-852-3. Washington, DC: HQDA, https://armypubs.army.mil/epubs/DR_pubs/DR_a/pdf/web/tm5_852_3.pdf. 
1983. Arctic and Subarctic Construction: Foundations for Structures. Army Technical Manual TM-5-852-4. Washington, DC: HQDA, https://www.wbdg.org/FFC/ARMYCOE/COETM/ARCHIVES/tm_5_852_4.pdf [Canceled \& replaced by UFC 3-130-04].

HQUSACE (Headquarters, U.S. Army Corps of Engineers) (Preparing agency). 2004. Foundations for Structures: Arctic and Subarctic Construction. Unified Facilities Criteria (UFC) 3-130-04 (Inactive). Washington, DC: HQUSACE, Naval Facilities Engineering Command (NAVFAC), Air Force Civil Engineer Support Agency (AFCESA).

Johnston, G. 1981. Permafrost: Engineering Design and Construction. Toronto, CA: J. Wiley.

Johnston, G. H. 1966. "Engineering Site Investigations in Permafrost Areas.” Proceedings: Permafrost International Conference, pp. 371-374. https://nrcpublications.canada.ca/eng/view/ft/?id=813de3e9-eef3-471c-937d-e1c9be89a98d.

Johnson, J. B., and J. S. Buska. 1988. Frost Heave Forces on H and Pipe Piles Embedded in Fairbanks Silt. FHWA-AK-RD-88-02. Fairbanks, AK: Alaska Department of Transportation and Public Facilities, Research Section. http://www.dot.state.ak.us/stwddes/research/assets/pdf/fhwa_ak_rd_88_02.pdf.

Jorgenson, M. T., and R. A. Kreig. 1988. "A Model for Mapping Permafrost Distribution Based on Landscape Component Maps and Climatic Variables.” Paper presented at $5^{\text {th }}$ International Conference on Permafrost, August 2-5, 1988. Trondheim, Norway: Tapir Publishers.

Jorgenson, M. Torre, Jennifer Harden, Mikhail Kanevskiy, Jonathan O'Donnell, Kim Wickland, Stephanie Ewing, Kristen Manies, Qianlai Zhuang, Yuri Shur, Robert Striegl, and Josh Koch. 2013. "Reorganization of Vegetation, Hydrology and Soil Carbon after Permafrost Degradation across Heterogeneous Boreal Landscapes." Environmental Research Letters 8(3):1-14, doi:10.1088/1748-9326/8/3/035017.

Jorgenson, M. T., V. Romanovsky, J. Harden, Y. Shur, J. O'Donnell, E. A. G. Schuur, M. Kanevskiy, and S. Marchenko. 2010. "Resilience and Vulnerability of Permafrost to Climate Change." Canadian Journal of Forest Research. 4O(7):1219-1236, doi:10.1139/x10-060.

Kanevskiy, M., D. Fortier, Y. Shur, M. Bray, and T. Jorgenson, 2008. "Detailed Cryostratigraphic Studies of Syngenetic Permafrost in the Winze of the CRREL Permafrost Tunnel, Fox, Alaska." Proceedings of the Ninth International Conference on Permafrost. 1:889-894. Fairbanks, Alaska: Institute of Northern Engineering, University of Alaska Fairbanks.

Kreig, R. A., and R. D. Reger. 1982. Airphoto Analysis and Summary of Landform Soil Properties along the Route of the Trans-Alaska Pipeline System. Geologic Report 66. College, AK: Alaska Division of Geological and Geophysical Surveys, p. 149.

OSGeo (The Open Source Geospatial Foundation). 2018. QGIS: A Free and Open Source Geographic Information System. Web page. Phoenix, AZ: OSGeo, https://qgis.org/en/site/ 
Osterkamp, T. E., and M. T. Jorgenson. 2009. Permafrost conditions and processes. Geological Monitoring, R. Young and L. Norby, eds. Boulder, CO: Geological Society of America, doi:10.1130/2009.monitoring(09), pp. 205-227.

Osterkamp, T. E., M. T. Jorgenson, E. A. G. Schuur, Y. L. Shur, M. Z. Kanevskiy, J. G. Vogel, and V. E. Tumskoy. 2009. Physical and ecological changes associated with warming permafrost and thermokarst in Interior Alaska. Permafrost and Periglacial Processes 20:235-256, doi:10.1002/ppp.656.

Panda, S. K., A. Prakash, D. N. Solie, V. E. Romanovsky, and M. T. Jorgenson. 2010. Remote sensing and field-based mapping of permafrost distribution along the Alaska Highway Corridor, Interior Alaska. Permafrost and Periglacial Processes 21(3):271-281, doi:10.1002/ppp.686.

Pastick, N. J., M. Rigge, B. K. Wylie, M. T. Jorgenson, J. R. Rose, K. D. Johnson, and L. Ji. 2014. Distribution and landscape controls of organic layer thickness and carbon within the Alaskan Yukon River Basin. Geoderma, 230:79-94, doi:10.1016/j.geoderma.2014.04.008.

Penner, E., and L. E. Goodrich. 1983. Adfreezing stresses on steel pipe piles, Thompson, Manitoba. Pp. 979-983. National Research Council Canada, Division of Building Research.

Péwé, Troy Lewis. 1958. Geology of the Fairbanks (D-2) Quadrangle, Alaska. Washington, DC: The Survey. https://pubs.er.usgs.gov/publication/gq110.

Péwé, T. L. 1975. Quaternary Geology of Alaska. U.S. Geological Survey Professional Paper 835. Washington, DC: U.S. Department of the Interior, U.S. Geological Survey.

Péwé, T. L., and J.W. Bell, 1974. Map Showing Distribution of Permafrost in the Fairbanks D-2 SW Quadrangle, Alaska. Washington, DC: U.S. Department of the Interior, U.S. Geological Survey. (No. 829-B). https://doi.org/10.3133/i829B.

Péwé, T. L., J. W. Bell, R. B. Forbes, and F. R. Weber. 1976a. Geologic Map of the Fairbanks D-2 SW Quadrangle, Alaska (No. 829-A).

Péwé, T. L., J. W. Bell, R. B. Forbes, and F. R. Weber 1976b. Geologic Map of the Fairbanks D-2 Quadrangle, Alaska. SUN. Misc. Invst. Map. Washington, DC: U.S. Geological Survey (USGS), pp. 1-942.

Péwé, T. L., J. W. Bell, J. R. Williams, and R. A. Paige. 1976c. Geologic Map of the Fairbanks D-1 SW Quadrangle, Alaska (No. 949).

Péwé, T. L., J. W. Bell, R. B. Forbes, and F. R. Weber. 1977. Geologic Map of the Fairbanks D-2 NE Quadrangle, Alaska, 1976 (No. 950).

Péwé, T. L. 1983. "Alpine Permafrost in the Contiguous United States: A Review.” Arctic and Alpine Research 15(2):145-156.

R Foundation, The. 2018. The $R$ Project for Statistical Computing. Web page. Vienna, Austria: the R Foundation, https://www.r-project.org/ 
Raynolds, M. K., and D. A. Walker. 2008. Circumpolar relationships between permafrost characteristics, NDVI, and Arctic vegetation types. In Ninth International Conference on Permafrost, University of Alaska Fairbanks, June 29-July 3, 2008, D. Kane, ed. Washington, DC: National Academy Press, pp. 1469-1474.

Sellmann, Paul V. 1967. Geology of the USA CRREL Permafrost Tunnel, Fairbanks Alaska. CRREL-TR-199. Hanover, NH: Cold Regions Research and Engineering Laboratory. https://erdc-library.erdc.dren.mil/jspui/bitstream/11681/5591/1/CRRELTechnical-Report-199.pdf.

Shur, Y., H. M. French, M. T. Bray, and D. A. Anderson. 2004. "Syngenetic Perma-Frost Growth: Cryostratigraphic Observations from the CRREL Tunnel near Fairbanks, Alaska." Permafrost and Periglacial Processes 15(4):339-347.

Shur, Y. L., and M. T. Jorgenson. 2007. Patterns of permafrost formation and degradation in relation to climate and ecosystems. Permafrost and Periglacial Processes 18:7-19.

Smith, S. L., V. E. Romanovsky, A. G. Lewkowicz, C. R. Burn, M. Allard, G. D. Clow, K. Yoshikawa, and J. Throop. 2010. "Thermal State of Permafrost in North America: A Contribution to the International Polar Year." Permafrost and Periglacial Processes 21(2):117-135. https://onlinelibrary.wiley.com/doi/epdf/10.1002/ppp.690.

Scenarios Network for Alaska and Arctic Planning (SNAP). 2018. SNAP: Scenarios Network for Alaska + Arctic Planning. Web page. Fairbanks, AK: University of Alaska at Fairbanks (UAF) International Arctic Research Center (IARC), https://www.snap.uaf.edu/

Walker, D. A., G. Kofinas, M. K. Raynolds, M. Z. Kanevskiy, Y. Shur, K. Ambrosius, G. V. Matyshak, V. E. Romanovsky, T. Kumpula, B. C. Forbes, A. Khukmotov, M. O. Leibman, O. Khitun, M. Lemay, M. Allard, S. F. Lamoureux, T. Bell, D. L. Forbes, W. F. Vincent, E. Kuznetsova, D. A. Streletskiy, N. I. Shiklomanov, G. Fondahl, A. Petrov, L. P. Roy, P. Schweitzer, and M. Buchhorn. 2015. Rapid Arctic Changes due to Infrastructure and Climate (RATIC) in the Russian North., paper presented at American Geophysical Union Fall Meeting. San Francisco, December 14-18, 2015. 


\section{Acronyms and Abbreviations}

\begin{tabular}{|c|c|}
\hline Term & Definition \\
\hline AJAX & Asynchronous JavaScript And XML \\
\hline BAS & Building Automation System \\
\hline $\mathrm{BH}$ & Borehole \\
\hline CCHRC & Cold Climate Housing Research Center \\
\hline CCHRC-RTF & Cold Climate Housing Research Center Research Test Facility \\
\hline CCR & Capacity Coupled Resistivity \\
\hline CRREL & Cold Regions Research and Engineering Laboratory \\
\hline DDF & Development Difficulty Factor \\
\hline DEM & Digital Elevation Model \\
\hline DoD & U.S. Department of Defense \\
\hline DSS & Decision Support System \\
\hline ERDC & U.S. Army Engineer Research and Development Center \\
\hline ERDC-CRREL & $\begin{array}{l}\text { Engineer Research and Development Center, Cold Regions Research } \\
\text { and Engineering Laboratory }\end{array}$ \\
\hline ERT & Electrical Resistivity Tomography \\
\hline FL & Farmer's Loop \\
\hline FLP & Farmers Loop Site \\
\hline GIS & Geographic Information System \\
\hline GMC & Gravimetric Moisture Content \\
\hline GPR & Ground-Penetrating Radar \\
\hline IARC & International Arctic Research Center \\
\hline LiDAR & Light Detection and Ranging \\
\hline MAAT & Mean Annual Air Temperature \\
\hline MIPR & Military Interdepartmental Purchase Request \\
\hline MVC & Model-View-Controller \\
\hline OMB & Office of Management and Budget \\
\hline PFFDSS & Permafrost Foundation Decision Support System \\
\hline PF & Permafrost \\
\hline PFT & Permafrost Tunnel \\
\hline PT & Permafrost Tunnel \\
\hline RTD & Resistance Temperature Device \\
\hline RTF & Research and Testing Facility \\
\hline SERDP & Strategic Environmental Research and Development Program \\
\hline SF & Standard Form \\
\hline SfM & Structure from Motion \\
\hline SNAP & Scenarios Network for Alaska and Arctic Planning \\
\hline TM & Army Technical Manual \\
\hline TR & Technical Report \\
\hline UAF & University of Alaska at Fairbanks \\
\hline
\end{tabular}


Term

USACE

USCS

USGS

VIC

WFS

WMS
Definition

U.S. Army Corps of Engineers

Unified Soils Classification System

U.S. Geological Survey

Visible Ice Content

(Open Geospatial Consortium) Web Feature Service

(Open Geospatial Consortium) Web Map Service 


\section{Appendix A: Cryostratigraphic Classification of CCHRC Cores from Transect 3 Bore- holes}

Eight cryostratigraphic units were detected within the profile of the highresolution sampling along Transect $\mathrm{T}_{3}$ (Table A-1); Figure 11, p 23). Every unit was subdivided into several sub-units depending on state of soil (frozen/unfrozen), type of permafrost (syngenetic, quasi-syngenetic, epigenetic, or thawed and refrozen), or soil texture (e.g., silt/peat, sandy gravel / gravelly sand). In many cases, it was not easy to distinguish syngenetic permafrost from quasi-syngenetic and original epigenetic permafrost from thawed and refrozen soils, but what is most important for geotechnical studies is that the former two types are generally ice-rich while the latter ones are mostly ice-poor. Table A-1 lists a simplified classification for engineering purposes.

Cryostratigraphic units and sub-units (described from the surface with depth) include

1. Unfrozen active layer, peat and mucky peat (Sub-unit 1A), and silt (Sub-unit 1B), at places - strongly oxidized sandy silt (Segments A and B, Sub-unit 1B), thickness $44 \mathrm{~cm}$ to $90 \mathrm{~cm}$ (17 in.to $35 \mathrm{in}$.), $62.2 \mathrm{~cm}$ (24 in.) average (except Segment A with the lowered permafrost table: $480 \mathrm{~cm}$ (189 in.) at T3-50 and $190 \mathrm{~cm}$ (75 in.) at T3-53).

1. Frozen peat, mucky peat; up to $50 \mathrm{~cm}(20 \mathrm{in}$.) thick $(80 \mathrm{~cm}$ [31 in.] at T3-104, which is transitional to Segment C); was observed from T3-56 to T3-104 (Segment B); in T3-50 and T3-53 (Segment A) these soils are unfrozen (Sub-unit 2UF); the upper part of this unit at some places is icepoor (visible ice o to 10\%), probably thawed and refrozen (Sub-unit 2A), but mostly it is very ice-rich, syngenetically and quasi-syngenetically frozen with visible ice content from 30 to $60 \%$ (Sub-unit 2B).

2. Frozen silt with organic inclusions; presumably lacustrine, eolian, and alluvial-fan deposits; contain 3 to $20 \%$ of organic matter, oxidized at places, with layers of sandy silt (within Segment D); was observed from T3-56 to T3-149 (Segments B to D), in T3-50 and T3-53 (Segment A) these soils are unfrozen (Sub-unit $3 \mathbf{U F}$ ); thickness $80 \mathrm{~cm}$ to $150 \mathrm{~cm}$ (31 in.to 59 in.) within Segment B, $80 \mathrm{~cm}$ to $180 \mathrm{~cm}$ (31 in.to 71 in.) within Segment C, and $230 \mathrm{~cm}$ to $330 \mathrm{~cm}$ (90 in.to 130 in.) within Segment D; 
mostly ice-rich (visible ice 30 to $70 \%$ ), quasi-syngenetically (intermediate layer) and syngenetically frozen within Segment B (Sub-unit $\mathbf{3 A}$ ); quasi-syngenetically (ice-rich intermediate layer up to $70 \mathrm{~cm}$ thick, visible ice 20 to $50 \%$, Sub-unit 3A) and epigenetically frozen within Segments C and $\mathrm{D}$ (ice-poor soils below the intermediate layer, visible ice o to $3 \%$, up to 10 to $20 \%$ at some places, Sub-unit 3B). Within Segment B, this unit contains epigenetic ice wedges with vertical extent of $1.5 \mathrm{~m}$ to $2 \mathrm{~m}$ ( $5 \mathrm{ft}$ to $7 \mathrm{ft}$ ).

3. Frozen peat, mucky peat (buried) was observed from $\mathrm{T}_{3}-107$ to $\mathrm{T}_{3}-$ 149 (Segments C to D); thickness $10 \mathrm{~cm}$ to $100 \mathrm{~cm}$ (4 in.to 39 in.) within Segment C, and $1 \mathrm{~cm}$ to $20 \mathrm{~cm}$ (o.39 in. to $8 \mathrm{in}$.) within Segment D; mostly ice-poor with visible ice content o to $5 \%$, (Sub-unit 4A) probably thawed and refrozen, except $\mathrm{T}_{3}-107$ and $\mathrm{T}_{3}-110$, with visible ice up to $30 \%$, probably quasi-syngenetically and syngenetically frozen (Sub-unit 4B) within Segment C, no visible ice within Segment D.

4. Frozen silt with organic inclusions; presumably lacustrine, eolian and alluvial-fan deposits; was observed from T3-107 to T3-143 (Segments C to D); thickness $30 \mathrm{~cm}$ to $140 \mathrm{~cm}$ (12 in. to 55 in.) within Segment C, and o to $170 \mathrm{~cm}$ (o to 67 in.) within Segment D; organicrich, especially within Segment C, where these sediments contain $5 \%$ to $50 \%$ of organic matter; mostly ice-rich within Segment C, with visible ice content $10 \%$ to $60 \%$ (Sub-unit $\mathbf{5 A}$ ) quasi-syngenetically and syngenetically frozen, and ice-poor within Segment $D$, with visible ice content $0 \%$ to $7 \%$ (Sub-unit 5B).

1. Frozen sandy silt and very fine to fine silty sand; alluvial fan and floodplain deposits; $<1 \%$ to $5 \%$ of organic matter (up to $10 \%$ at some locations, mostly within Segment B), at places - with layers of silt (mostly within Segment D) and thin layers of organic detritus; with relatively thick (up to $30 \mathrm{~cm}$ [12 in.]) layers and lenses of fine to medium sand and silt observed in several boreholes within Segments B and C); oxidized at places (strong oxidation in the upper part of this unit within Segments A and B, especially from $\mathrm{T}_{3}-50$ to T3-74); was observed from T3-53 to T3-149 (Segments A to D), in T3-50 these sediments are unfrozen (Sub-unit 6UF); thickness 70 (Segment D) to $320 \mathrm{~cm}$ (126 in.) (Segment B); the upper part of this unit within Segment B is relatively ice-rich (visible ice $5 \%$ to $20 \%$, up to $40 \%$ at places), syngenetically frozen (Sub-unit 6A), but generally sediments are ice-poor (visible ice o to $3 \%$ ), epigenetically frozen (Sub-unit 6B).

2. Frozen fine to medium sand; fluvial (point bar?) deposits; $<1 \%$ to $3 \%$ of organic matter, with layers and lenses of silty sand / sandy silt up to 6o-cm (24-in.) thick; oxidized at places (strong oxidation in the upper 
part of this unit within Segment B, especially from T3-56 to T3-74); thickness 50 (Segment C) to $190 \mathrm{~cm}$ (Segment B); was observed from T3-53 to T3-131 (Segments A to C), in T3-50 these sediments are unfrozen (Subunit 7UF); soils are ice-poor epigenetically frozen, without visible ice.

3. Frozen gravelly sand (Sub-unit $7 \mathbf{A}$ ) and sandy gravel (Sub-unit 7B); fluvial channel deposits; total thickness is unknown ( $>140 \mathrm{~cm}$ [>55 in.] at T3-50); was observed from T3-50 to T3-149 (Segments A to D), the upper $20 \mathrm{~cm}$ of this unit is unfrozen (Sub-unit 8UF); soils of both sub-units are ice-poor epigenetically frozen, without visible ice.

These units have a different manifestation at different segments of the Transect T3 profile (Figures A-1, A-2, A-3, Table A-1). Segment A is characterized by the lowered permafrost table; no visible ground ice was detected here, and moisture contents of frozen soils are very low. Segment D is generally ice-poor (except the upper $20 \mathrm{~cm}$ to $70 \mathrm{~cm}$ (8 in. to $28 \mathrm{in}$.), which represent the ice-rich intermediate layer of the upper permafrost). By contrast, Segments B and C contain large amounts of ground ice to a depth of $2.5 \mathrm{~m}$ to $4 \mathrm{~m}$ ( $8 \mathrm{ft}$ to $13 \mathrm{ft}$ ). The highest ground ice content was detected at Segment B, where the ice-rich peat and quasi-syngenetically frozen silt forming the intermediate layer (Sub-units 2B and $3 \mathrm{~A}$ ) are underlain by syngenetically frozen silt and sandy silt (Sub-units 3A, 6A).

These ice-rich soils contain epigenetic ice wedges with vertical extent of $1.5 \mathrm{~m}$ to $2 \mathrm{~m}$ ( $5 \mathrm{ft}$ to $7 \mathrm{ft}$ ). A total of four wedges were detected (T3-62, $\mathrm{T}_{3}-$ 82, T3-98, and T3-101). Occurrence of other wedges within Segment B is questionable, but three massive ice bodies $10 \mathrm{~cm}$ to $30 \mathrm{~cm}$ (4 in. to 12 in.) thick were detected at $\mathrm{T}_{3}-65, \mathrm{~T}_{3}-71$, and $\mathrm{T}_{3}-80$ at depths similar to other ice wedges, so we can presume that they may have the same origin. Only one wedge is vulnerable to thermokarst (at $\mathrm{T}_{3}-101$, where the ice wedge was detected at the base of the active layer), while all other wedges are separated from the base of the active layer by frozen soil $30 \mathrm{~cm}$ to $80 \mathrm{~cm}$ (12 in. to 31 in.) thick.

Within Segment C, two layers of ice-rich soils were detected: (1) ice-rich silt (modern intermediate layer 50-cm to 90-cm (20-in. to 35-in.) thick, Sub-unit 3A) underlain by ice-poor silt (Sub-unit 3B), and (2) 30-cm to 130-cm (12-in. to 51-in.) thick inclined layer of ice-rich silt detected at depths of $2 \mathrm{~m}$ to $4 \mathrm{~m}$ ( $7 \mathrm{ft}$ to $13 \mathrm{ft}$ ) (Sub-unit $5 \mathrm{~A}$ ), which we consider a buried intermediate layer. The latter formed beneath the layer of buried peat (Unit 4), which is very typical of quasi-syngenetic permafrost; occurrence 
of ice-rich mineral soils beneath buried organic soils have been frequently observed in various permafrost regions of Eurasia and North America.

Table A-1. Properties of cryostratigraphic units and sub-units, segments A, B, C, and D of the profile T3.

\begin{tabular}{|c|c|c|c|c|c|c|}
\hline $\begin{array}{l}\text { Unit/Sub } \\
\text {-unit }\end{array}$ & Properties & $\begin{array}{c}\text { Segments } \\
\text { A, } \\
\text { T3-50-T3-53 }\end{array}$ & $\begin{array}{c}\text { B, } \\
\text { T3-56-T3-101 }\end{array}$ & $\begin{array}{c}\text { C, } \\
\text { Т3-104-Т3- } \\
128\end{array}$ & $\begin{array}{c}\text { D, } \\
\text { T3-131-T3- } \\
149\end{array}$ & $\begin{array}{c}\text { A-D, total } \\
\text { T3-50-T3-149 }\end{array}$ \\
\hline \multirow[t]{4}{*}{$1 \mathrm{~A}$} & Elevation, $\mathrm{m}$ & $132.8-132.9$ & 132.8-133.4 & $133.4-134.0$ & $\begin{array}{l}134.0- \\
134.4\end{array}$ & 132.8-134.4 \\
\hline & Soil / Permafrost type* & Peat / UF & Peat / AL-UF & Peat / AL-UF & Peat / AL-UF & Peat / AL-UF \\
\hline & Thickness, $\mathrm{cm}$ & $10-20$ & $50-70$ & $20-70$ & $20-50$ & $10-70$ \\
\hline & Gravimetric moisture content, \% & - & $169.0 \pm 39.9(n=18)$ & $\begin{array}{c}147.0 \pm 51.2 \\
(n=4)\end{array}$ & $257.0(n=1)$ & $169.0 \pm 45.0(n=23)$ \\
\hline \multirow[t]{3}{*}{$1 \mathrm{~B}$} & Soil / Permafrost type* & Sandy silt / UF & Sandy silt / AL-UF & Silt / AL-UF & Silt / AL-UF & Silt, sandy silt/AL-UF \\
\hline & Thickness, $\mathrm{cm}$ & 70 & $10-50$ & $0-50$ & $0-50$ & $0-70$ \\
\hline & Gravimetric moisture content, \% & $34.4 \pm 4.4(n=5)$ & $43.1 \pm 13.7(n=5)$ & $\begin{array}{c}62.6 \pm 32.9 \\
(n=3)\end{array}$ & $\begin{array}{c}32.9 \pm 5.1 \\
(n=8)\end{array}$ & $39.9 \pm 13.9(n=21)$ \\
\hline \multirow[t]{3}{*}{ Unit 1 total } & | Soil / Permafrost type* & $\begin{array}{c}\text { Peat, sandy silt } \\
\text { / UF }\end{array}$ & $\begin{array}{l}\text { Peat, silt, sandy silt } \\
\text { / AL-UF }\end{array}$ & $\begin{array}{l}\text { Peat, silt, / AL- } \\
\text { UF }\end{array}$ & $\begin{array}{c}\text { Peat, silt, / } \\
\text { AL-UF }\end{array}$ & Peat, silt, sandy silt / AL-UF, UF \\
\hline & Thickness of the active layer, $\mathrm{cm}$ & $-* *$ & $64.8 \pm 13.7(n=16)$ & $\begin{array}{c}60.6 \pm 8.7 \\
(n=9)\end{array}$ & $\begin{array}{c}58.6 \pm 8.8 \\
(n=7)\end{array}$ & $62.28 \pm 11.5(n=32)$ \\
\hline & Gravimetric moisture content, \% & $34.4 \pm 4.4(n=5)$ & $\begin{array}{c}141.6 \pm 63.9 \\
(n=23)\end{array}$ & $\begin{array}{c}110.8 \pm 58.9 \\
(n=7)\end{array}$ & $\begin{array}{c}57.8 \pm 74.9 \\
(n=9)\end{array}$ & $107.4 \pm 73.3(n=44)$ \\
\hline $2 \mathrm{~A}$ & $\begin{array}{l}\text { Soil / Permafrost type* Thickness, cm } \\
\text { Gravimetric moisture content, \% } \\
\text { Visible ice content,\% Cryostructures*** } \\
\text { Soil / Permafrost type* Thickness, cm } \\
\text { Gravimetric moisture content, \% } \\
\text { Visible ice content,\% Cryostructures*** }\end{array}$ & $\begin{array}{l}- \\
- \\
- \\
- \\
-\end{array}$ & $\begin{array}{c}\text { Peat / T 0-40 } \\
242.6 \pm 62.6(n=7) \\
0-10 \\
\text { N, OM } \\
\text { Peat / QS, S 0-80 }\end{array}$ & $\begin{array}{l}- \\
- \\
-\end{array}$ & $\begin{array}{l}- \\
- \\
-\end{array}$ & $\begin{array}{c}\text { Peat / T 0-70 } \\
242.6 \pm 62.6(n=7) \\
0-10 \\
\text { N, OM } \\
\text { Peat / QS, S 0-170 } \\
614.9 \pm 266.6(n=24)\end{array}$ \\
\hline $2 B$ & $\begin{array}{l}\text { Soil / Permafrost type* Thickness, cm } \\
\text { Gravimetric moisture content, } \%\end{array}$ & $\begin{array}{l}- \\
- \\
- \\
-\end{array}$ & $\begin{array}{l}646.9 \pm 273.0 \\
(\mathrm{n}=18) \\
30-60 \\
\mathrm{OM}, \mathrm{MB}, \mathrm{B} \\
- \\
-\end{array}$ & $\begin{array}{c}\text { Peat / QS, S } \\
0-170 \\
518.8 \pm 242.5 \\
(\mathrm{n}=6) \\
20-40 \\
\mathrm{OM}, \mathrm{MB}\end{array}$ & $\begin{array}{l}- \\
- \\
- \\
-\end{array}$ & $\begin{array}{c}20-60 \\
\text { OM, MB, B } \\
\text { Peat / UF } 70 \\
182.7 \pm 63.6(n=5)\end{array}$ \\
\hline $2 \mathrm{UF}$ & & $\begin{array}{c}\text { Peat / UF 70 } \\
182.7 \pm 63.6(n=5)\end{array}$ & & - & - & \\
\hline Unit 2 & Soil / Permafrost type* & Peat / UF & Peat / T, QS, S & Peat / T, QS, S & - & Peat / T, QS, S, \\
\hline \multirow[t]{4}{*}{ total } & & & & & & UF \\
\hline & Thickness, $\mathrm{cm}$ & 70 & $0-80$ & $0-170$ & - & $0-170$ \\
\hline & Gravimetric moisture & $182.7 \pm 63.6$ & $533.7 \pm 296.8$ & $518.8 \pm 242.5$ & - & $482.5 \pm 290.2$ \\
\hline & content, \% & $(n=5)$ & $(n=25)$ & $(n=6)$ & & $(n=36)$ \\
\hline \multirow[t]{7}{*}{$3 \mathrm{~A}$} & Soil / Permafrost type* & - & Silt / QS, S & Silt / QS, S & Silt / QS & Silt / QS, S \\
\hline & Thickness, cm & - & $50-150$ & $50-90$ & $20-70$ & $20-150$ \\
\hline & Gravimetric moisture & - & $194.7 \pm 123.6$ & $\begin{array}{c}96.2 \pm 42.6 \\
(\mathrm{n}=23)\end{array}$ & $\begin{array}{c}84.7 \pm 28.7 \\
(n=12)\end{array}$ & $151.0 \pm 109.1$ \\
\hline & content, \% & . & $(n=47)$ & & & $(n=82)$ \\
\hline & Visible ice content,\% & - & $30-70$ & $20-50$ & $20-50$ & $20-70$ \\
\hline & Cryostructures*** & - & $\mathrm{A}, \mathrm{MA}, \mathrm{MB}, \mathrm{B}$, & A, MA, MB, B, & $\begin{array}{c}\text { A, MA, MB, } \\
\text { B, }\end{array}$ & A, MA, MB, B, \\
\hline & & & $\mathrm{Br}, \mathrm{ML}$ & $\mathrm{Br}, \mathrm{ML}$ & $\mathrm{Br}, \mathrm{ML}$ & $\mathrm{Br}, \mathrm{ML}$ \\
\hline $3 B$ & Soil / Permafrost type* & - & Silt / $T$ (above & Silt / $T$ (below) & $\begin{array}{l}\text { Silt / T, E } \\
\text { (below) }\end{array}$ & Silt / T, E \\
\hline
\end{tabular}




\begin{tabular}{|c|c|c|c|c|c|c|}
\hline $\begin{array}{c}\text { Unit/Sub } \\
\text {-unit }\end{array}$ & Properties & $\begin{array}{c}\text { Segments } \\
\text { A, } \\
\text { T3-50-T3-53 }\end{array}$ & $\begin{array}{c}\text { B, } \\
\text { T3-56-T3-101 }\end{array}$ & $\begin{array}{c}\text { C, } \\
\text { Т3-104-T3- } \\
128\end{array}$ & $\begin{array}{c}\text { D, } \\
\text { T3-131-T3- } \\
\text { 149 }\end{array}$ & $\begin{array}{c}\text { A-D, total } \\
\text { T3-50-T3-149 }\end{array}$ \\
\hline & & & Sub-unit 3A) & Sub-unit 3A) & Sub-unit 3A) & \\
\hline & Thickness, $\mathrm{cm}$ & - & $20-30$ & $0-120$ & $180-290$ & $0-350$ \\
\hline & Gravimetric moisture & - & $67.3 \pm 11.8$ & $\begin{array}{c}40.0 \pm 16.4 \\
(n=19)\end{array}$ & $40.9 \pm 7.0$ & $41.7 \pm 11.2$ \\
\hline & content, \% & & $(n=3)$ & & $(n=59)$ & $(n=81)$ \\
\hline & Visible ice content, $\%$ & - & $0-10$ & $0-10$ & $0-10$ & $0-10$ \\
\hline & Cryostructures*** & - & $\mathrm{N}, \mathrm{L}, \mathrm{LL}$ & $\mathrm{N}, \mathrm{L}, \mathrm{LL}$ & $\mathrm{N}, \mathrm{L}, \mathrm{LL}$ & $\mathrm{N}, \mathrm{L}, \mathrm{LL}$ \\
\hline \multirow[t]{4}{*}{$3 \mathrm{UF}$} & Soil / Permafrost type* & Silt / UF & - & - & - & Silt / UF \\
\hline & Thickness, cm & $40-60$ & - & - & - & $40-60$ \\
\hline & Gravimetric moisture & $48.6 \pm 7.8$ & - & - & - & $48.6 \pm 7.8$ \\
\hline & content, $\%$ & $(n=3)$ & & & & $(n=3)$ \\
\hline \multirow[t]{3}{*}{ Unit 3 total } & I Soil / Permafrost type* & Silt / UF & Silt / T, QS, S & Silt / T, QS, S & $\begin{array}{l}\text { Silt / T, E, } \\
\text { QS }\end{array}$ & $\begin{array}{c}\text { Silt / T, QS, S, UF } \\
40-300\end{array}$ \\
\hline & Gravimetric moisture & $48.6 \pm 7.8$ & $187.0 \pm 123.6$ & $70.8 \pm 43.5$ & $48.3 \pm 21.0$ & $95.8 \pm 94.3$ \\
\hline & content. $\%$ & $(n=3)$ & $(n=50)$ & & & $(n=166)$ \\
\hline \multirow[t]{6}{*}{$4 \mathrm{~A}$} & Soil / Permafrost type* & - & - & Peat $/ T$ & Peat / T, E & Peat / T, E \\
\hline & Thickness, cm & - & - & $0-30$ & $1-20$ & $0-30$ \\
\hline & Gravimetric moisture & _- & _- & $227.6 \pm 87.6$ & 80.5 & $206.5 \pm 97.4$ \\
\hline & content, \% & & & & $(n=1)$ & $(n=7)$ \\
\hline & Visible ice content,\% & - & - & $0-10$ & 0 & $0-10$ \\
\hline & Cryostructures $* * *$ & - & - & $\mathrm{N}, \mathrm{OM}$ & $\mathrm{N}$ & N. OM \\
\hline \multirow[t]{6}{*}{$4 \mathrm{~B}$} & Soil / Permafrost tvpe* & $\ldots$ & _- & Peat / OS.S & - & Peat / OS.S \\
\hline & Thickness, cm & _- & - & \begin{tabular}{|c|}
$0-170$ \\
\end{tabular} & - & $0-170$ \\
\hline & Gravimetric moisture & - & - & $622.8 \pm 438.6$ & - & $622.8 \pm 438.6(n=6)$ \\
\hline & content. $\%$ & & & $(n=6)$ & 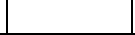 & \\
\hline & Visible ice content, $\%$ & - & - & $20-40$ & - & $20-40$ \\
\hline & Crvostructures*** & $\ldots$ & $\ldots$ & OM. MB. B & - & OM. MB.B \\
\hline Unit 4 & Soil / Permafrost type* & - & - & Peat / T, QS, & Peat $/ \mathrm{T}, \mathrm{E}$ & Silt / T, OS, S, \\
\hline \multicolumn{7}{|l|}{ total } \\
\hline & Thickness, cm & $\ldots$ & _- & $10-170$ & $1-20$ & $1-170$ \\
\hline & Gravimetric moisture & - & - & $425.2 \pm 365.4$ & 80.5 & $398.6 \pm 362.7$ \\
\hline & content. \% & 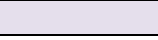 & & $(n=12)$ & $(n=1)$ & $(n=13)$ \\
\hline \multirow[t]{6}{*}{$5 \mathrm{~A}$} & Soil / Permafrost type* & - & - & Silt / QS, S & - & Silt / QS, S \\
\hline & Thickness, cm & - & - & $30-130$ & - & $30-130$ \\
\hline & Gravimetric moisture & _- & - & $121.4 \pm 82.0$ & - & $121.4 \pm 82.0$ \\
\hline & content, $\%$ & 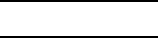 & 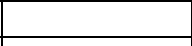 & $(n=24)$ & 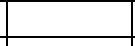 & $(n=24)$ \\
\hline & Visible ice content,\% & _- & _- & $10-60$ & _- & \\
\hline & Crvostructures $* * *$ & _- & - & A. Br. B, MB & - & A. Br. B, MB \\
\hline \multirow[t]{7}{*}{$5 B$} & Soil / Permafrost type* & _- & _- & - & Silt, sandy & Silt, sandy silt / \\
\hline & & & & & T.E & T.E \\
\hline & Thickness. cm & - & _- & - & $0-100$ & $0-100$ \\
\hline & Gravimetric moisture & _- & - & _- & $37.1 \pm 5.1$ & $37.1 \pm 5.1$ \\
\hline & content. \% & 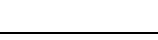 & & & $(n=11)$ & $(n=11)$ \\
\hline & Visible ice content, $\%$ & - & 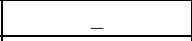 & $\ldots$ & $0-7$ & \\
\hline & Cryostructures $* * *$ & $\ldots$ & $\ldots$ & _- & $N, L, L L$ & N.L.LL \\
\hline Unit 5 & Soil / Permafrost type* & - & - & Silt / QS, S & Silt, sandy & Silt / QS, S, T, E \\
\hline \multirow[t]{4}{*}{ total } & & & & & $\mathrm{T}, \mathrm{E}$ & \\
\hline & Thickness. cm & - & - & $30-130$ & $0-100$ & $0-130$ \\
\hline & Gravimetric moisture & - & - & $121.4 \pm 82.0$ & $37.1 \pm 5.1$ & $94.9 \pm 78.3$ \\
\hline & content. \% & & & $(n=24)$ & $(n=11)$ & $(n=35)$ \\
\hline \multirow[t]{5}{*}{$6 \mathrm{~A}$} & Soil / Permafrost type* & - & Sandy silt, silty & - & - & Sandy silt, silty \\
\hline & & & sand / S & & & sand / S \\
\hline & Thickness, cm & - & $0-130$ & - & - & $0-130$ \\
\hline & Gravimetric moisture & _- & $65.3 \pm 27.4(n=26)$ & $\ldots$ & $\ldots$ & $65.3 \pm 27.4$ \\
\hline & content. $\%$ & & & & & $(n=26)$ \\
\hline
\end{tabular}




\begin{tabular}{|c|c|c|c|c|c|c|}
\hline $\begin{array}{c}\text { Unit/Sub } \\
\text {-unit }\end{array}$ & Properties & $\begin{array}{c}\text { Segments } \\
\text { A, } \\
\text { T3-50-T3-53 }\end{array}$ & $\begin{array}{c}\text { B, } \\
\text { T3-56-T3-101 }\end{array}$ & $\begin{array}{c}\text { C, } \\
\text { T3-104-T3- } \\
128\end{array}$ & $\begin{array}{c}\text { D, } \\
\text { T3-131-T3- } \\
149\end{array}$ & $\begin{array}{c}\text { A-D, total } \\
\text { T3-50-T3-149 }\end{array}$ \\
\hline & Visible ice content,\% & _- & $10-40$ & _- & _- & $10-40$ \\
\hline & Crvostructures*** & - & MB, ML, L & _- & _- & MB, ML, L \\
\hline \multirow[t]{7}{*}{$6 \mathrm{~B}$} & Soil / Permafrost tvpe* & Sandv silt, siltv & Sandv silt, siltv & Sandv silt. & Sandv silt. & Sandv silt, siltv \\
\hline & & sand / E & sand / E & sand/E & sand, silt / & sand. silt / E \\
\hline & Thickness. cm & 170 & $80-260$ & $160-290$ & $70-160$ & $70-290$ \\
\hline & Gravimetric moisture & $38.5 \pm 4.9$ & $38.9 \pm 4.9$ & $37.7 \pm 6.7$ & $34.5 \pm 4.1$ & $37.8 \pm 5.7$ \\
\hline & content, \% & $(n=6)$ & $(n=83)$ & $(n=74)$ & $(n=26)$ & $(n=189)$ \\
\hline & Visible ice content, $\%$ & 0 & $0-3$ & $0-10$ & $0-7$ & $0-10$ \\
\hline & Cryostructures $* * *$ & $\mathrm{~N}$ & $\mathrm{~N}, \mathrm{~L}, \mathrm{LL}$ & $\mathrm{N}, \mathrm{L}, \mathrm{LL}$ & $\mathrm{N}, \mathrm{L}, \mathrm{LL}$ & $\mathrm{N}, \mathrm{L}, \mathrm{LL}$ \\
\hline \multirow[t]{5}{*}{ 6UF } & Soil / Permafrost type* & Sandy silt, silty & - & - & - & Sandy silt, silty \\
\hline & & sand / UF & & & & sand / UF \\
\hline & Thickness, cm & 120 & - & - & - & 120 \\
\hline & Gravimetric moisture & $29.7 \pm 2.0$ & - & 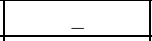 & $\ldots$ & $29.7 \pm 2.0$ \\
\hline & content. \% & $(n=4)$ & & & & $(n=4)$ \\
\hline Unit 6 & Soil / Permafrost type* & Sandy silt, silty & Sandy silt, silty & Sandy silt, & Sandy silt, & Sandy silt, silty \\
\hline \multirow[t]{5}{*}{ total } & & sand / E, UF & sand / E,S & sand / E, S & sand, silt / & sand, silt / E, S. \\
\hline & & & & & & UF \\
\hline & Thickness, cm & $120-170$ & $130-320$ & $160-290$ & $70-160$ & $70-320$ \\
\hline & Gravimetric moisture & $35.0 \pm 5.9$ & $45.2 \pm 17.9$ & $37.7 \pm 6.7$ & $34.5 \pm 4.1$ & $40.9 \pm 14.0$ \\
\hline & content. \% & $(n=10)$ & $(n=109)$ & $(n=74)$ & $(n=26)$ & $(n=219)$ \\
\hline \multirow[t]{7}{*}{7} & Soil / Permafrost type* & Fine to medium & Fine to medium & Fine to & Fine to & Fine to medium \\
\hline & & sand / E & sand / E & sand $/ E$ & sand $/ E$ & sand / E \\
\hline & Thickness, cm & 120 & $120-190$ & $100-160$ & $0-70$ & $0-190$ \\
\hline & Gravimetric moisture & $35.1 \pm 8.3$ & $30.8 \pm 3.3$ & $31.9 \pm 1.9$ & $31.7 \pm 3.3$ & $31.2 \pm 3.3$ \\
\hline & content, $\%$ & $(n=3)$ & $(\mathrm{n}=79)$ & $(n=25)$ & $(n=3)$ & $(n=110)$ \\
\hline & Visible ice content, $\%$ & 0 & 0 & 0 & 0 & 0 \\
\hline & Cryostructures $* * *$ & $\mathrm{~N}$ & $\mathrm{~N}$ & $\mathrm{~N}$ & $\mathrm{~N}$ & $\mathrm{~N}$ \\
\hline \multirow[t]{5}{*}{ 7UF } & Soil / Permafrost type* & Fine to medium & _- & - & - & Fine to medium \\
\hline & & sand / UF & & & & sand / UF \\
\hline & Thickness, cm & 50 & - & - & - & 50 \\
\hline & Gravimetric moisture & $22.7 \pm 5.2$ & _- & $\ldots$ & $\ldots$ & $22.7 \pm 5.2$ \\
\hline & content. \% & $(n=4)$ & & & & $(n=4)$ \\
\hline Unit 7 & Soil / Permafrost type* & Fine to medium & Fine to medium & Fine to & Fine to & Fine to medium \\
\hline \multirow[t]{4}{*}{ total } & & sand / E. UF & sand / E & sand $/ E$ & sand / E & sand / E. UF \\
\hline & Thickness. cm & $50-120$ & $120-190$ & $100-160$ & $0-70$ & $0-190$ \\
\hline & Gravimetric moisture & $28.0 \pm 9.0(n=7)$ & $30.8 \pm 3.3$ & $31.9 \pm 1.9$ & $31.2 \pm 3.3$ & $30.9 \pm 3.7$ \\
\hline & content. \% & & $(n=79)$ & $(n=25)$ & $(n=3)$ & $(n=114)$ \\
\hline \multirow[t]{7}{*}{$8 \mathrm{~A}$} & Soil / Permafrost type* & Gravelly sand / & Gravelly sand / E & Gravelly sand & Gravelly & Gravelly sand / E \\
\hline & & $E$ & & & & \\
\hline & Thickness, cm & $10->70$ & $0-30$ & $0-20$ & $0-30$ & $0 \rightarrow 70$ \\
\hline & Gravimetric moisture & $27.3 \pm 5.5$ & $24.5 \pm 7.2$ & $19.5 \pm 10.7$ & 29.7 & $25.6 \pm 6.5$ \\
\hline & content, \% & $(n=6)$ & $(n=2)$ & $(n=2)$ & $(n=1)$ & $(n=11)$ \\
\hline & Visible ice content, $\%$ & 0 & 0 & 0 & 0 & 0 \\
\hline & Cryostructures $* * *$ & $\mathrm{~N}$ & N & $\mathrm{N}$ & $\mathrm{N}$ & $\mathrm{N}$ \\
\hline \multirow[t]{7}{*}{$8 B$} & Soil / Permafrost type* & Sandy gravel / & Sandy gravel / $\mathrm{E}$ & Sandy gravel & Sandy & Sandy gravel / E \\
\hline & & $E$ & & & & \\
\hline & Thickness, cm & $10-20$ & $0->80$ & $0 \rightarrow 20$ & $0>>10$ & $0>>80$ \\
\hline & Gravimetric moisture & 8.1 & $15.6 \pm 8.6$ & 11.6 & $10.6 \pm 5.0$ & $13.5 \pm 7.4$ \\
\hline & content, $\%$ & $(n=1)$ & $(n=9)$ & $(n=1)$ & $(n=4)$ & $(n=15)$ \\
\hline & Visible ice content.\% & 0 & 0 & 0 & 0 & 0 \\
\hline & Crvostructures $* * *$ & $\mathrm{~N}$ & $\mathrm{~N}$ & $\mathrm{~N}$ & $\mathrm{~N}$ & $\mathrm{~N}$ \\
\hline \multirow[t]{5}{*}{ BUF } & Soil / Permafrost type* & Sandy gravel/ & $\ldots$ & $\ldots$ & - & Sandy gravel// \\
\hline & & UF & & & & UF \\
\hline & Thickness, cm & 20 & - & - & - & 20 \\
\hline & Gravimetric moisture & 10.0 & - & - & - & 10.0 \\
\hline & content, \% & $(n=1)$ & & & & $(n=1)$ \\
\hline Unit 8 & Soil / Permafrost type* & Gravelly sand, & Gravelly sand, & Gravelly sand, & Gravelly & Gravelly sand, \\
\hline \multirow[t]{2}{*}{ cotal } & & sandy gravel/ & sandy gravel / E & sandy gravel & sandy & sandy gravel / $E$, \\
\hline & & $E, U F$ & & & & UF \\
\hline
\end{tabular}




\begin{tabular}{|c|c|c|c|c|c|c|}
\hline $\begin{array}{c}\text { Unit/Sub } \\
\text {-unit }\end{array}$ & Properties & $\begin{array}{c}\text { Segments } \\
\text { A, } \\
\text { T3-50-T3-53 }\end{array}$ & $\begin{array}{c}\text { B, } \\
\text { T3-56-T3-101 }\end{array}$ & $\begin{array}{c}\mathrm{C}, \\
\text { T3-104-T3- } \\
128\end{array}$ & $\begin{array}{c}\text { D, } \\
\text { T3-131-T3- } \\
149\end{array}$ & $\begin{array}{c}\text { A-D, total } \\
\text { T3-50-T3-149 }\end{array}$ \\
\hline & Thickness. cm & $>120$ & $>100$ & $>30$ & $>30$ & $>100$ \\
\hline & Gravimetric moisture & $22.8 \pm 9.7$ & $17.2 \pm 8.8$ & $16.8 \pm 8.8$ & $14.4 \pm 9.6$ & $18.3 \pm 9.2$ \\
\hline & content. \% & $(n=8)$ & $(n=11)$ & $(n=3)$ & $(n=5)$ & $(n=27)$ \\
\hline & & & & & & $\mathrm{N}=654$ (tot.) \\
\hline
\end{tabular}

Table A-2. (Tbl B-1 simplified). Visible ice content (VIC) and gravimetric moisture content (GMC) of cryostratigraphic units and sub-units, segments A, B, C, and D of the profile T3.

\begin{tabular}{|c|c|c|c|c|c|c|c|c|c|c|c|}
\hline $\begin{array}{l}\text { Sub- } \\
\text { unit }\end{array}$ & Soil & PF type* & A & & B & & C & & D & & $A-D$ \\
\hline $1 \mathrm{~A}$ & AL, unfrozen & AL-UF & $\begin{array}{l}\text { VIC, } \% \\
-\end{array}$ & GMC, $\%$ & VIC, \% & GMC,\% 169.0 & VIC, \% & GMC,\% 147.0 & VIC, \% & GMC,\% 257.0 & $\begin{array}{l}\text { GMC, } \% \\
169.0\end{array}$ \\
\hline & peat & & & & & $(n=18)$ & & $(n=4)$ & 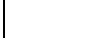 & $(n=1)$ & $(n=23)$ \\
\hline \multirow[t]{2}{*}{$1 \mathrm{~B}$} & AL, unfrozen & ALLUF & - & 34.4 & - & 43.1 & - & 62.6 & - & 32.9 & 39.9 \\
\hline & silt & & & $(n=5)$ & & $(n=5)$ & & $(n=3)$ & & $(n=8)$ & $(n=21)$ \\
\hline $2 A$ & Frozen peat & $T$ & - & F & $0-10$ & $242.6(n=7)$ & - & 5 & - & F & $\begin{array}{l}242.6 \\
(n=7)\end{array}$ \\
\hline $2 B$ & $\begin{array}{l}\text { Frozen peat, ice-rich } \\
\text { Unfrozen peat }\end{array}$ & es, s & - & - & $30-60$ & $646.9(n=18)$ & $20-40$ & $518.8(n=6)$ & - & - & $\begin{array}{l}614.9(n=24) \\
182.7\end{array}$ \\
\hline $2 \mathrm{UF}$ & & UF & - & $\begin{array}{l}182.7 \\
(n=5)\end{array}$ & - & & - & & - & - & $(n=5)$ \\
\hline $3 A$ & Frozen silt, ice-rich & QS, S & - & - & $30-70$ & $194.7(n=47)$ & $20-50$ & $96.2(n=23)$ & $20-50$ & $84.7(n=12)$ & $\begin{array}{l}151.0 \\
(n=82)\end{array}$ \\
\hline 3B & Frozen silt & T, E & - & - & $0-10$ & $67.3(n=3)$ & $0-10$ & $40.0(n=19)$ & $0-10$ & $40.9(n=59)$ & $\begin{array}{l}41.7 \\
(n=81)\end{array}$ \\
\hline \multirow[t]{2}{*}{$3 \mathrm{UF}$} & Unfrozen silt & UF & - & 48.6 & - & - & - & - & - & - & 48.6 \\
\hline & & & & $(n=3)$ & & & & & & & $(n=3)$ \\
\hline $4 \mathrm{~A}$ & Frozen peat & T, E & - & - & $F$ & - & $0-10$ & $227.6(n=6)$ & 0 & $80.5(n=1)$ & $\begin{array}{l}206.5 \\
(n=7)\end{array}$ \\
\hline $4 B$ & $\begin{array}{l}\text { Frozen peat, } \\
\text { ice-rich }\end{array}$ & QS, S & - & - & - & - & $20-40$ & $622.8(n=6)$ & - & - & $\begin{array}{l}622.8 \\
(n=6)\end{array}$ \\
\hline $5 A$ & Frozen silt, ice-rich & QS, S & - & - & - & - & $10-60$ & $121.4(n=24)$ & - & - & $\begin{array}{l}121.4 \\
(n=24)\end{array}$ \\
\hline \multirow[t]{2}{*}{$5 B$} & Frozen silt & $\mathrm{T}, \mathrm{E}$ & - & - & - & - & - & - & $0-7$ & 37.1 & 37.1 \\
\hline & & & & & & & & & & $(n=11)$ & $(n=11)$ \\
\hline $6 A$ & $\begin{array}{l}\text { Frozen sandy silt, } \\
\text { silty sand, } \\
\text { ice-rich }\end{array}$ & $s$ & - & - & $10-40$ & $65.3(n=26)$ & - & - & - & - & $\begin{array}{l}65.3 \\
(n=26)\end{array}$ \\
\hline \multirow[t]{2}{*}{$6 B$} & Frozen sandy & E & 0 & 38.5 & $0-3$ & 38.9 & $0-10$ & 37.7 & $0-7$ & 34.5 & 37.8 \\
\hline & silt, silty sand & & & $(n=6)$ & & $(n=83)$ & & $(n=74)$ & & $(n=26)$ & $(n=189)$ \\
\hline \multirow[t]{3}{*}{ GUF } & Unfrozen & UF & - & 29.7 & - & - & - & - & - & - & 29.7 \\
\hline & sandy silt, silty & & & $(n=4)$ & & & & & & & $(n=4)$ \\
\hline & sand & & & & & & & & & & \\
\hline \multirow[t]{2}{*}{7} & Frozen fine to & E & 0 & 35.1 & 0 & 30.8 & o & 31.9 & 0 & 31.7 & 31.2 \\
\hline & medium sand & & & $(n=3)$ & & $(n=79)$ & & $(n=25)$ & & $(n=3)$ & $(n=110)$ \\
\hline \multirow[t]{3}{*}{$7 \mathrm{UF}$} & Unfrozen fine & UF & - & 22.7 & - & - & - & - & - & - & 22.7 \\
\hline & to medium & & & $(n=4)$ & & & & & & & $(n=4)$ \\
\hline & sand & & & & & & & & & & \\
\hline \multirow[t]{2}{*}{$8 \mathrm{~A}$} & Frozen & E & 0 & 27.3 & 0 & 24.5 & o & 19.5 & 0 & 29.7 & 25.6 \\
\hline & gravelly sand & & & $(n=6)$ & & $(n=2)$ & & $(n=2)$ & & $(n=1)$ & $(n=11)$ \\
\hline
\end{tabular}




\begin{tabular}{|c|c|c|c|c|c|c|c|c|c|c|c|}
\hline $\begin{array}{l}\text { Sub- } \\
\text { unit }\end{array}$ & Soil & PF type* & A & & B & & C & & D & & $A-D$ \\
\hline \multirow[t]{2}{*}{$8 \mathrm{~B}$} & Frozen sandy & E & 0 & 8.1 & 0 & 15.6 & 0 & 11.6 & 0 & 10.6 & 13.5 \\
\hline & gravel & & & $(n=1)$ & & $(n=9)$ & & $(n=1)$ & & $(n=4)$ & $(n=15)$ \\
\hline \multirow[t]{3}{*}{$8 \mathrm{UF}$} & Unfrozen & UF & - & 10.0 & - & - & - & - & - & - & 10.0 \\
\hline & sandy gravel & & & $(n=1)$ & & & & & & & $(n=1)$ \\
\hline & & & & & & & & & & & $N=654$ \\
\hline
\end{tabular}

Figure A-1. Unfrozen peat (Sub-unit 2UF), T3-50, depth $110 \mathrm{~cm}$ to $140 \mathrm{~cm}$ (43 in. to $55 \mathrm{in}$.).

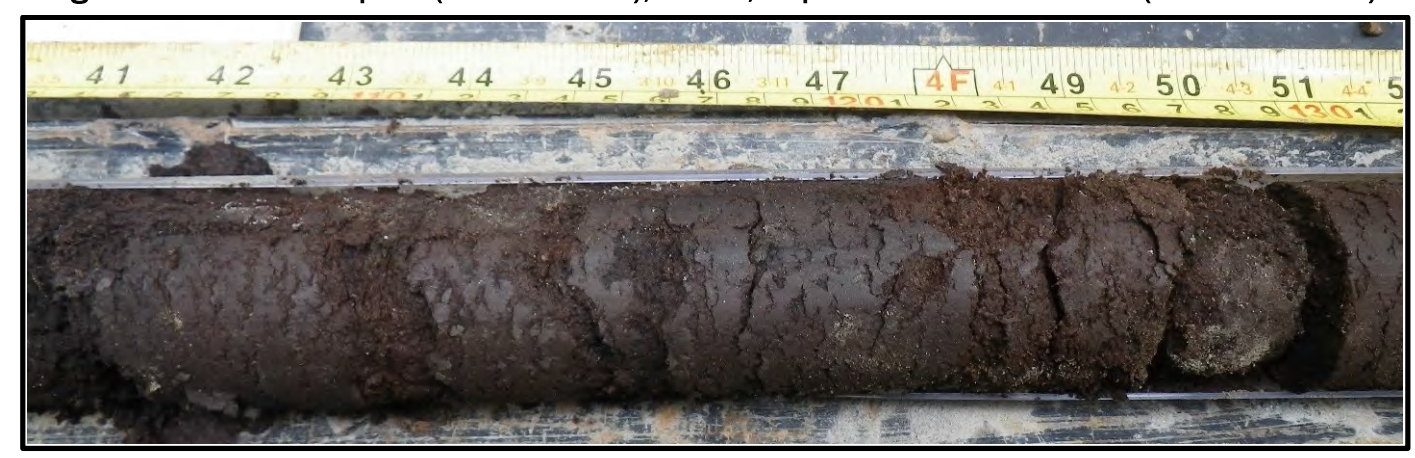

Figure A-2. Frozen peat, no visible ice (Sub-unit 2A), T3-56, depth $90 \mathrm{~cm}$ to $110 \mathrm{~cm}$ (35 in. to 43 in.).

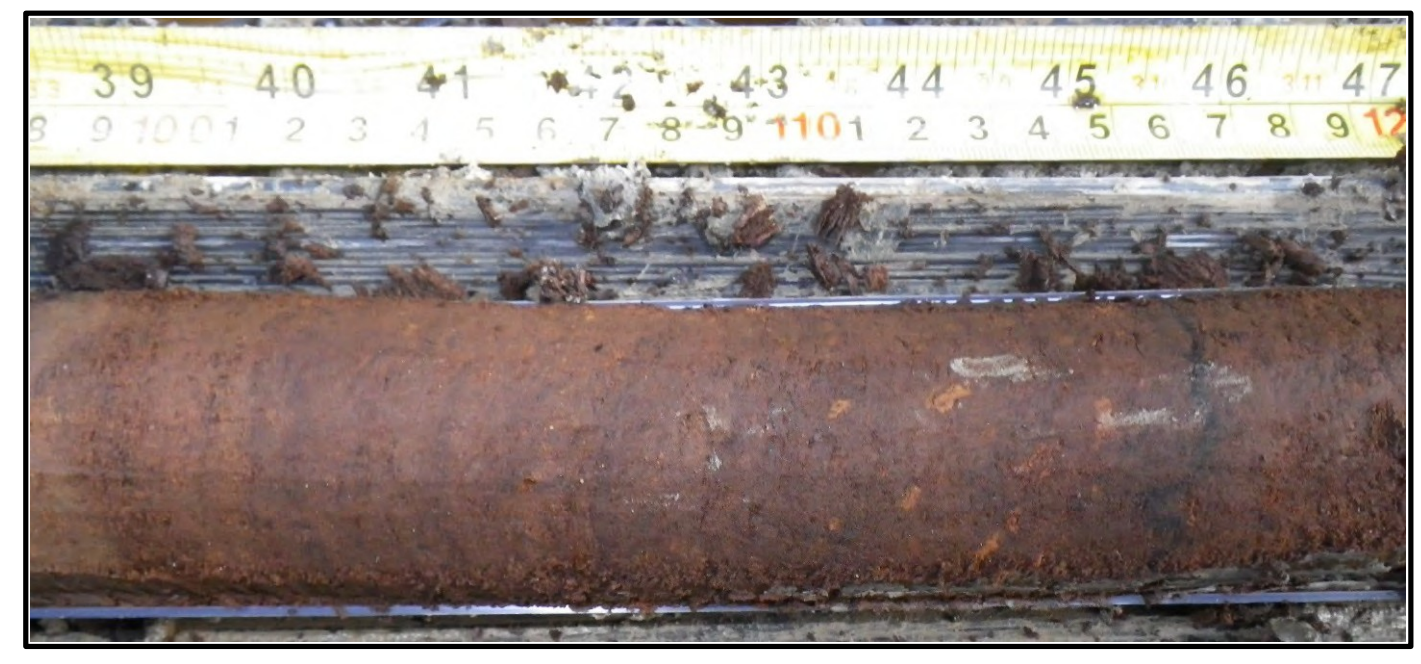


Figure A-6. Ice-rich syngenetically frozen silty sand, very fine to fine, strongly oxidized, with micro-braided cryostructure and thick ice belts (Sub-unit 6A), T3-62, depth $210 \mathrm{~cm}$ to $230 \mathrm{~cm}$ (83 in. to 90 in.).

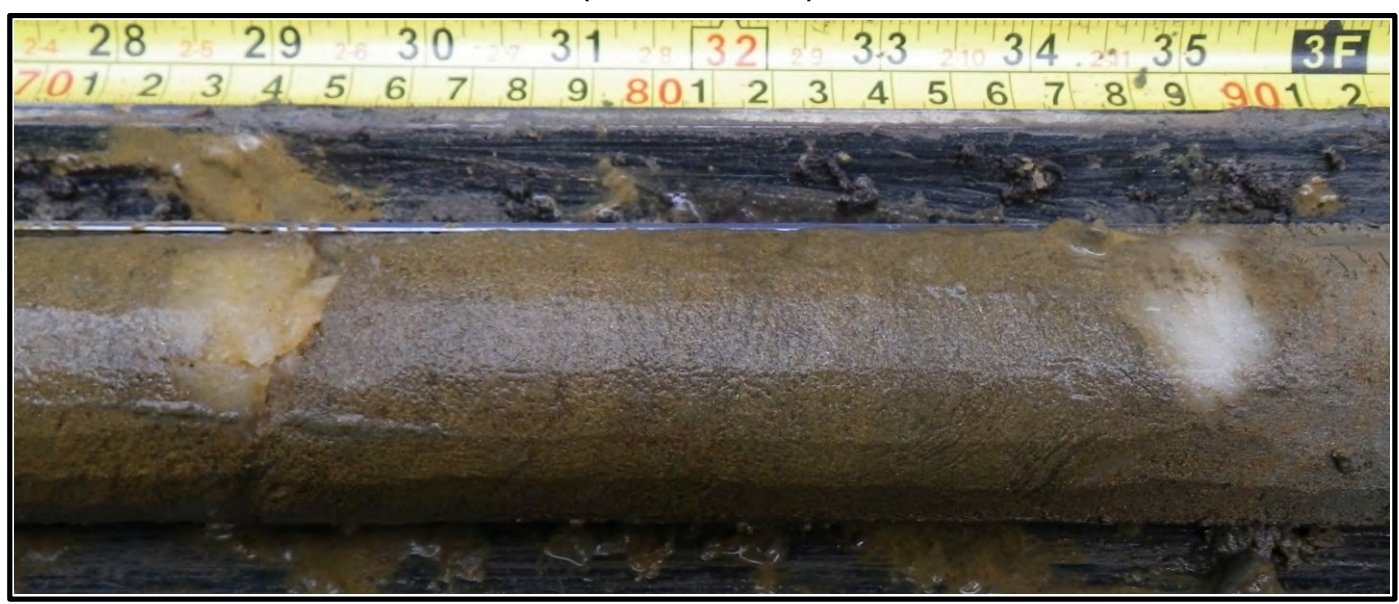

Figure A-7. Ice-rich quasi-syngenetically frozen silt (intermediate layer) with ataxiticcryostructure and thick ice belts (Sub-unit 3A), T3-65, depth $110 \mathrm{~cm}$ to $130 \mathrm{~cm}$ (43 in. to 51 in.).

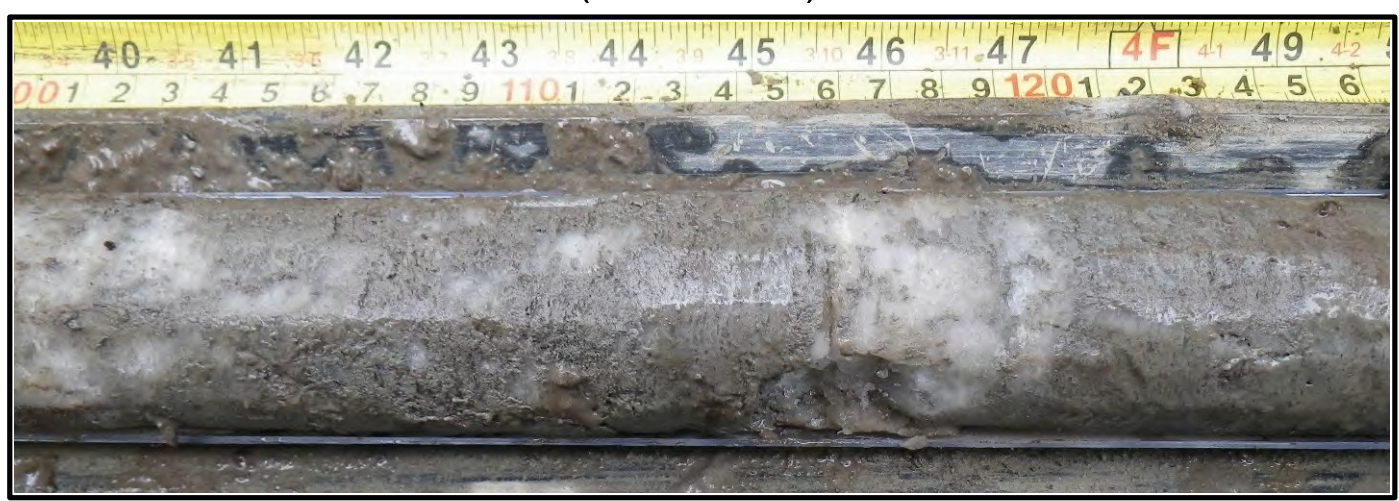

Figure A-8. Ice-rich quasi-syngenetically (or syngenetically) frozen peat with organic-matrix to micro-braided and ataxiticcryostructure and thick ice belts (Sub-unit 2B), T3-68, depth $80 \mathrm{~cm}$ to $95 \mathrm{~cm}$ (31 in. to $37 \mathrm{in}$.).

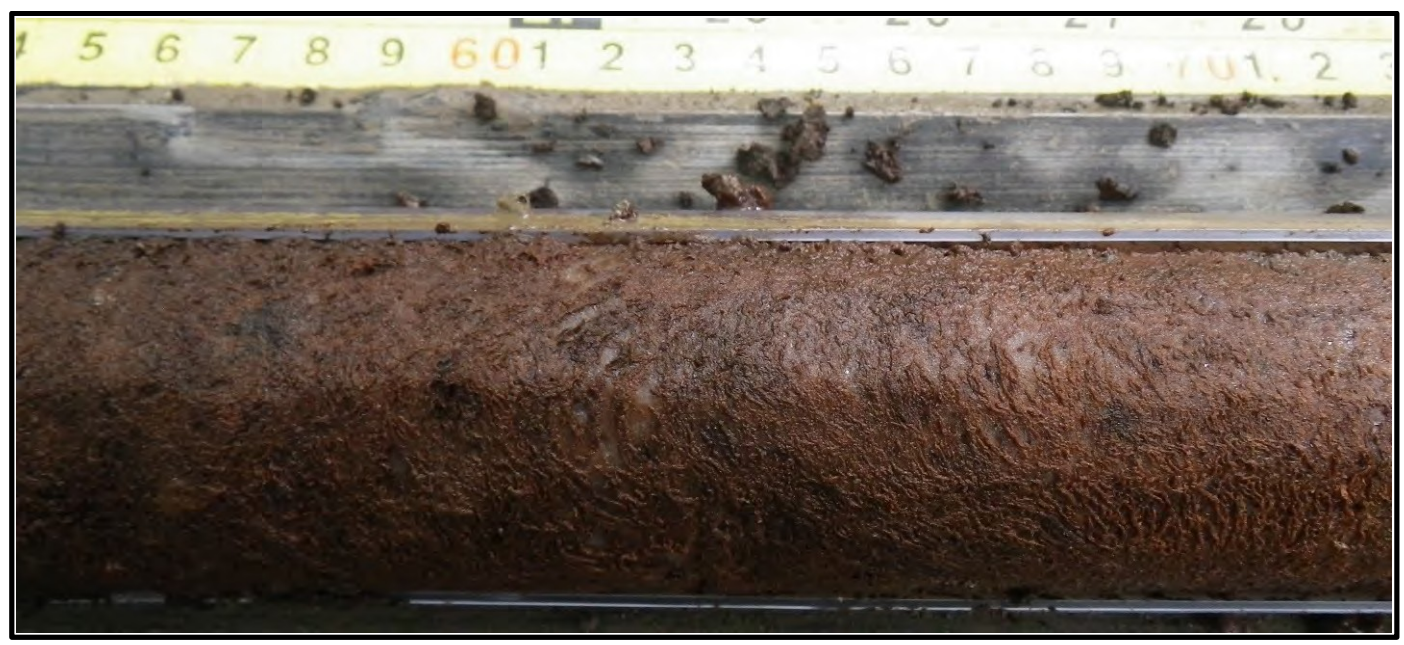


Figure A-9. Epigenetically frozen very fine to fine silty sand, with thin layers of organic detritus (Sub-unit 6B), no visible ice, T3-68, depth $390 \mathrm{~cm}$ to $410 \mathrm{~cm}$ (153 in. to $161 \mathrm{in}$.).

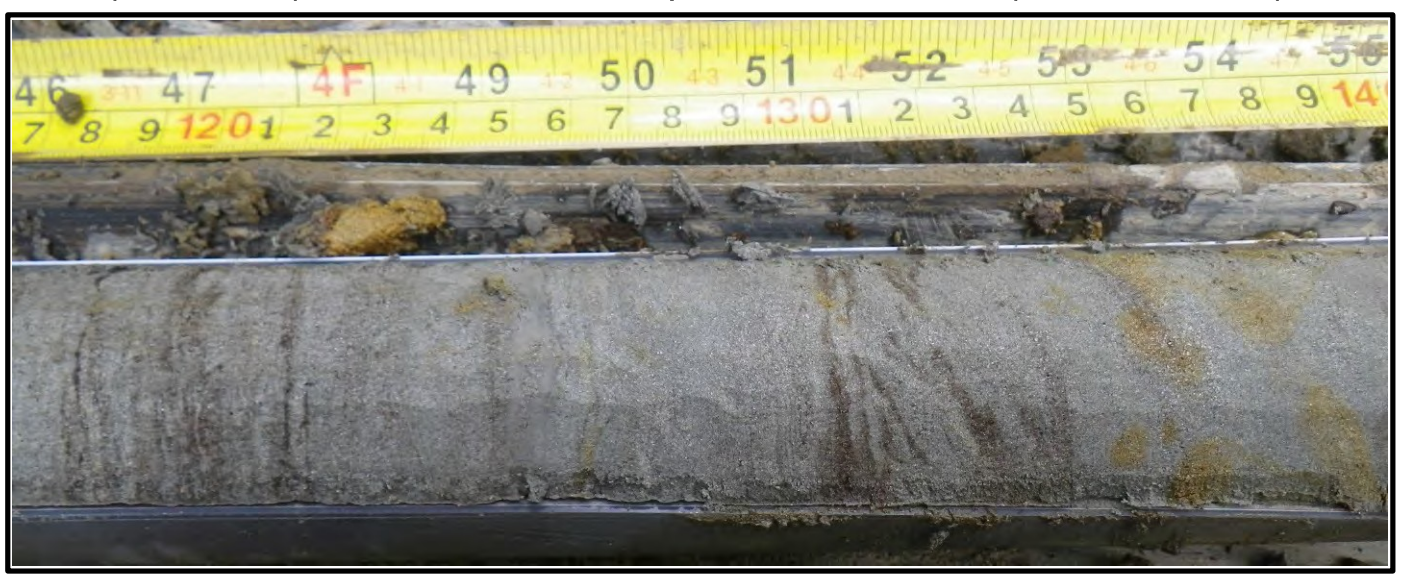

Figure A-10. Ice-rich quasi-syngenetically frozen silt with ataxiticcryostructure (Sub-unit 3A), T3-71, depth $185 \mathrm{~cm}$ to $200 \mathrm{~cm}$ (73 in. to $79 \mathrm{in}$.).

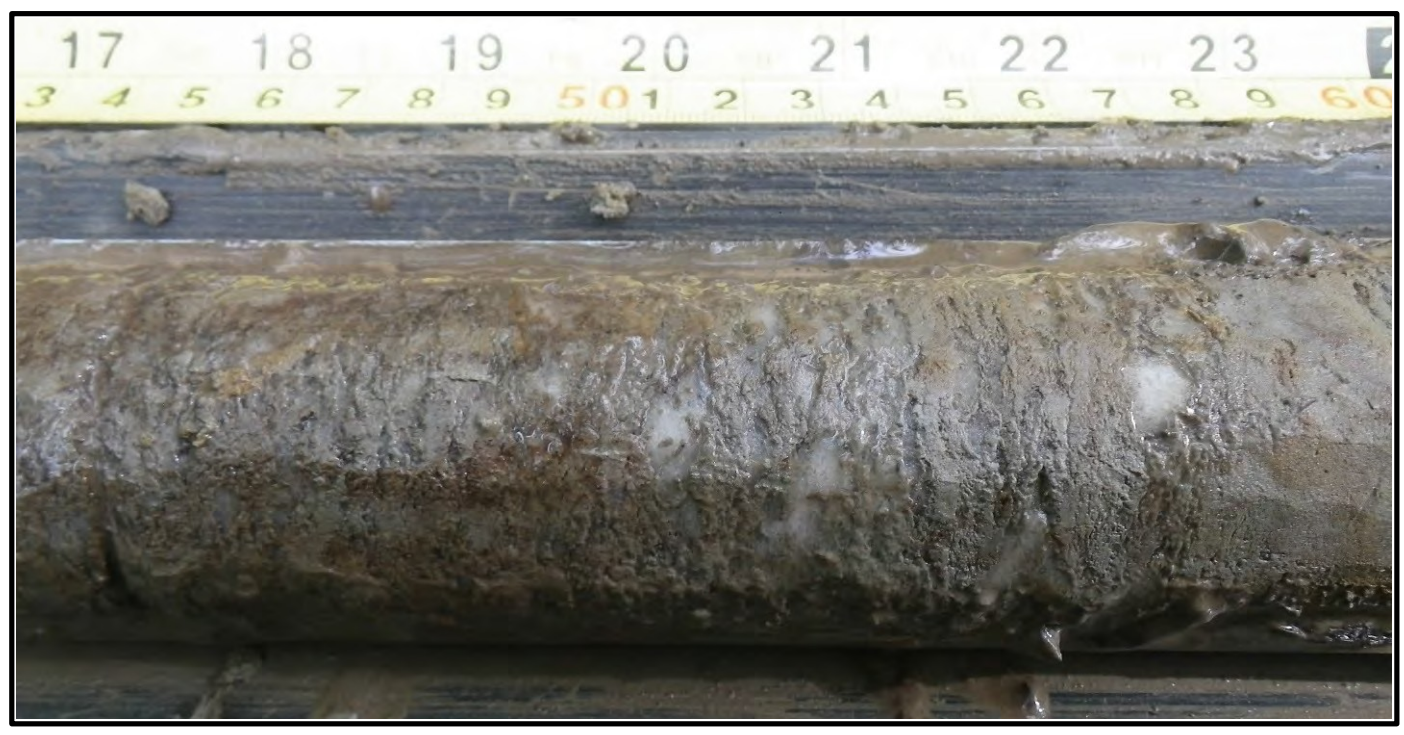


Figure A-11. Contact between the ice wedge and syngenetically frozen sandy silt with microlayered cryostructure (Sub-unit 6A), T3-83, depth $225 \mathrm{~cm}$ to $235 \mathrm{~cm}$ (88 in. to $92 \mathrm{in}$.).

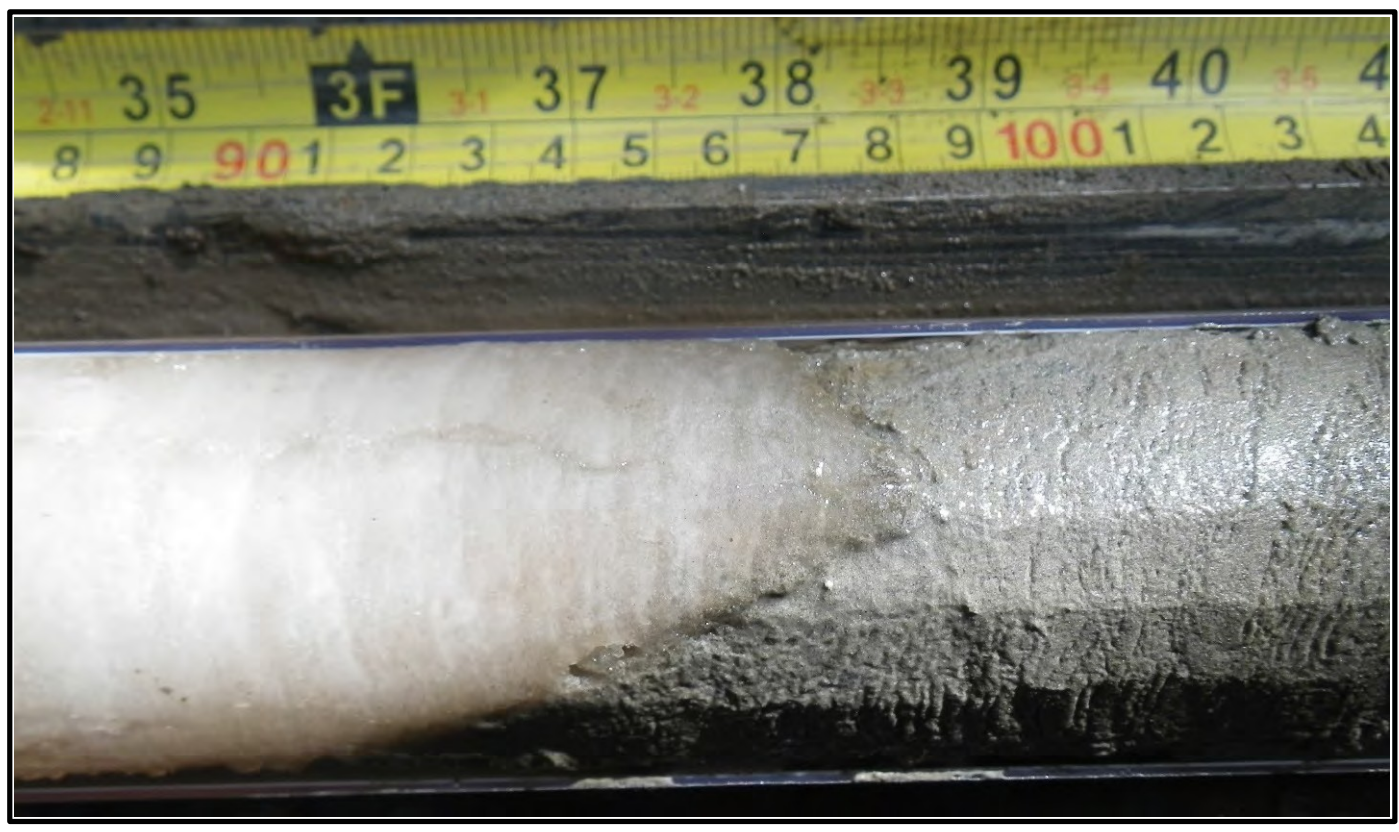

Figure A-12. Boundary between epigenetically frozen sand, fine to medium, with inclusions of very coarse sand (Unit 7) and sandy gravel (Sub-unit 8B), no visible ice, T3-98, depth $670 \mathrm{~cm}(263 \mathrm{in}$.).

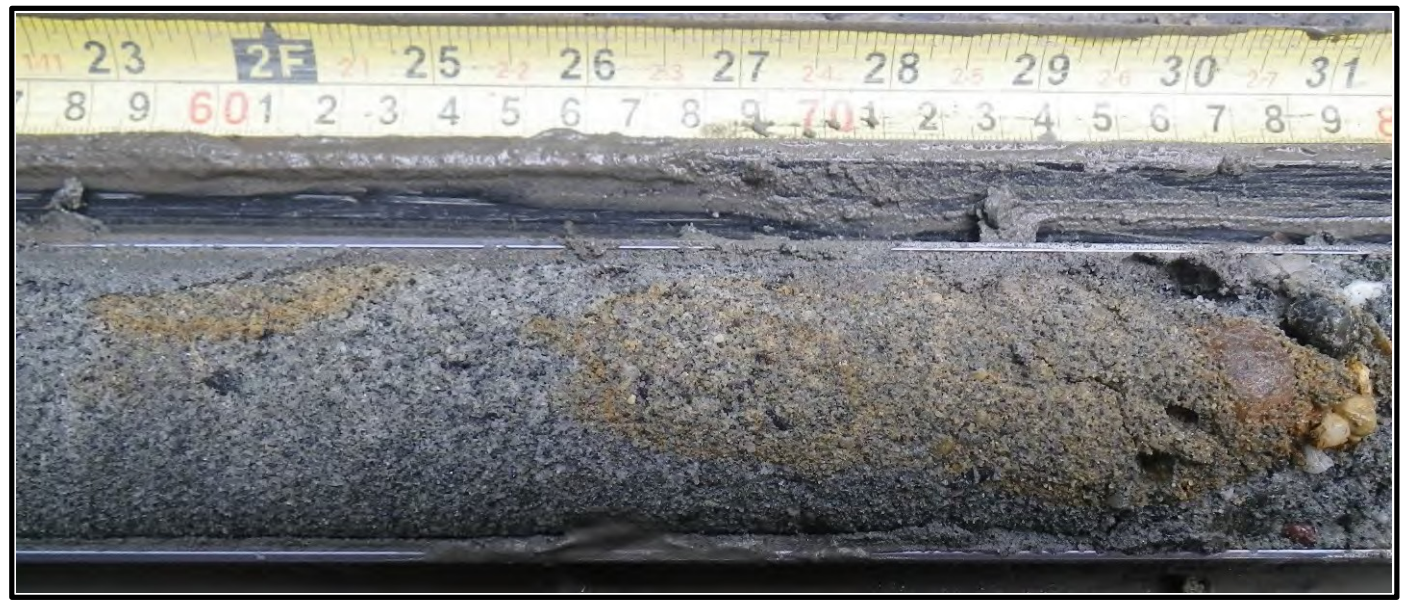


Figure A-13. Syngenetically frozen silty sand, friable, with micro-layered cryostructure (Subunit 6A), T3-101, depth $310 \mathrm{~cm}$ to $315 \mathrm{~cm}$ (122 in. to 124 in.).

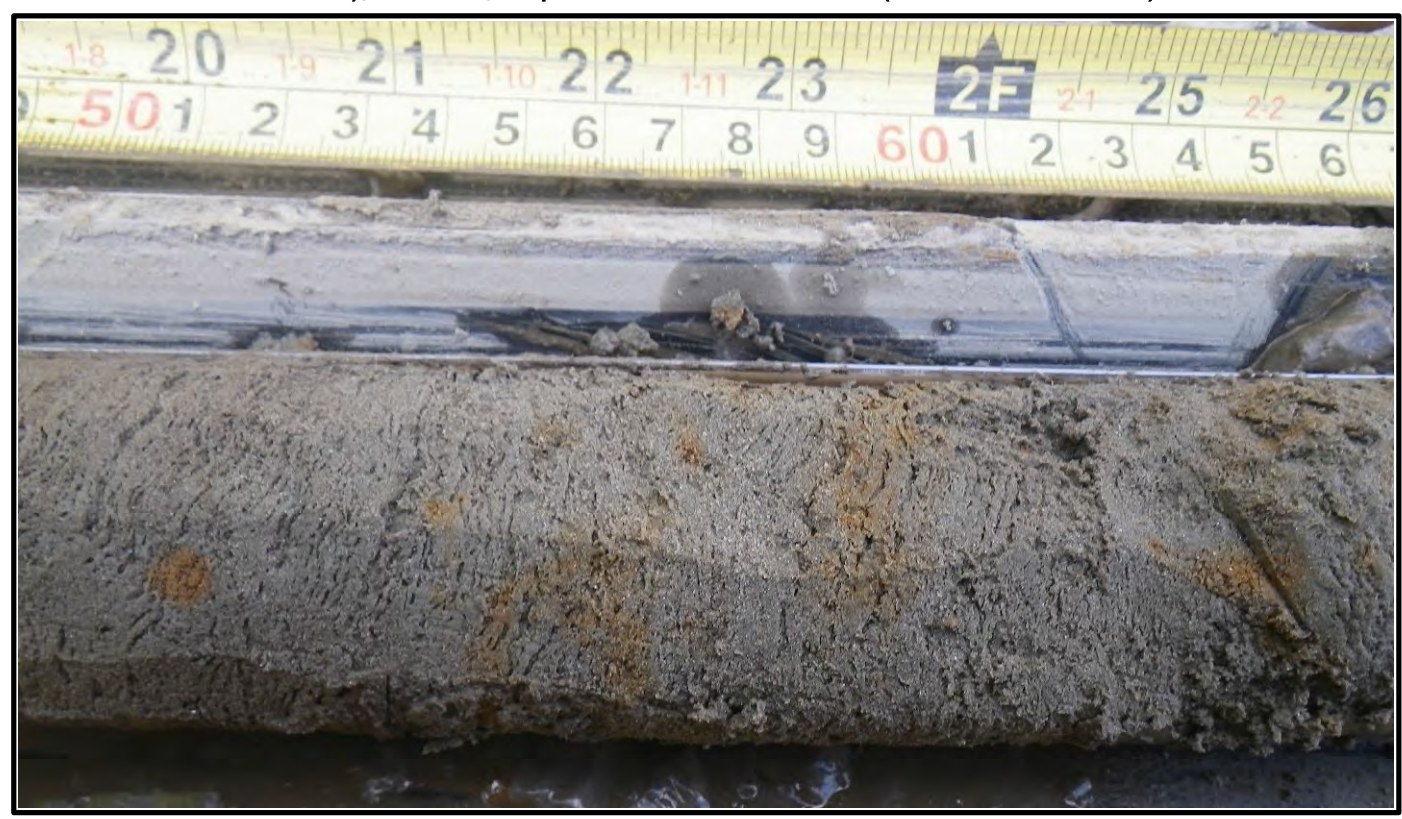

Figure A-14. Quasi-syngenetically frozen silt (intermediate layer), with micro-braided to microataxiticcryostructure and thick ice belts (Sub-unit 2B), T3-107, depth $90 \mathrm{~cm}$ to $110 \mathrm{~cm}$ (35 in. to $43 \mathrm{in.}$.).

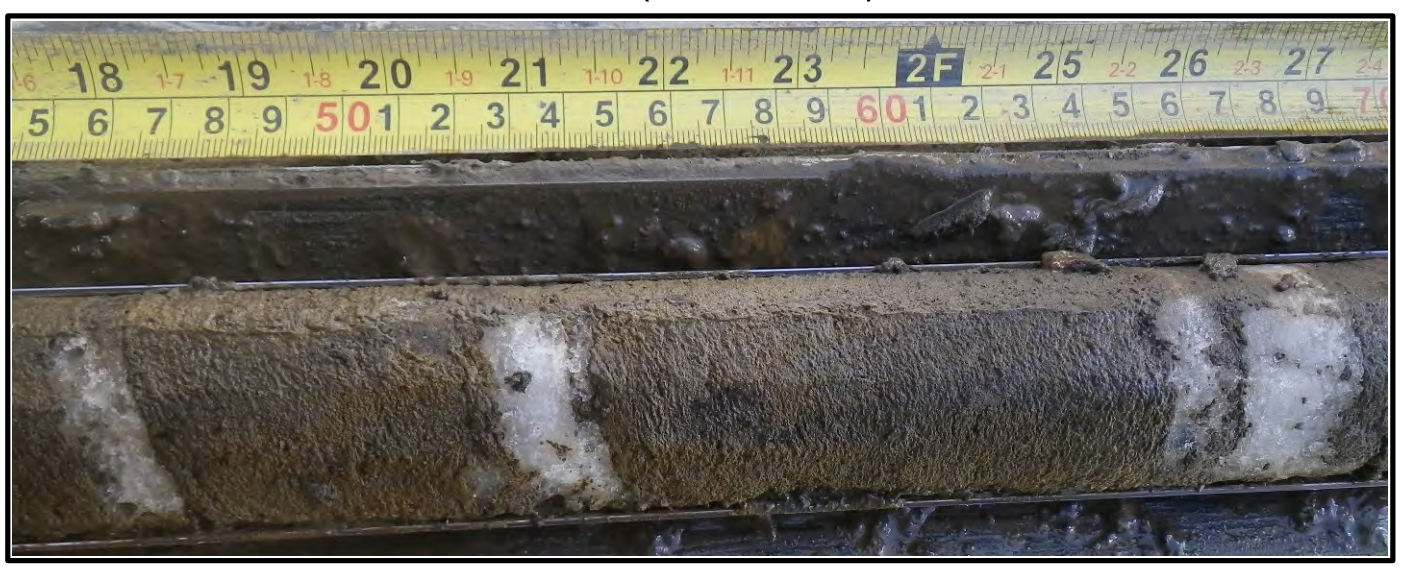


Figure A-15. Quasi-syngenetically frozen peat (buried), with organic-matrix to microataxiticcryostructure (Sub-unit 4B), T3-107, depth $220 \mathrm{~cm}$ to $240 \mathrm{~cm}$ (86 in. to $94 \mathrm{in}$.).

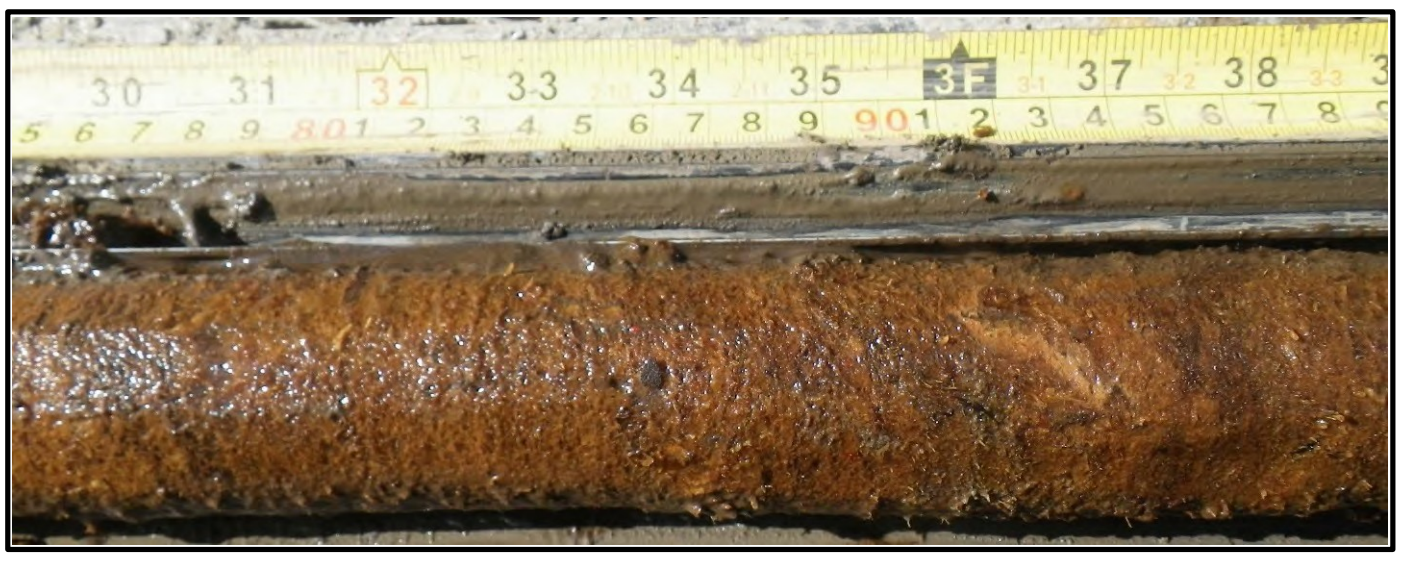

Figure A-16. Quasi-syngenetically frozen silt (buried intermediate layer), with braided to ataxiticcryostructure (Sub-unit 5A), T3-107, depth $280 \mathrm{~cm}$ to $295 \mathrm{~cm}$ (110 in. to $116 \mathrm{in}$.).

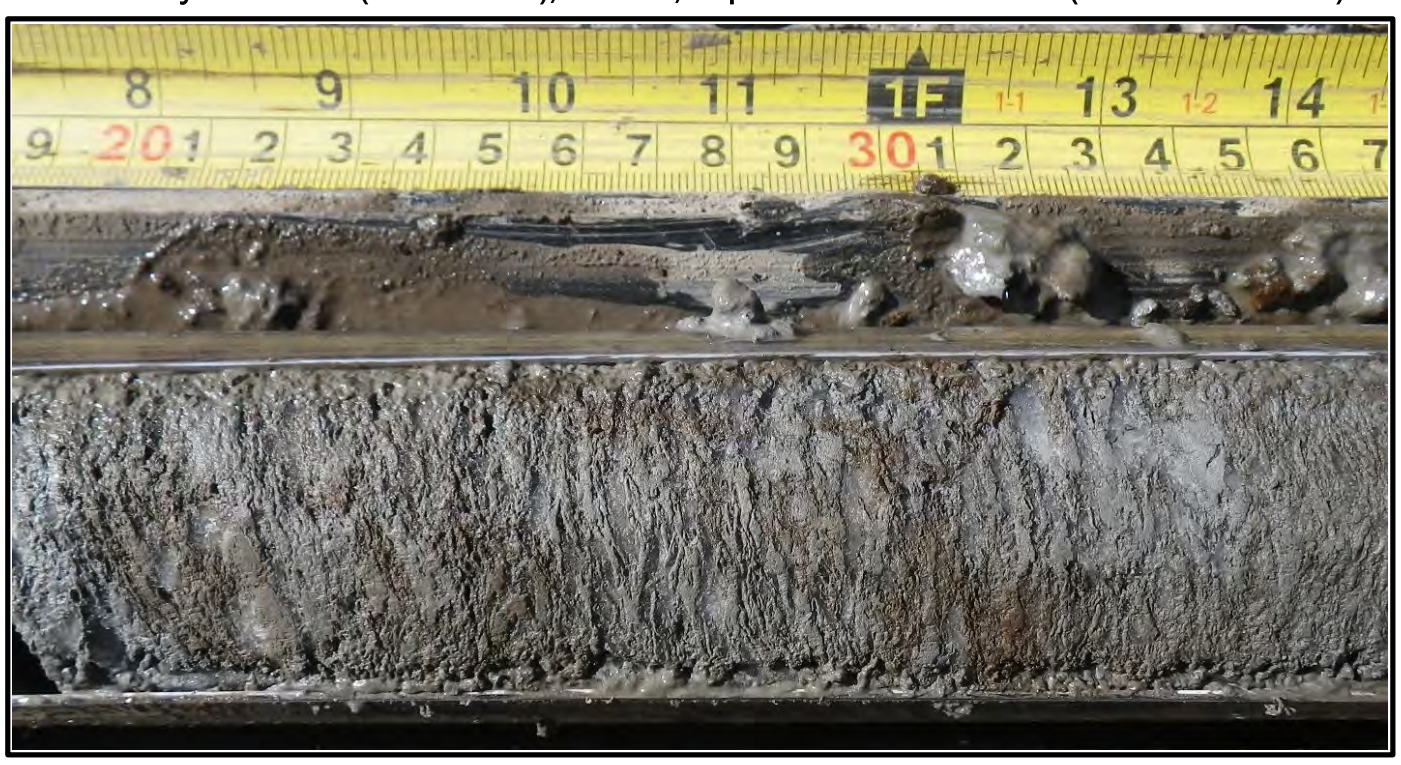


Figure A-17. Epigenetically frozen laminated silty sand / very fine to fine sandy silt with thin layers of organic detritus (Sub-unit 6B), no visible ice, T3-137, depth $370 \mathrm{~cm}$ to $380 \mathrm{~cm}$ (145 in. to 149 in.).

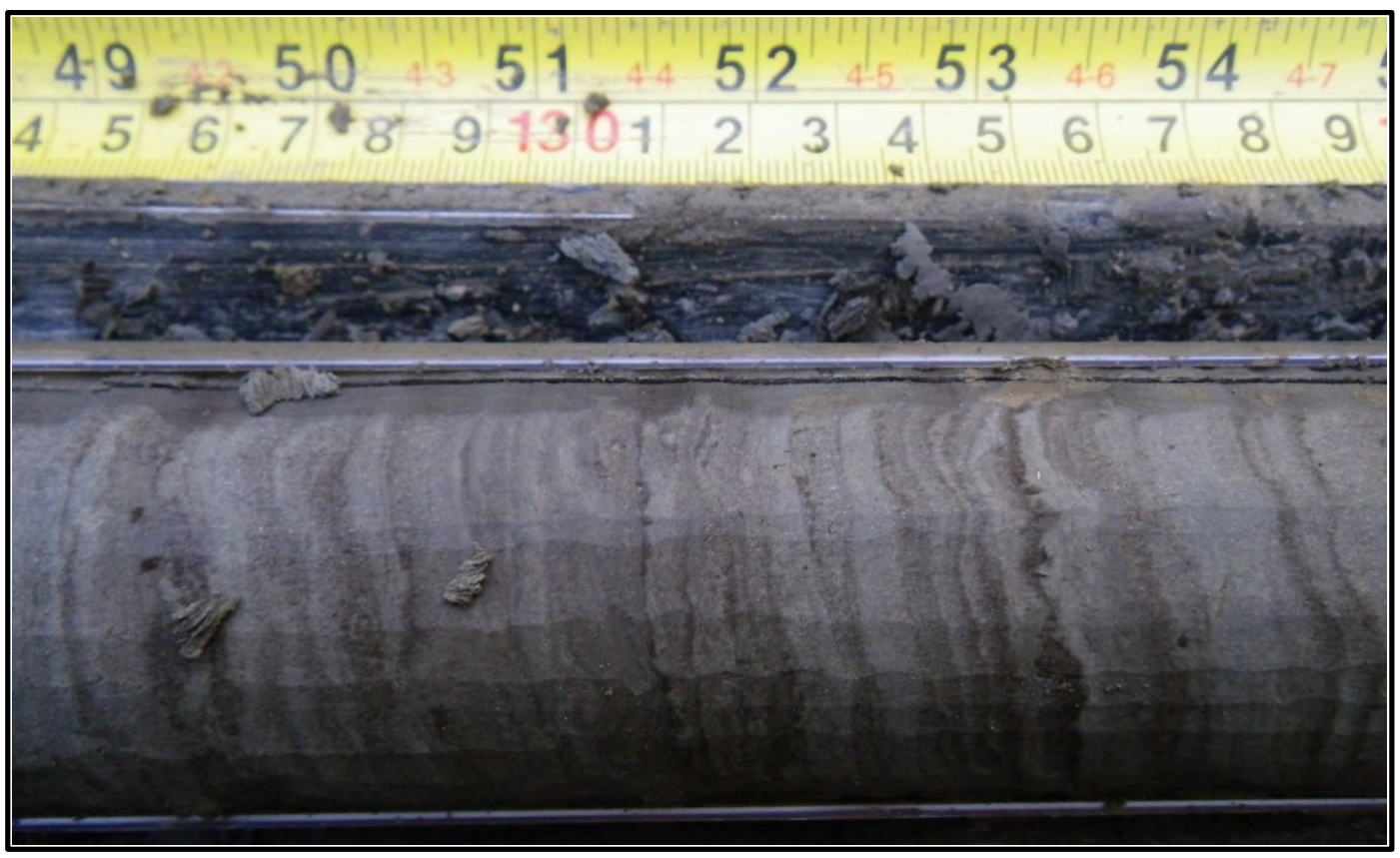

Figure A-18. Quasi-syngenetically frozen silt (intermediate layer), with braided to ataxiticcryostructure (Sub-unit 3A), T3-146, depth $70 \mathrm{~cm}$ to $80 \mathrm{~cm}$ (28 in. to $31 \mathrm{in}$.).

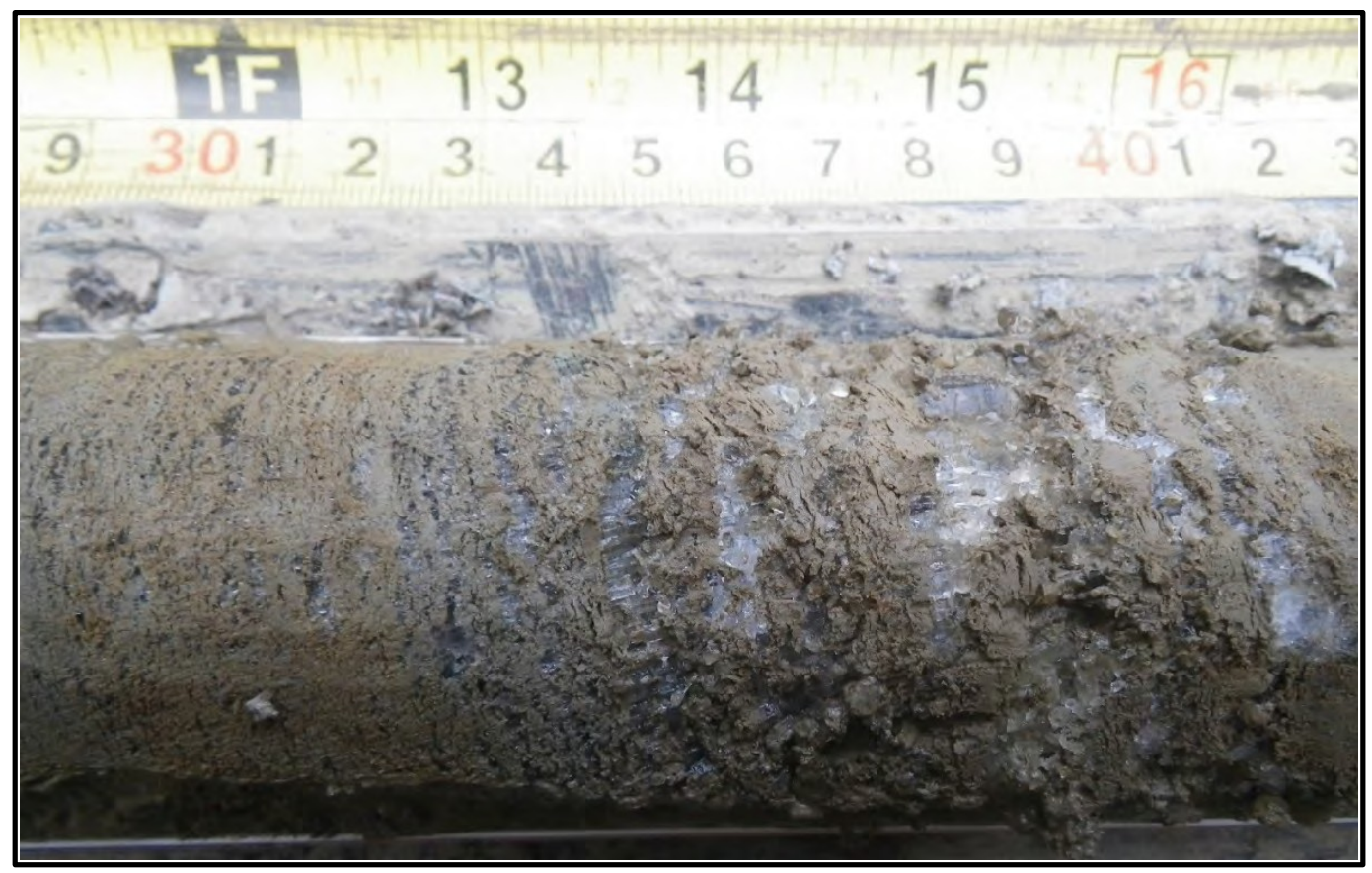




\section{Appendix B: Review of Russian Literature}

To inform our ability to propose effective foundations for building on permafrost and to expand our understanding of prior research, we began a literature review of Russian publications on building on permafrost. These publications span the past 100 years and establish a thorough bibliography on topics that guided our recommendations and DSS. The following sections include an annotated listing of relevant publications.

\section{B.1 Bondarev, P.D. 1957. Deformation of Buildings in Vorkuta Re- gion, Their Causes and Methods of Their Prevention. Moscow: Academy of Sciences.}

Before and during WWII, the engineering and scientific community was of the opinion that permafrost in the Vorkuta region was degrading; hence, buildings should be constructed with an assumption that permafrost would thaw beneath them. As a result, until 1946, industrial and civil structures were constructed according to the active design alternative, despite the permafrost conditions, soil properties, and hydrology of construction sites. In expectation of thawed soils under foundations, the allowed bearing capacity of soil varied from $0.5 \mathrm{~kg} / \mathrm{cm}^{2}$ to $2.0 \mathrm{~kg} / \mathrm{cm}^{2}(7 \mathrm{psi}$ to $28 \mathrm{psi}$ ). At the same time (except for two buildings), measures against unacceptable deformation were not taken into consideration. Development of thaw bulbs under buildings led to differential settlement and deformation of buildings, especially in industrial areas.

The first experimental building designed and constructed according to the passive design alternative was a nursing home; this was built in 1946 with a ventilated crawl space. The permafrost table under part of the building was originally at a depth of $5 \mathrm{~m}(16 \mathrm{ft})$. Several years after construction, the permafrost table had reached the bottom of the active layer. This positive experience changed the approach to building design, and most buildings since the late 1940 s have been constructed with permafrost protection. The author concluded that in areas of discontinuous warm permafrost as in the Vorkuta region, the passive design alternative, supported by proper construction and maintenance, is a reliable approach to ensuring the stability of buildings.

The author inspected 165 buildings and found that 130 of them had deformations. Some buildings only had cracks in the wall plaster, but other 
buildings were completely destroyed. The main cause of deformation was thawing permafrost under buildings, with differential settlement of inner and external walls. Frost heave impact was also documented. Table B-1 lists the types of deformation.

Table B-1. Types of deformation.

\begin{tabular}{|l|c|c|c|}
\hline \multirow{2}{*}{ Type of Deformations } & \multicolumn{2}{|c|}{ Number of Buildings Affected } & \multirow{2}{*}{ Total } \\
\cline { 2 - 3 } & Made of Brick & Made of Wood & 15 \\
\hline Partial destruction of wall material & 15 & & 5 \\
\hline Total destruction of walls & 5 & & 101 \\
\hline Open cracks in walls & 52 & 49 & 47 \\
\hline Settlement of furnaces & 14 & 33 & 51 \\
\hline Settlement of floors & 34 & 17 & 93 \\
\hline $\begin{array}{l}\text { Deformation of plaster of wall and ceilings } \\
\text { requiring annual repair }\end{array}$ & 28 & 65 & 61 \\
\hline Frost heave of Arctic entries & 21 & 40 & 67 \\
\hline Skewness of windows and doors & 22 & 45 & \\
\hline
\end{tabular}

At that time, the author classified the causes leading to hazards as follows

- Insufficient geotechnical data. Proceeding with a design without a geotechnical investigation of the building site. In areas of discontinuous permafrost, part of a building would be on permafrost, while the rest of the building would be on unfrozen soil or on permafrost with a lowered table.

- Wrong choice of a design alternative. Choosing the active design alternative instead of the passive design alternative.

- Wrong design. Designing the layout of buried utility lines, especially heating lines close to building foundations, according to the passive design alternative, and an absence of measures to protect ventilated crawl space and foundations from surface water. Constructing foundations in the active layer and insufficient cooling impact of ventilated ducts.

- Mistakes during construction. Flooding of open trenches and pits and their backfill without proper compaction, unfinished construction without protection in winter.

- Maintenance negligence. Discharging water and condensate on the ground next to walls; leaking utility lines. 


\section{B.2 Aleksandrov, A.S., I.I. Zhelezniak, and Y.M. Mosenkis, 1990. En- gineering Development of Permafrost in Transbaikalia. Novosi- birsk: Nauka.}

The region discussed in this publication covered a wide area, the northern part of which is underlain by continuous permafrost. In the southern part of this region, the permafrost is considered warm and discontinuous. Chita, the biggest city described in this Aleksandrov et al. (1990), has a population of more than 300,000 . The mean annual air temperature in Chita is $-1.4^{\circ} \mathrm{C}\left(29^{\circ} \mathrm{F}\right)$ The permafrost temperature is $-0.2{ }^{\circ} \mathrm{C}\left(31.6^{\circ} \mathrm{F}\right)$. The authors mainly presented their experience in the construction of buildings in Chita and some other cities in the discontinuous permafrost zone. They inspected 61 buildings, some of them multistory.

Thirteen buildings were built to preserve the frozen state of soil (using the passive design alternative). Others were built in areas that had permafrost thawing during the life of the structures (active design alternative).

Most of the buildings constructed according to the active design alternative had deformations that led to loss of the buildings' integrity; several buildings were demolished. The maximum thaw settlement under several buildings exceeded $30 \mathrm{~cm}$ (12 in.). The highest rate of deformation occurred during the first 5 to 6 years following construction. The authors concluded that the design of $75 \%$ to $80 \%$ of the deformed buildings was not based on sufficient geotechnical information. As a result, the wrong design alternative was chosen.

The authors found that even in such warm permafrost, the passive design alternative can be the best solution, although, some professionals expressed doubts regarding the possibility of preservation of the frozen state of soil under buildings. Among the 13 buildings inspected, only two were severely damaged. In both cases, deformations were caused by poor maintenance, which led to water discharge under buildings from leaking utilities.

The authors stated that field inspection during soil excavation and foundation construction should be required, and that extra measures should be taken when real soil conditions differ from the conditions that are expected during design. 


\section{B.3 Roman, L.T., 1987. Frozen Peaty Soils as Bases of Structures. Novosibirsk: Nauka.}

This publication was the only monograph reviewed on the topic of physical and mechanical properties of frozen organic soils including peat. The author's original data on creep and the long-term strength of frozen peaty soils and thaw strain are included. Three types of piles are recommended (see Figure B-1). The author concluded that frozen peaty soils can be a reliable foundation base for structures.

Figure B-1. Three recommended types of piles.

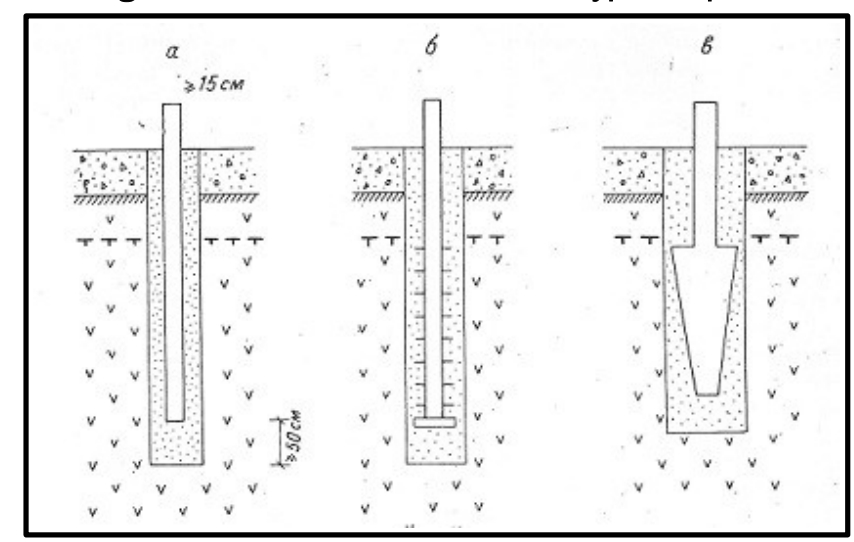

\section{B.4 Aksenov, V.I. 2008. Saline Frozen Soils of Arctic Shore as Foun- dations of Structures - Everything about Construction. Moscow: VMS publisher.}

This book is based on the author's more than 30 years of experience in the research of properties of frozen saline soils of the Russia Arctic. The author provided information on one-dimensional and three-dimensional compression, cohesion, creep, and long-term strength of frozen saline soils and adfreeze strength of frozen saline soils with foundations. The author also presented data on deformation of frozen saline soils under dynamic loading. The author also provided rare data on field testing the bearing capacity of piles in frozen saline soils. Case studies of buildings and some other structures are presented, with detailed analysis of failures. The main cause of building failure was insufficient characterization of saline soils. The author described that the bearing capacity of piles designed according to the contemporary Russian Building Codes for the permafrost region is not safe. Aksenov recommended design data on the bearing capacity of shallow foundations and the adfreeze strength of frozen saline soils with piles. 


\section{B.5 Kim, M.V., B.F. Bitadze, et al. 1962. Construction of Foundations on Permafrost. Krasnoiarsk: Gosstroylzdat.}

This book presented experience in construction on permafrost in Noril'sk, the biggest industrial city in the Arctic. Noril'sk is located in the continuous permafrost zone. Mean annual permafrost temperature generally varies from $-2{ }^{\circ} \mathrm{C}$ to $-4{ }^{\circ} \mathrm{C}\left(28.4{ }^{\circ} \mathrm{F}\right.$ to $\left.24.8^{\circ} \mathrm{F}\right)$. Soil conditions vary from bedrock at a depth of $10 \mathrm{~m}$ to thick layers of gravely to fine soils. The thaw strain of gravels varies from 0.005 to 0.06 . The thaw strain of fine-grained soils varies from 0.05 to 0.2 and even greater depending on ice content.

Noril'sk became the first location in Russia's permafrost region where piles were used as the main type of foundation for industrial buildings and multistory apartment houses. Initially, piles were installed in steam-thawed soil. Uncontrolled thawing and long freezeback were disadvantages of this method. Progress in permafrost drilling made possible the installation of piles in predrilled holes. Precast concrete piles were installed in holes of a larger diameter. Just before installation of a pile, one-quarter to one-third the depth of a hole was filled with slurry made of local clayey soil mixed with drilling cuttings. The time required for freezeback of piles in permafrost with temperatures from -2 to $-4{ }^{\circ} \mathrm{C}\left(28.4^{\circ} \mathrm{F}\right.$ to $\left.24.8^{\circ} \mathrm{F}\right)$ varies from 5 to 10 days for piles installed at the end of winter and from 10 to 20 days for piles installed in summer and autumn. Freezeback is controlled by monitoring the temperature of a pile. The passive design alternative has been found to be the best approach for foundations in Noril'sk.

The authors also presented a case study in which the active design alternative was applied during construction of a big industrial building. The soil at the site was gravel with inclusions of silt and silty clay. The thaw strain of the soil varied from 0.015 to 0.035. The building was designed with an anticipation of differential thaw settlement. The one restriction was that no deviation of columns from the vertical position should be permitted. Sufficient thaw settlement occurred several years after construction. Maximum thaw settlement was $30 \mathrm{~cm}$ (12 in.); minimum thaw settlement was only $1.8 \mathrm{~cm}$. The maximum difference in settlement between neighboring foundations was $15 \mathrm{~cm}$ ( 6 in.). Crane runways were damaged and required numerous repairs. The concrete frame of the building was not damaged. The authors summarized the conditions required for application of the active design alternative: (1) detailed geotechnical site investigation, (2) construction of buildings on coarse soils without visible ice inclusions, (3) building design that includes flexible connections and section division 
by settlement joints, (4) crane-runway girder that is adjustable vertically and horizontally.

\section{B.6 Saltykov, N.I. 1959. Foundation Bases and Foundations in Per- mafrost Regions. Moscow: Academy of Sciences.}

Saltykov advised that a passive design alternative should be considered as a simple and reliable approach in situations if thaw settlement is high and the bearing capacity of soil in its thawed state is low. Ventilated crawl spaces are designed with the anticipation that thawed soil in summer would freeze up, with a safety factor of 1.25 to 1.5. Extra cooling of soil should be avoided because it would lead to an elevated heat loss from the floor above the ventilated crawl space and would increase in construction cost. Open crawl space is not recommended. Ventilation should be provided through openings in the wall around the crawl space. The total area of openings can be preliminarily evaluated as the area covered by a building, multiplied by the coefficient $\mathrm{M}$ (Table $\mathrm{B}-2)$. The module of ventilation $\mathrm{M}$ is the ratio of the total area of openings to the planned area of a building.

Table B-2. Total area of openings.

\begin{tabular}{|c|c|c|c|c|}
\hline \multirow{2}{*}{$\begin{array}{c}\text { Thermal } \\
\text { Resistance } \\
\text { Above Crawl } \\
\text { Space, } \\
\mathrm{m}^{2} \mathrm{hr}^{\circ} \mathrm{C} / \mathrm{kcal} / \\
\left(\mathrm{BTU} / \mathrm{h} \mathrm{ft}^{\circ}{ }^{\circ} \mathrm{F}\right)\end{array}$} & \multirow{2}{*}{$\begin{array}{c}\text { Air } \\
\text { Temperature } \\
\text { at Floor Level } \\
\text { Above Crawl } \\
\text { Space, } \\
{ }^{\circ} \mathrm{C} /{ }^{\circ} \mathrm{F}\end{array}$} & \multicolumn{3}{|c|}{ Module of Ventilation of a Crawl Space, M } \\
\hline & & Tundra & Taiga & $\begin{array}{c}\text { Transbaikalia } \\
\text { Region }\end{array}$ \\
\hline \multirow[t]{2}{*}{$1(0.204)$} & $15 / 59$ & $0.0025-0.005$ & $0.005-0.02$ & $0.02-0.03$ \\
\hline & $30 / 86$ & $0.0075-0.015$ & $0.015-0.05$ & $0.05-0.08$ \\
\hline \multirow[t]{2}{*}{$2(0.408)$} & $15 / 59$ & $0.0015-0.003$ & $0.003-0.01$ & $0.01-0.015$ \\
\hline & $30 / 86$ & $0.0035-0.007$ & $0.007-0.02$ & $0.02-0.03$ \\
\hline \multirow[t]{2}{*}{$3(0.612)$} & $15 / 59$ & $0.008-0.002$ & $0.002-0.006$ & $0.006-0.009$ \\
\hline & $30 / 86$ & $0.002-0.0035$ & $0.0035-0.01$ & $0.01-0.015$ \\
\hline
\end{tabular}

The stability of a building designed according to the passive design alternative can be greatly affected by the thermal impact of utility lines, especially heating lines constructed according to the active design alternative. In Noril'sk, the safe distance from heating lines to building foundations is $20 \mathrm{~m}$ to $25 \mathrm{~m}$ ( $66 \mathrm{ft}$ to $82 \mathrm{ft}$ ). The release of water from broken utility lines is the most hazardous for foundations based on frozen soil.

Practical applications of the active design alternative could be valuable with the following suggestions: better understanding of the interaction of 
thawing soil with foundations and aboveground structures; development of improved methods of evaluating the depth and shape of the thaw bowl; use of light construction material; improved methods of predicting the thaw strain of soils; better construction of settlement joints; improved measures of protecting foundations from frost heaving; accumulation of building monitoring data.

The author discussed pre-thawing of permafrost before construction, and proposed four main cases of pre-thawing (Figure B-2):

1. Pre-thawing under the entire building to a depth of the predicted thaw bulb under a building

2. Pre-thawing under the entire building of the upper part to a depth that is sufficient to reduce thaw settlement and its rate

3. Pre-thawing of permafrost only inside the outline of a foundation to the entire depth of the predicted thaw bulb

4. Pre-thawing of permafrost only inside the outline of a foundations to a depth smaller than a depth of the predicted thaw bulb

Figure B-2. Proposed four main cases of pre-thawing.

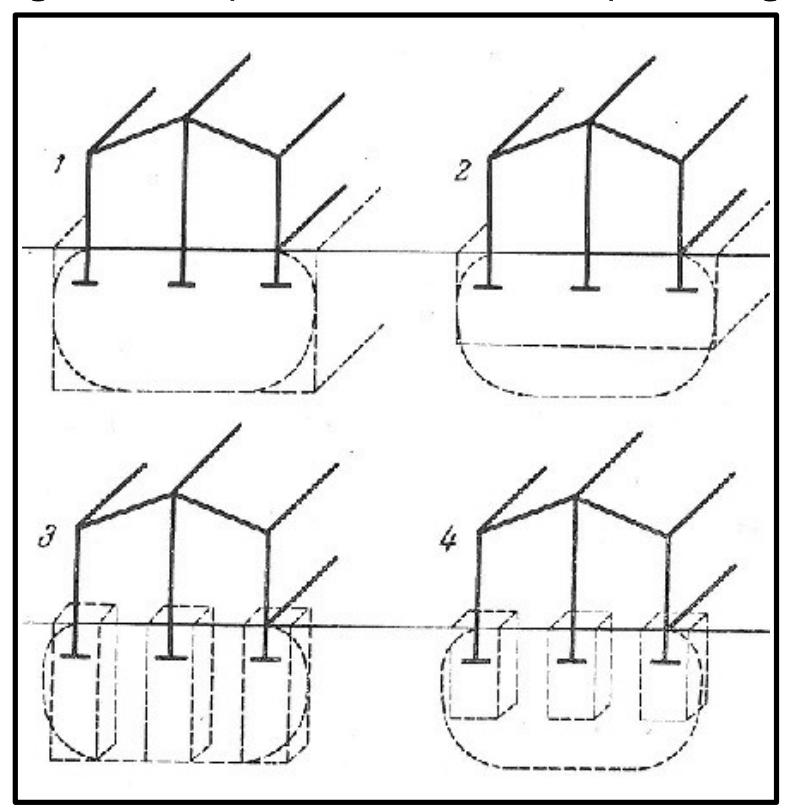

The author prescribed thaw settlement information for some soils in relation to their initial void ratio and pressure. Table B-3 lists example average and differential thaw settlements under structures. 
Table B-3. Thaw settlement for some soils in relation to their initial void ratio and pressure.

\begin{tabular}{|l|c|c|c|c|}
\hline Soil and Its Genesis & $\begin{array}{c}\text { Void Ratio, } \\
\mathbf{e}\end{array}$ & $\begin{array}{c}\text { Pressure, } \\
\mathrm{kPa} / \mathrm{psi}\end{array}$ & Thaw Strain & Differential Settlement \\
\hline Jurassic silty clay & 0.54 & $40 / 5.8$ & $0.01-0.025$ & $0.007-0.025$ \\
\hline Chita region & 0.68 & $150 / 21.8$ & $0.02-0.06$ & $0.02-0.035$ \\
\cline { 2 - 5 } & 1.2 & $150 / 21.8$ & $0.1-0.15$ & $0.035-0.05$ \\
\hline $\begin{array}{l}\text { Colluvial silty clay, } \\
\text { Chita region }\end{array}$ & 1.35 & $150 / 21.8$ & $0.08-0.21$ & $0.025-0.07$ \\
\hline Moraine silty clay & $0.4-0.7$ & $100 / 14.5$ & $0.02-0.04$ & $0.002-0.008$ \\
\hline with gravel, Vorkuta & $0.7-1.1$ & $50 / 7.25$ & $0.07-0.075$ & $0.012-0.015$ \\
\hline Weathered bedrock & & $\begin{array}{l}350-550 / \\
50.8-79.8\end{array}$ & $0.018-0.02$ & $0.006-0.08$ \\
\hline
\end{tabular}

In choosing the active design alternative, an engineer should consider soils in which thaw strain usually does not exceed o.1. With greater thaw strain, there is practically only the passive design alternative available.

\section{B.7 Porkhaev, G.V. 1970. Thermal Interaction of Buildings and Struc- tures with Permafrost. Moscow: Nauka.}

The author provided a comprehensive analysis of the thermal interaction of buildings and pipelines with permafrost. He developed original methods of predicting permafrost thawing under buildings. In Russian and international literature, before Porkhaev's work, time-dependent depth of permafrost thawing was evaluated on the basis of one-dimensional solutions that were proportional to the square root of time. Porkhaev developed a two-dimensional solution for the evaluation of permafrost thawing under the center and edge of a building, with and without thermal insulation of the floor. His solution is based on the quasi-stable thermal state of soil under a building and thus is called a method of auxiliary temperatures. Porkhaev's solutions included in every edition of Russian Building Codes for permafrost regions since 1966. He also developed analytical methods of evaluating the thermal state of permafrost under a building constructed according to the passive design alternative, including a method of evaluating the module of ventilation of ventilated crawl spaces; a method of limited thaw depth with foundations in frozen soil; and a method of soil cooling using a system of ventilated ducts. Additionally, he developed a method of predicting the thermal impact of several neighboring buildings on permafrost and a method of evaluating permafrost thawing under a pipeline. 


\section{B.8 Orlov, V.0. 1962. Frost Heave of Fine Grained Soils. Moscow: Academy of Sciences.}

The author of this book described the results of long-term field studies of frost heave in Igarka; he studied frost heave and frost heave forces in natural conditions at developed sites.

Before Orlov's study, it was not known that, at sites where seasonal thawing of soil is limited by the thermal insulation of the soil surface, frost heaves continue the entire summer. The rate of frost heave decreases with depth of soil freezing. Orlov found that the thermal gradient in freezing soil is the main factor that defines frost heaving in homogeneous soil. He developed a frost heave probe to evaluate the intensity of frost heaves at different depths.

Tangential frost heave stresses and forces were measured at 16 experimental piles. The maximum of tangential frost heave stress at pile surfaces had usually been observed at the beginning stage of soil freezing, before soil movement along a pile (Table B-4). For a woodpile, it was found that, when depth of freezing was $25 \mathrm{~cm}$ to $30 \mathrm{~cm}$ (10 in. to $12 \mathrm{in}$.) and the tangential frost heave stress was equal for wood $280 \mathrm{kPa}$ ( $41 \mathrm{psi}$ ) and for concrete, the initial tangential frost heave stress reached $300 \mathrm{kPa}$ (44 psi). With an increase in soil freezing depth, tangential frost heave stress decreases. During 4 years of measurements, the average for the entire layer of seasonally frozen soil, the tangential frost heave stress did not exceed $136 \mathrm{kPa}(20 \mathrm{psi})$. The author also studied basal frost heave forces. Basal frost heave stress increases with the thickness of frozen soil beneath a foundation and decreases with the increase in depth of the foundation. Basal frost heave stress varied widely; in several tests it was over $1 \mathrm{MPa}$ (145 psi).

Table B-4. Average along freezing layer, tangential frost heave stress ( $\mathrm{kPa} / \mathrm{psi})$.

\begin{tabular}{|l|l|c|c|c|c|c|}
\hline \multirow{2}{*}{ Permafrost Conditions } & \multirow{2}{*}{$\begin{array}{l}\text { Foundation } \\
\text { Material }\end{array}$} & $\begin{array}{c}0-0.5 \mathrm{~m} \\
(\mathbf{0}-2 \mathrm{ft})\end{array}$ & $\begin{array}{c}01.0 \mathrm{~m} \\
(\mathbf{0}-3 \mathrm{ft})\end{array}$ & $\begin{array}{c}01.5 \mathrm{~m} \\
(0-5 \mathrm{ft})\end{array}$ & $\begin{array}{c}02.0 \mathrm{~m} \\
(0-7 \mathrm{ft})\end{array}$ & $\begin{array}{c}03.5 \mathrm{~m} \\
(0-11 \mathrm{ft})\end{array}$ \\
\cline { 3 - 8 } & Wreezing soil reaches & $270(39)$ & $140(20)$ & $100(15)$ & - & - \\
\hline permafrost table & Cood & $300(44)$ & $160(23)$ & $110(16)$ & - & - \\
\hline $\begin{array}{l}\text { Freezing soil does not reach } \\
\text { permafrost table, or no }\end{array}$ & Wood & $270(39)$ & $140(20)$ & $120(17)$ & $100(15)$ & $80(12)$ \\
\hline permafrost & & & & & & \\
\hline
\end{tabular}




\section{B.9 Vialov, S.S., V.V. Dokuchaev, and D.R. Sheinkman, 1976. Mas- sive Ice and Ice-Rich Soils as Foundation of Structures. Lenin- grad: Stroyizdat.}

Vialov et al. (1976) emphasized that the main goal of structure design at sites with massive ice or ice-rich soil is to limit the settlement of a foundation and protect the surrounding area from hazardous permafrost-related processes. Numerous structure failures were related to thermokarst and thermal erosion that started outside of structures. Site development should begin with construction of a pad or an embankment of sufficient thickness. Examples from Tiksi and Khatanga showed that roads with embankments of insufficient thickness were destroyed within one summer. A thickness of pad or embankment should provide complete freezing of the original active layer. An application of thermal insulation is required because it not only minimizes thermal erosion, but it also decreases pad or embankment thickness.

The authors presented data on physical and mechanical properties of ice and ice-rich soil and a method to evaluate the settlement of ice and icerich soil beneath foundations. Most data are based on laboratory studies with remolded soils.

Post and pile foundations were discussed. Post foundations should be based on a layer of compacted sand or gravel with a thickness of $15 \mathrm{~cm}$ to $20 \mathrm{~cm}$ ( 6 in.to 8 in.). With massive ice beneath a foundation, the thickness of a layer of compacted gravel should be equal to at least half of the foundation width. The gravel layer decreases the viscous deformation of ice. The authors presented a method of evaluating the settlement of ice-rich soil and ice under post foundations. Piles are placed in holes that have a diameter greater than the pile diameter by $7 \mathrm{~cm}$ to $15 \mathrm{~cm}$ (3 in. to 6 in.). The end of the pile should be placed on a layer of gravel, not less than $0.5 \mathrm{~m}$ ( $2 \mathrm{ft}$ ) thick. There is no reliable method of evaluating the viscous settlement of a pile using laboratory data on properties of ice. The existing practice of using piles in massive ice is very limited, and the allowed load on piles should be based on pile tests.

\section{B.10 Zhelezniak, I.I. 1990. Reliability of Frozen Soils as a Base of Structures. Novosibirsk: Nauka.}

The authors have examined numerous case studies of building failures in the southern part of the discontinuous permafrost zone. Some buildings 
were constructed at sites without permafrost, and their deformations were caused by frost heave forces. Errors in design and construction and increases in the groundwater table led to hazardous impacts of basal and tangential frost heave forces. One building damaged by basal frost heave force was protected from further frost heave impact by a layer of thermal insulation and a heating cable, which automatically operated when the depth of seasonal freezing reached $1 \mathrm{~m}(3 \mathrm{ft})$. The permafrost temperature at the sites that were studied was greater than $-0.5{ }^{\circ} \mathrm{C}\left(31.1^{\circ} \mathrm{F}\right)$. Many engineers and scientists are of the opinion that the active design alternative is the only solution for design and construction. Buildings under discussion were constructed with measures that increase the resistance of a building to differential settlement. For one of the damaged buildings-a telephone station, according to data on soil properties from the original geotechnical investigations-the choice of the active design alternative looked reasonable. The water content of soil was generally less than the plastic limit. It is unknown how the frozen soil was drilled and tested. Forensic geotechnical studies provided by experienced permafrost engineers or scientists did not describe the soil as a good candidate for application of the active design alternative. Soil at several depths had a well-developed cryostructure, with ice layers and lenses that had visible ice content reaching 0.5. The author mentions several causes leading to failure. Perhaps the most important cause was the poor quality of geotechnical investigation. A multistory building with 152 apartments was designed in anticipation of the absence of frozen soil. The building was damaged, and later studies showed the occurrence of isolated lenses of frozen soil. Heat from the building and leaking utilities thawed the frozen soil, causing sufficient differential settlement.

\section{B.11 Bykov, N.I., and P.N. Kapterev. 1940. Permafrost and Construc- tion on It. Moscow: State Publishing House on Railroads.}

This is one of the most important books written on frozen-ground engineering. It is based on extensive permafrost engineering research in Igarka and Skovorodino. The authors conducted numerous field tests on the impacts of frost heave on posts and piles. They found tangential frost heave forces and recommended a design of $150 \mathrm{~kg}(331 \mathrm{lb})$ on each $1 \mathrm{~cm}$ (o in.) of a pile perimeter. The most important result of the authors' studies is an understanding of the interaction of foundations with heaving soil. They showed that frost heave stress is equal to the adfreeze strength of soil only for a short part of winter. Later, the bond between freezing soil and a foundation is broken, and freezing soil slides along the foundation. The authors prove this claim by a simple but very convincing field test. Their findings 
were later supported by numerous studies in Russia and Canada. The other very important finding, which remained unnoticed for dozens of years, was the understanding of the impact of non-frost-susceptible soil above frost-susceptible freezing soil. The authors wrote

Let's assume that there is a layer of surface water about $10 \mathrm{~cm}-15 \mathrm{~cm}$ [4 in. -6 in.] above the active layer. Water freezes first and ice develops adfreeze bond with piles, but without frost heave. Freezing soil beneath the layer of ice tries to break the adfreeze bond between ice and piles. Frost heave force can increase significantly compare with similar condition without ice.

Much later, this effect was found in field studies (Johnson and Buska 1988, Penner and Goodrich 1983).

The authors studied the time of freezeback of driven piles in prethawed soil and found that freezeback in a group of piles in the discontinuous permafrost zone can take several months. The best time for the installation of piles is the period from February to the beginning of June. Piles installed in autumn and at the beginning of winter are greatly affected by frost heaves because the adfreeze bond of the piles and permafrost is not well developed. The authors showed that the passive design alternative remains valuable in the southern part of the discontinuous permafrost zone.

\section{B.12 Sal'nikov, P.I. 1996. Stability of Foundations of Buildings on Fro- zen Soils of Southern Transbaikalia. Yakutsk: Publisher Perma- frost Institute}

Sal'nikov considered the stability of buildings in relation to terrain units. He describes the permafrost conditions of main terrain units and presents their soil properties as water content, bulk unit weight, and void ratiotheir range and average values. Average values characterize permafrost as appropriate for application of the active design alternative. At the same time, Sal'nikov assessed hundreds of buildings constructed according to active and passive alternatives that had experienced severe deformations. Depth to the permafrost table and permafrost properties can vary sufficiently over a short distance. Permafrost temperature in the region is greater than $-0.5^{\circ} \mathrm{C}\left(31.1^{\circ} \mathrm{F}\right)$.

Deformation of buildings constructed according to the active alternative is explained by insufficient geotechnical data, higher differential settlement 
than designed for of inner and outer walls, and permafrost thawing greater than the design rate due to the impact of water from leaking utility lines. Thawing of permafrost under the center of a building is greater and faster than under external walls, and thawing of permafrost on the south-facing side of buildings is greater than on the north-facing side. Deformation of buildings constructed according to the passive alternative is explained by the thermal impact of utility lines and failure due to the discharge of water and thawing of permafrost around and under foundations (Figure B-3).

The author recommends using the active design alternative or pre-thawing of permafrost, or using deep piles if confident soil is available at a reasonable depth.

Figure B-3. Icing from leaking utility in the ventilated crawl space of multistory building.

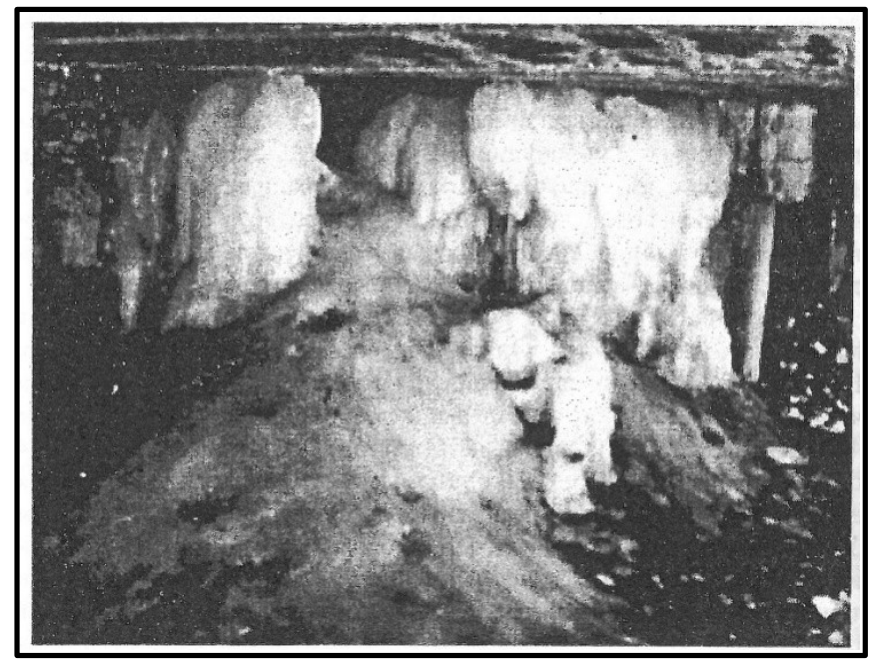

\section{B.13 Kiselev, M.F. 1978. Theory of Consolidation of Thawing Soils Un- der Load. Leningrad: Stroylzdat.}

Evaluation of the settlement of thawing soil is based on an evaluation of the thaw depth and thaw strain of soil. Stress on thawing soil changes with depth, and thaw strain should be assigned as a function of stress. The thaw strain of soil is a function of the initial void ratio of frozen soil and the final void ratio of thawed soil. The initial void ratio of frozen soil can easily be found from simple physical characteristics of frozen soils. There were numerous attempts to evaluate the final void ratio of thawed soils without laboratory or field testing, and practically all of them were unsuccessful. The author conducted, at first glance, a simple but very time-consuming study. He tested the compression of more than 400 samples of frozen soil under 
stress, from $10 \mathrm{kPa}$ to $600 \mathrm{kPa}$ ( $1 \mathrm{psi}$ to $87 \mathrm{psi}$ ). Tested soils included different sands, silts, silty clays, and clays. As a result, he found the relationship of thaw strain. For fine-grained soils, the author developed the equation

$$
\delta=\frac{W-(P L+K P I}{\gamma_{\mathrm{w}}+\mathrm{WG}_{\mathrm{s}} \gamma_{\mathrm{w}}}
$$

where

$$
\begin{aligned}
\mathrm{W} & =\text { the initial water content as part of the unit } \\
\mathrm{PL} & =\text { plastic limit } \\
\mathrm{PI} & =\text { plasticity index. }
\end{aligned}
$$

\begin{tabular}{|c|c|c|c|c|c|c|c|c|c|}
\hline \multirow[b]{2}{*}{ Soil } & \multirow{2}{*}{$\begin{array}{l}\text { Plasticity } \\
\text { Index PI }\end{array}$} & \multicolumn{8}{|c|}{$K_{\Delta}$ for pressure, $\mathrm{MPa}(\mathrm{psi})$} \\
\hline & & $0.05(7)$ & 0.075 (11) & $0.1(15)$ & $0.2(29)$ & $0.3(44)$ & $0.4(58)$ & $0.5(73)$ & $0.6(87)$ \\
\hline \multirow{3}{*}{ Silt } & $\mathrm{PI} \leq 0.03$ & 2.5 & 2.0 & 1.6 & 1.3 & 1.1 & 0.9 & 0.8 & 0.7 \\
\hline & $0.03<\mathrm{PI} \leq 0.05$ & 2.0 & 1.6 & 1.3 & 1.1 & 0.9 & 0.8 & 0.7 & 0.55 \\
\hline & $0.05<\mathrm{PI} \leq 0.07$ & 1.7 & 1.4 & 1.2 & 1.0 & 0.8 & 0.75 & 0.65 & 0.5 \\
\hline Silty & $0.07<\mathrm{PI} \leq 0.09$ & 1.5 & 1.3 & 1.1 & 0.9 & 0.75 & 0.7 & 0.6 & 0.45 \\
\hline \multirow{2}{*}{ Clay } & $0.09<\mathrm{PI} \leq 0.13$ & 1.3 & 1.2 & 1.0 & 0.8 & 0.7 & 0.6 & 0.5 & 0.4 \\
\hline & $0.13<\mathrm{PI} \leq 0.17$ & 1.2 & 1.1 & 0.9 & 0.7 & 0.6 & 0.5 & 0.4 & 0.35 \\
\hline \multirow{4}{*}{ Clay } & $0.17<\mathrm{PI} \leq 021$ & 1.1 & 1.0 & 0.8 & 0.6 & 0.5 & 0.45 & 0.35 & 0.3 \\
\hline & $0.21<\mathrm{PI} \leq 0.26$ & 1.0 & 0.9 & 0.7 & 0.5 & 0.4 & 0.35 & 0.3 & 0.25 \\
\hline & $0.26<\mathrm{PI} \leq 0.32$ & 0.9 & 0.8 & 0.6 & 0.4 & 0.35 & 0.3 & 0.25 & 0.2 \\
\hline & $\mathrm{Pl}>0.32$ & 0.8 & 0.7 & 0.5 & 0.35 & 0.3 & 0.25 & 0.2 & 0.15 \\
\hline
\end{tabular}

Table B-5 lists the relationship of thaw strain for fine-grained soils, in which $\mathrm{K}=$ coefficient.

Table B-5. Relationship of thaw strain for fine-grained soils.

The method was tested in the field and shown to be conservative. The relationship between the thaw strain of sand and its physical characteristics and stresses was not found.

\section{B.14 Votiakov, I.N. 1975. Physical and Mechanical Properties of Fro- zen and Thawing Soils in Yakutia. Novosibirsk: Nauka.}

Votiakov's work was a compilation of long-term studies that included the evaluation of physical properties of frozen soils, creep and the strength properties of frozen soils, and the thaw strain values of thawing soils. Based on numerous tests, the author found that the bulk density of frozen soil can be determined from the equation

$$
\gamma=\frac{2.4(1+W)}{2.7 W+0.9}
$$


where $W=$ soil water content presented by a part of 1 .

The error in evaluation of frozen soil bulk density should not exceed $2 \%$ if its water content is greater than the following: $5 \%$ for gravel, $15 \%$ for sand, $20 \%$ for silt and silty clay, $25 \%$ for clay, and 10 to $15 \%$ for weathered bedrock. The high boundary of water content has no limit. The author studied the long-term strength of frozen soils and their adfreeze strength with concrete, shown in Tables B-6 and B-7, respectively.

Table B-6. Long-term strength of frozen soils (MPa [psi]) of Yakutia as a function of temperature.

\begin{tabular}{|c|c|c|c|c|c|}
\hline \multirow[b]{2}{*}{ Soil } & \multicolumn{5}{|c|}{ Temperature, ${ }^{\circ} \mathrm{C}\left({ }^{\circ} \mathrm{F}\right)$} \\
\hline & $\begin{array}{c}-0.2 \text { to }-0.5 \\
\text { (31.6 to 31.1) }\end{array}$ & $\begin{array}{c}-1 \text { to }-1.5 \\
\text { (30.2 to 29.3) }\end{array}$ & $\begin{array}{c}-2 \text { to }-2.5 \\
\text { (28.4 to } 27.5)\end{array}$ & $\begin{array}{c}-3 \text { to }-4 \\
(26.6 \text { to } 24.8)\end{array}$ & $\begin{array}{c}-5 \text { to }-6 \\
\text { (23 to } 21.2)\end{array}$ \\
\hline Sand & $\begin{array}{c}0.8-1.1 \\
(116-160)\end{array}$ & $\begin{array}{c}1.1-1.6 \\
(160-232)\end{array}$ & $\begin{array}{c}1.6-2.0 \\
(232-290)\end{array}$ & $\begin{array}{c}2.0-3.0 \\
(290-435)\end{array}$ & $\begin{array}{c}3.0-4.0 \\
(435-580)\end{array}$ \\
\hline Silt & $\begin{array}{c}0.5-0.8 \\
(73-116)\end{array}$ & $\begin{array}{c}0.8-1.1 \\
(116-160)\end{array}$ & $\begin{array}{c}1.1-1.6 \\
(160-232)\end{array}$ & $\begin{array}{c}1.6-2.0 \\
(232-290)\end{array}$ & $\begin{array}{c}2.0-3.0 \\
(290-435)\end{array}$ \\
\hline Silty clay & $\begin{array}{l}0.4-0.6 \\
(58-87)\end{array}$ & $\begin{array}{c}0.6-0.8 \\
(87-116)\end{array}$ & $\begin{array}{c}0.8-1.1 \\
(116-160)\end{array}$ & $\begin{array}{c}1.1-1.6 \\
(160-232)\end{array}$ & $\begin{array}{c}1.6-2.0 \\
(232-290)\end{array}$ \\
\hline
\end{tabular}

Table B-7. Adfreeze strength of frozen soils with concrete.

\begin{tabular}{|c|c|c|c|}
\hline \multirow{4}{*}{ Soil } & $\begin{array}{c}\text { Water Content, } \\
\%\end{array}$ & $\begin{array}{c}\text { Temperature, } \\
{ }^{\circ} \mathrm{C}\left({ }^{\circ} \mathrm{F}\right)\end{array}$ & $\begin{array}{c}\text { Long-term Adfreeze Strength of Soil } \\
\text { with Concrete, } \mathrm{kPa}(\mathrm{psi})\end{array}$ \\
\hline \multirow{4}{*}{ Sand } & 20.6 & $-6.0(21.2)$ & $800(116)$ \\
\cline { 2 - 4 } & 24.5 & $-6.0(21.2)$ & $850(123)$ \\
\cline { 2 - 4 } & 23.8 & $-3.5(21.2)$ & $600(87)$ \\
\cline { 2 - 4 } & 22.3 & $-1.5(29.3)$ & $250(36)$ \\
\cline { 2 - 4 } & 20.5 & $-1.0(30.2)$ & $180(26)$ \\
\hline \multirow{6}{*}{ Silty clay } & 32.4 & $-4.5(23.9)$ & $350(51)$ \\
\cline { 2 - 4 } & 30.0 & $-3.4(25.88)$ & $300(44)$ \\
\cline { 2 - 4 } & 30.2 & $-2.0(28.4)$ & $250(36)$ \\
\cline { 2 - 4 } & 29.3 & $-2.0(28.4)$ & $220(32)$ \\
\cline { 2 - 4 } & 29.0 & $-1.6(29.12)$ & $200(29)$ \\
\cline { 2 - 4 } & 29.6 & $-0.8(30.56)$ & $250(36)$ \\
\cline { 2 - 4 } & 30.7 & $-0.6(30.92)$ & $120(17)$ \\
\hline
\end{tabular}

By studying the properties of ice, Votiakov found that, for practical purposes, ice can be considered a strong base for structures. Votiakov also studied the adfreeze strength of frozen soil with steel, which happened to be much smaller than the adfreeze strength of soil with concrete. Table B8 lists the allowed bearing capacity (MPa) of frozen soils in Yakutia. 
Table B-8. The allowed bearing capacity (MPa) of frozen soils in Yakutia.

\begin{tabular}{|c|c|c|c|}
\hline Soil Temperature ${ }^{\circ} \mathrm{C}\left({ }^{\circ} \mathrm{F}\right)$ & Sand & Silt & Silty Clay \\
\hline-0.3 to $-0.5(31.46$ to 31.46$)$ & 0.6 & 0.4 & 0.3 \\
\hline-1.0 to $-1.5(31.82$ to 29.3$)$ & 0.9 & 0.6 & 0.5 \\
\hline-2.0 to $-2.5(28.4$ to 27.5$)$ & 1.2 & 0.9 & 0.7 \\
\hline-3.0 to $-4.0(26.6$ to 24.8$)$ & 1.7 & 1.2 & 0.9 \\
\hline-5.0 to -6.0 (23 to 21.2$)$ & 2.2 & 1.7 & 1.2 \\
\hline
\end{tabular}

Thaw settlement was studied in a laboratory and in the field. Unique data form the relationship between thaw strain and water content for weathered bedrock and the thaw strain of gravel, shown in the Figures B-4 and B-5, respectively.

Figure B-4. Thaw strain of weathered bedrock with water content.

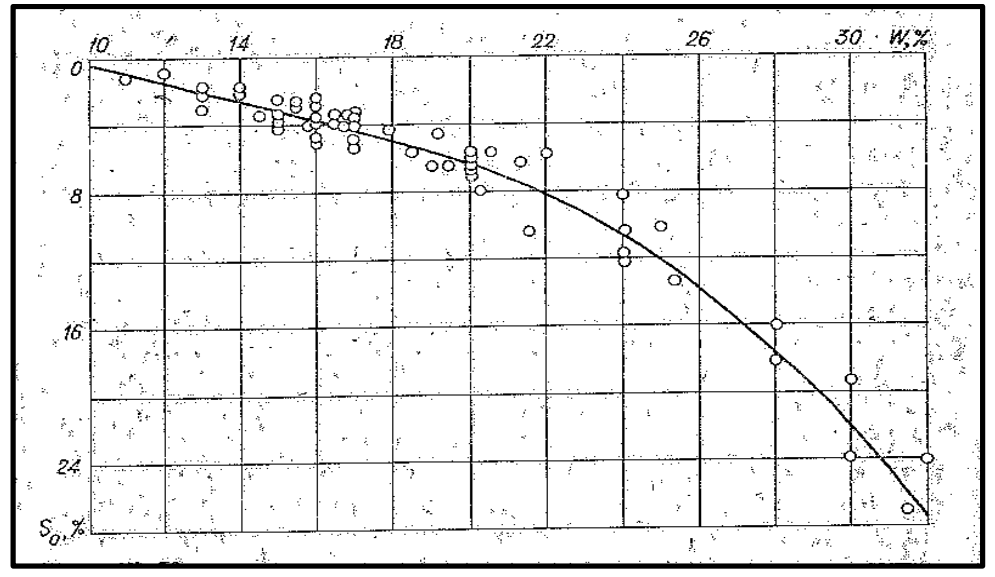

Figure B-5. Thaw strain of gravel vs. water content.

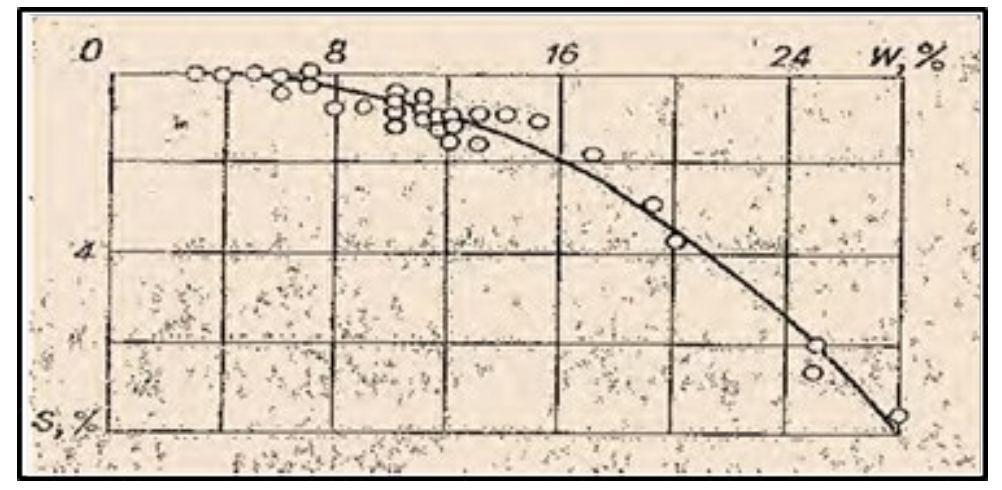




\section{B.15 Dokuchaev, V.V. 1963. Foundations and Foundation Soils on Per- mafrost. Leningrad-Moscow: Stroyizdat.}

The author of this book is one of the most experienced Arctic engineers. The book covered general information on permafrost properties, and outlines procedures of design of structures on permafrost. Dokuchaev's methods of evaluating the bearing capacities of shallow foundations and piles in permafrost were accommodated by the Russian Building Codes on permafrost and were considered by Army Technical Manual TM-5-852-4 (HQDA 1983). Figure B-6 shows the allowable bearing capacity of mineral frozen soils $\left(\mathrm{p}^{\mathrm{n}} \mathrm{kg} / \mathrm{c} \mathrm{m}^{2}\right)$ as a function of maximum soil temperature $\left(\mathrm{t}_{\max }\right)$.

Figure B-6. Allowable bearing capacity of mineral frozen soils as a function of maximum soil temperature: (1) gravel, (2) coarse sand, (3) medium sand, (4) fine sand and silt, (5) silty clay and clay, (7) any soil with ice layers, (8) ice $\left(1 \mathrm{~kg} / \mathrm{c} \mathrm{m}^{2}\right.$ is equal to $\left.100 \mathrm{kPa}\right)$.

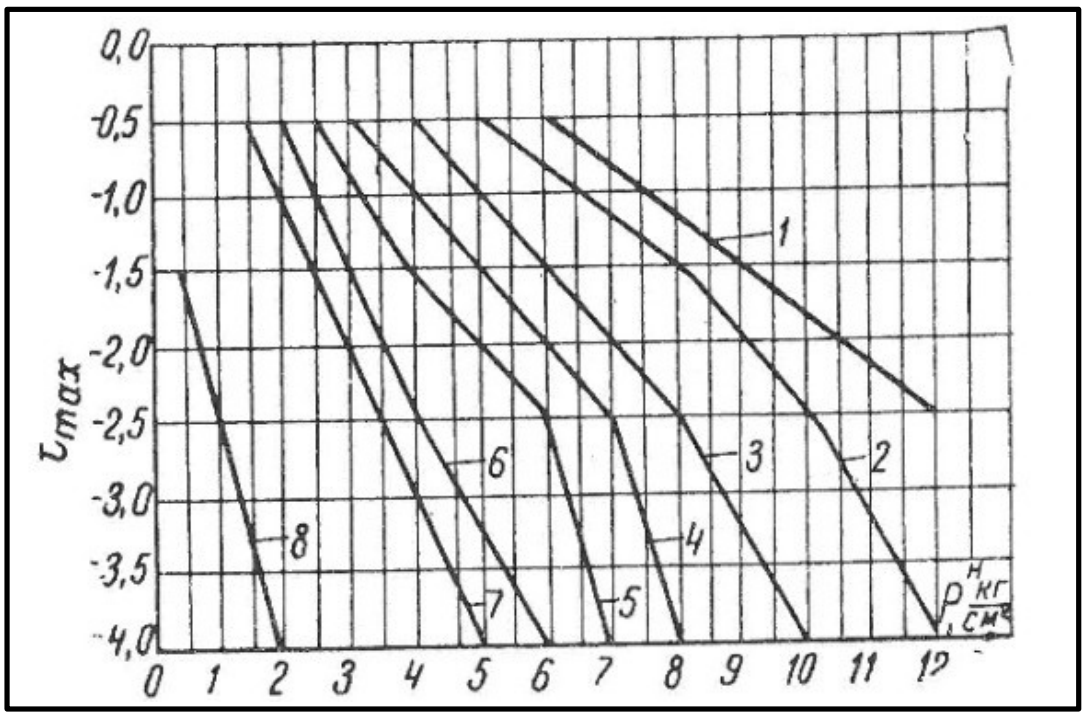

Table B-9 lists the allowed bearing capacity of saline soils.

Table B-9. The allowed bearing capacity of saline soils.

\begin{tabular}{|c|c|c|c|c|c|c|c|}
\hline \multirow[b]{2}{*}{ Soil } & \multirow[b]{2}{*}{$\begin{array}{l}\text { Water } \\
\text { Content }\end{array}$} & \multirow[b]{2}{*}{$\begin{array}{l}\text { Salinity \% to } \\
\text { Dry Weight }\end{array}$} & \multicolumn{5}{|c|}{$\begin{array}{l}\text { Allowable Soil-Bearing Capacity } \mathrm{kPa}(\mathrm{psi}) \text { at Soil } \\
\text { Temperature, }{ }^{\circ} \mathrm{C}\left({ }^{\circ} \mathrm{F}\right)\end{array}$} \\
\hline & & & $\begin{array}{c}-1 \\
(30.2)\end{array}$ & $\begin{array}{l}-1.5 \\
(29.3)\end{array}$ & $\begin{array}{l}-2.0 \\
(28.4)\end{array}$ & $\begin{array}{l}-3.0 \\
(26.6)\end{array}$ & $\begin{array}{l}-4.5 \\
(23.9)\end{array}$ \\
\hline Clay & $0.23-0.28$ & 0.8 & - & - & $400(58)$ & $500(73)$ & $850(123)$ \\
\hline \multirow[t]{3}{*}{ Silty clay } & $0.24-0.38$ & Up to 0.3 & 250 (36) & $300(44)$ & $400(58)$ & 500 (73) & $650(94)$ \\
\hline & $0.24-0.38$ & $0.4-0.8$ & $120(17)$ & $150(22)$ & 200 (29) & 300 (44) & $500(73)$ \\
\hline & $0.24-0.38$ & $0.9-1.5$ & $60(9)$ & $70(10)$ & 100 (15) & $150(22)$ & $250(36)$ \\
\hline Silt & $0.49-0.56$ & 0.6 & - & - & 250 (36) & 300 (44) & $350(51)$ \\
\hline Fine sand & $0.49-0.56$ & 0.7 & - & - & $700(102)$ & - & - \\
\hline
\end{tabular}


Dokuchaev suggested that designing and constructing foundations using the passive alternative should protect frozen soils under structures from the heat impact of moving groundwater. Structures discharging water can present a hazard for nearby buildings. Gravel is most susceptible to such impacts. Main utility lines should be located not less than $12 \mathrm{~m}$ from structures, and building intakes should be aboveground. Structures designed by different design alternatives should be isolated from each other by ensuring sufficient distance between the buildings.

Permafrost thawing under structures to a depth greater than a depth of the active layer should be allowed when permafrost is presented by bedrock of unbounded coarse frozen soil or any soil that will undergo settlement upon thawing that does not exceed that allowed for a structure. It has been noticed that there are buildings constructed on bedrock that have hazardous deformations and should be repaired. Deformations occurred when (1) there was "false" bedrock and drilling was stopped by boulders, (2) when the foundation was based on the weathered upper part of bedrock mixed with ice-rich soil or even ice, and (3) when local sinking of the surface of the bedrock occurred between borings and was not noticed during a geotechnical survey. Experience has shown that replacement of soil to a depth of $4 \mathrm{~m}$ and sometimes more can be economically sound.

\section{B.16 Brattsev, L.A., and V.F. Zhukov (eds.). 1965. Theory and Practice of Permafrost Research in Construction. Moscow: Nauka.}

This monograph presented the experience in design and construction of industrial and apartment buildings in the Vorkuta region, an area of discontinuous permafrost. The temperature of permafrost is $-2{ }^{\circ} \mathrm{C}\left(28^{\circ} \mathrm{F}\right)$ and greater. The chapters and methodologies described in Brattsev's book are briefly summarized below.

\section{B.16.1 Chapters}

Chapter I. Geotechnical properties of frozen and unfrozen soils of the Vorkuta region.

Chapter II. Impact of development on the permafrost thermal regime.

Chapter III. Methods of evaluation of permafrost temperature in developed areas. 
Chapter IV. Permafrost investigations.

Chapter V. Pre-construction improvement of soil.

Chapter VI. Methods of construction on permafrost and conditions of their implementation.

Chapters VII and VIII. These chapters are specific to mining.

Chapter IX. Objectives of permafrost monitoring during the life of structures.

\section{B.16.2 Methods}

Method I. As in temperate regions, when foundations are based on bedrock or unfrozen soil.

Comment on Method I. When foundations are placed on bedrock, consider that weathered bedrock can be ice-rich and thaw-susceptible.

There are numerous known building hazards associated with the thawing of weathered bedrock. Site investigation should evaluate properties of bedrock, which also should be proved during construction.

Method II. With protection of the frozen state of soil during the entire life of a structure.

Comment on Method II. Buildings are constructed with a ventilated crawl space, with openings in the skirting walls. The total area of openings should be not less than $2 \%$ of the area occupied by a building. Most deformation is due to thermal impacts of utilities, nearby structures, and water from leaking utilities. Depth to the permafrost table often varies, and foundations under several buildings are constructed at different depths.

Method III. With accommodation of permafrost thawing under structures.

Comment on Method III. An analysis of deformation of buildings constructed using different methods shows that most deformation occurred in buildings constructed according to Method III. Deformation is usually large and usually begins in inner structures, because deeper 
thawing occurs under the center of a building. Two to $3 \mathrm{~s}$ later, the external walls begin to deform.

Method IV. With pre-thawing of frozen soil.

Comment on Method IV. A few buildings were constructed according to this method. Electrical thawing was implemented.

\section{B.16.3 Piles}

Piles are the best foundations to use in the Arctic. The most reliable piles are end-bearing piles that reach unfrozen bedrock. The bearing capacity of friction concrete piles with a diameter of $35 \mathrm{~cm}$ (14 in.) and a length of $5 \mathrm{~m}$ to $8 \mathrm{~m}$ ( $16 \mathrm{ft}$ to $26 \mathrm{ft}$ ) in permafrost with temperature from $-0.4{ }^{\circ} \mathrm{C}$ to $-0.8{ }^{\circ} \mathrm{C}\left(31.3^{\circ} \mathrm{F}\right.$ to $\left.30.5^{\circ} \mathrm{F}\right)$ is about 35 tons to 45 tons $(31752 \mathrm{~kg}$ to $40823 \mathrm{~kg}$ ). Creep deformations have been observed. When the permafrost temperature is $-1{ }^{\circ} \mathrm{C}\left(30.2^{\circ} \mathrm{F}\right)$ and above, piles are driven in permafrost. With lower permafrost temperatures, piles are installed in prethawed soil, or are driven in pilot holes that are of a diameter less than the diameter of the pile, or installed in holes with slurry. 


\section{Appendix C: PFFDSS Model Design Diagram}

Figure C-1. PFFDSS Model Design Diagram.

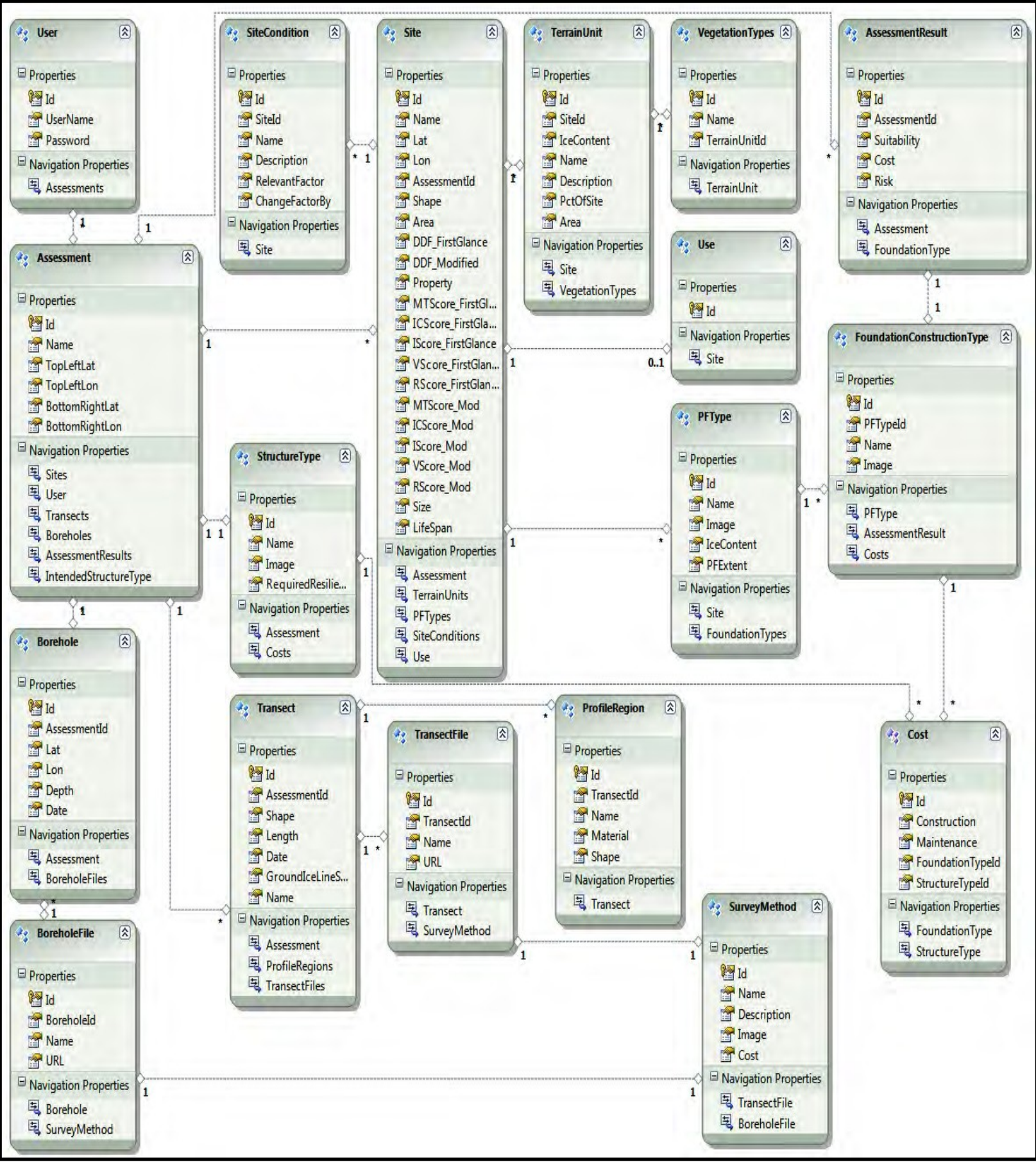




\section{C.1 PFFDSS architecture}

The PFFDSS is a web app developed as an ASP.Net MVC (model-view-controller) application. Figure C-2 shows a diagram in the general system architecture. The PFFDSS has the following attributes and specifications:

1. The tool was developed with Microsoft (MS) Visual Studio 2015.

2. The software architecture is based on a MS MVC (Model-View-Controller) 4.0 single-page application paradigm.

a. The code for the web server is written in $\mathrm{C \#}$.

b. Client side is coded with a blend of JavaScript and (HyperText Markup Language) HTML5.

c. Several AJAX* (Asynchronous JavaScript and XML) calls are included for client-to-server communication without page refresh.

Figure C-2. PFFDSS General System Architecture.

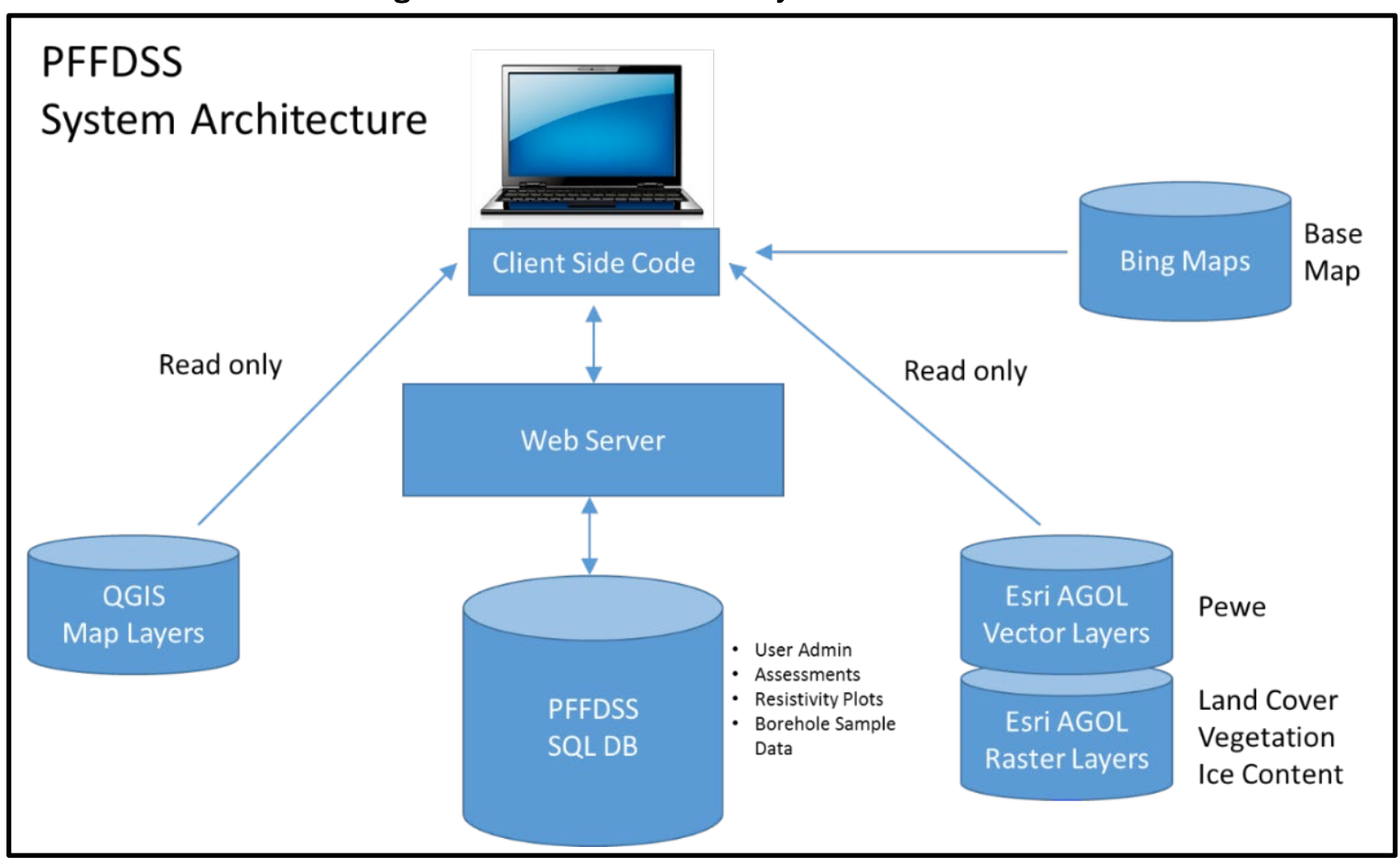

d. User administration is based on the MS individual user accounts paradigm with associated authentication protocols.

* Asynchronous JavaScript And XML (AJAX) is a set of Web development techniques using many Web technologies on the client side to create asynchronous Web applications. 
e. The code layout follows the MVC model, including the files for models, controllers, and views. Figure C-3 shows the code layout. Note that Account, Home, and Search controllers and views are standardized and are included with the MVC 4.0 template for individual user account single-page applications. The wizard controller and view are added for the purposes of the DSS and do the majority of the work of leading the user through the assessment process. The models are customized with defined classes to capture the features for the assessment, and are aligned with the central database through entity framework.

3. A central MS SQL Server database with a custom-designed schema is used to store assessments including the resistivity plot and borehole sample datasets.

4. Communication between database and client is done through MS entity framework (v4.0).

5. The tool incorporates an open-layers 3.0 map.
Figure C-3. MVC Layout for PFFDSS code.

Solution 'PFFDSS' (1 project)

4 雷 PFFDS

D $\boldsymbol{f}$ Properties

D I- References

- Service References

D _bin_deployableAssemblies

$D$ App_Data

D bin

D Content

4 G Controllers

D c\# AccountController.cs

D C\# DonorsController.cs

D c* HomeController.cs

D c\# SearchController.cs

D C\# WizardController.cs

$D$ DAL

$D$ Data

D Help

D I Images

D Migrations

D Migrations_Old

$\triangle \subseteq$ Models

D C\# AccountModels.cs

D C\# Assessment.cs

D c* BHSample.cs

D c\# Borehole.cs

D C\# Donor.cs

D C\# Transect.cs

D C\# TransectImage.cs

D C* TransectPoint.cs

D : obj

$D$ Scripts

4 드 Views

$D$ Account

D Donor

D Home

$D$ Shared

D 1 Wizard

[@]_ViewStart.cshtml [7] Web.config

圈 favicon.ico

D.] Global.asax

$\$$ packages.config

D Web.config 
6. The map layers services include:

a. Base map from Bing Maps.

b. Project specific layers including geology and ice content through Esri ArcGIS Online. These map services were created using Atkins Esri account. They will likely need to be moved to a server of the U.S. Army Corps of Engineers' (USACE's) choice when the project is complete.

c. QGIS layers-the majority of the work in QGIS was conducted by the UAF team to prove the concept of the ability to provide their data to the DSS. However, the specific data they were serving were not relevant to the general model of the DSS-the QGIS data consisted of all borehole samples collected whereas the DSS allows users to import their own borehole data. As such, the DSS is not currently consuming any layers from QGIS, though this is an attractive, open option for bringing more data into the DSS in the future.

7. The tool has a stacked transect plotter tool that presents elevation, resistivity plots, stability and soil type, as well as thaw settlement for a single transect as stacked charts. The open CanvasJS (v1.8) plug-in is being used for this and in the assessment results section of the process.

8. Throughout the tool, help files in PDF format are available explaining the procedures and algorithms, and providing general help each step of the way. These files are stored in a repository in the "Help" folder in the code project folder.

9. JQuery (v3.1) is used for some of the JavaScript coding on the client side.

\section{C.1.1 Hosting environments}

The PFFDSS is currently hosted on Microsoft Azure's cloud services. Development is conducted locally on development machines, while the public-facing production version is hosted on Azure. Azure deployment has been particularly streamlined due to the publish features available in MS Visual Studio.

\section{C.1.2 PFFDSS prototype deployment to USACE}

Azure services are paid up for the 12 months following the end of the project by Atkins. The prototype can be migrated for transition to USACE's preferred hosting environment. Atkins has provided a 12-month warranty service to continue and maintain the PFFDSS for further testing. This warranty included assistance that can be provided in deployment to USACE. This warranty did not include additions made to the PFFDSS that were beyond the current scope of work as defined in the scope documentation. 


\section{C.2 User Guide and Instructions}

The current PFFDSS web app consists of a landing page (Figure C-4) that presents

1. "About the Project," a section that describes the objectives, project team, and sponsors;

4. "Arctic Foundations 101," a section of helpful files on Arctic Engineering and Foundation design in the Arctic; and

5. "Your Assessments," a section that shows the users recent assessments as well as a button to start a new assessment.

Figure C-4. The PFFDSS web app landing page.

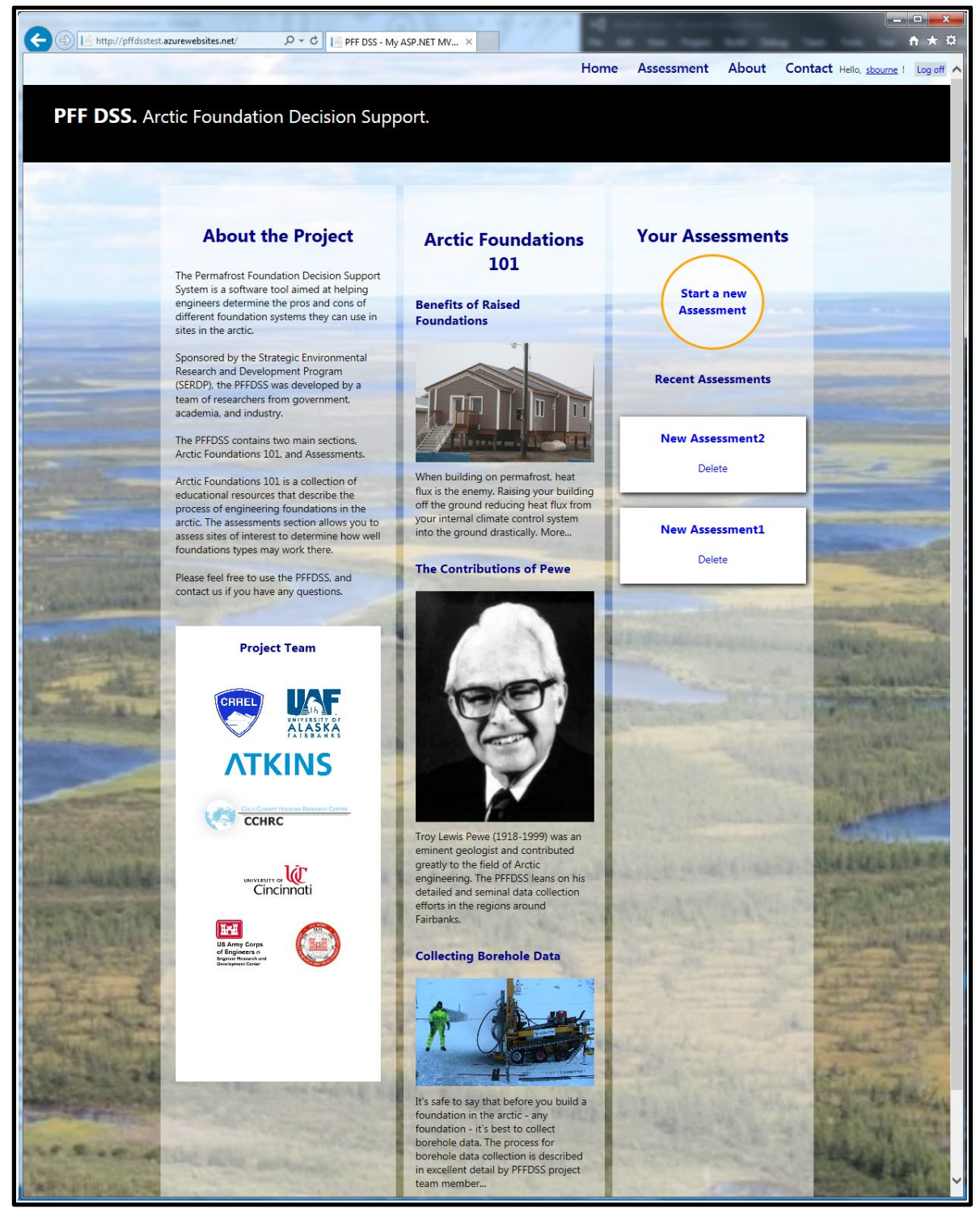




\section{C.2.1 About the project}

This "About the Project" section provides a brief, contextual background for the PFFDSS, including the description of this SERDP project. It also identifies the agencies and institutions associated with the team members.

\section{C.2.2 Arctic foundations 101}

Arctic Foundations 101 is a collection of PDFs that describe the process of building foundations in the Arctic. Users are shown a snippet about the subject of each article on the landing page and have the option to click through to see the full article.

Since the completion of the project, this section has been created on the landing page and populated with three articles. The full complement of help articles has not been appended into the web app. However, the help documents have been added to the "help" folder in the project. Links for each can be added to the landing page in HTML5. A more elaborate option would be to create a database of help articles that are presented on the landing page in a more data-driven paradigm.

It is important to note that the Arctic Foundations 101 section is only intended for viewers with non-login access. Any user can review the documentation.

\section{C.2.3 Your assessments}

The "Your Assessment" section contains the bulk of the functionality present in the PFFDSS. In order to log in and access this section, users are required to register an account. A button allows the users to create new assessments, and to access existing or saved assessments. Clicking any saved assessment opens a map-based interface (Figure C-5). If the user opens an existing assessment, the assessment is opened at the place they left off. A new assessment starts at the desktop assessment section. 
Figure C-5. Initial page for the Desktop Assessment within the PFFDSS web app.

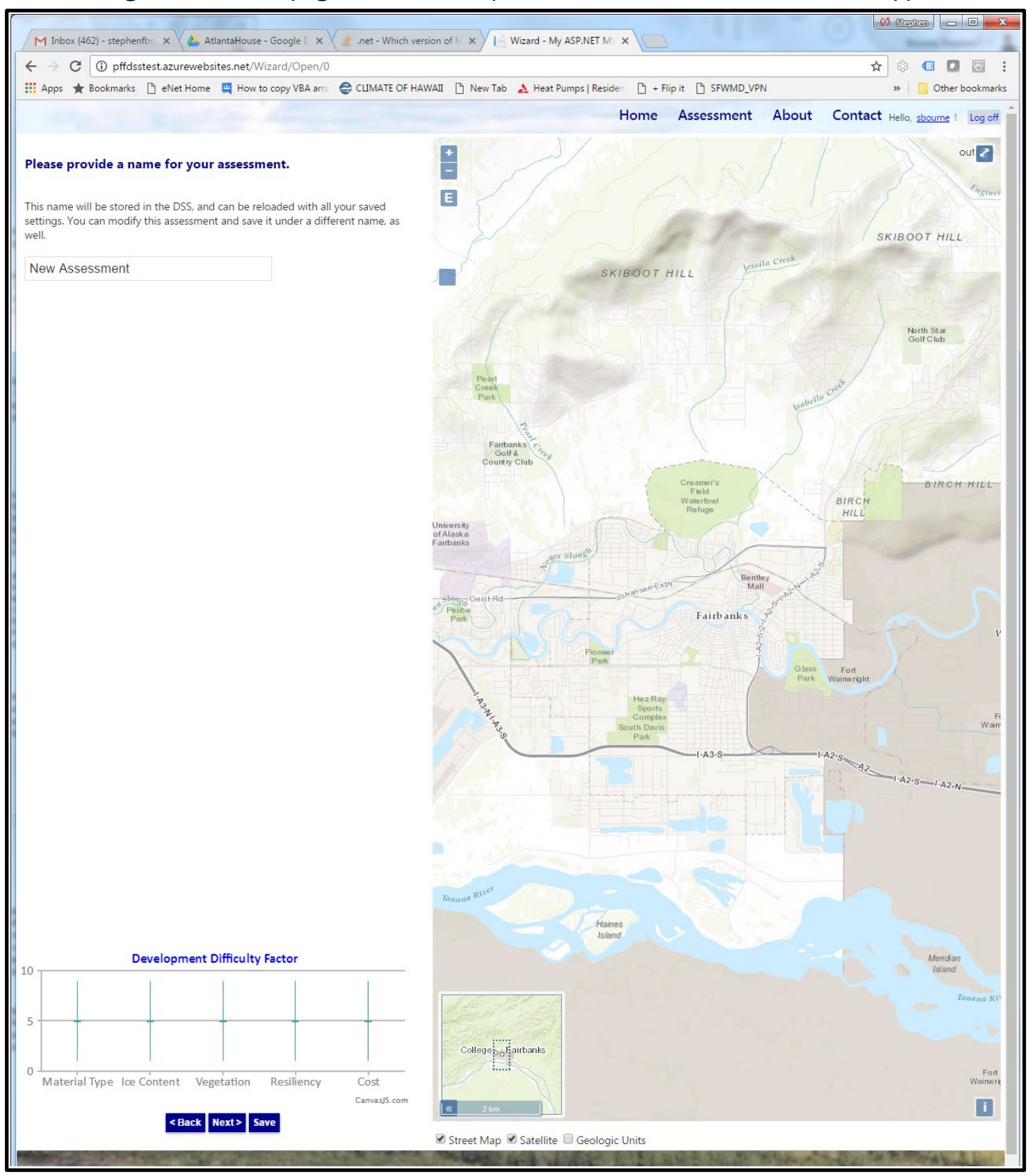

\section{C.2.3.1 Assessment phases}

The assessment is broken into a desktop assessment, a field survey, and a foundation type assessment. Each are described in the following.

- Desktop Assessment. This tool leads the user through a questionnaire on the type of building they would like to build and the conditions they have observed from walking the site. Using the questionnaire an- 
swers and GIS-based databases about permafrost and geological conditions in the Arctic, the tool provides a rough or initial assessment of the site. This initial assessment includes a DDF that summarizes the difficulty or any issues that may be encountered in the building, including vegetation and ice content.

- Field Survey Assessment. The field survey assessment uses data collected in the field to get a more detailed input of the subsurface conditions. The tool guides the user through the collection of such field data as electromagnetic resistivity plots and borehole samples, as well as the process of uploading the data. When data are uploaded, the user can review the integrated data to interpret potential soil stability and thaw settlement. These are the two driving factors in understanding the likelihood of foundation failure.

- Foundation Type Assessment. Finally, the tool assesses the suitability of various foundation types against the conditions presented, and provides a qualitative estimate of cost and risk for each.

\section{C.2.3.2 Desktop assessment process}

Wizard layout

The wizard for the assessment contains a map and pane as shown on the right and left sides, respectively, of Figure C-6. The DDF chart is presented at the bottom of the wizard pane. The map contains multiple tools like scales, compass, an overview map, and controls to turn layers on and off. The map works like most web maps, with scroll-to-zoom, and drag to pan features.

Sketching the assessment area

The user is asked to sketch an assessment area on the base map using the mouse. This constitutes the specific area for potential infrastructure locations where they investigate and conduct geophysical transects. Specifying this area prompts the tool to query the geology and ice content map services to ascertain general information about the intended region where the foundation would likely be built. Figure C-6 shows an example of the result of sketching the assessment area. 
Figure C-6. PFFDSS User-sketched Assessment Area (gold outline) with overlay of Péwé's (1975) Surficial Geologic Terrain Units (blue lines).

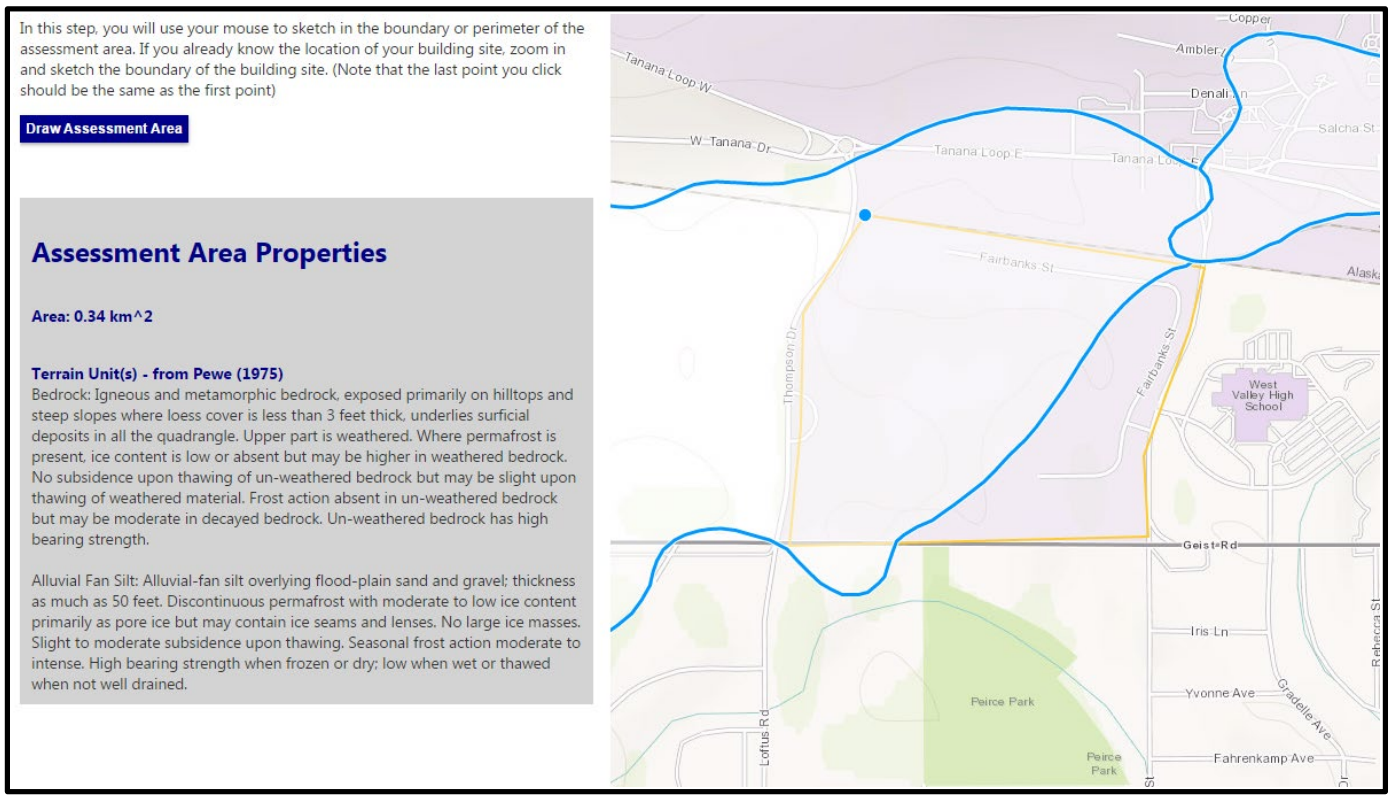

Intended structure type

The assessment includes a section on intended structure type. The user can select from a list of structure types tied to the International Building Code (IBC) database, or they can specify "other" and manually answer questions related to the structure type. These questions include structure usage, required lifespan, acceptable risk level, and whether the structure will be heated.

What do you need to know to conduct a desktop assessment?

To conduct a desktop assessment, the user must have at least seen the site. This can be done through a site walk, or possibly through viewing photos of the site. Ideally, the user would take a tablet on the site walk and run through the questionnaire while conducting the site walk. The DSS presents example photos of each tell-tale sign of subsurface permafrost, which can be a valuable help in the site walk.

\section{Desktop assessment result}

When the user has completed the desktop assessment, a result is presented that shows a section on assessment details as well as conclusions and recommendations (Figure $\mathrm{C}-7$ ). The conclusions and recommendations section describes the DDF result and contributing factors, and provides a summary of likely subsurface conditions. 
Figure C-7. PFFDSS Assessment: Map Query Results.

Map Query Results

A preliminary assessment, based on the publically available data and the

information you provided, yields a DDF score of 25 . This suggests that building at

this site might be problematic, but it is difficult to be more certain without

additional information. This means that, to be safe, you are advised to obtain more

information that is specific to the building site such as soil cores or geophysical

surveys. The DSS will guide you through this process. Just hit close and move to

the next screen.

Conditions Increasing Difficulty

Foundation on Grade

Medium Acceptable Risk of Failure

Heated Structure

Ice Wedges Present

Conditions Decreasing Difficulty

Light Structure Type 3

Moderate Topography

Thermokarst Not Present

Drunken Forest Not Present

Deciduous

Marshes Standing Water Not Present

Streams Not Present

It also provides general recommendations for next steps, such as collecting resistivity and borehole data. The summary shows the list of conditions found that might increase difficulty, and a condition list that might decrease difficulty. The detailed assessment restates the geological assessment and provides the ice content assessment and a deeper explanation of the DDF assessment.

Saving assessments

The DSS stores assessments indefinitely. The user may open, edit, and delete their assessments as they would like.

Field assessment process

The DSS guides the users through the process of collecting field data. A user would initially sketch out the transects for collecting the resistivity data. The user is free to sketch any transects, but the tool recommends following cleared paths, and to keep the transects on orthogonal (parallel and perpendicular) pattern to cover as much area as possible and avoiding duplicative information and cutting down on costs. 


\section{Sketching transects}

The user sketches each transect on the map (Figure C-8). Transects are automatically assigned an ID (e.g., Transect 17-1) derived from the numeric ID of the assessment (Assessment 17) and incremented according to the number of transects in the assessment. The user can plot this transect to have a reference for when they do resistivity data collection in the field.

Figure C-8. User-sketched transect for geophysical surveys and borehole placement (gold line: Transect 17-1).

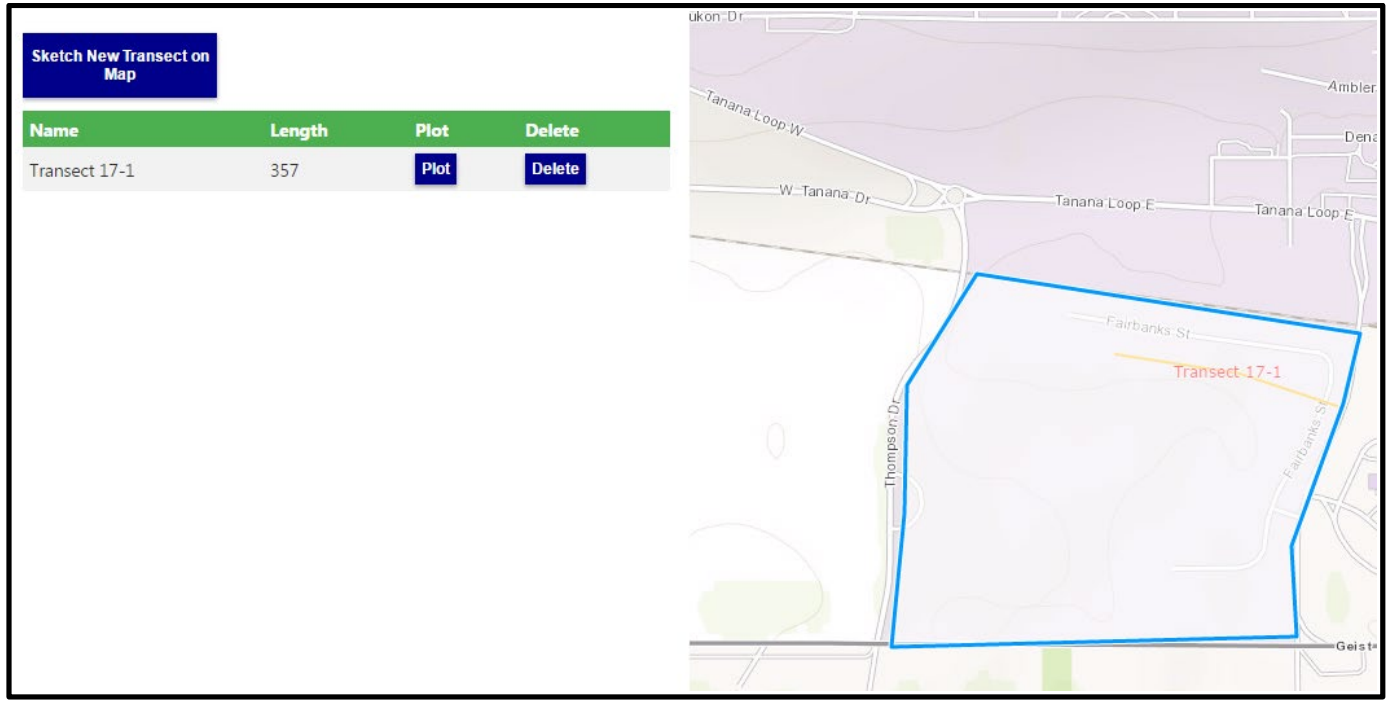

Uploading resistivity plots

Once the user has done the resistivity plot for the intended transect, they can upload the data to the system. To upload, the user simply clicks Add on the plot upload screen (Figure C-9); a window pops up asking the user to specify the file location on the user's computer and to input the start and end station. This information is used to register the image in the transect plotter (described below) and includes the minimum and maximum values on the $\mathrm{X}$-axis of the resistivity plot.

Integrating transect data in the transect plotter

When the data is uploaded, the user can click the "plot" button and the elevation and resistivity data are plotted together in the transect plotter (Figure $\mathrm{C}-10$ ). Note that there are fine tuning controls above the resistivity plot that allow the user to move the left and right side of the image to make the alignment with the elevation transect more accurate. 
Figure C-9. PFFDSS Upload page for imagery from geophysical transects.

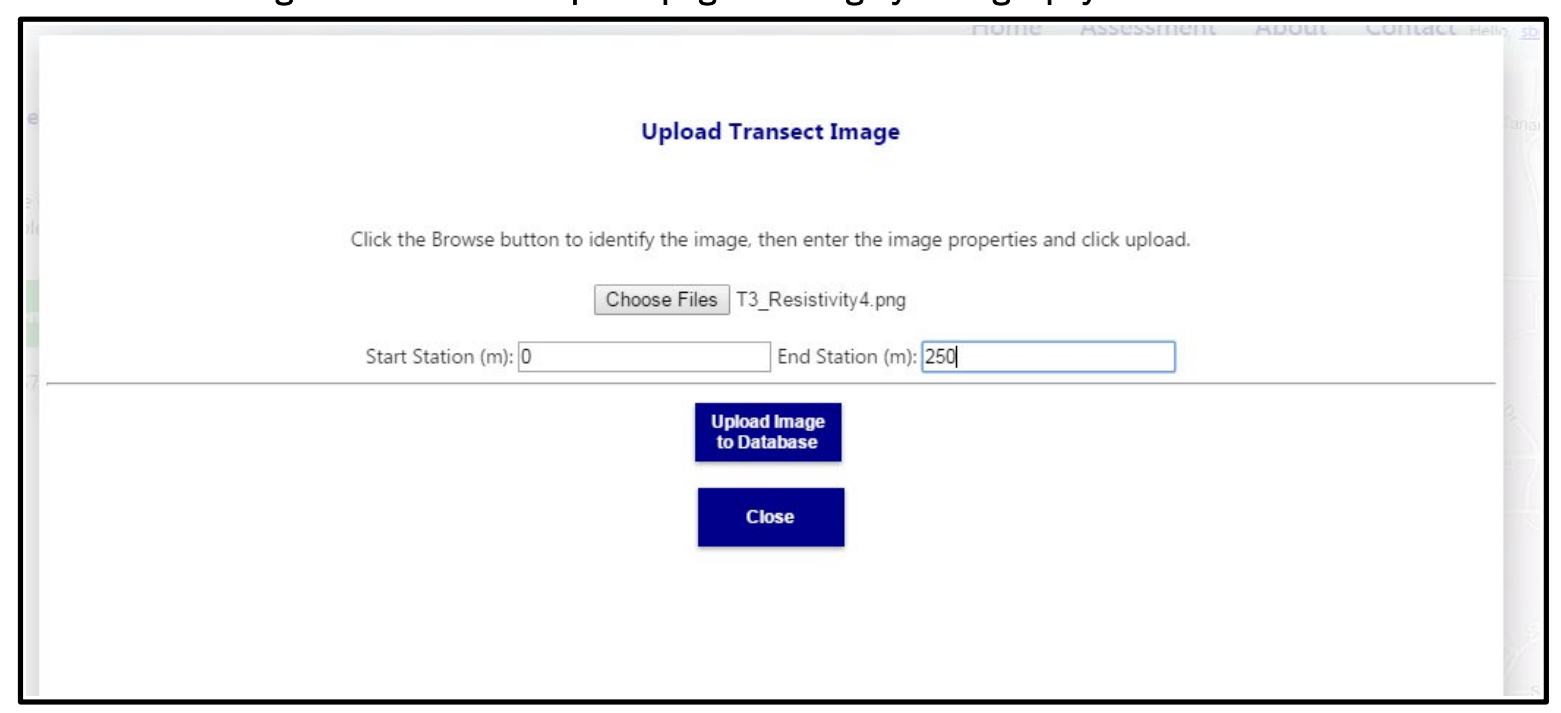

Figure C-10. Geophysical transect image (2D vertical) plot.

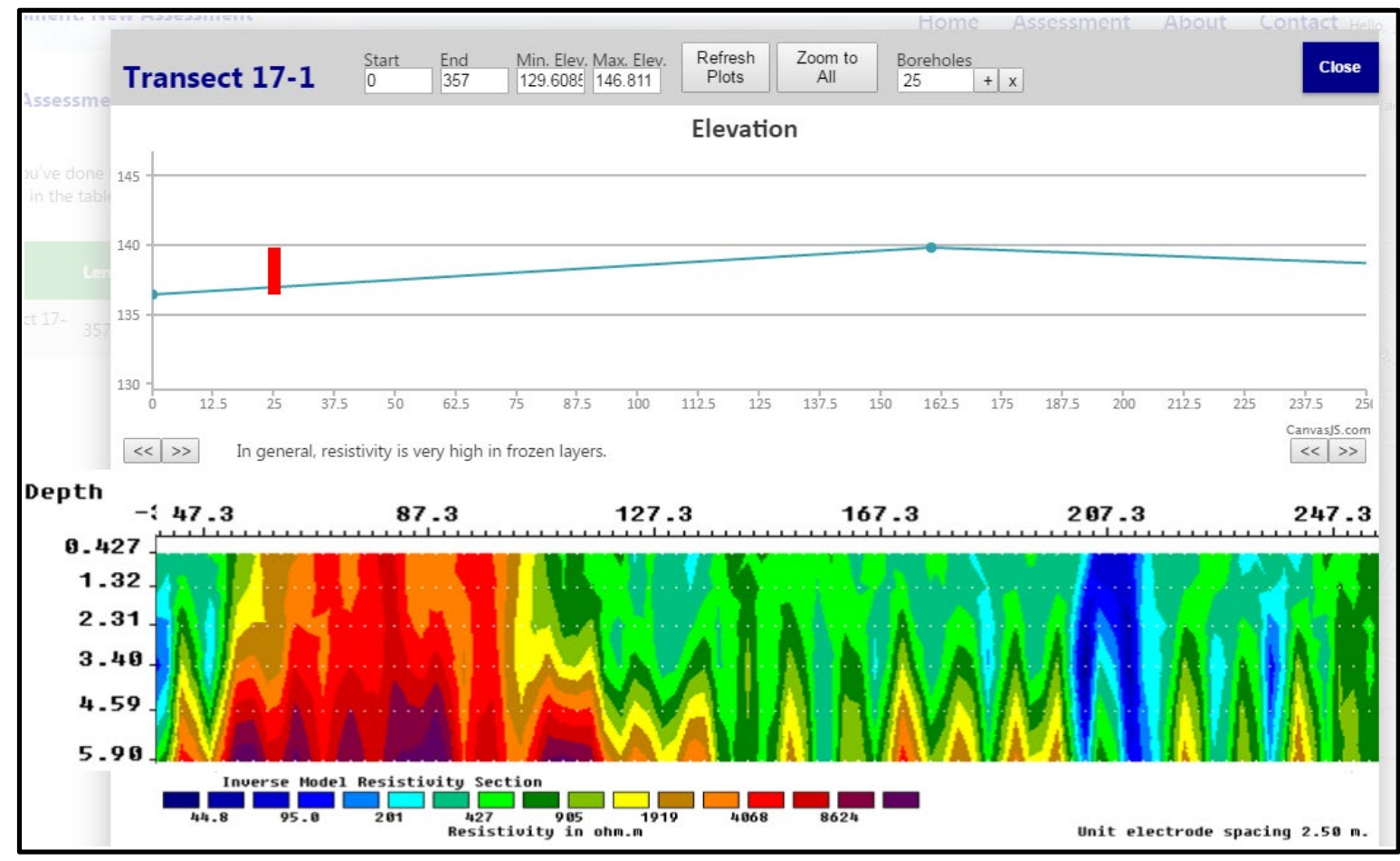

Planning boreholes locations based on resistivity

At this point the user can add locations for boreholes sampling to the transect based on where the resistivity plot. The plot might bring up questions in certain locations about the presence and depth of permafrost that need to be answered through borehole sampling. The user can add the borehole locations by clicking the "+" sign button in the Boreholes dropdown and entering the station along the transect where they would like a borehole. 
The red vertical line on the elevation chart in Figure $\mathrm{C}-10$ shows an exam-

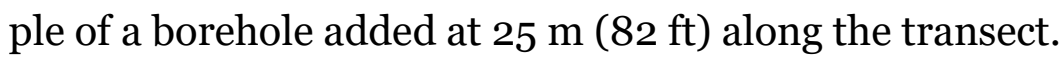

The transect plotter can be closed once the user is finished entering the locations and the map shows the proposed borehole locations. The user can print the map then to act as a borehole drilling plan.

Uploading borehole sample data

The DSS allows the user to upload the borehole sample data they have collected to the central database for analysis. Uploading consists of pasting two sets of data from Excel format into the data importer window (Figure C-11). The data consist of

- Location data: a single row for each borehole with

- ID (integer),

- Latitude (decimal degrees),

- Longitude (decimal degrees),

- Station along transect (m), and

- Elevation of surface $(\mathrm{m})$.

- Core Data: a single row for each sample with

- Borehole ID (integer),

- Depth $(\mathrm{cm})$,

- USCS_Code (soil type),

○ PF_code (frozen=1, nonfrozen $=0$ ),

- GMC (gravimetric moisture content), and

$\circ$ Any notes.

Column headings should not be included in the paste boxes. When the data are pasted, the user clicks the import borehole data button under the paste box (see Figure C-11) to make sure the data will be interpreted correctly. When all data are interpreted, the user clicks the main Import Data button to upload the data. The boreholes will be plotted on the map when the data are imported correctly and will be displayed on the maps as the user proceeds with the analysis. Note that each borehole is labeled with its ID. 
Figure C-11. Importing borehole data into the PFFDSS.

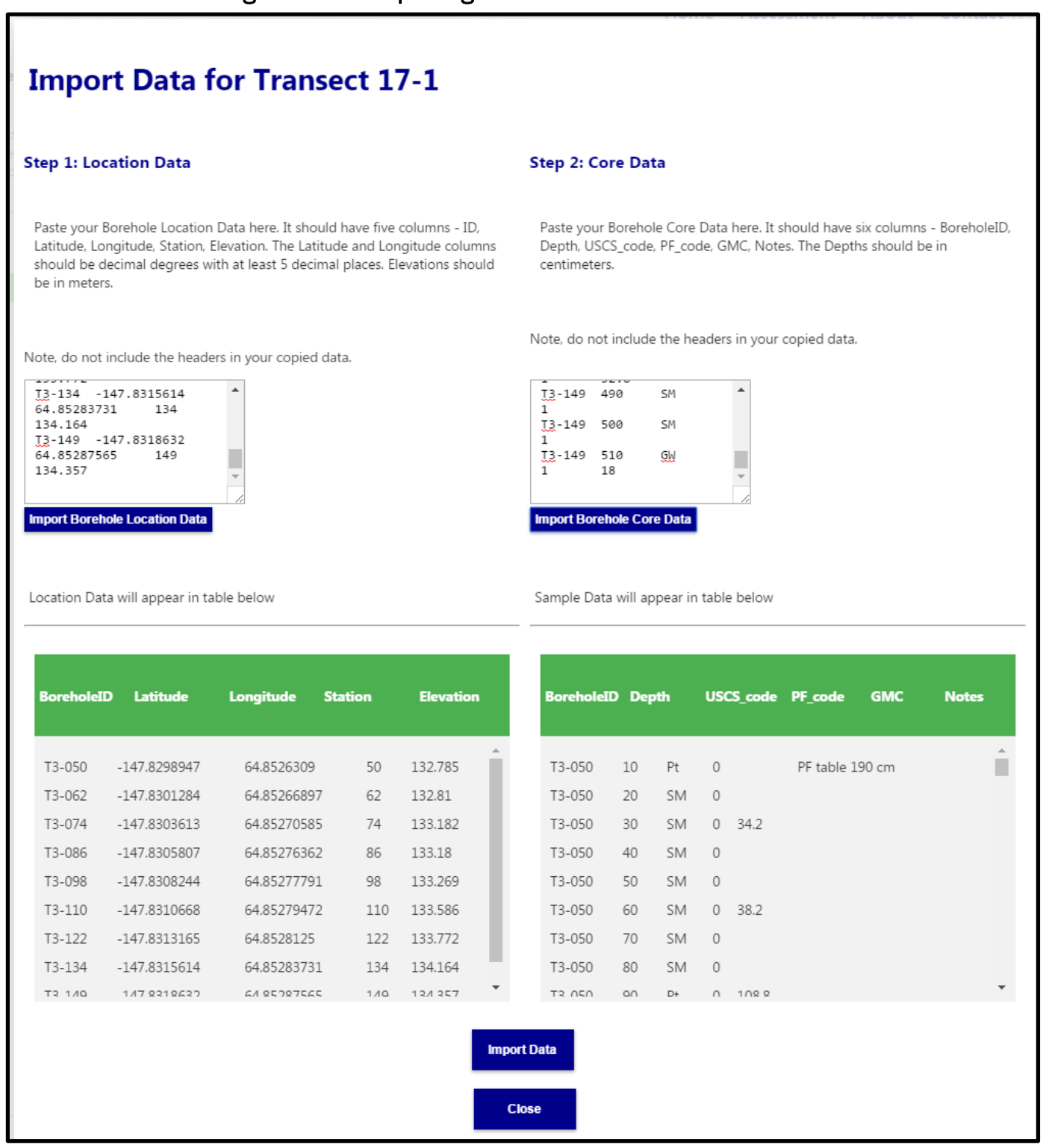

\section{Building placement}

Once the borehole data are loaded into the system, the user can conduct a stability, and potential thaw settlement analyses. The algorithms for these assessments are presented in the methods section below. The assessments provide the user a good idea of stable places where the building can be placed. The next step is to actually place the building. A tool provides a way for the user to click on the map at the center of the location of the building. A box is added to the map with the specified building footprint. The user can then rotate the box clockwise or counter-clockwise to align the building 
depending on the design preference (Figure C-12). Note that the tool presents a "before" and "after" style image of the soil column for the borehole closest to the intended building location. This shows a potential settlement of $66 \mathrm{~cm}$ ( $26 \mathrm{in}$.) with the reference foundation type of slab-on-grade with heated structure.

Figure C-12. Examining building footprint impacts around the site.

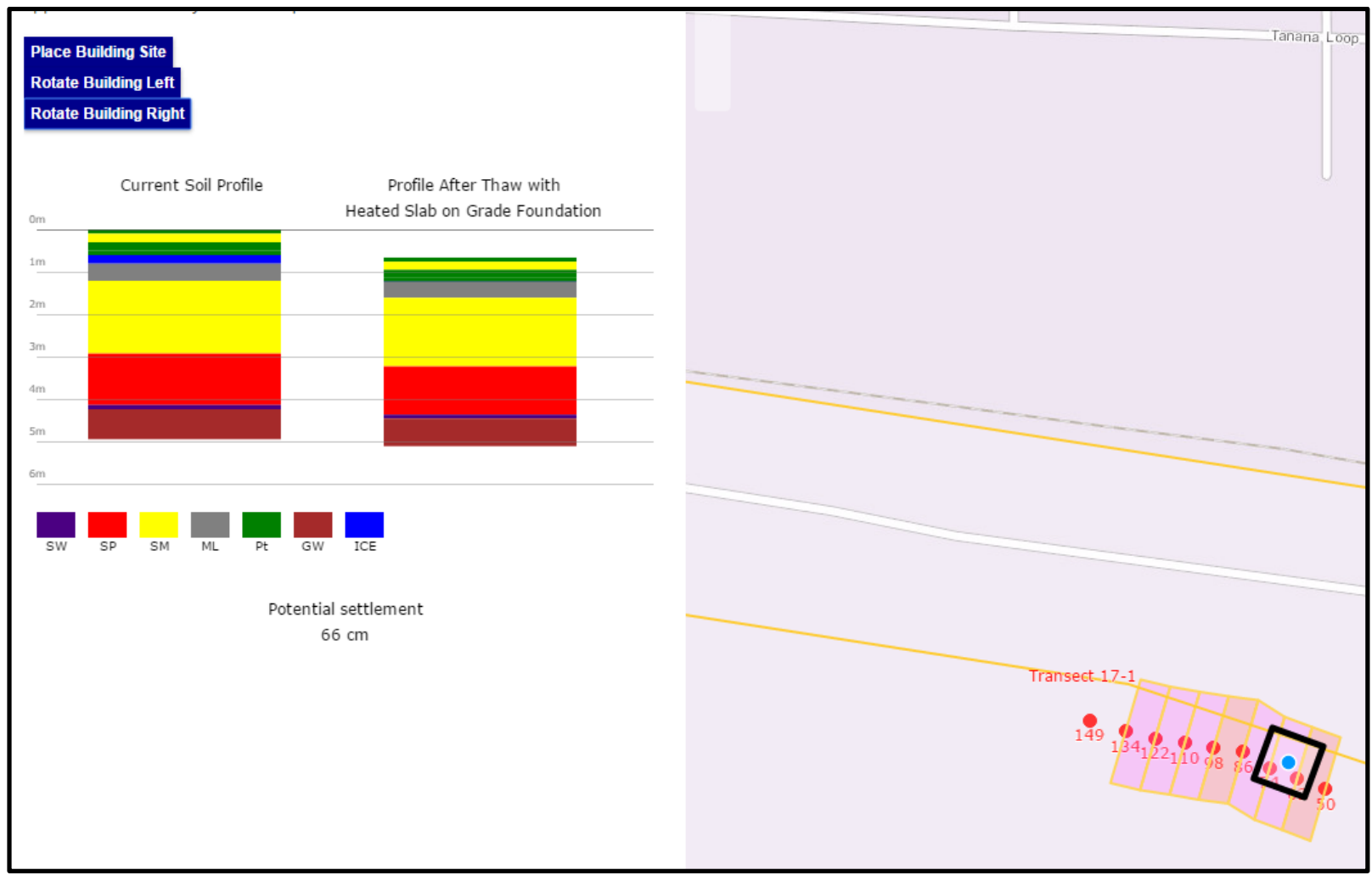

\section{C.2.3.3 Foundation type assessment process}

The final step in the assessment is a foundation type assessment. This assessment is fully described in the methods section shown in Figure C-13. For the specified location, the DSS has estimated that, for example, Slabon-Grade will most likely cause thawing, and that the $66 \mathrm{~cm}$ (26 in.) of settlement is very likely to be detrimental to the foundation. As a result, the risk is high for this foundation type, while cost is low.

The end-bearing piles option, because it relies on supporting the structure at the stable layer, presents a lower risk (low risk) and moderate cost

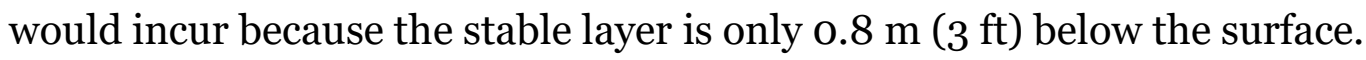
The DSS concludes this might be the best option of the five types. 
Figure C-13. Foundation Type Assessment Results.

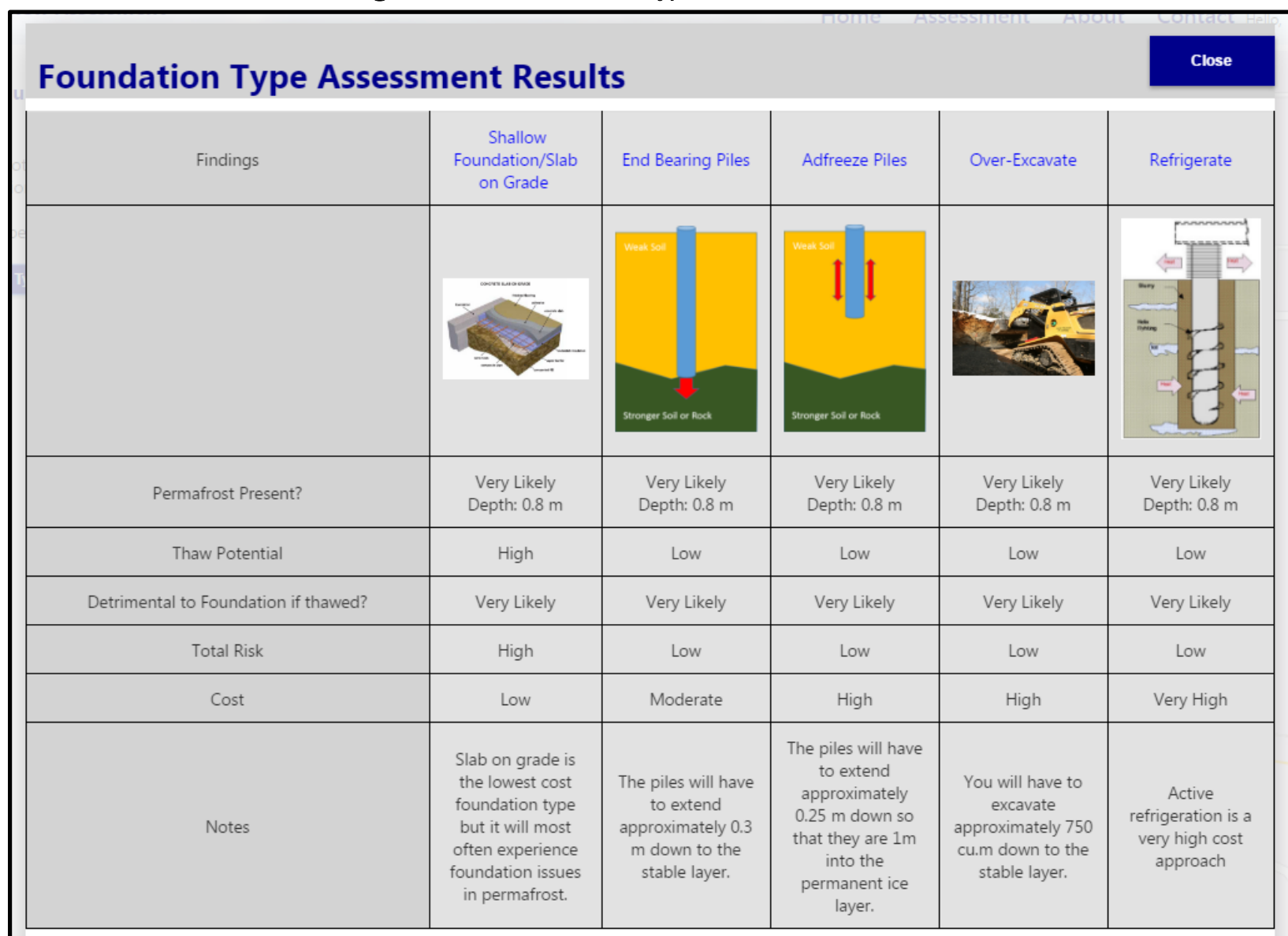

Conclusions 


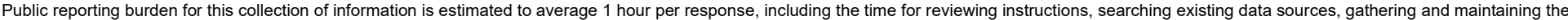

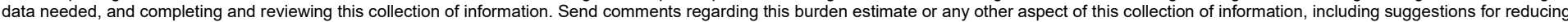

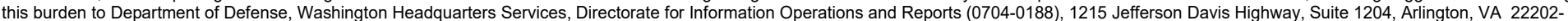

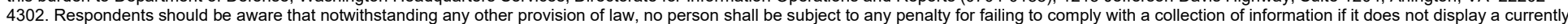
4302. Respondents should be aware that notwithstanding any other provision of law, no person shall
valid OMB control number. PLEASE DO NOT RETURN YOUR FORM TO THE ABOVE ADDRESS.
1. REPORT DATE (DD-MM-YYYY) $09 / 01 / 2020$
Final Technical Report (TR)

\section{TITLE AND SUBTITLE}

Improving Design Methodologies and Assessment Tools for Building on Permafrost in a Warming Climate

3. DATES COVERED (From - To)

\section{5a. CONTRACT NUMBER}

5b. GRANT NUMBER

5c. PROGRAM ELEMENT

5d. PROJECT NUMBER

SERDP

Kevin L. Bjella, Yuri Shur, Misha Kanevskiy, Paul Duvoy, Bruno Grunau, John Best, Stephen Bourne, and Rosa Affleck

\section{5f. WORK UNIT NUMBER}

\section{PERFORMING ORGANIZATION NAME(S) AND ADDRESS(ES)}

U.S. Army Engineer Research and Development Center (ERDC)

Cold Regions Research and Engineering Laboratory (CRREL)

72 Lyme Road,

Hanover, NH 03755-1290

\section{PERFORMING ORGANIZATION REPORT} NUMBER

ERDC/CRREL TR-20-13

\section{SPONSORING / MONITORING AGENCY NAME(S) AND ADDRESS(ES)}

Strategic Environmental Research and Development Program (SERDP)

480o Mark Center Drive

Suite 17Do3

Alexandria, VA 22350-3605

11. SPONSOR/MONITOR'S REPORT NUMBER(S)

\section{DISTRIBUTION / AVAILABILITY STATEMENT}

Approved for public release; distribution is unlimited.

\section{SUPPLEMENTARY NOTES}

Funding for this demonstration was provided by SERDP under Customer Order W74RDV33512287, SERDP Project RC-2436, "Improving Design Methodology and Assess-ment Tools for Building on Permafrost in a Warming Climate."

\section{ABSTRACT}

The U.S. Department of Defense (DoD) operates numerous Arctic and Subarctic installations, including Alaska. Changes to permafrost can threaten critical built infrastructure. It is critical to accurately characterize and compare site conditions in permafrost regions to enable the efficient, cost-effective design and construction of an infrastructure well suited to the permafrost environment and that meets DoD requirements. This report describes three research efforts to establish (1) field investigation approaches for ground ice detection and delineation, (2) methods and modeling for early warning detection of thawing permafrost under infrastructure, and (3) an outline of a decision support system that determines the most applicable foundation design for warming and degrading permafrost. Outcomes of these interrelated efforts address needs to improve construction of DoD mission critical infrastructure on Arctic and Subarctic permafrost terrains. Field investigation processes used systematic methodologies including borehole data and geophysical measurements to effectively characterize subsurface permafrost information. The Permafrost Foundation Decision Support System (PFFDSS) tool implements and logically links field survey information and foundation type assessments. The current version of PFFDSS is designed to be accessible to design-engineers of a broad range of experience, that will reduce the effort and cost, and improve the effectiveness of site assessment.

\section{SUBJECT TERMS}

Frozen ground--Thawing, Permafrost--Thawing, Cold regions--Climatic changes, Foundations--Cold weather conditions, Foundations--Design and construction

\section{SECURITY CLASSIFICATION OF:}

\section{a. REPORT}

Unclassified

\section{b. ABSTRACT \\ Unclassified}

\section{LIMITATION OF ABSTRACT}

\section{c. THIS PAGE}

Unclassified
SAR
18. NUMBER OF PAGES

220 19a. NAME OF RESPONSIBLE PERSON

19b. TELEPHONE NUMBER (include area code) 